\title{
Global Nuclear Energy Partnership Technology Development Plan
}

Global Nuclear Energy Partnership Technical Integration Office

July 25,2007 



\title{
Global Nuclear Energy Partnership Technology Development Plan
}

\author{
July 25, 2007 \\ Global Nuclear Energy Partnership \\ Technical Integration Office \\ Idaho National Laboratory \\ Idaho Falls, Idaho 83415
}

Prepared for the U.S. Department of Energy Office of Nuclear Energy Under DOE Idaho Operations Office

Contract DE-AC07-05ID14517 


\section{EXECUTIVE SUMMARY}

This plan is the combined effort of ten Department of Energy national laboratories: Savannah River National Laboratory, Sandia National Laboratory, Pacific Northwest National Laboratory, Oak Ridge National Laboratory, Los Alamos National Laboratory, Lawrence Livermore National Laboratory, Lawrence Berkeley National Laboratory, Idaho National Laboratory, Brookhaven National Laboratory, and Argonne National Laboratory. The plan describes the Global Nuclear Energy Partnership (GNEP) Technology Development Program as envisioned by the laboratories. This plan does not necessarily reflect the views and decisions of the Department of Energy (DOE) with regard to current or future activities of the GNEP program. It has been prepared to guide the development by DOE of integrated plans for realizing the domestic portion of the GNEP vision as well as providing a basis for developing international cooperation. The cost information in this document is based on estimates from the national laboratory participants, and does not represent annual budget estimates from the Department of Energy.

Beginning with the GNEP overall goals, this plan describes the basic technical objectives for each element of the program, summarizes the technology status and identifies the areas of greatest technical risk. On this basis a proposed technology development program is described that can deliver the required information for a Secretarial decision on the path forward of GNEP in 2008 and support construction of new advanced fuel cycle facilities, if the chosen path includes them.

The proposed technology development program is predicated on the construction of an integrated suite of fuel cycle facilities in the following decade. However, at this time the United States (U.S.) Government has not decided on a particular process for facility construction or on the scope of international cooperation. Furthermore, siting of any of the proposed facilities will be determined by a separate process, following applicable laws and appropriate decision-making processes. Therefore, this document focuses entirely on what the technology needs are, why they are needed, and when it could be completed and not on where, or by whom, any of the required development work would be done.

\section{GNEP Objectives}

GNEP seeks to bring about a significant, wide-scale use of nuclear energy and take actions now that would allow that vision to be achieved while decreasing the risk of nuclear weapons proliferation and effectively addressing the challenge of nuclear waste disposal. GNEP would advance the nonproliferation and national security interests of the U.S. by reinforcing U.S. nonproliferation policies, reducing the spread of enrichment and reprocessing technologies abroad, and reducing or eliminating excess civilian plutonium stocks that have accumulated.

To enable the expansion of nuclear energy for peaceful purposes and make a major contribution to global development into the $21^{\text {st }}$ century, the U.S. seeks to pursue and accelerate cooperation to:

- Expand nuclear power to help meet growing energy demand in an environmentally sustainable manner.

- Develop, demonstrate, and deploy advanced technologies for recycling spent nuclear fuel that do not separate plutonium, with the goal over time of ceasing separation of plutonium, reducing or eliminating excess stocks of civilian plutonium, and drawing down existing stocks of civilian spent fuel. Such advanced fuel cycle technologies would substantially reduce nuclear waste, simplify its disposition, and in the U.S. would help ensure the need for only one geologic repository through the end of this century.

- Develop, demonstrate, and deploy advanced reactors that consume transuranic elements from recycled spent fuel. 
- Establish supply arrangements among nations to provide reliable fuel services worldwide for generating nuclear energy by providing nuclear fuel and taking back spent fuel for recycling without spreading enrichment and reprocessing technologies.

- Develop, demonstrate, and deploy advanced, proliferation-resistant nuclear power reactors appropriate for the power grids of developing countries and regions.

- In cooperation with the International Atomic Energy Agency, develop enhanced nuclear safeguards to effectively and efficiently monitor nuclear materials and facilities to ensure commercial nuclear energy systems are used only for peaceful purposes.

The need for nuclear energy to play a major role in meeting base-load electrical energy requirements is now recognized by most of the world's industrialized nations. Similarly, in the U.S. there is growing recognition of the need to start building new nuclear power plants as soon as possible and to rebuild our national nuclear infrastructure - needs supported by both the Energy Policy Act of 2005 and the DOE's Nuclear Power 2010 program. DOE has produced a strategic plan that outlines an implementation strategy to enable a world-wide increase in the use of nuclear energy safely, without contributing to the spread of nuclear weapons capabilities, and in a manner that responsibly disposes of waste products from nuclear power generation.

\section{GNEP Criteria}

GNEP must meet the following criteria:

1. Proliferation/Safeguards Risk: The risk of non-peaceful use of the civilian nuclear fuel cycle comes from two principal sources: (1) a nation wanting to advance toward the capability to build nuclear weapons in a short period of time following the withdrawal from the Non-Proliferation Treaty, and (2) a terrorist group seeking to obtain nuclear materials to quickly fabricate and explode an improvised nuclear device or a dirty bomb. GNEP aims to address both of these issues by providing incentives to limit the number of countries possessing enrichment and reprocessing facilities, and by eliminating over time excess stockpiles of civil plutonium and strengthening controls over materials.

2. Proliferation Prevention: Preventing the spread of commercial nuclear technology does not by itself prevent the spread of weapons capability. The plutonium contained in spent fuel discharged from a light water reactor (LWR) is not considered "weapons grade." However, plutonium separated from spent nuclear fuel could be fashioned into a weapon and achieve a nuclear yield of some magnitude. While the safeguarding of bulk-handling facilities will continue to pose significant technical challenges, advances have been made in developing processes that: are easier to safeguard, allow improved materials accountability, are more resistant to terrorist threats, and offer the possibility of placing a much reduced burden on our waste disposal facilities. However, there is no technology "silver bullet" that can be built into an enrichment plant or reprocessing plant that can prevent a country from diverting these commercial fuel cycle facilities to nonpeaceful use. GNEP seeks to develop advanced fuel cycle technology for civil purposes, centered in existing fuel-cycle states, that would allow them to provide fuel services more cheaply and reliably than the remaining states could provide indigenously.

3. Terrorist Threat Reduction. In the most general terms, GNEP seeks to eliminate (over time) excess stocks of separated plutonium and reduce stocks of spent fuel worldwide, thereby strengthening nuclear security worldwide. In more specific terms, a key objective with respect to any GNEP recycling facility is to deny access to fissile nuclear materials of critical mass that could be readily made into a nuclear device. Supportive policies can be implemented in this regard: (1) minimize transportation - keep fissile materials inside one integrated facility from the time used fuel enters until recycled material leaves; (2) maintain a mixture of fissile material with nonfissile material in a ratio 
that is not easily useable as a weapon; (3) use advanced safeguards and security techniques; and (4) maintain a goal of minimizing the buildup of, and eventually eliminating, stockpiles of separated civilian plutonium or its near equivalent.

4. Reduce Repository Burden. Commercial spent nuclear fuel can either be disposed of directly into a repository or reprocessed/recycled with the byproduct high-level waste sent to a repository.

Reprocessing and recycle using proven and currently available technologies (variants of PUREX and light-water reactor recycle with a mixed oxide fuel) would offer some minor benefit to the repository but not meet the GNEP objectives. The full benefit envisioned for the separations process in GNEP anticipates substantial repository benefits (by separating out all the actinides) and a reduction in liquid process waste. The most significant repository benefits can be achieved by removing the very longlived minor actinides and recycling them as part of the fuel for fast reactors. Further repository benefit can be achieved by removing the fission products cesium and strontium from the high-level waste stream and allowing them to decay separately. These elements have a relatively short half-life, and, after decay, could be disposed of as low level waste. Additionally, removing the technetium and fixing it in a matrix with the cladding hulls could reduce the possibility of this fission product migrating away from the repository area.

5. Assured Fuel Supply. The U.S. seeks to encourage the world's leading nuclear exporters to create a safe, orderly system that spreads nuclear energy without proliferation. States that refrain from enrichment and reprocessing would have reliable access at reasonable cost to fuel for civil nuclear power reactors. If the U.S. is going to participate in assuring access to nuclear fuel and, in the longer term, spent fuel services to these countries as they enter the nuclear arena, it must have the capability to provide the needed fuel cycle services - capability that we do not currently possess. Our fuel-cycle technology should also build our ability and that of our partners to establish and sustain cradle to grave fuel service or leasing arrangements over time and at a scale commensurate with the anticipated expansion of nuclear energy by helping in a major way to solve the nuclear waste challenge.

6. Capability and leverage. The GNEP vision has been well received by the international nuclear community, particularly among the leading fuel-cycle states. Sustaining and building on that enthusiasm depends on the ability of the U.S. to get back in the commercial nuclear business and assume an active role. Participating fully in that business is essential in shaping the rules that apply to it. We have a vision of a future world that can universally enjoy the benefits of safe, economical, emission-free energy; and we have programs and plans to put the U.S. back in the nuclear energy game in a leadership role. Access to our market is itself a form of leverage.

\section{GNEP implementation model}

The implementation of GNEP is based on the concept of a government/industry partnership.

There are three facilities (see Figure E-1) required to implement and thus affirm our commitment to GNEP: (1) an advanced recycling facility to separate the components of spent fuel and production-scale fabrication of transmutation fuel required by GNEP, herein termed a Consolidated Fuel Treatment Center (CFTC); (2) a fast reactor to burn the actinide based fuel, herein termed an Advanced Burner Reactor (ABR) to transform the actinides in a way that makes them easier to store as waste, not a proliferation concern, and produce electricity; and (3) an Advanced Fuel Cycle Facility (AFCF) to serve as a research and development (R\&D) center of excellence for developing transmutation fuels and improving fuel cycle technology.

The pursuit of these three facilities constitutes a pathway with two complementary components. The first component, the CFTC and the ABR, could, as an option, be led by industry with technology support from laboratories, international partners, and universities. The second component, research and development, 
led by the national laboratories, would include the AFCF funded by the DOE and located at a government site. The two components would work closely together to move GNEP forward by integrating the capabilities of the national laboratories with the needs of industry.

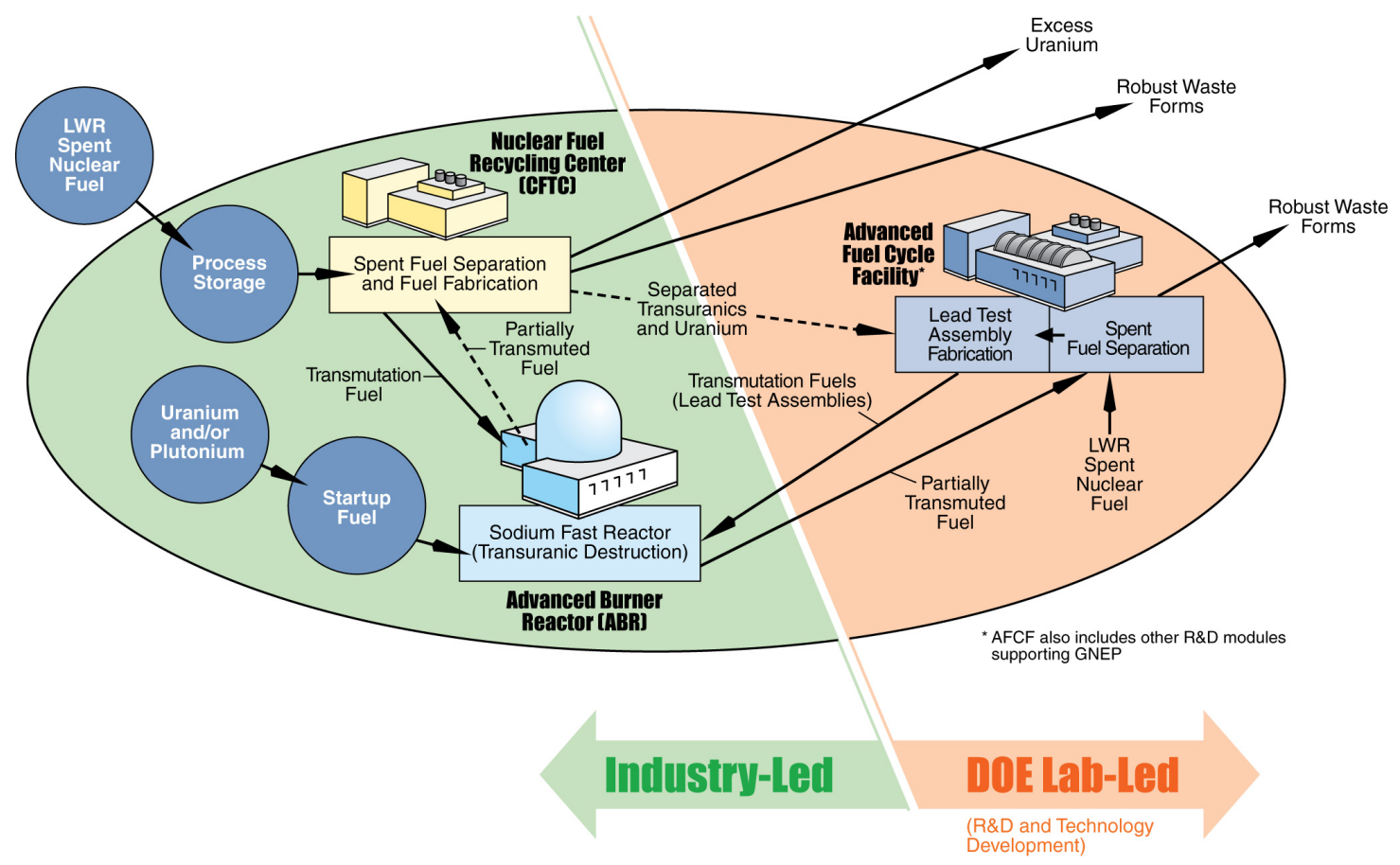

Figure E-1. Initial GNEP Facilities

Technical challenges remain for the implementation of the closed-fuel cycle as envisioned under GNEP. Many of the technologies essential for the successful implementation of GNEP have been demonstrated at laboratory and bench scale. But uncertainties, such as scaling-up the chemical separations for the recycle process or fabricating and qualifying the transmutation fuel for the advanced burner reactor, exist and require careful attention. These technical risks will be addressed by continued R\&D and technology development for GNEP. This plan discusses how these needs could be met.

\section{GNEP Technology Development}

The technology development program (TDP) described herein is established using a requirements-driven process. It begins with the proposed GNEP deployment system, identifies the technology gaps, and develops requirements that the system must meet to satisfy the GNEP goals. This systems integration approach will be a constant focus of the GNEP TDP. In so doing, improved understanding of technology options can be introduced into both the deployment system and first facilities, thereby ensuring that the program direction is constantly being monitored and changed as deemed necessary. This approach will also allow comparison with other deployment options being implemented elsewhere or being considered as backup options for this program.

There are four basic functions that the technologies must accomplish to meet the GNEP vision: light water reactor (LWR) spent nuclear fuel separation, fabrication of transmutation fuels incorporating the separated transuranics (as a group), irradiation of transmutation fuels, and separation of transuranics (as a group) from the transmutation fuels after irradiation. The technology development necessary for each of these functions is described by first considering the performance objectives and identifying a baseline 
technology. The status of each technology pathway is briefly discussed with special emphasis on the level of technical maturity and technical risk. The summary tables with fast reactor infrastructure and programmatic risk and the technology readiness levels (TRLs) for LWR spent fuel processing, waste form development, fast reactor spent fuel processing, fuel fabrication, and fuel performance are shown in Tables E-1 through E-6. This assessment of maturity and risk is used to develop the TDP. R\&D needs for alternative technologies in the case of moderate- and high-risk program elements are also identified. Fabrication and separation of transmutation fuels are considered together as the technologies are intimately coupled. Finally, estimated costs for the next five years (generated by the national laboratory participants) with associated milestones are provided for each program element (see Tables E-7 and E-8).

Table E-1. Fast Reactor Infrastructure and Programmatic Risk

\begin{tabular}{|l|l|}
\hline $\begin{array}{l}\text { Fast Reactor } \\
\text { Infrastructure }\end{array}$ & \multicolumn{1}{c|}{ Programmatic Risk } \\
\hline $\begin{array}{l}\text { Fast Reactor } \\
\text { Component Design } \\
\text { Infrastructure }\end{array}$ & $\begin{array}{l}\text { Demonstrated at full scale. The U.S. has not built a fast reactor in } \\
\text { decades and human resources are limited. } \\
\text { Programmatic risk is high because of the lack of U.S. infrastructure to } \\
\text { support commercial deployment of fast reactor technology. }\end{array}$ \\
\hline $\begin{array}{l}\text { Fast Reactor } \\
\text { Component Testing }\end{array}$ & $\begin{array}{l}\text { Programmatic risk is high because of the lack of U.S. infrastructure to } \\
\text { support fast reactor component testing and development. International } \\
\text { infrastructure is also severely degraded. }\end{array}$ \\
\hline $\begin{array}{l}\text { Fast Reactor } \\
\text { Manufacturing }\end{array}$ & $\begin{array}{l}\text { Programmatic risk is high for the ABR prototype. Infrastructure for } \\
\text { manufacturing fast reactor components is currently insufficient to } \\
\text { support technology demonstration. Subsequent advanced recycling } \\
\text { reactors will benefit from the infrastructure development activities } \\
\text { during the ABR prototype development }\end{array}$ \\
\hline $\begin{array}{l}\text { Fast Reactor Safety } \\
\text { Analysis Tools }\end{array}$ & $\begin{array}{l}\text { Programmatic risk is medium because of the personnel infrastructure } \\
\text { to support safety code development and maintenance. Updating and } \\
\text { validation of safety analysis and design tools is recommended. In } \\
\text { addition, test facilities for safety testing and code validation will be } \\
\text { required. }\end{array}$ \\
\hline Licensing Infrastructure & $\begin{array}{l}\text { Programmatic risk is high. Licensing strategy is unknown. NRC has } \\
\text { very few staff who understands sodium technology. } \\
\text { Technical criteria for licensing need to be clarified and the regulatory } \\
\text { structure re-established. }\end{array}$ \\
\hline
\end{tabular}


Table E-2. LWR Spent Fuel Processing - Technology Readiness Levels

\begin{tabular}{|c|c|c|}
\hline TRL & Category & Description \\
\hline 1 & \multirow{3}{*}{ Concept Development } & $\begin{array}{l}\text { Concept for separations process developed; process options (e.g., } \\
\text { contactor type, solvent extraction steps) identified; separations criteria } \\
\text { established. }\end{array}$ \\
\hline 2 & & $\begin{array}{l}\text { Calculated mass-balance flowsheet developed; scoping experiments } \\
\text { on process options completed successfully with simulated LWR spent } \\
\text { fuel; preliminary selection of process equipment. }\end{array}$ \\
\hline 3 & & $\begin{array}{l}\text { Laboratory-scale batch testing with simulated LWR spent fuel } \\
\text { completed successfully; process chemistry confirmed; reagents } \\
\text { selected; preliminary testing of equipment design concepts done to } \\
\text { identify development needs; complete system flowsheet established. }\end{array}$ \\
\hline 4 & \multirow{3}{*}{ Proof of Principle } & $\begin{array}{l}\text { Unit operations testing at engineering scale for process validation with } \\
\text { simulated LWR spent fuel consisting of unirradiated materials; } \\
\text { materials balance flowsheet confirmed; separations chemistry models } \\
\text { developed. NOTE: engineering scale is defined as a process } \\
\text { equipment scale and throughput rate that can with confidence be } \\
\text { scaled to industrial operations levels. }\end{array}$ \\
\hline 5 & & $\begin{array}{l}\text { Unit operations testing completed at engineering scale with actual } \\
\text { LWR spent fuel for process chemistry confirmation; reproducibility of } \\
\text { process confirmed by repeated batch tests; simulation models } \\
\text { validated. }\end{array}$ \\
\hline 6 & & $\begin{array}{l}\text { Unit operations testing in existing hot cells with full-scale equipment } \\
\text { completed successfully, using actual LWR spent fuel; process } \\
\text { monitoring and control system proven; process equipment design } \\
\text { validated. }\end{array}$ \\
\hline 7 & \multirow{3}{*}{ Proof of Performance } & $\begin{array}{l}\text { Integrated system cold shakedown testing completed successfully with } \\
\text { full-scale equipment (simulated fuel). }\end{array}$ \\
\hline 8 & & $\begin{array}{l}\text { Demonstration of integrated system with full-scale equipment and } \\
\text { actual LWR spent fuel completed successfully; short ( } \sim 1 \text { month) } \\
\text { periods of sustained operation. }\end{array}$ \\
\hline 9 & & $\begin{array}{l}\text { Full-scale demonstration with actual LWR spent fuel successfully } \\
\text { completed at } \geq 100 \text { metric tons per year rate; sustained operations for a } \\
\text { minimum of three months. }\end{array}$ \\
\hline
\end{tabular}

* The current TRL for this technology is highlighted in blue. 
Table E-3. Waste Form Development - Technology Readiness Levels

\begin{tabular}{|c|c|c|}
\hline TRL & Category & Description \\
\hline 1 & \multirow{3}{*}{ Concept Development } & Identification of waste form options and related processes. \\
\hline 2 & & $\begin{array}{l}\text { Waste acceptance criteria evaluation, flowsheet development, process } \\
\text { options scoping experiments, and preliminary systems engineering. }\end{array}$ \\
\hline 3 & & $\begin{array}{l}\text { Laboratory-scale simulated waste streams batch testing, preliminary } \\
\text { equipment design testing, systems engineering, and waste form } \\
\text { screening. }\end{array}$ \\
\hline 4 & \multirow{3}{*}{ Proof of Principle } & $\begin{array}{l}\text { Waste form production testing of simulated waste streams, actinide } \\
\text { and non-radioactive fissions products at engineering scale, process } \\
\text { validation, short-term characterization testing, and initial model } \\
\text { development. }\end{array}$ \\
\hline 5 & & $\begin{array}{l}\text { Waste form production with representative radioactive fission product } \\
\text { content at engineering scale, long-term characterization testing, and } \\
\text { waste acceptance criteria confirmation. }\end{array}$ \\
\hline 6 & & $\begin{array}{l}\text { Waste form production of actual process waste streams using full- } \\
\text { scale equipment, process and equipment final validation, and model } \\
\text { verification. }\end{array}$ \\
\hline 7 & \multirow{3}{*}{ Proof of Performance } & $\begin{array}{l}\text { Integrated waste form production in industrial facility using full-scale } \\
\text { equipment; cold shakedown testing of production operations. }\end{array}$ \\
\hline 8 & & $\begin{array}{l}\text { Demonstration of integrated waste form production as part of initial } \\
\text { demonstration of separations systems. }\end{array}$ \\
\hline 9 & & $\begin{array}{l}\text { Full-scale demonstration of waste form production with the full fission } \\
\text { product loading derived from treatment of actual spent nuclear fuel. }\end{array}$ \\
\hline
\end{tabular}

* The current TRL for this technology is highlighted in blue. 
Table E-4. Fast Reactor Spent Fuel Processing - Technology Readiness Levels

\begin{tabular}{|c|c|c|}
\hline TRL & Category & Description \\
\hline 1 & \multirow{3}{*}{ Concept Development } & $\begin{array}{l}\text { Concept for separations process developed; process options } \\
\text { (e.g., electrolyte composition, process equipment) identified; } \\
\text { separations criteria established. }\end{array}$ \\
\hline 2 & & $\begin{array}{l}\text { Calculated mass-balance flowsheet developed; scoping } \\
\text { experiments on process options completed successfully with } \\
\text { simulated advanced recycling reactor spent fuel; preliminary } \\
\text { selection of process equipment. }\end{array}$ \\
\hline 3 & & $\begin{array}{l}\text { Bench-scale batch testing with simulated advanced recycling } \\
\text { reactor spent fuel completed successfully; process chemistry } \\
\text { confirmed; reagents selected; preliminary testing of equipment } \\
\text { design concepts done to identify development needs; complete } \\
\text { system flowsheet established. }\end{array}$ \\
\hline $4^{*}$ & \multirow{3}{*}{ Proof of Principle } & $\begin{array}{l}\text { Unit operations testing at engineering scale for process } \\
\text { validation with simulated advanced recycling reactor spent fuel } \\
\text { consisting of unirradiated materials; materials balance } \\
\text { flowsheet confirmed; separations chemistry models developed. } \\
\text { NOTE: engineering scale is defined as a process equipment } \\
\text { scale and throughput rate that can with confidence be scaled to } \\
\text { industrial operations levels. }\end{array}$ \\
\hline 5 & & $\begin{array}{l}\text { Unit operations testing completed at engineering scale with } \\
\text { actual fast reactor spent fuel for process chemistry } \\
\text { confirmation; reproducibility of process confirmed by repeated } \\
\text { batch tests; simulation models validated. }\end{array}$ \\
\hline 6 & & $\begin{array}{l}\text { Unit operations testing in existing hot cells with full-scale } \\
\text { equipment completed successfully, using actual fast reactor } \\
\text { spent fuel; process monitoring and control system proven; } \\
\text { process equipment design validated. }\end{array}$ \\
\hline 7 & \multirow{3}{*}{ Proof of Performance } & $\begin{array}{l}\text { Integrated system cold shakedown testing completed } \\
\text { successfully with full-scale equipment (simulated fuel). }\end{array}$ \\
\hline 8 & & $\begin{array}{l}\text { Demonstration of integrated system with full-scale equipment } \\
\text { and actual advanced recycling reactor spent fuel completed } \\
\text { successfully; short ( } \sim 1 \text { month) periods of sustained operation. }\end{array}$ \\
\hline 9 & & $\begin{array}{l}\text { Full-scale demonstration with actual advanced recycling reactor } \\
\text { spent fuel successfully completed at throughput rate consistent } \\
\text { with annual discharge from a cluster of advanced recycle } \\
\text { reactors at a collocated site; sustained operations for a } \\
\text { minimum of three months. }\end{array}$ \\
\hline
\end{tabular}

* The current TRL for this technology is highlighted in blue. 
Table E-5. Fuel Fabrication - Technology Readiness Levels

\begin{tabular}{|c|c|c|c|}
\hline$\overline{T R L}$ & TRL Function & Generic Definition & $\begin{array}{c}\text { Fuel Performance-Specific } \\
\text { Definition }\end{array}$ \\
\hline 1 & \multirow{3}{*}{$\begin{array}{l}\text { Concept } \\
\text { Development }\end{array}$} & $\begin{array}{l}\text { Basic principles } \\
\text { observed and formulated }\end{array}$ & $\begin{array}{l}\text { Technical review leading to identified } \\
\text { technical options. Identification of } \\
\text { criteria for candidate selection. }\end{array}$ \\
\hline 2 & & $\begin{array}{l}\text { Technology concepts } \\
\text { and/or applications } \\
\text { formulated }\end{array}$ & $\begin{array}{l}\text { Fuel candidates selected from options } \\
\text { based on performance data on similar } \\
\text { systems, based on selection criteria. }\end{array}$ \\
\hline 3 & & $\begin{array}{l}\text { Analytical and } \\
\text { experimental } \\
\text { demonstration of critical } \\
\text { function and/or proof of } \\
\text { concept }\end{array}$ & $\begin{array}{l}\text { Analysis and lab-scale experimentation } \\
\text { and characterization addressing } \\
\text { feasibility including small fabrication } \\
\text { tests with surrogate materials. }\end{array}$ \\
\hline 4 & \multirow{3}{*}{ Proof-of-principle } & $\begin{array}{l}\text { Component and/or } \\
\text { bench-scale validation } \\
\text { in a laboratory } \\
\text { environment }\end{array}$ & $\begin{array}{l}\text { Establish proof of concept. Fabrication } \\
\text { of irradiation testing samples in } \\
\text { accordance with requirements. At this } \\
\text { scale, legacy materials are blended } \\
\text { together and a feedstock spec is not } \\
\text { available. }\end{array}$ \\
\hline 5 & & $\begin{array}{l}\text { Component and/or } \\
\text { breadboard validation in } \\
\text { a relevant environment }\end{array}$ & $\begin{array}{l}\text { Fabrication of irradiation testing samples } \\
\text { in accordance with requirements. At this } \\
\text { scale, actual separated materials are used } \\
\text { and feedstock specs are developed. }\end{array}$ \\
\hline 6 & & $\begin{array}{l}\text { System/subsystem } \\
\text { model or prototype } \\
\text { demonstration in } \\
\text { relevant environment }\end{array}$ & $\begin{array}{l}\text { Fabrication at multiple pin level using } \\
\text { actual materials and scalable fabrication } \\
\text { techniques. A full set of fabrication } \\
\text { specifications is developed. Design } \\
\text { parameters investigated. Information is } \\
\text { sufficient to support a Fuel Specification } \\
\text { and a Fuel Safety Case. }\end{array}$ \\
\hline 7 & \multirow[t]{3}{*}{$\begin{array}{l}\text { Proof-of- } \\
\text { performance }\end{array}$} & $\begin{array}{l}\text { System prototype } \\
\text { demonstration in } \\
\text { prototypic environment }\end{array}$ & $\begin{array}{l}\text { Fabrication of reference fuel at assembly } \\
\text { levels using actual equipment and with } \\
\text { actual feedstock materials with statistical } \\
\text { demonstration of performance. }\end{array}$ \\
\hline 8 & & \multicolumn{2}{|c|}{$\begin{array}{l}\text { Prototype fabrication facility completed and qualified through test } \\
\text { and demonstration. }\end{array}$} \\
\hline 9 & & \multicolumn{2}{|c|}{$\begin{array}{l}\text { Actual fabrication facility proven through successful mission } \\
\text { onerations }\end{array}$} \\
\hline
\end{tabular}

* The current TRL for this technology is highlighted in blue. 
Table E-6. Fuel Performance - Technology Readiness Levels

\begin{tabular}{|c|c|c|c|}
\hline TRL & TRL Function & Generic Definition & $\begin{array}{c}\text { Fuel Development-Specific } \\
\text { Definition }\end{array}$ \\
\hline 1 & \multirow{3}{*}{$\begin{array}{l}\text { Concept } \\
\text { Development }\end{array}$} & $\begin{array}{l}\text { Basic principles } \\
\text { observed and formulated }\end{array}$ & $\begin{array}{l}\text { Technical review leading to identified } \\
\text { technical options. Identification of } \\
\text { criteria for candidate selection. }\end{array}$ \\
\hline 2 & & $\begin{array}{l}\text { Technology concepts } \\
\text { and/or applications } \\
\text { formulated }\end{array}$ & $\begin{array}{l}\text { Fuel candidates selected from options } \\
\text { based on performance data on similar } \\
\text { systems, based on selection criteria. }\end{array}$ \\
\hline 3 & & \begin{tabular}{|l|} 
Analytical and \\
experimental \\
demonstration of critical \\
function and/or proof of \\
concept
\end{tabular} & $\begin{array}{l}\text { Analysis and lab-scale experimentation } \\
\text { and characterization addressing } \\
\text { feasibility including property } \\
\text { measurement, and ex-pile tests. }\end{array}$ \\
\hline 4 & \multirow{3}{*}{ Proof-of-principle } & $\begin{array}{l}\text { Component and/or } \\
\text { bench-scale validation } \\
\text { in a laboratory } \\
\text { environment }\end{array}$ & $\begin{array}{l}\text { Establish proof of concept. Performance } \\
\text { phenomena identified with proof-of- } \\
\text { concept irradiation testing of small } \\
\text { samples completed. }\end{array}$ \\
\hline 5 & & $\begin{array}{l}\text { Component and/or } \\
\text { breadboard validation in } \\
\text { a relevant environment }\end{array}$ & $\begin{array}{l}\text { Irradiation testing of prototypic } \\
\text { rods/compacts under nominal } \\
\text { representative conditions (e.g., fission } \\
\text { densities, fuel and cladding } \\
\text { temperatures, cladding damage rates) is } \\
\text { performed and assessed. }\end{array}$ \\
\hline 6 & & $\begin{array}{l}\text { System/subsystem } \\
\text { model or prototype } \\
\text { demonstration in } \\
\text { relevant environment }\end{array}$ & $\begin{array}{l}\text { Prototypic rod/compact and } \\
\text { assembly/element irradiation in } \\
\text { representative environment, under full } \\
\text { range of relevant normal and off-normal } \\
\text { conditions. }\end{array}$ \\
\hline 7 & \multirow[t]{3}{*}{$\begin{array}{l}\text { Proof-of- } \\
\text { performance }\end{array}$} & $\begin{array}{l}\text { System prototype } \\
\text { demonstration in } \\
\text { prototypic environment }\end{array}$ & Irradiation of Lead Test Assemblies \\
\hline 8 & & \multicolumn{2}{|c|}{$\begin{array}{l}\text { Irradiation of multiple test assemblies over multiple years of } \\
\text { fabrication. }\end{array}$} \\
\hline 9 & & \multicolumn{2}{|c|}{ Commercial scale use of the fuel in commercial facilities. } \\
\hline
\end{tabular}

* The current TRL for this technology is highlighted in blue. 
July 25,2007

Table E-7. GNEP Overall Cost Estimates to Achieve Milestones in the Report

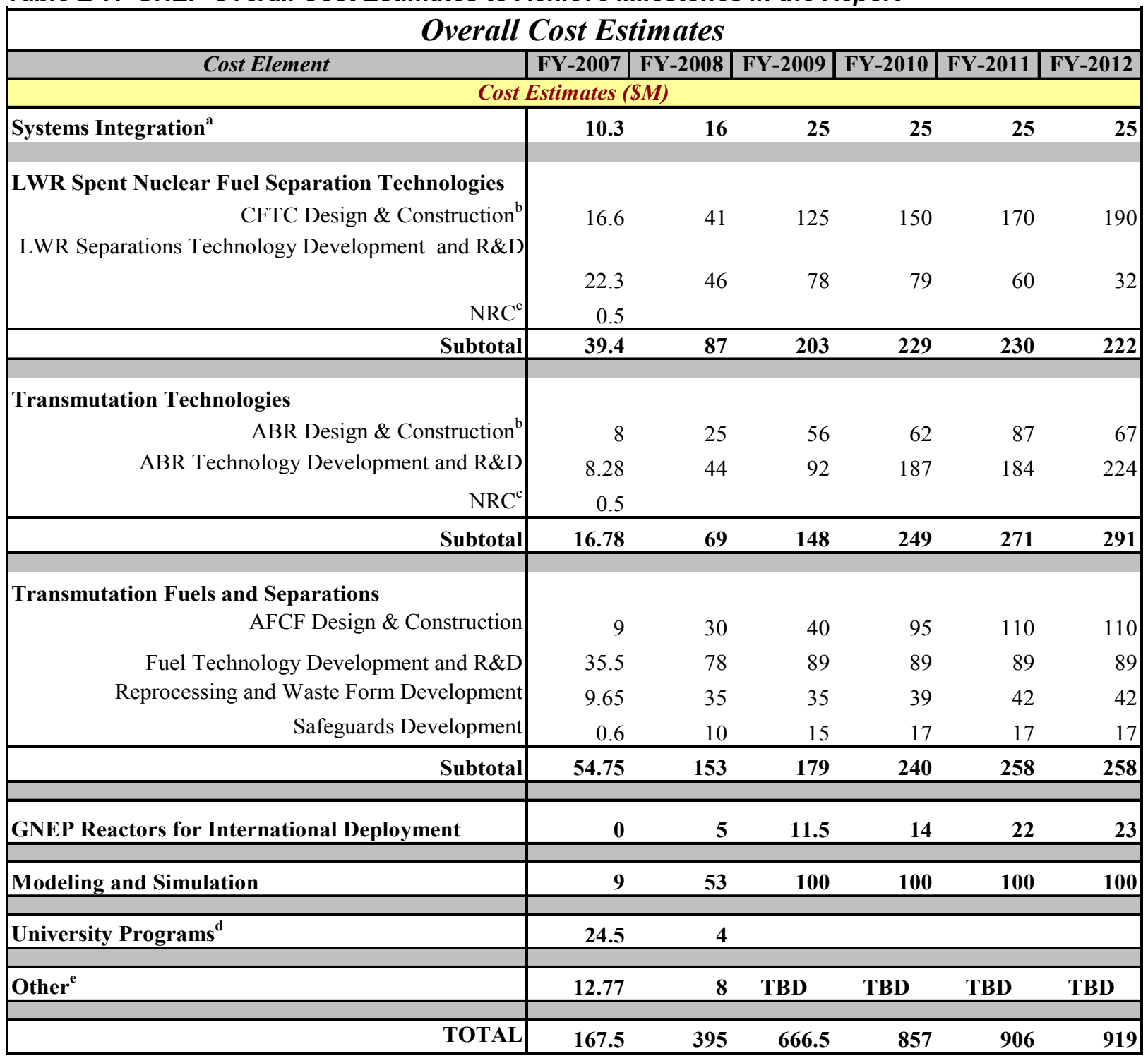

${ }^{a}$ Includes Systems Analysis and Technical Integration

${ }^{\mathrm{b}}$ Includes industry support.

${ }^{\mathrm{C}}$ Not explicitly called out after FY-07

${ }^{\mathrm{d}} \mathrm{FY}-08$ includes only on going grants, after ' 08 fund are embedded in the rest of the cost estimates

${ }^{\mathrm{e}}$ Includes International Collaboration, Internal Commitments, SBIR/STTR, etc. 
Table E-8. GNEP Milestone Projection

\begin{tabular}{|c|c|}
\hline & Date \\
\hline \multicolumn{2}{|l|}{ FY07 } \\
\hline \multicolumn{2}{|l|}{ Systems Integration and Analysis } \\
\hline AFCI Status Report to Congress - draft to DOE & January 2007 \\
\hline FY-07 Comparison Report to Congress - draft to DOE & February 2007 \\
\hline $\begin{array}{l}\text { Establish Partnership Knowledge Center (PKC) Steering Committee consisting of } \\
\text { representatives inside and outside of the GNEP community. }\end{array}$ & April 2007 \\
\hline Initial GNEP waste form descriptions & August 2007 \\
\hline Small reactors requirements & August 2007 \\
\hline $\begin{array}{l}\text { Report on waste form and waste process technology specific data developed to } \\
\text { support an Integrated Waste Management Strategy }\end{array}$ & August 2007 \\
\hline $\begin{array}{l}\text { DOE-NE technical input for Secretarial recommendation to congress on the need for } \\
\text { a second repository }\end{array}$ & September 2007 \\
\hline Initial Qualitative Program Risk Factor Assessment & September 2007 \\
\hline GNEP deployment systems analysis & September 2007 \\
\hline \multicolumn{2}{|l|}{ LWR Spent Nuclear Fuel Separation Technologies } \\
\hline $\begin{array}{l}\text { Complete Engineering Alternatives Study (EAS) inputs to the Programmatic } \\
\text { environmental Impact Statement (PEIS) for a spent fuel recycling facility }\end{array}$ & June 2007 \\
\hline Provide input for industry engagement on conceptual design studies & June 2007 \\
\hline Develop remote contactor design concepts and initiate test component fabrication & September 2007 \\
\hline \multicolumn{2}{|l|}{ Transmutation Technologies } \\
\hline Develop Reference commercial ABR Concept & September 2007 \\
\hline First mechanical tests performed on 155 dpa HT-9 Duct (AC)3) & September 2007 \\
\hline \multicolumn{2}{|l|}{ Transmutation Fuels and Separations Technologies } \\
\hline AFCF $30 \%$ conceptual design for review & January 2007 \\
\hline Insert FUTURIX-FTA irradiation test in Phenix reactor (external) & May 2007 \\
\hline Begin ATR irradiation of metal transmutation fuels containing Ln & September 2007 \\
\hline Revision of fuels handbook/with available characterization data & September 2007 \\
\hline \multicolumn{2}{|l|}{ GNEP Reactors for International Deployment } \\
\hline Select SMR technology for near-term deployment & May 2007 \\
\hline Complete initial needs/requirements assessments & September 2007 \\
\hline \multicolumn{2}{|l|}{ Modeling and Simulation } \\
\hline $\begin{array}{l}\text { Complete simulations of heat transport and oxygen diffusion coupled with thermal } \\
\text { expansion in } \mathrm{UO}_{2} \text { fuels with metal cladding }\end{array}$ & September 2007 \\
\hline Complete models of thermo-mechanical properties and phase stability of metal fuels & September 2007 \\
\hline Status report on oxide model development for SE2 & September 2007 \\
\hline Report on uncertainty quantification for selected ATWS sequences & September 2007 \\
\hline \multicolumn{2}{|l|}{ FY08 } \\
\hline \multicolumn{2}{|l|}{ Systems Integration and Analysis } \\
\hline AFCI Status Report to Congress - draft to DOE & December 2007 \\
\hline
\end{tabular}




\begin{tabular}{|c|c|}
\hline & Date \\
\hline GNEP Technical Requirements & December 2007 \\
\hline FY-08 Comparison Report to Congress - draft to DOE & February 2008 \\
\hline Input and support for NEPA alternatives and technology options evaluations & March 2008 \\
\hline Complete input to 2008 Decision Package & March 2008 \\
\hline Integrated Waste Management Strategy & March 2008 \\
\hline Global Benefits Analysis of GNEP & March 2008 \\
\hline Report on evaluation of GNEP fuel cycle deployment options & April 2008 \\
\hline Report on initial assessment of global proliferation risk and GNEP impact & May 2008 \\
\hline Report on GNEP Facilities and Fuel Cycle Strategy & June 2008 \\
\hline Decision on startup fuel (oxide or metal) for fast reactor & August 2008 \\
\hline $\begin{array}{l}\text { Implement pilot PKC that demonstrates multiple predefined use cases for specific } \\
\text { applications. }\end{array}$ & August 2008 \\
\hline Evaluation of material management requirement for fuel take-back strategies & September 2008 \\
\hline Report on domestic and global demand for GNEP technology & September 2008 \\
\hline GNEP Initial Facilities Systems Analysis & September 2008 \\
\hline Update GNEP Deployment Systems Analysis & September 2008 \\
\hline \multicolumn{2}{|l|}{ LWR Spent Nuclear Fuel Separation Technologies } \\
\hline Develop Tc solidification flowsheet and initiate bench-scale tests & March 2008 \\
\hline Support $30 \%$ completion of industrial conceptual designs & April 2008 \\
\hline Complete pilot-scale testing of $\mathrm{Cs} / \mathrm{Sr}$ steam reforming process & April 2008 \\
\hline Complete EAS design package for review & April 2008 \\
\hline Develop instrumentation and control systems conceptual designs & May 2008 \\
\hline Initiate procurement of off gas system components for testing & June 2008 \\
\hline Demonstrate metallic waste form for cladding hulls incorporating technetium & September 2008 \\
\hline \multicolumn{2}{|l|}{ Transmutation Technologies } \\
\hline Retrieve FFTF irradiated (up to $200 \mathrm{dpa}$ ) mechanical test specimens & January 2008 \\
\hline ABR Prototype Design Study Complete & May 2008 \\
\hline Sodium component testing infrastructure evaluation & May 2008 \\
\hline Initiate sodium component technology development evaluation & September 2008 \\
\hline Identification of Prototype Design Tools by Industrial Team & September 2008 \\
\hline Complete Study on Alternate Configurations Options & September 2008 \\
\hline Identify key experiments using representativity techniques & September 2008 \\
\hline \multicolumn{2}{|l|}{ Transmutation Fuels and Separations Technologies } \\
\hline Complete AFCF system trade studies & April 2008 \\
\hline Begin ATR irradiation of oxide transmutation fuels & April 2008 \\
\hline Establish a list of advanced instruments to be further developed for demonstration & June 2008 \\
\hline AFCF 70\% Conceptual Design for Review & September 2008 \\
\hline Metal Fuel RFFL ready for operation & September 2008 \\
\hline Complete JOYO irradiation test plan & September 2008 \\
\hline
\end{tabular}




\begin{tabular}{|c|c|}
\hline & Date \\
\hline Complete FUTURIX-FTA PIE plan & September 2008 \\
\hline SESAME framework completed & September 2008 \\
\hline \multicolumn{2}{|l|}{ GNEP Reactors for International Deployment } \\
\hline Initial screening of next-generation SMR concepts & March 2008 \\
\hline Select next-generation SMR(s) for pre-conceptual design & June 2008 \\
\hline \multicolumn{2}{|l|}{ Modeling and Simulation } \\
\hline $\begin{array}{l}\text { Document the GNEP business (why) and functional (what) requirements for all } \\
\text { Modeling and Simulation activities. }\end{array}$ & December 2007 \\
\hline Formal software releases in support of ABR design studies & September 2008 \\
\hline GNEP System Level Planning Tool Design Document & September 2008 \\
\hline \multicolumn{2}{|l|}{ FY09 } \\
\hline \multicolumn{2}{|l|}{ Systems Integration and Analysis } \\
\hline AFCI Status Report to Congress- draft to DOE & December 2008 \\
\hline FY-09 Comparison Report to Congress - draft to DOE & February 2009 \\
\hline Report on evaluation of international implementation issues & March 2009 \\
\hline Detailed fuel cycle performance data for GNEP reference technology option & July 2009 \\
\hline Generate the specification for the hardware system necessary to support the PKC & July 2009 \\
\hline $\begin{array}{l}\text { Databases that contain historical data not currently accessible from modern } \\
\text { repositories will be developed and made available to PKC users }\end{array}$ & August 2009 \\
\hline Integrated total quantitative GNEP risk analysis & September 2009 \\
\hline Update GNEP Initial Facilities Systems Analysis & September 2009 \\
\hline Update GNEP Deployment Systems Analysis & September 2009 \\
\hline Report on cost and performance experience for GNEP technologies & September 2009 \\
\hline \multicolumn{2}{|l|}{ LWR Spent Nuclear Fuel Separation Technologies } \\
\hline Develop initial waste formulation for fission product HLW & December 2008 \\
\hline Develop reference off-gas treatment process & January 2009 \\
\hline Complete initial characterization of mixed transuranic solid product & January 2009 \\
\hline Initiate demonstration of remote waste form packaging & March 2009 \\
\hline Complete evaluation of HLW forms & April 2009 \\
\hline Complete initial demonstration of steam reforming Cs/Sr product & May 2009 \\
\hline Validate UREX process performance with solvent recycle & May 2009 \\
\hline Complete demonstration of Tc solidification process & May 2009 \\
\hline Complete bench-scale demonstration of mixed transuranics solidification & June 2009 \\
\hline Complete bench-scale demonstration of $\mathrm{Cs} / \mathrm{Sr}$ solidification technology & September 2009 \\
\hline Complete initial integrated testing of separation processes with surrogates & September 2009 \\
\hline Support completion of conceptual design for nuclear fuel recycling center & September 2009 \\
\hline \multicolumn{2}{|l|}{ Transmutation Technologies } \\
\hline Sodium Component Test Infrastructure Design/Build Start & October 2008 \\
\hline Retrieve Specimens from MATRIX irradiation in Phoenix Reactor & November 2008 \\
\hline
\end{tabular}




\begin{tabular}{|c|c|}
\hline & Date \\
\hline Startup Fuel Fabrication Options Study with Down Selection & January 2009 \\
\hline Implementation Plan for TREAT Restart & April 2009 \\
\hline ABR Prototype Preliminary Hazards Analysis Complete & June 2009 \\
\hline ABR Prototype Conceptual Design Complete & September 2009 \\
\hline ABR Prototype CD-1 Approval & September 2009 \\
\hline Plan for Prototype Design Tools V\&V & September 2009 \\
\hline Complete Initial Design Options Evaluation & September 2009 \\
\hline Produce new evaluations from and covariance for priority isotopes & September 2009 \\
\hline \multicolumn{2}{|l|}{ Transmutation Fuels and Separations Technologies } \\
\hline Complete AFCF alternatives analysis strategy & December 2008 \\
\hline Acquisition strategy submittal for approval & March 2009 \\
\hline Complete $\mathrm{CD}-1$ package for $\mathrm{AFCF}$ & June 2009 \\
\hline Complete FUTURIX-FTA irradiations (external) & June 2009 \\
\hline $\begin{array}{l}\text { Develop baseline pyrochemical flowsheets for treating spent metal and oxide } \\
\text { transmutation fuel }\end{array}$ & July 2009 \\
\hline $\begin{array}{l}\text { Demonstrate feasibility of fast reactor MOX fuel to metal conversion by electrolytic } \\
\text { reduction process }\end{array}$ & August 2009 \\
\hline Demonstrate metal fuel fabrication in RFFL's & September 2009 \\
\hline Demonstrate feasibility of voloxidation of fast reactor MOX fuel & September 2009 \\
\hline Define framework for advanced control logic & September 2009 \\
\hline Evaluate alternative crucibles for TRU recovery & September 2009 \\
\hline \multicolumn{2}{|l|}{ GNEP Reactors for International Deployment } \\
\hline Select near-term PRIMR design for safety evaluation support & January 2009 \\
\hline \multicolumn{2}{|l|}{ Modeling and Simulation } \\
\hline $\begin{array}{l}\text { M\&S tools (legacy and developing) directly supporting the ABR will be identified, } \\
\text { qualified through V\&V assessments, and placed under configuration control in } \\
\text { conformance with a QA plan. }\end{array}$ & December 2008 \\
\hline $\begin{array}{l}\text { M\&S tools (legacy and developing) directly supporting the CFTC will be identified, } \\
\text { qualified through V\&V assessments, and placed under configuration control in } \\
\text { conformance with a QA plan. }\end{array}$ & December 2008 \\
\hline $\begin{array}{l}\text { M\&S tools (legacy and developing) directly supporting the AFCF will be identified, } \\
\text { qualified through V\&V assessments, and placed under configuration control in } \\
\text { conformance with a QA plan. }\end{array}$ & December 2008 \\
\hline Formal V\&V assessment of ABR software & March 2009 \\
\hline Issue Initial GNEP System Level Planning Tool 1.0. & September 2009 \\
\hline Formal software releases for ABR design studies & September 2009 \\
\hline \multicolumn{2}{|l|}{ FY10 } \\
\hline \multicolumn{2}{|l|}{ Systems Integration and Analysis } \\
\hline AFCI Status Report to Congress - draft to DOE & December 2009 \\
\hline FY-10 Comparison Report to Congress - draft to DOE & February 2010 \\
\hline
\end{tabular}




\begin{tabular}{|c|c|}
\hline & Date \\
\hline Transition the pilot into the production level PKC & August 2010 \\
\hline $\begin{array}{l}\text { Create a specification for the addition of future data sets into the PKC that will be } \\
\text { automatically curated }\end{array}$ & August 2010 \\
\hline Update GNEP Initial Facilities Systems Analysis & September 2010 \\
\hline Update GNEP Deployment Systems Analysis & September 2010 \\
\hline \multicolumn{2}{|l|}{ LWR Spent Nuclear Fuel Separation Technologies } \\
\hline Complete initial Cs/Sr waste form characterization & October 2009 \\
\hline Demonstrate off-gas treatment system and waste forms & November 2009 \\
\hline Complete bench-scale demonstration of fission product waste form & March 2010 \\
\hline Complete mockup testing of prototype head-end equipment & July 2010 \\
\hline \multicolumn{2}{|l|}{ Transmutation Technologies } \\
\hline Code validation facilities plan & October 2009 \\
\hline Conceptual Design of Startup Fuel Fab Line & January 2010 \\
\hline Complete tensile and fracture toughness testing of FFTF irradiated materials & January 2010 \\
\hline Restart/construct required validation facilities & September 2010 \\
\hline Scaled demonstration of supercritical $\mathrm{CO}_{2}$ Brayton Cycle & September 2010 \\
\hline Prepare material specimens of advanced materials for JOYO irradiation & September 2010 \\
\hline Issue new revision of materials handbook with FFTF material data & September 2010 \\
\hline Perform uncertainty analysis with new covariance date & September 2010 \\
\hline \multicolumn{2}{|l|}{ Transmutation Fuels and Separations } \\
\hline Oxide Fuel RFFL ready for operation & December 2009 \\
\hline Demonstrate scale-up of ceramic waste process & March 2010 \\
\hline Complete initial testing of synroc and zeolite waste forms for cesium/strontium & April 2010 \\
\hline Identify safeguards requirements for pyroprocessing facility & May 2010 \\
\hline Identify optimum fission product loading and decay heat for ceramic waste form & May 2010 \\
\hline $\begin{array}{l}\text { Select product processing / consolidation technology for uranium product and TRU } \\
\text { product }\end{array}$ & August 2010 \\
\hline Begin PIE of FUTURIX-FTA specimens (dependant upon external schedule) & September 2010 \\
\hline Develop Sphere-pac fuel design concepts & September 2010 \\
\hline Develop Dispersion fuel design concepts & September 2010 \\
\hline Complete Feasibility assessment of innovative processes (microwave, combustion) & September 2010 \\
\hline $\begin{array}{l}\text { Identify and evaluate alternative product processing technologies selecting preferred } \\
\text { alternative }\end{array}$ & September 2010 \\
\hline Establish preliminary TRU recovery process parameters & September 2010 \\
\hline Validate performance of novel crucible materials in cathode processor system & September 2010 \\
\hline Conduct feasibility studies for preferred alternative product processing technology & September 2010 \\
\hline
\end{tabular}




\begin{tabular}{|c|c|}
\hline & Date \\
\hline Establish a test bed with relevant environment for instrument testing & September 2010 \\
\hline \multicolumn{2}{|l|}{ GNEP Reactors for International Deployment } \\
\hline Submit application for NRC design approval for near-term SMR & September 2010 \\
\hline \multicolumn{2}{|l|}{ Modeling and Simulation } \\
\hline Conduct demonstration of simulation capabilities for ABR & December 2009 \\
\hline Issue GNEP System Level Planning Tool 2.0. & June 2010 \\
\hline \multicolumn{2}{|l|}{ FY11 } \\
\hline \multicolumn{2}{|l|}{ Systems Integration and Analysis } \\
\hline AFCI Status Report to Congress - draft to DOE & December 2010 \\
\hline FY-11 Comparison Report to Congress - draft to DOE & February 2011 \\
\hline First Release of New Systems Level Planning Tool & August 2011 \\
\hline Per need-to-know, extend PKC user base to include universities and private industry & August 2011 \\
\hline Update GNEP Initial Facilities Systems Analysis & September 2011 \\
\hline Update GNEP Deployment Systems Analysis & September 2011 \\
\hline \multicolumn{2}{|l|}{ LWR Spent Nuclear Fuel Separation Technologies } \\
\hline Demonstrate process monitoring and control system for separation processes & May 2011 \\
\hline Convert AMUSE code to higher level platform, and incorporate transients & July 2011 \\
\hline Support completion of preliminary design for nuclear fuel recycling center & September 2011 \\
\hline \multicolumn{2}{|l|}{ Transmutation Technologies } \\
\hline ABR Prototype Preliminary Safety Analysis Report Complete & April 2011 \\
\hline Preliminary Design of Startup Fuel Fab Line & July 2011 \\
\hline Initiate Validation Studies for Advanced Methods & September 2011 \\
\hline \multicolumn{2}{|l|}{ Transmutation Fuels and Separations Technologies } \\
\hline Begin ATR irradiation of remotely fabricated fuels & October 2010 \\
\hline TRU metal-fuel specimens for JOYO fabricated in RFFL & December 2010 \\
\hline $\begin{array}{l}\text { Complete voloxidation demonstration and make go/no go decision of inclusion in } \\
\text { initial UREX+ testing. }\end{array}$ & April 2011 \\
\hline Develop process simulation model for treating spent advanced burner reactor fuel & August 2011 \\
\hline AFCF $70 \%$ preliminary design review & September 2011 \\
\hline Start ATR irradiation of dispersion, sphere-pac fuels, targets & September 2011 \\
\hline Complete Nitride fuel fabrication process baseline design & September 2011 \\
\hline Demonstrate electrorefining with salt containing a high TRU concentration & September 2011 \\
\hline Initial model for AFCF aqueous processing module & September 2011 \\
\hline \multicolumn{2}{|l|}{ GNEP Reactors for International Deployment } \\
\hline Down-select to 2 next-generation SMR conceptual designs & January 2011 \\
\hline \multicolumn{2}{|l|}{ Modeling and Simulation } \\
\hline GNEP System Level Planning Tool 3.0 & March 2011 \\
\hline
\end{tabular}




\begin{tabular}{|c|c|}
\hline & Date \\
\hline \multicolumn{2}{|l|}{ FY12 } \\
\hline \multicolumn{2}{|l|}{ Systems Integration and Analysis } \\
\hline AFCI Status Report to Congress - draft to DOE & December 2011 \\
\hline FY-12 Comparison Report to Congress - draft to DOE & February 2012 \\
\hline Update GNEP Initial Facilities Systems Analysis & September 2012 \\
\hline Update GNEP Deployment Systems Analysis & September 2012 \\
\hline Decision on Transmutation Fuel for Fast Reactor & September 2012 \\
\hline \multicolumn{2}{|l|}{ LWR Spent Nuclear Fuel Separation Technologies } \\
\hline Complete initial characterization of high-level waste forms & July 2012 \\
\hline \multicolumn{2}{|l|}{ Transmutation Technologies } \\
\hline $\begin{array}{l}\text { Complete mechanical testing of specimens from MATRIX irradiation (advanced } \\
\text { materials irradiated up to } 70 \mathrm{dpa} \text { ) }\end{array}$ & November 2011 \\
\hline Validate multiscale materials performance modeling code & February 2012 \\
\hline ABR Prototype Preliminary Design Complete & April 2012 \\
\hline ABR Prototype CD-2 Approve Performance Baseline & May 2012 \\
\hline Complete Validation of First Improved Structural Material & September 2012 \\
\hline \multicolumn{2}{|l|}{ Transmutation Fuels and Separations Technologies } \\
\hline Begin ATR irradiation for high temperature limits & October 2011 \\
\hline Domestic fast spectrum rodlet irradiation capability available & December 2011 \\
\hline Evaluate UREX+1a flowsheet for transmutation fuel & August 2012 \\
\hline Demonstrate on-line product recovery from uranium electrorefiner system & August 2012 \\
\hline Complete AFCF preliminary design & September 2012 \\
\hline Ship initial fuel for JOYO irradiations & September 2012 \\
\hline Complete ATR irradiations of dispersion and sphere-pac fuels, targets & September 2012 \\
\hline Down-select instrumentation for initial demonstration & September 2012 \\
\hline Initial demonstration of advanced control logic & September 2012 \\
\hline Initial model for AFCF pyroprocessing module & September 2012 \\
\hline \multicolumn{2}{|l|}{ GNEP Reactors for International Deployment } \\
\hline Award up to two contracts for conceptual designs of next-generation SMR & March 2012 \\
\hline \multicolumn{2}{|l|}{ Modeling and Simulation } \\
\hline GNEP System Level Planning Tool 4.0 & September 2012 \\
\hline
\end{tabular}


There are two important but distinct crosscutting areas that are considered in this plan: modeling and simulation $(M \& S)$ and international safeguards and proliferation risk reduction. M\&S offers the prospect of reduced costs and accelerated demonstration if the advances in modern computation can be harnessed to support the development of nuclear technology. International safeguards and proliferation risk reduction is a core element of the GNEP vision that must be viewed as an integral part of the technology demonstration. In both cases, the basic technology functions identify their needs in terms of these crosscutting technologies. These needs are then integrated into a separate program element with associated cost estimates and milestones.

Establishing the highest degree of safety for the facilities and operations of the entire GNEP system as currently envisioned is essential both for the success of the program and for the future of nuclear energy in the U.S. The outstanding overall safety record of commercial nuclear power in the U.S., along with a decades-long trend of improving operational and personnel safety statistics, is steadily overcoming public concerns about nuclear safety. However, the GNEP infrastructure will require the development of several new types of facilities, as described in the previous section, for which there is no relevant commercial experience within the U.S. To support the successful development of the commercial GNEP facilities, the first GNEP facilities (ABR, CFTC, and AFCF) would establish that the desired level of safety for all facilities can be achieved.

This report documents a proposed plan for the GNEP Technology Development Program, which will continue to evolve. More detailed planning now in progress will include consideration of systems analyses, improved risk identification and management, and incorporation of additional decisions on facility sizing and technology selections. This plan provides a basis for merging technology planning with DOE project management for the GNEP program. It also provides a basis for initiating work among DOE, national laboratories, universities, industry, and the international community to define and develop areas of technical cooperation for the program.

A key assumption in the development of this plan is that the cost information for FY-2007 is based on the actual budget of $\$ 167.5 \mathrm{M}$, and the FY-2008 cost estimate total is set to the president's request. Cost estimates beyond FY-2008 are unconstrained. 


\section{CONTENTS}

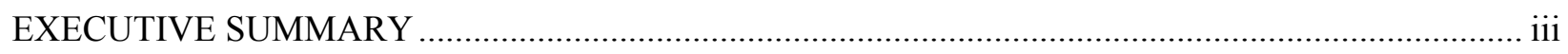

1.0 Introduction to the Global Nuclear Energy Partnership (GNEP) Technology Development

Plan

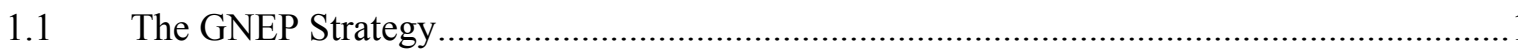

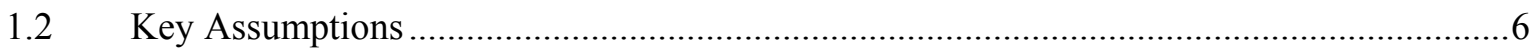

1.3 GNEP Deployment System Architecture .....................................................................

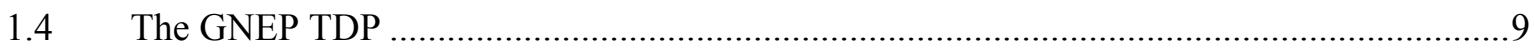

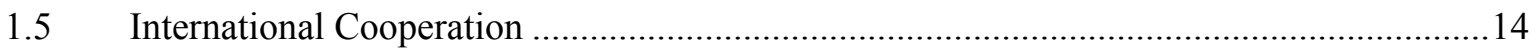

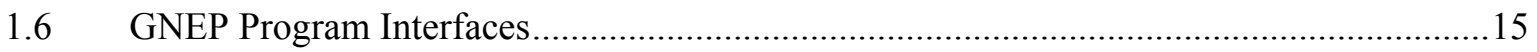

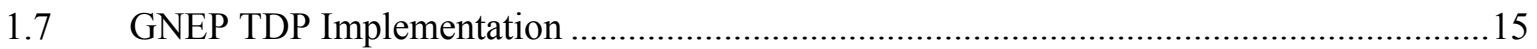

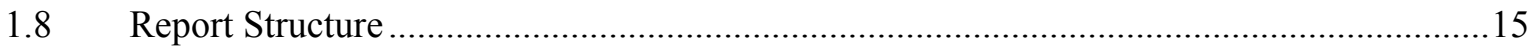

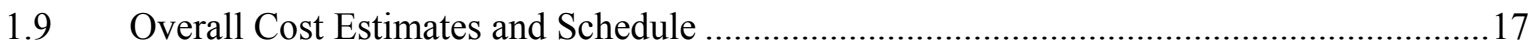

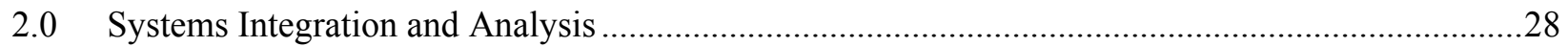

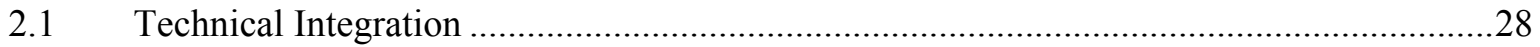

2.2 Systems Analysis to Support GNEP Deployment ….....................................................

2.3 Systems Analysis to Support First GNEP Facilities .......................................................3

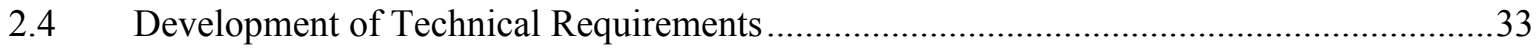

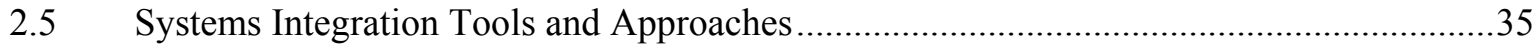

2.6 Systems Analysis Support to 2008 Decision on GNEP Path Forward ...............................40

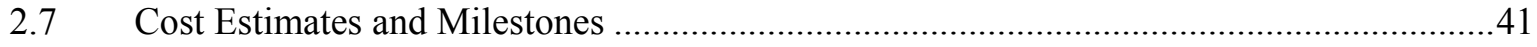

3.0 LWR Spent Nuclear Fuel Separation Technologies ................................................................43

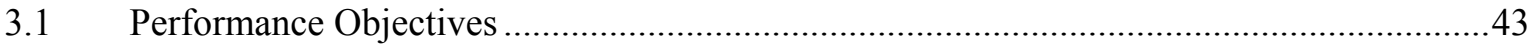

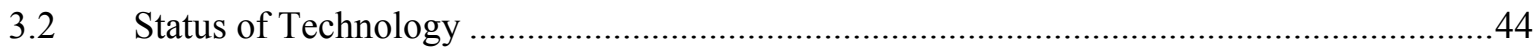

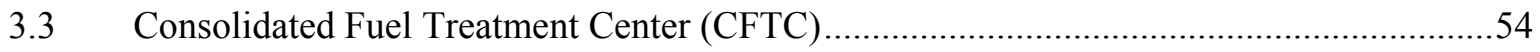

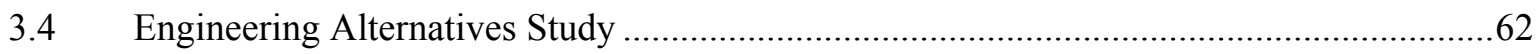

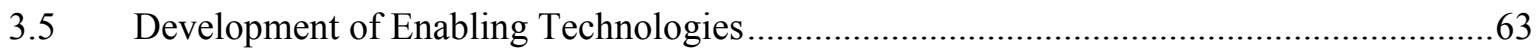




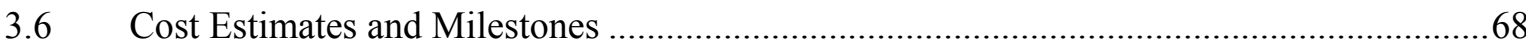

4.0 Transmutation Technologies using Fast Reactors...................................................................... 70

4.1 Advanced Recycling Reactor Performance Objectives ...................................................70

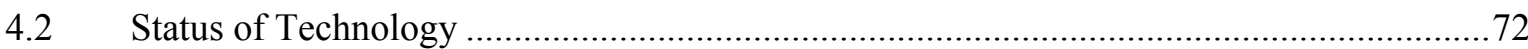

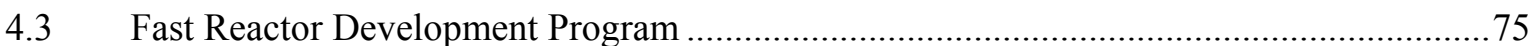

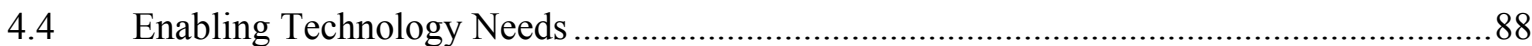

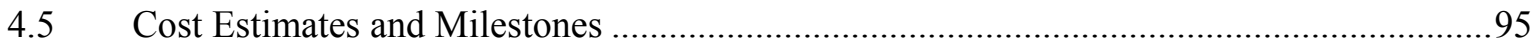

5.0 Transmutation Fuels and Separations Technologies.................................................................. 100

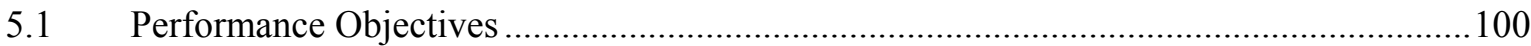

5.2 Status of Transmutation Fuels and Separations Technologies.........................................102

5.3 Transmutation Fuels and Separations Demonstration Program .......................................115

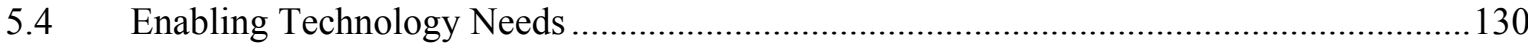

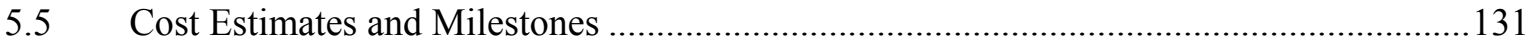

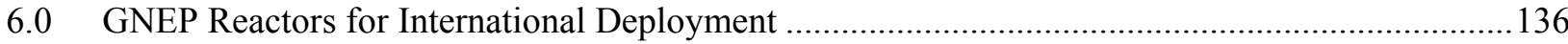

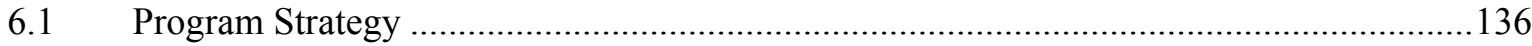

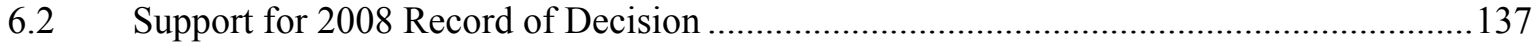

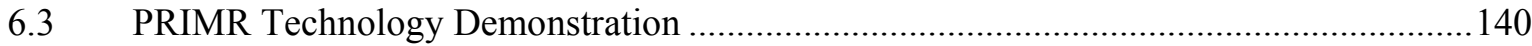

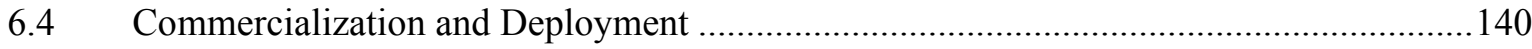

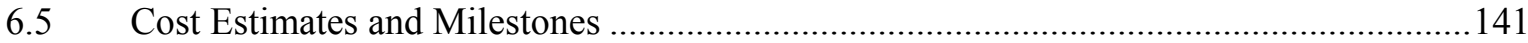

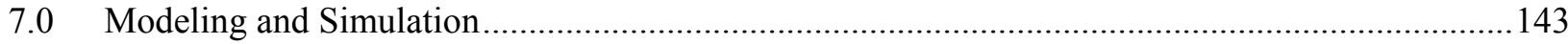

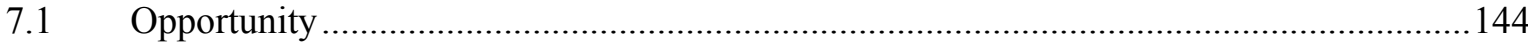

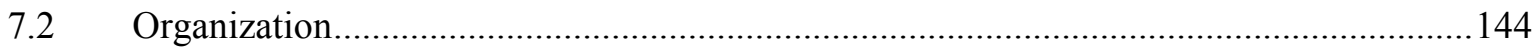

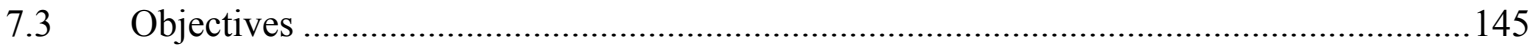

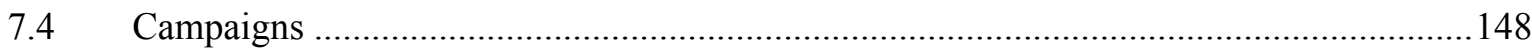

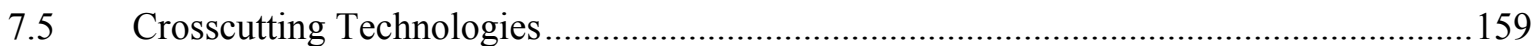

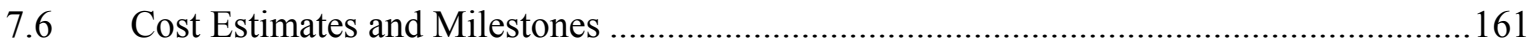


8.0 International Safeguards and Proliferation Risk Reduction .......................................................163

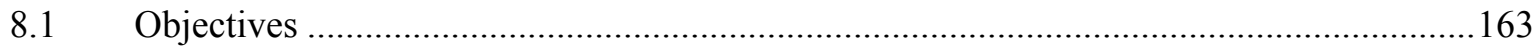

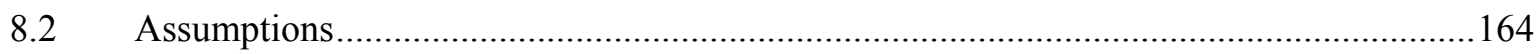

8.3 Proliferation Risk Reduction Assessment .................................................................... 166

8.4 Challenges in Meeting IAEA Safeguards Goals and Requirements for GNEP

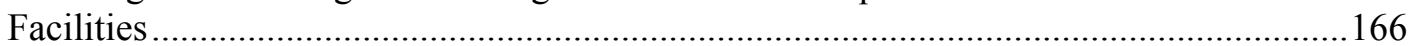

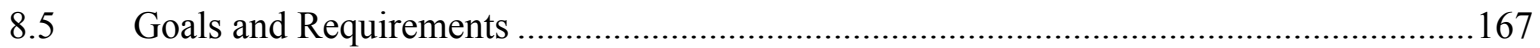

8.6 IAEA Significant Quantities, Conversion Times and Diversion Scenarios.......................168

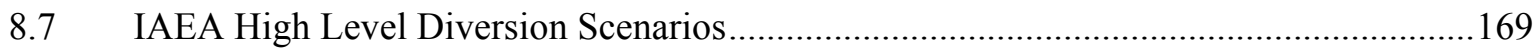

8.8 International Safeguards Approach for GNEP Facilities ...............................................169

8.9 Comprehensive Approach to Safeguards ................................................................ 170

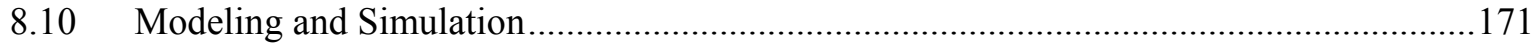

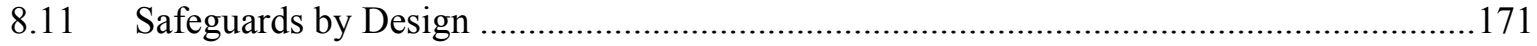

8.12 Advanced Measurement Technologies and Instrumentation .........................................172

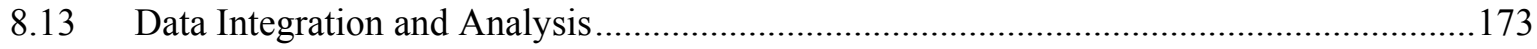

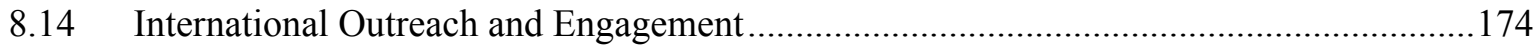

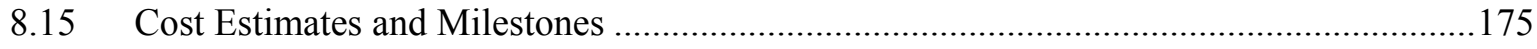




\section{Tables}

Table 1. GNEP Overall Cost Estimates Needed to Achieve Milestones in the Report .17

Table 2. GNEP Overall Milestones Projection .21

Table 3. Cost Estimates for Systems Integration and Analysis ............................................................41

Table 4. Systems Integration and Analysis Milestones ........................................................................ 41

Table 5. Cost Estimates for the LWR Spent Nuclear Fuel Separation Technologies ...............................68

Table 6. LWR Spent Nuclear Fuel Separations Technology Development Milestones............................69

Table 7. Cost Estimates for Transmutation Technologies...................................................................95

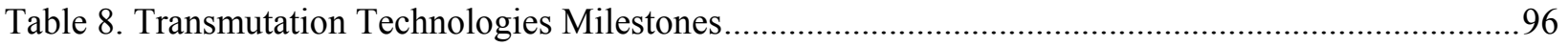

Table 9. Transmutations, Fuels, and Separations Technologies Milestones ......................................... 132

Table 10. Cost Estimates for Transmutations, Fuels, and Separations Technologies .............................134

Table 11. Cost Estimates Projection for PRIMR System Development and Demonstration ....................141

Table 12. Top Level Milestones for PRIMR System Development and Demonstration .........................142

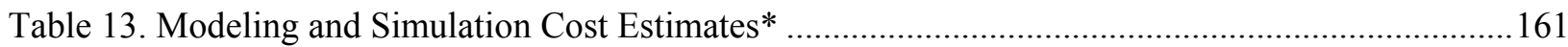

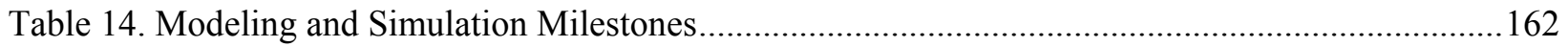

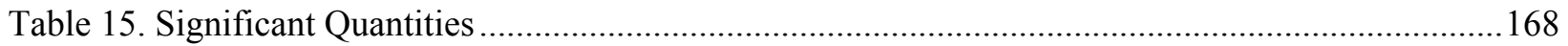

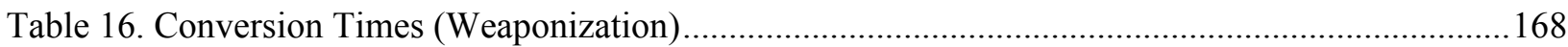

Table 17. Cost Estimates for International Safeguards and Proliferation Risk Reduction....................... 175

Table 18. International Safeguards and Proliferation Risk Reduction Milestones..................................176 


\section{Figures}

Figure 1. Initial GNEP deployment system architecture ...............................................................

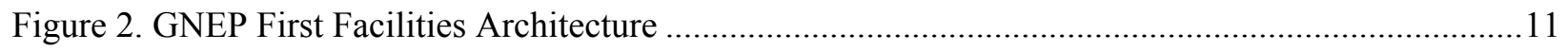

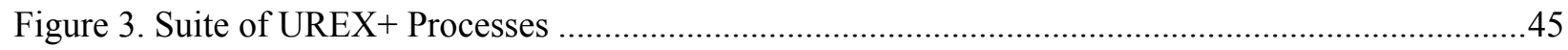

Figure 4. Schematic Illustration of the Reference UREX+1a Separations Process..................................48

Figure 5. Principal activities to develop GNEP reactors for international deployment .........................138 
ABR

ACRR

AFCF

AFCI

ALMR

ALWR

AMUSE

ANS

ASME

ATR

AXRF

BOP

$\mathrm{C} / \mathrm{S}$

CANDU

CCD-PEG

CD

CEA

CFD

CRBRP

DA

DBT

DD

DEPO

DFT

DNL

DOE

DOT

DTPA

EAS

EBR

EFL

EIS

EM

ENDF

EPACT

FBSR

FCF

FFTF

FKMP

FMF

FOAK

FPEX

FR

GIF

GNEP

\section{ACRONYMS}

Advanced Burner Reactor

Annular Core Research Reactor

Advanced Fuel Cycle Facility

Advanced Fuel Cycle Initiative

Advanced Liquid Metal Reactor

Advanced Light Water Reactor

Argonne Model for Universal Solvent Extraction

American Nuclear Society

American Society of Mechanical Engineers

Advanced Test Reactor

Accelerator Stimulated X-Ray Fluorescence

Balance of Plant

Containment/Surveillance

Canadian deuterium-uranium

Chlorinated Cobalt Dicarbollide-polyethylene Glycol

Critical Decision

Commissariat a l'Energie Atomique

Computational Fluid Dynamics

Clinch River Breeder Reactor Project

Destructive Assay

Design Basis Threat

Dislocation Dynamics

Design and Evaluation Process Outline

Density Functional Theory

Delayed Neutron Lifetime Measurement

U.S. Department of Energy

Department of Transportation

Diethylene Triamine Pentaacetic Acid

Engineering Alternatives Study

Experimental Breeder Reactor

Eligible Facilities List

Environmental Impact Statement

Electro-Magnetic

Evaluated Nuclear Data Files

Energy Policy Act

Fluidized Bed Steam Reforming

Fuel Conditioning Facility

Fast Flux Test Facility

Flow Key Measurement Points

Fuel Manufacturing Facility

First-of-a-kind

Fission Product Extraction

Fast Reactors

Generation IV International Forum

Global Nuclear Energy Partnership 
GNEP-TD

GNEP-TDP

GRID

HEU

$\mathrm{HF}$

HLNW

HLW

HPC

IAEA

ID

IFR

IKMP

INL

INSEP

IPCS

IR

ISCADA

JOYO

KMC

LANSCE

LEU

LLW

LTA

LWR

$M \& S$

MA

MC\&A

MD

MONJU

MOTA

MOX

MTHM

MTS

MUF

NDA

NE

NEPA

NICS

NNSA

NNWS

NOAK

NRC

NRTA
Global Nuclear Energy Partnership Technology Demonstration

Global Nuclear Energy Partnership Technology Development Program

GNEP Reactors for International Deployment

High Enriched Uranium

Hydrogen Fluoride

High-level nuclear waste

High level waste

High Performance Computing

International Atomic Energy Agency

Inventory Difference

Integral Fast Reactor

Inventory Key Measurement Points

Idaho National Laboratory

International Nuclear Safeguards and Engagement Program

Intelligent Process Control System

Interrogation Radiation

Intelligent Supervisory Control and Data Acquisition Systems

Japan Experimental Fast Reactor

Kinetic Monte Carlo

Los Alamos Neutron Science Center

Low Enriched Uranium

Low level waste

Lead Test Assembly

Light Water Reactor

Modeling and Simulation

Minor Actinide

Material Control and Accountability

Molecular Dynamics

MONJU Fast Reactor (Japan)

Materials Open Test Assemblies

Mixed Oxide Fuel

Metric tons of original heavy metal

Materials Test Station

Materials Unaccounted For

None-destructive Assay

Office of Nuclear Energy

National Environmental Policy Act

Neutron Integral Cross Section Spectroscopy

National Nuclear Security Administration

None-nuclear Weapon States

Nth-of-a-kind

Nuclear Regulatory Commission

Near-Real-Time-Accountancy 


\begin{tabular}{|c|c|}
\hline NWS & Nuclear Weapon State \\
\hline OECD & Organization for Economic Cooperation and Development \\
\hline OSP & Other Strategic Points \\
\hline PEER & Planar Electrode Electrorefiner \\
\hline PEIS & Programmatic Environmental Impact Statement \\
\hline PEP & Project Execution Plan \\
\hline PIE & Post Irradiation Examination \\
\hline PKC & Partnership Knowledge Center \\
\hline $\mathrm{PP}$ & Physical Protection \\
\hline PPS & Physical Protection System \\
\hline PR & Proliferation Risk \\
\hline PR\&PP & Proliferation Resistance and Physical Protection \\
\hline PRA & Probabilistic Risk Assessment \\
\hline PRIMR & Proliferation-resistant International Modular Reactors \\
\hline PRISM LMR & Power Reactor Innovative Small Module Liquid-Metal Reactor \\
\hline PUREX & Plutonium-Uranium Extraction (plant) \\
\hline QA & Quality Assurance \\
\hline $\mathrm{R} \& \mathrm{D}$ & Research and Development \\
\hline RCRA & Resource Conservation and Recovery Act \\
\hline RFFL & Remote Fuel Fabrication Laboratory \\
\hline RFID & Radio-Frequency Identification Device \\
\hline RW & Office of Civilian Radioactive Waste Management \\
\hline $\mathrm{S} / \mathrm{U}$ & Sensitivity and Uncertainty \\
\hline $\mathrm{SC}$ & Office of Science \\
\hline SCA & Safeguards Cooperation Agreements \\
\hline SESAME & Simulation Enabled Safeguards Assessment Methodology \\
\hline SFR & Sodium-cooled Fast Reactors \\
\hline SMR & Small Modular Reactor \\
\hline SNF & Spent Nuclear Fuel \\
\hline SQ & Significant Quantity \\
\hline SSI & Soil-structure-interaction \\
\hline TALSPEAK & $\begin{array}{l}\text { Trivalent Actinide Lanthanide Separations by Phosphorus-reagent Extraction from } \\
\text { Aqueous Complexes }\end{array}$ \\
\hline TIMC & Transformational Intelligent Accounting and Control \\
\hline TREAT & Transient Reactor Test Facility \\
\hline TRU & Transuranic \\
\hline TRUEX & Transuranic Extraction \\
\hline UREX & Uranium Extraction (plant) \\
\hline $\mathrm{V} \& \mathrm{~V}$ & Verification and Validation \\
\hline VISION & Verifiable Fuel Cycle Simulation Model \\
\hline WAC & Waste Acceptance Criteria \\
\hline
\end{tabular}


ZIRFLEX

ZPPR

ZPR

Zirconium Fluoride Extraction

Zero Power Physics Reactor

Zero-Power Reactors 


\section{GLBAL NUCLEAR ENERGY PARTNERSHIP TECHNOLOGY DEVELOPMENT PLAN}

July 25, 2007

\subsection{Introduction to the Global Nuclear Energy Partnership (GNEP) Technology Development Plan}

This plan is the combined effort of ten Department of Energy national laboratories: Savannah River National Laboratory, Sandia National Laboratory, Pacific Northwest National Laboratory, Oak Ridge National Laboratory, Los Alamos National Laboratory, Lawrence Livermore National Laboratory, Lawrence Berkeley National Laboratory, Idaho National Laboratory, Brookhaven National Laboratory, and Argonne National Laboratory. The plan describes the Global Nuclear Energy Partnership (GNEP) Technology Development Program as envisioned by the laboratories. It has been prepared to guide the development by DOE of integrated plans for realizing the domestic portion of the GNEP vision as well as providing a basis for developing international cooperation. The cost information in this document is based on estimates from the national laboratory participants, and does not represent annual budget estimates from the Department of Energy.

Beginning with the GNEP overall goals, this plan describes the basic technical objectives for each element of the program, summarizes the technology status and identifies the areas of greatest technical risk. On this basis a proposed technology development program is described that can deliver the required information for a Secretarial decision on the path forward of GNEP in 2008 and support construction of new advanced fuel cycle facilities, if the chosen path includes them.

The proposed TDP is predicated upon the construction of an integrated suite of fuel cycle facilities in the following decade. However, at this time the United States (U.S.) Government has not finalized a specific process for facility construction or the scope of international cooperation. Furthermore, siting of any of the proposed facilities will be determined by a separate process, following applicable laws and appropriate decision-making precesses. Therefore, this document focuses entirely on what the technology needs are, why they are needed, and when it could be completed and not on where or by whom any of the required development work is to be done. This plan does not necessarily reflect the views and decisions of DOE with regard to current and future activities of the GNEP program, and may be updated, as needed.

The Global Nuclear Energy Partnership Strategic Plan (GNEP-167312) describes the strategy for realizing the GNEP vision. A brief summary of the Strategic Plan is included in this section to set the stage for the TDP.

\subsection{The GNEP Strategy}

\subsubsection{GNEP Objectives}

GNEP seeks to bring about a significant, wide-scale use of nuclear energy and to take actions now that will allow that vision to be achieved while decreasing the risk of nuclear weapons proliferation and effectively addressing the challenge of nuclear waste disposal. GNEP will advance the nonproliferation and national security interests of the U.S. by reinforcing U.S. nonproliferation policies, reducing the 
spread of enrichment and reprocessing technologies abroad, and eventually eliminating excess civilian plutonium stocks that have accumulated.

To enable the expansion of nuclear energy for peaceful purposes and make a major contribution to global development into the $21^{\text {st }}$ century, the U.S. seeks to pursue and accelerate cooperation to:

- Expand nuclear power to help meet growing energy demand in an environmentally sustainable manner.

- Develop, demonstrate, and deploy advanced technologies for recycling spent nuclear fuel that do not separate plutonium, with the goal (over time) of ceasing separation of plutonium and reducing or eliminating excess stocks of civilian plutonium and drawing down existing stocks of civilian spent fuel. Such advanced fuel cycle technologies would substantially reduce nuclear waste requiring disposal in a geologic repository, and help to ensure the need for only one geologic repository in the U.S. through the end of this century.

- Develop, demonstrate, and deploy advanced reactors that consume transuranic (TRU) elements from recycled spent fuel.

- Establish supply arrangements among nations to provide reliable fuel services worldwide for generating nuclear energy, by providing nuclear fuel and taking back spent fuel for recycling, without spreading enrichment and reprocessing technologies.

- Develop, demonstrate, and deploy advanced, proliferation-resistant nuclear power reactors appropriate for the power grids of developing countries and regions.

- In cooperation with the International Atomic Energy Agency (IAEA), develop enhanced nuclear safeguards to effectively and efficiently monitor nuclear materials and facilities to ensure commercial nuclear energy systems are used only for peaceful purposes.

Most industrialized nations now recognize the need for nuclear energy to play a major role in meeting base-load electrical energy requirements. Similarly, there is growing recognition within the U.S. of the need to start building new nuclear power plants as soon as possible and to rebuild our national nuclear infrastructure - needs supported by both the Energy Policy Act of 2005 and DOE's Nuclear Power 2010 program. DOE produced a strategic plan that outlines an implementation strategy to enable a world-wide increase in the use of nuclear energy safely, without contributing to the spread of nuclear weapons capabilities, and in a manner that responsibly disposes of the waste products of nuclear power generation. The GNEP strategic plan describes (1) some key evaluative criteria any GNEP fuel cycle must meet to be successful; (2) the GNEP technology requirements for government and industry, with a focus on those facilities of GNEP to be built and proven in the U.S.; and (3) a two year GNEP Program Technology Action Plan that will inform a DOE Secretarial decision in 2008 on the path forward for GNEP.

\subsubsection{GNEP Criteria}

GNEP must meet the following criteria:

1. Proliferation/Safeguards Risk: The risk of non-peaceful use of the civilian nuclear fuel cycle comes from two principal sources: (1) a nation wanting to advance toward the capability to build nuclear weapons in a short period of time following the withdrawal from the Non-Proliferation Treaty, and (2) a terrorist group seeking to obtain nuclear materials to quickly fabricate and explode an improvised nuclear device or a dirty bomb. GNEP aims to address both of these issues by providing incentives to limit the number of countries possessing enrichment and reprocessing facilities, and by eliminating over time excess stockpiles of civil plutonium and strengthening controls over materials. 
2. Proliferation Prevention: Preventing the spread of commercial nuclear technology does not by itself prevent the spread of weapons capability. The plutonium contained in spent fuel discharged from a light water reactor (LWR) is not considered "weapons grade." However, plutonium separated from spent nuclear fuel could be fashioned into a weapon and achieve a nuclear yield of some magnitude. While the safeguarding of bulk-handling facilities will continue to pose significant technical challenges, advances have been made in developing processes that: are easier to safeguard, allow improved materials accountability, are more resistant to terrorist threats, and offer the possibility of placing a much reduced burden on our waste disposal facilities. However, there is no technology "silver bullet" that can be built into an enrichment plant or reprocessing plant that can prevent a country from diverting these commercial fuel cycle facilities to nonpeaceful use. GNEP seeks to develop advanced fuel cycle technology for civil purposes, centered in existing fuel-cycle states, that would allow them to provide fuel services more cheaply and reliably than the remaining states could provide indigenously.

3. Terrorist Threat Reduction. In the most general terms, GNEP seeks to eliminate (over time) excess stocks of separated plutonium and reduce stocks of spent fuel worldwide, thereby strengthening nuclear security worldwide. In more specific terms, a key objective with respect to any GNEP recycling facility is to deny access to fissile nuclear materials of critical mass that could be readily made into a nuclear device. Supportive policies can be implemented in this regard: (1) minimize transportation-keep fissile materials inside one integrated facility from the time used fuel enters until recycled material leaves; (2) maintain a mixture of fissile material with nonfissile material in a ratio that is not easily useable as a weapon; (3) use advanced safeguards and security techniques; and (4) maintain a goal of minimizing the buildup of, and eventually eliminating, stockpiles of separated civilian plutonium or its near equivalent.

4. Reduce Repository Burden. Commercial spent nuclear fuel can either be disposed of directly into a repository or reprocessed/recycled and the byproduct high-level waste sent to a repository. Reprocessing and recycle using proven and currently available technologies (variants of PUREX and light-water reactor recycle with a mixed oxide fuel) would offer some minor benefit to the repository but not meet the GNEP objectives. The full benefit envisioned for the separations process in GNEP anticipates substantial repository benefits (by separating out all the actinides) and a reduction in liquid process waste. The most significant repository benefits can be achieved by removing the very longlived minor actinides and recycling them as part of the fuel for fast reactors. Further repository benefit can be achieved by removing the fission products cesium and strontium from the high-level waste stream and allowing them to decay separately. These elements have a relatively short half-life, and, after decay, could be disposed of as low level waste. Additionally, removing the technetium and fixing it in a matrix with the cladding hulls could reduce the possibility of this fission product migrating away from the repository area.

5. Assured Fuel Supply. The U.S. seeks to encourage the world's leading nuclear exporters to create a safe, orderly system that spreads nuclear energy without proliferation. States that refrain from enrichment and reprocessing would have reliable access at reasonable cost to fuel for civil nuclear power reactors. If the U.S. is going to participate in assuring access to nuclear fuel and, in the longer term, spent fuel services to these countries as they enter the nuclear arena, it must have the capability to provide the needed fuel cycle services - capability that we do not currently possess. Our fuel-cycle technology should also build our ability and that of our partners to establish and sustain cradle to grave fuel service or leasing arrangements over time and at a scale commensurate with the anticipated expansion of nuclear energy by helping in a major way to solve the nuclear waste challenge.

6. Capability and leverage. The GNEP vision has been well received by the international nuclear community, particularly among the leading fuel-cycle states. Sustaining and building on that 
enthusiasm depends on the ability of the U.S. to get back in the commercial nuclear business and assume an active role. Participating fully in that business is essential in shaping the rules that apply to it. We have a vision of a future world that can universally enjoy the benefits of safe, economical, emission-free energy; and we have programs and plans to put the U.S. back in the nuclear energy game in a leadership role. Access to our market is itself a form of leverage.

\subsubsection{GNEP implementation model}

The implementation of GNEP is based on the concept of a government/industry partnership.

There are three facilities required to implement and thus affirm our commitment to GNEP: (1) an advanced separations facility to separate the components of spent fuel required by GNEP (here termed a Consolidated Fuel Treatment Center [CFTC]); (2) a fast reactor to burn the actinide based fuel (here termed an Advanced Burner Reactor [ABR]) to transform the actinides in a way that makes them easier to store as waste, not a proliferation concern, and produce electricity; and (3) an Advanced Fuel Cycle Facility (AFCF) to serve as an R\&D center of excellence for developing transmutation fuels and improving fuel cycle technology.

The pursuit of these three facilities constitutes a pathway with two complementary components. The first component, the CFTC and the ABR, could, as an option, be led by industry with technology support from laboratories, international partners, and universities. The second component, R\&D led by the national laboratories, would include the AFCF funded by DOE and located at a government site. The two components would work closely together to move GNEP forward by integrating the national laboratories' capabilities with the needs of industry.

Although technical challenges for the implementation of the closed-fuel cycle as envisioned under GNEP exist, many of the technologies essential for the successful implementation of GNEP have been demonstrated at laboratory and bench-scale. Such uncertainties as scaling up the chemical separations for the recycle process or fabricating and qualifying the transmutation fuel for the advanced burner reactor require consideration. These technical risks warrant continued $R \& D$ and technology development for GNEP.

A government-industry partnership is desired to implement GNEP. The approach outlined requires expanded involvement of industry in the design of facilities in preparation for expansion to commercial scale. The approach is to define a technology roadmap to resolve those uncertainties in conjunction with assets available to the government (i.e., National Laboratories, universities, and international partners), but does so in a way that obviates the need to build engineering scale facilities. If successful, the approach could reduce overall costs and increase the speed of arriving at a commercially operated system of prototype GNEP facilities without significantly increasing programmatic risk.

\subsubsection{GNEP Program Technology Action Plan}

The objective of the GNEP technology and facilities implementation plan is to harness and coordinate the strengths, capabilities, and resources of industry, national laboratories, universities, and international partners with the clear objective of getting commercial-scale facilities that accomplish our GNEP vision into use as quickly and economically as possible. At the core of this effort will be the development of a sound, achievable business plan. The primary task for the next year is to assemble the requisite technology, economic, and environmental information that can present a path forward to commercialscale facilities that can be considered by the Secretary of Energy in reaching a decision whether to proceed with plans for a closed nuclear fuel cycle and whether to construct and operate the proposed 
GNEP facilities. Specific programmatic actions planned - subject to funding, risk, and project management processes specified in DOE Orders ${ }^{\mathrm{a}}$ - to reach this decision-point include:

- Obtain input from U.S. and international industries and governments on how best to bring the needed GNEP facilities into being, what technology and policy issues must be resolved, and what business obstacles must be overcome.

- Develop a detailed GNEP technology roadmap for demonstrating solutions to the remaining technical issues in order to support commercial GNEP facilities. Inform and adjust this roadmap with input received from industry, international partners, and other interested stakeholders.

- Pursue industry participation in the development of conceptual design and other engineering studies that support both the Consolidated Fuel Treatment Center (CFTC) and the Advanced Burner Reactor (ABR).

- Prepare a programmatic GNEP Environmental Impact Statement.

- Prepare a decision package for the Secretary of Energy to consider whether to proceed with development of proposed GNEP facilities.

\subsubsection{GNEP as a Transformation Tool for Nuclear Engineering Research}

Nuclear research in the U.S. has known its heyday from the 1950s until the early 1980s. At that time, strong research budgets and an enthusiastic community had evolved a model where they had created strong links between basic science as the generator of knowledge in the form of data and computational models, the computer science community as the builder of simulation tools, and the nuclear research community as the user of these tools. Since then, these links have disappeared due to much reduced budgets. The nuclear engineering community has only slowly evolved the tools it uses, while at the same time the possibilities of basic science and advanced simulation have significantly progressed. In the early 1980s, simulation capabilities were almost always limited to lumped parameter models. Today it is possible to envision models with their roots in first principles and the capability to model nuclear systems with very high precision and accuracy.

In consequence of this lack of engagement, the research model used by the nuclear engineering community is still characterized by a heavy dose of empiricism with significant reliance on expensive and time consuming representative mock-up experiments. The goal of GNEP is to modernize nuclear research by creating the basic science and simulation tools that will lead to higher quality products with lower costs and shorter development schedules.

That transformation has already occurred in other industries such as the aeronautics industry. The nuclear weapons programs at DOE, which are more like GNEP, have very successfully implemented this vision and their example, significantly adapted to the physical and regulatory differences between the products, can be used to achieve this goal.

Three workshops organized by the Office of Science and the Office of Nuclear Energy during the summer of 2006 have paved the way to implementing this approach. They focused successively on the role of basic sciences, nuclear data, and simulation and modeling in GNEP, and indicated the key areas where these disciplines will help improve the quality of the GNEP technologies:

- Separations technologies, which are currently characterized by an empirical research model, will, in the short term, benefit from better measurements of fundamental properties, better thermodynamic modeling of processes, and better optimization tools for integrating the

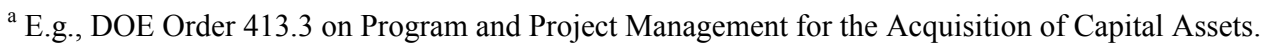


processes and designing nuclear facilities. In the longer term, novel processes could be developed based on better simulation capabilities at the molecular level.

- Waste forms are one of the ultimate products of GNEP and must be demonstrated to survive for extremely long times in complex geological environments. Currently, that demonstration is essentially empirical and therefore affected with rather large uncertainties. Better understanding of the fundamental physical phenomena and the capability to model the evolution of waste forms in complex geological media will bring added confidence to the nuclear enterprise.

- Nuclear fuels are probably the most technically demanding element of the GNEP technologies as they undergo a series of phenomena during fabrication and irradiation: from physical, to chemical, to metallurgical, to thermo mechanical. In GNEP, these difficulties are compounded by the fact that fuel forms must contain significant amounts of minor actinides. The understanding of these phenomena and, even more so, their modeling are still in their infancy; consequently, the fuels development process is extremely empirical based today on a "cookand-look" approach. The current development cycle length of a fuel form is about 15 years, with successive irradiation and post-irradiation examinations at increasing scales consuming most of that time. Better understanding of the fundamental phenomena and the capability to model the evolution of fuels in reactor environments have the potential to reduce the length of that development cycle, but will also pave the way for developing novel fuel forms with significantly improved characteristics.

- Advanced reactors that can effectively transmute the isotopes of interest from spent fuel are the most costly component of a fully deployed GNEP system. The current design and licensing approach for these reactors is based on older lumped parameter models that not only imply significant design margins, but also limit the capability of innovation in new designs, new materials, and new concepts. The key areas where significantly improved performance is expected with modern simulation techniques are thermal hydraulics, mechanical behaviour, and safety analyses. Significant cost reductions are expected from implementing these techniques.

The detailed process for implementing these advances and fundamentally modifying nuclear engineering research is still being defined and is by itself a key challenge that the GNEP community of scientists and engineers must address. The current plan is to organize GNEP R\&D in a series of campaigns focused around each key technology — separations, fuels, waste forms, and reactors - that will associate the engineering and scientific disciplines and define a requirements-driven process to build and implement better tools to meet the overall GNEP objectives.

\subsection{Key Assumptions}

This TDP provides the following initial data to meet two key objectives of the DOE GNEP Strategic Plan:

- A summary of the current knowledge needed to develop a detailed GNEP technology roadmap for demonstrating solutions to the remaining technical issues in order to support commercial GNEP facilities.

- A summary of the current knowledge needed to prepare a decision package for the Secretary of Energy to proceed with a government-industry partnership to build a CFTC and prototype ABR.

Two key assumptions for developing the TDP were made:

- Cost information: The total cost for FY 2007 reflects the actual FY 2007 budget; the total FY 2008 cost estimate matches the president's budget request. Cost estimates for the following years are unconstrained. 
- Reference technologies: Reference technologies have been chosen that meet the GNEP goals. LWR spent fuel separation will be based on the UREX+ concept, which separates all constituents of the spent fuel into manageable streams. TRU elements will be recycled in sodium-cooled fast reactors, and uranium will be separated at high enough purity that it might be disposed of as low-level waste or easily stored for future use. The remaining material will be disposed of in waste forms optimized for long-term disposal.

\subsection{GNEP Deployment System Architecture}

\subsubsection{Domestic System Architecture}

The domestic portion of the overall GNEP deployment system architecture must be defined and used to guide the determination of performance requirements and criteria for technology selection. This system architecture has been identified based on previous studies carried out in the Advanced Fuel Cycle Initiative and will be documented in the GNEP Deployment System Architecture Report ${ }^{\text {b. }}$

The performance of transmutation systems based on both thermal and fast reactor systems has been assessed by many international teams. From these studies an international consensus has emerged ${ }^{c}$ :

- Thermal reactors are well suited for a partial transmutation of plutonium, as implemented in today's commercial mixed oxide (MOX) approach. Nevertheless, total transmutation of plutonium and transmutation of the minor actinides does not seem practically feasible in these reactors, essentially, because the fuel cycle requirements for these schemes make the approach impractical.

- Fast reactors are well suited for transmuting all transuranics.

These capabilities have led the international teams to propose two system architectures to manage and recycle nuclear materials:

- A dual tier approach, where plutonium is first recycled in thermal reactors and the remaining plutonium and all other transuranics are recycled into fast reactors. This approach has the advantage of making use of the existing thermal reactors, and reduces the need to build fast reactors.

- A single tier approach, where all transuranics are extracted as a group from the spent commercial nuclear fuel and recycled into the fast reactors.

A key issue for the U.S. in the use of thermal reactors for recycling as implemented in today's commercial MOX approach is that the process requires the separation of relatively pure plutonium, which is contrary to current U.S. nonproliferation policy. The AFCI program has done limited research on MOX fuels containing the minor actinides in addition to the plutonium, but recycle in fast reactors is still needed to realize significant repository benefits.

Countries such as France and Japan already have an installed commercial MOX infrastructure and differ with the U.S. on the policy of separation of plutonium. They have therefore chosen the dual tier approach to maximize the use of the existing infrastructure. The U.S., which does not possess the commercial oxide infrastructure, has initially identified the single tier approach as its preferred architecture.

Figure 1 shows the proposed system architecture for the U.S. under GNEP.

\footnotetext{
${ }^{\mathrm{b}}$ This report is planned to be prepared by $9 / 30 / 07$.

c. The Physics of TRU Transmutation - A Systematic Approach to the Intercomparison of Systems, PHYSOR 2004, April 24-29, 2004.
} 


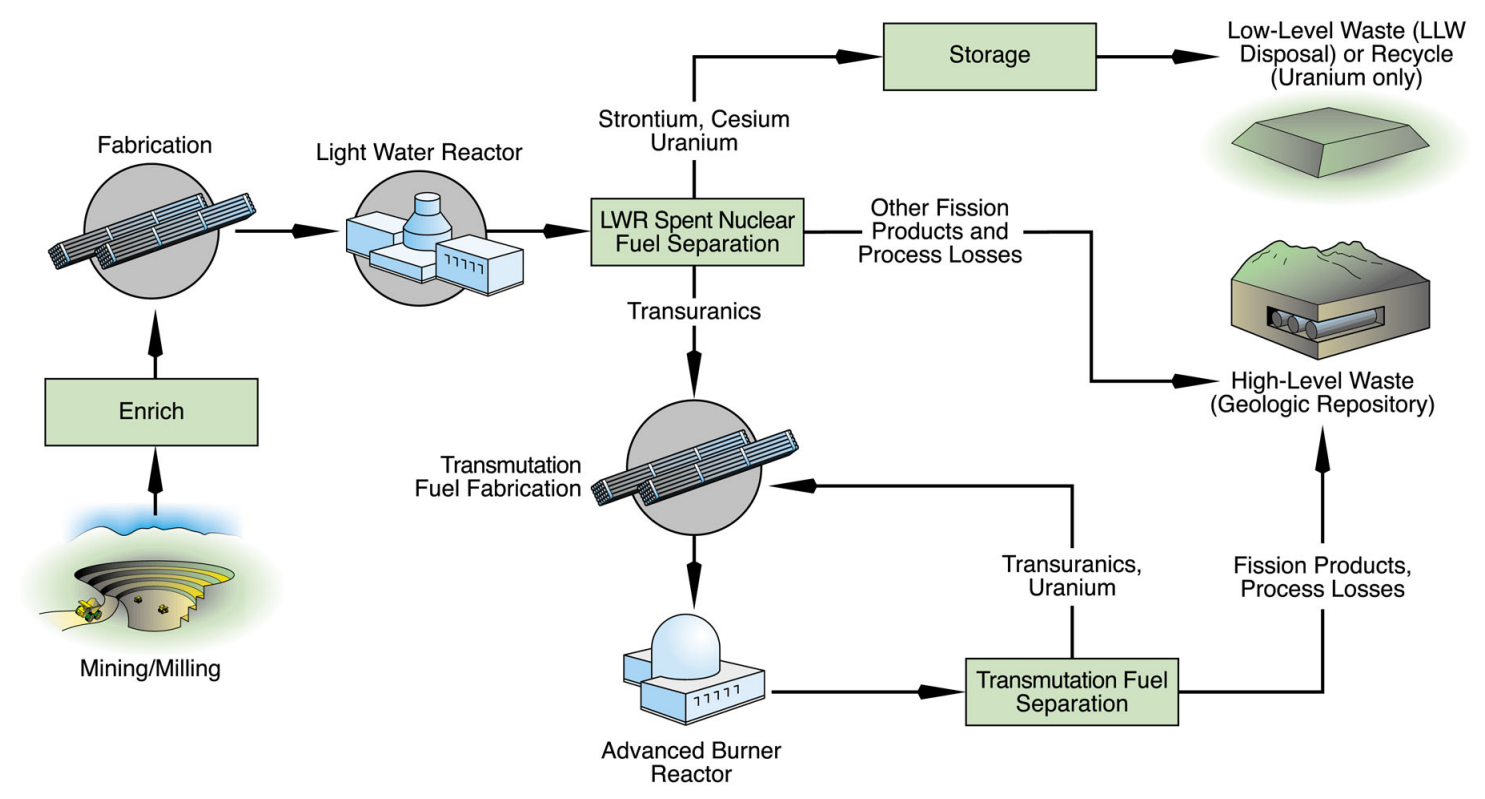

Figure 1. Initial GNEP deployment system architecture.

This initial GNEP deployment system architecture shown in Figure 1 is described as follows:

1. U.S. commercial reactors, which are all LWRs, are the major producers of electricity; during their operation they also produce spent nuclear fuel at a rate of more than 2000 MT per year. These may eventually be augmented by ALWRs and/or Generation IV reactors.

2. The LWR spent nuclear fuel separations plant separates the constituents of that SNF into a series of product and waste streams that facilitate waste management: fission products for storage and disposal, uranium for storage, structural elements for disposal, and transuranic elements destined to be destroyed through transmutation. To improve security against terrorism and to improve proliferation risk management, transuranic elements should be kept together and diluted as much as practical. This material form is less easily used in a nuclear weapon than concentrated, chemically pure forms of plutonium.

3. The transuranic elements are fabricated into transmutation fuels ${ }^{\mathrm{d}}$

4. The transmutation fuel is irradiated in fast reactors, which results in a partial destruction of the transuranics with a fraction of the original transuranics remaining in the irradiated fuel along with newly created fission products.

5. A separations process, likely different from the LWR spent nuclear fuel separations process, is then used to extract the remaining transuranics from the transmutation fuel. As with LWR spent nuclear fuel separations, other constituents, including fission products, processing losses, and structural materials are encased in specific waste forms suited for ultimate disposal.

6. The separated transuranics are then refabricated into a new transmutation fuel and again irradiated in a fast reactor. This closed cycle continues to destroy the initial transuranics while also accepting additional transuranics from the LWR spent nuclear fuel.

\footnotetext{
${ }^{\mathrm{d}}$ Transmutation fuels contain a significant amount of transuranic elements, along with uranium or a non-fuel matrix material.
} 


\subsubsection{International System Studies}

Although the architecture for the domestic deployment system has been determined, studies will continue throughout the program on architectures that might provide alternatives for domestic deployment and also those architectures being implemented in other countries.

The full GNEP strategy includes establishment of reliable fuel cycle services. This may also require the development of reactors that are deployable in countries that do not possess the infrastructure for large systems as well as an overall approach to proliferation risk reduction. These elements are also addressed in the systems portion of this plan.

\subsection{The GNEP TDP}

Development of technology for an integrated implementation of the proposed system is the purpose of the GNEP TDP. Such an integrated program will be driven by technology demonstration at prototype facilities, together with a supporting TDP in specific facilities that delivers the required technologies as well as research and development programs that address the areas of highest risk and provide technical alternatives for risk mitigation.

\subsubsection{The GNEP Facilities}

Three facilities are needed to demonstrate the key technologies in the GNEP deployment system:

- The CFTC, which will conduct LWR spent nuclear fuel separations at an appropriate scale (to be determined in conjunction with the 2008 Secretarial Decision) using commercial reactor spent nuclear fuel. The CFTC will also have the future capability to fabricate transmutation fuel at a production scale, once the technology is sufficiently demonstrated at an engineering-scale. The CFTC may also provide the future capability to recycle spent fuel from an advanced recycling reactor.

- An AFCF to separate limited quantities of LWR spent nuclear fuel, fabricate and recycle the transmutation test fuels needed for qualifying these fuels, and provide the experience needed to design and operate the commercial-scale fuel fabrication and separations facilities. The AFCF will also provide the nation during the 21 st century with the ability to develop and demonstrate advanced aqueous and pyroprocessing separations technologies, transmutation fuel fabrication technologies, and state-of-the-art safeguards instrumentation and monitoring systems.

- A prototype ABR that will demonstrate transmutation of actinides and inform fast reactor technology development for the commercial ABR and eventually fast breeder reactor fuels in support of the Generation IV program.

The sizes and scopes of the initial facilities are currently being determined.

\subsubsection{Timing of the GNEP Facilities}

Based on the actual 2007 budget, and the 2008 budget request, the following planning milestones have been established:

- FY 2020 for initial operation of the LWR spent nuclear fuel separations facility (CFTC)

- FY 2022 for the startup of the prototype fast spectrum reactor designed to demonstrate the destruction of transuranics (ABR)

- FY 2020 for operations to commence in the first module of a multipurpose separations and transmutation fuel fabrication and research facility (AFCF).

The actual timing of the GNEP facilities will be evaluated via a structured analysis based on facility integration needs, technical readiness, actual budgets, and other considerations. From the point of view of 
system integration, the start-up and initial operation dates of each facility will depend on when that facility is needed to support the other facilities in the program. Based on current understanding of the technology development schedules, an initial assessment of the relative timing of the facilities has been made. This initial assessment worked backwards from the time that the first lead test assemblies (LTAs) of transmutation fuels are needed for the ABR, and assumed that:

- Thirty percent of the core of the ABR would be converted from the startup fuel to the transmutation fuel over a to-be-determined period once the size of the prototype ABR is established. Earlier stages of that conversion would be performed with transuranics processed in the AFCF; $30 \%$ conversion of a large reactor will likely require operation of the CFTC to provide adequate separated transuranics.

- Each LTA is resident in the reactor for 3 years (assumes $8 \%$ burnup). The first LTA would be available for insertion in the ABR in 2022.

- The AFCF will process at least 10-25MT SNF/year (the actual scale of the aqueous separations component of the AFCF will be determined by an expert panel; this scale was assumed only for this assessment).

Based on our current technology development schedule:

- AFCF must begin fabricating transmutation fuels 2 years prior to the time at which the first LTA is inserted in the ABR. This includes a contingency for shakedown testing of the fabrication process.

- In this plan, the cost constraints imply an operational range for the AFCF of 2020-2022 and 2022-2024 for ABR operations (start-up testing will need to be at least 2 years earlier for $\mathrm{ABR}$ ). The CFTC will begin operations around 2020, providing additional transuranics for $\mathrm{ABR}$ fuel fabrication.

This assessment was based only on technical requirements, and it should be recognized that other requirements may affect these estimates. In particular, the acquisition strategies for the three facilities are still being developed by DOE. Therefore, the cost and schedule ranges for design and construction of the facilities, as described in this plan, do not yet reflect a specific approach to acquisition of design and construction services. Once the acquisition strategies are finalized, the cost and schedule range will be updated accordingly. 


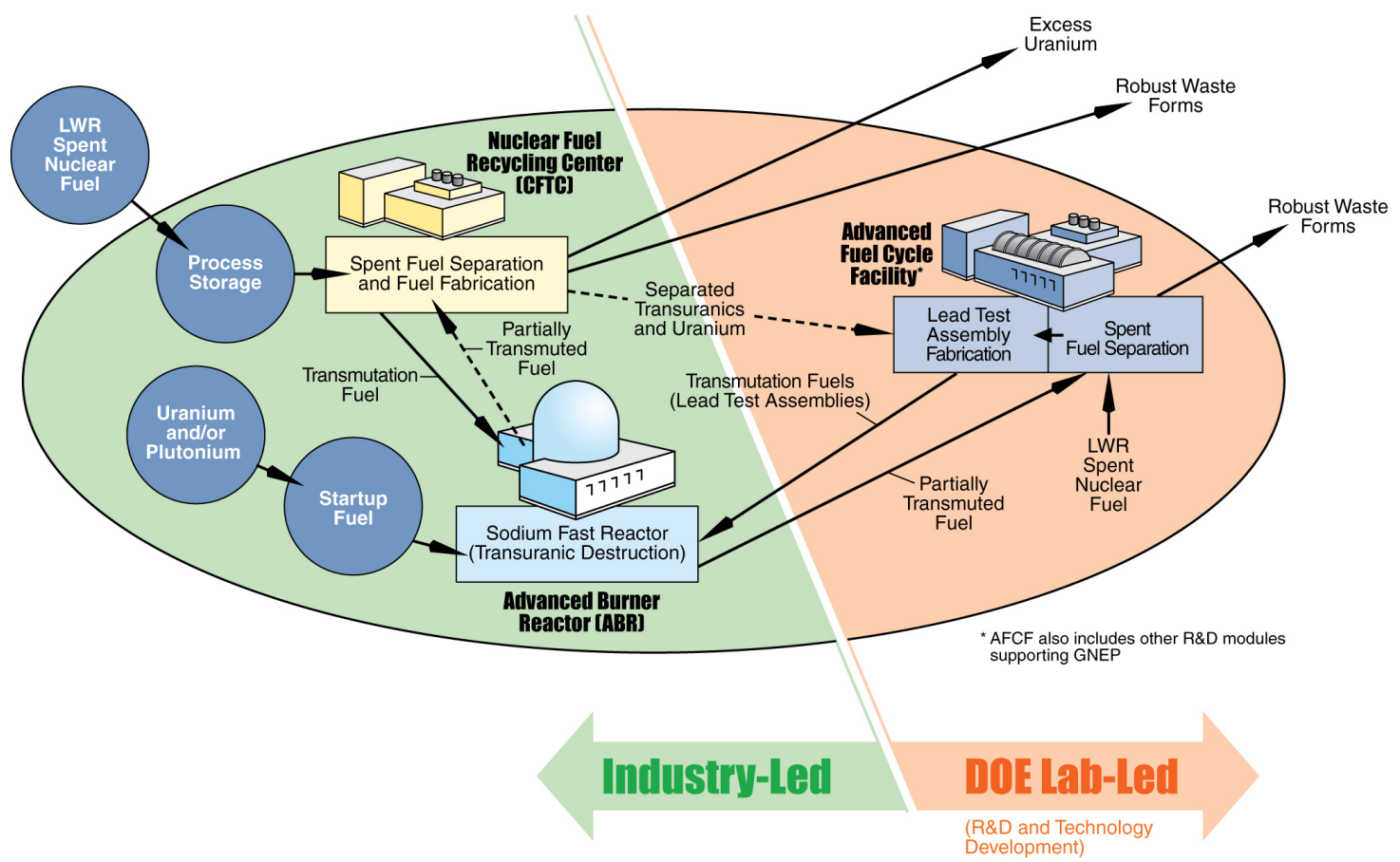

Figure 2. GNEP First Facilities Architecture

\subsubsection{Safety of the GNEP Facilities}

Establishing the highest degree of safety for the facilities and operations of the entire GNEP system as currently envisioned is essential both for the success of the program and for the future of nuclear energy in the U.S. The outstanding overall safety record of commercial nuclear power in the U.S., along with a decades-long trend of improving operational and personnel safety statistics, is steadily overcoming public concerns about nuclear safety. However, the GNEP infrastructure will require the development of several new types of facilities, as described in the previous section, for which there is no relevant commercial experience within the U.S. To support the successful development of the GNEP facilities, the first GNEP facilities (ABR, CFTC, and AFCF) will establish that the desired level of safety for all facilities can be achieved.

A strong and effective framework for commercial facilities exists in the U.S. that can be used to achieve the desired safety levels. The safety framework has the Nuclear Regulatory Commission (NRC) at its center with a well-developed regulatory philosophy that is implemented through an equally welldeveloped set of regulations and regulatory practices. This framework, although mostly developed for the safety regulation of LWRs, could be adapted to apply to both the GNEP advanced fast-spectrum reactor and the other GNEP facilities and activities. The safety framework also includes a strong and effective group of nuclear industry companies and organizations who, together, have successfully achieved the desired safety objectives. Industry codes and standards support all of the above along with major research institutions that maintain and enhance understanding of safety principles and address new safety issues as they arise. As a result, it is expected that any new safety issues that arise during the development of the first GNEP facilities can and will be successfully resolved.

\subsubsection{Safety Objectives}

Safety encompasses all aspects of facility design, construction, and operation. While safety can be defined in many ways, the following general comments describe the overall extent of safety considerations: 
- Personnel safety. The probability of any person being subjected to exposure in excess of regulatory limits from potential hazards, including radiation exposure and chemical exposure, as a result of designing, constructing, or operating a GNEP facility is acceptably low.

- Environmental safety. There are no harmful environmental consequences in excess of those judged to be acceptable as a result of designing, constructing, or operating a GNEP facility.

- Facility safety. The probability for creating conditions in a GNEP facility that would result in severe damage or destruction to the facility, potentially threatening personnel and the environment as well as resulting in a major economic loss, is judged to be acceptably low.

\subsubsection{Achieving Safety}

Since all of the facilities for the GNEP program will require the handling or use of highly radioactive materials as well as potentially hazardous chemicals, it is essential that all aspects of safety are considered and addressed for each of the proposed GNEP facilities. Consistent with past experimental or production facilities of a similar nature, the GNEP facilities are expected to be designed, constructed, and operated with adherence to all personnel, environmental, chemical, and nuclear safety regulations as set forth by the NRC and/or the DOE (e.g. 10 CFR Part 830). It is expected that safety will be integrated into the design of each facility and augmented by operational procedures designed to result in potential exposures and releases which are as low as reasonably achievable (ALARA).

It is expected, and in some cases required, that safety be designed into the facility so that certain classes of accidents are not possible. An example of this is using size, inventory, and geometry to prevent nuclear criticality events during all operations outside of the reactor core (e.g., separations, fuel fabrication and handling, etc.). The safety principle is to design each facility so that certain potentially unsafe operations are not possible, or that unsafe conditions are not achievable. This "intrinsic" safety is widely accepted as being part of good design and engineering practice. It is expected that "intrinsic" safety will be implemented to the greatest extent practicable in the GNEP facilities.

Safety, however, includes much more than what can be done in the design and during operations. For each of the GNEP facilities, it is also of utmost importance that the appropriate attitude towards safety, the "safety culture," be an integral part of all aspects of facility design, construction, and operation. A key component of safety culture is the development of appropriate operating procedures, along with the understanding and adherence by all personnel to not only the procedures, but also to the principles of working safely.

It must also be stressed that "safety" and "licensing" are two very different things. The latter describes how the U.S., through the NRC and other regulators, assures that the required safety performance is actually achieved in practice. But achieving "safety" is and must be the responsibility of the designing/operating entities and the individuals within them, and typically goes beyond meeting all applicable regulations. The safety philosophy that underlies all of GNEP's efforts will attempt everywhere to do as well as, if not better than, the current nuclear industry, which has to its credit already achieved a strong safety record in the U.S. It will do this by building on existing practices and adapting them to the new GNEP technologies.

The approach taken to achieve the desired safety objectives is different for each facility because each facility has its own set of hazards and regulatory requirements and is reviewed in the respective section for each facility. However, it is also important to be cognizant of other aspects of the GNEP infrastructure that may have potential safety implications that are not related to one of the three GNEP facilities. The major components in this category are storage facilities and transportation activities. An existing regulatory infrastructure and a strong safety culture already exist for these activities and have been very successful in that the safety record for storage and transportation has been exemplary. The importance of 
transportation for the GNEP program will depend on the siting of the facilities - the extent to which the three facilities are co-located. In the most challenging case, each facility would be located at a significant distance from the other facilities, maximizing the transportation of hazardous materials between sites. While shipments of nuclear materials occur routinely in the U.S., shipment of materials similar to the spent LWR fuel or processing products and waste forms is much less frequent. Part of the GNEP program will be to develop the systems and components needed for transport of these materials, and establish that transportation of these materials can be done with the required level of safety.

Similarly, while the handling and storage of spent LWR fuel is a routine occurrence in the United States, there is little experience with the handling and storage of the expected products from processing spent LWR fuel and the new and irradiated fast reactor fuel. The GNEP program will establish that the handling and storage of these materials can be done with the required level of safety as well.

\subsubsection{Evaluating and Verifying Achievement of Safety}

A significant aspect of ensuring that the desired level of safety has been achieved for all parts of the GNEP infrastructure is through independent verification and regulatory oversight. Both the NRC and the DOE have extensive regulations governing nuclear reactor design and operation and the handling and use of hazardous radioactive materials. They also have the responsibility for assessing the adequacy of the planned designs and operations in meeting the safety objectives. Successful outcome for these assessments results in a license being granted (NRC) or an authorization issued (DOE). These verifications and subsequent approvals not only provide for the independent review of the proposed designs and operations, but provide assurance to the public that the facilities and operations can achieve the safety objectives. The NRC, for example, continuously monitors the licensees to ensure that the public health and safety are being adequately protected.

None of the above can be achieved without thinking about safety at all times and in every aspect of design and operation of the GNEP nuclear facilities. This requires long-term commitments and follow-through, systems-type thinking of the broadest type, and a continuing endeavor to keep abreast of safety issues as they arise through safety research that is translated into safety practice.

\subsubsection{Technology Development}

Each part of the GNEP program has within it a Technology Development task designed to deliver the necessary technologies to support the facilities. It also identifies those areas that require research and development for risk mitigation. If particular technologies to be implemented in the three facilities are not proven, the associated $R \& D$ will provide technology alternatives that could be incorporated into the GNEP Program System Architecture. Furthermore, each technology implementation identifies needs for supporting capability in safeguards, security, and safety plus modeling and simulation.

\subsubsection{Coordination and Crosscut Elements}

In addition to the facility projects and associated technology development, the GNEP TDP contains several important coordination and crosscut elements. The first of these is the Systems Integration element, which serves three purposes:

- Technical Integration, which supports DOE program management of GNEP, risk management, and decision management.

- System Analysis of the deployment of GNEP facilities beyond the CFTC, ABR, and AFCF, including the global system. Analysis is undertaken of a variety of deployment system alternatives and continually evaluates the predicted performance of various deployment systems as new performance and cost data come available. 
- System Analysis of the first GNEP facilities (CFTC, ABR and AFCF), where these facilities, the system to support them, and the technology choices employed to implement the system are continually reevaluated to ensure that the optimum technology path is being followed and to allow for a structured decision making approach.

The Deployment System Analysis is responsible for the preparation of the GNEP Deployment System Architecture Report which will provide the basis for the initial system architecture and identifies those alternatives which need to remain under consideration as the program progresses. The Systems Analysis of the first GNEP facilities (CFTC, ABR, and AFCF) develops the technical requirements for the first facilities and the criteria that the technologies must meet for identification as the baseline or reference technologies.

The second major crosscut element of the program is that of Proliferation Risk Reduction. Global proliferation risk reduction is a major goal of the GNEP program and will involve international safeguards as well as the development of transformational safeguards technology using the domestic facilities as a test bed. Included here will be modeling and simulation, process control and safeguardability, advanced measurement technologies and data integration and analysis.

The third major crosscut element of the program is Modeling and Simulation, which will support the development and deployment of advanced fuel cycle technologies and ensure their safe and effective operation. This element will include objectives of a short, intermediate, and long-term character. The short-term objectives will focus on the development and validation of those tools required to help develop the three key technologies, probably focused on the modernization of existing codes rather than the creation of entirely new tools. The experience gained with the immediate activities will guide the identification of tools from other industries that can be readily adapted to problems associated with GNEP. The intermediate term objectives will be the adaptation and validation of these tools. Finally, the long-term objectives include the development of entirely new tools for modeling the fuel cycle and the associated technologies. Although the objectives, and therefore the benefits, are spread in time, it is important to recognize that they must proceed concurrently for maximum benefit to accrue to the GNEP program and to nuclear technology generally.

The design and construction of the three facilities, the associated technology research and development programs, a focus on proliferation risk reduction combined with robust systems analysis, and the development of modern tools to underpin the whole program, represents an integrated approach to demonstrating that technologies exist and are viable to make the GNEP vision a reality.

\subsection{International Cooperation}

International cooperation will be an important part of the TDP. This plan identifies some of the areas where such cooperation might be beneficial to the program, but not in a systematic fashion. The full international cooperation strategy will be developed using this plan as a guide but will also have to fully consider other factors such as governmental policies on cooperation, the capability of any country to contribute to the program and funding, in addition to the technical basis for cooperation.

The GNEP seeks to create an international regime to support large-scale growth in the worldwide use of nuclear energy. Fully meeting the GNEP vision may require the deployment of thousands of reactors in dozens of countries, many of which are in the developing world and currently do not use nuclear energy. Some of these needs will be met by large-scale Generation III and III+ reactors (>1000 MWe) and Generation IV reactors when they are available. However, many developing countries have small and immature electricity grids that make the currently available Generation III $(+)$ reactors unsuitable because they are too large, too expensive, and too complex. GNEP therefore envisions new types of reactors that must be developed for international deployment that are "right sized" for the developing countries and 
based on technologies, designs, and policies focused on reducing proliferation risk. Other countries such as France, Russia, Japan, Korea, and South Africa are moving forward with the development of such reactors, so it is vital that the U.S. also embark on the development of suitable reactor systems in order to influence the technologies that are deployed internationally and position U.S. industry for leadership in this growing international market. In the U.S., the Generation IV R\&D program is already investigating several small and medium-sized reactor concepts for various domestic applications, and some of these concepts may prove relevant to GNEP application.

The primary objective of the "GNEP Reactors for International Deployment (GRID)" element of GNEP is the development and demonstration of appropriately-sized reactor designs that can provide the worldparticularly developing countries - with safe, simple, and robust sources of energy to meet their expanding needs for electricity, potable water, and district heating at an affordable price, while minimizing the negative impacts on the local and global environment associated with large-scale burning of fossil fuels. Moreover, a deployment of these reactors, combined with a policy of reliable fuel services, can provide an attractive energy solution to many countries without the need for them to develop the more proliferation-vulnerable parts of the nuclear fuel cycle.

\subsection{GNEP Program Interfaces}

Proliferation Risk Reduction will be an activity carried out jointly with the National Nuclear Security Administration, which has the responsibility for international safeguards and associated technologies. Two other important program interfaces within DOE are the Office of Science (SC) and the Office of Civilian Radioactive Waste Management (RW).

SC has begun an activity to attract the best scientists to try and resolve the scientific problems that occur within the application of nuclear technology to energy production. This activity follows on the heels of similar ones addressing subjects such as Solar Energy and Hydrogen and will be carried out in analogous manner. The target for the SC is nuclear technology generally, rather than specifically GNEP, but the activity will be informed by GNEP and the results ultimately should come to benefit GNEP. In particular, the modeling and simulation element above will be carried out in cooperation with the Office of Advanced Scientific Computing Research within SC.

Since one of the main goals of GNEP is aimed at the current and future use of geologic repositories, there has to be an interface with RW. This interface will primarily be necessary to ensure that waste forms proposed by the GNEP program can indeed meet performance criteria for disposal in a geologic repository or be safely dispositioned in some other way. This interface will also facilitate the evaluation of the potential for future evolution of waste management requirements in order to optimize the waste management benefits from the GNEP closed fuel cycle.

\subsection{GNEP TDP Implementation}

Table 1 shows the cost estimates developed by the national laboratories to support this program plan to the end of fiscal year 2012. Planning is in a very early stage, and cost estimates will evolve as more detailed planning takes place, including determination of the acquisition strategy. A high-level schedule based on the cost estimates in Table 1 follows Table 1. Table 2 shows milestones for the program associated with these cost estimates.

\subsection{Report Structure}

The sections that follow will describe in more detail the GNEP systems integration, facilities, technologies, and crosscutting areas and their corresponding detailed objectives, mission needs, technical requirements, technology development needs, longer-term research and development needs, and cost and schedule. A brief justification will also be provided for the selection of the three technologies that will be implemented in the facilities. 
Section 2.0 describes the systems integration approach, in which the goal is to define and subsequently refine the technical requirements for both the deployment system and the initial GNEP facilities. To achieve this objective, strategic systems analyses are required to evaluate a variety of nuclear fuel cycle issues. Key results of existing domestic and international fuel cycle studies must be synthesized with consideration of GNEP priorities and mission objectives. Ongoing GNEP technology development and $R \& D$ results must be integrated to evaluate evolving technology performance and risk evaluations.

The LWR spent fuel separations TDP is described in Section 3.0. This program aims at demonstrating LWR spent nuclear fuel separations technologies at large scale in an adequate facility, the CFTC.

Sections 4.0 and 5.0 describe the ABR and Transmutation Fuels and Separations technologies, respectively. These two technologies are composed of a research and demonstration program to fabricate those transuranics removed from the LWR spent nuclear fuel into fuel elements suitable for irradiation in a fast reactor, and to develop a fast spectrum reactor that can be used to demonstrate the conversion of transuranics into isotopes that would pose a lower long-term risk. These programs will rely on two facilities: the AFCF where fuels and relevant separations technologies are demonstrated and the ABR where transmutation is demonstrated. The second facility must also possess the capability to recycle the fast reactor fuel to ensure more complete conversion of the transuranics.

Section 6.0 discusses GNEP reactors for international deployment.

Section 7.0 describes the crosscutting area of advanced modeling and simulation.

Section 8.0 describes the crosscutting section on safeguards and proliferation risk reduction. 
July 25,2007

\subsection{Overall Cost Estimates and Schedule}

Table 1. GNEP Overall Cost Estimates Needed to Achieve Milestones in the Report

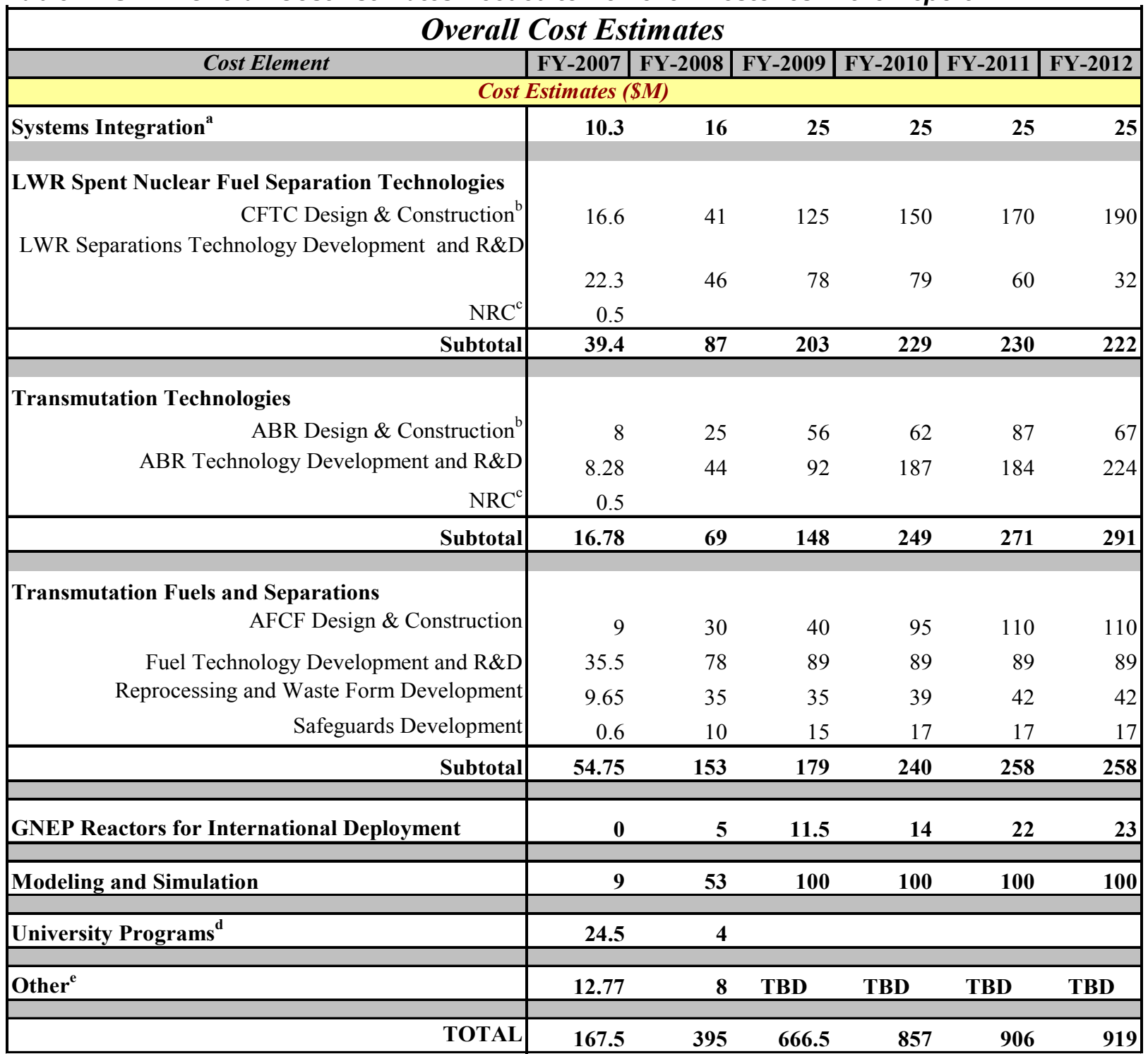

${ }^{\mathrm{a}}$ Includes Systems Analysis and Technical Integration

${ }^{\mathrm{b}}$ Includes industry support.

${ }^{\mathrm{c}}$ Not explicitly called out after FY-07

${ }^{\mathrm{d}} \mathrm{FY}-08$ includes only ongoing grants, after FY-08 funds are embedded in the rest of the cost estimates

${ }^{\mathrm{e}}$ Includes International Collaboration, Internal Commitments, SBIR/STTR, etc. 


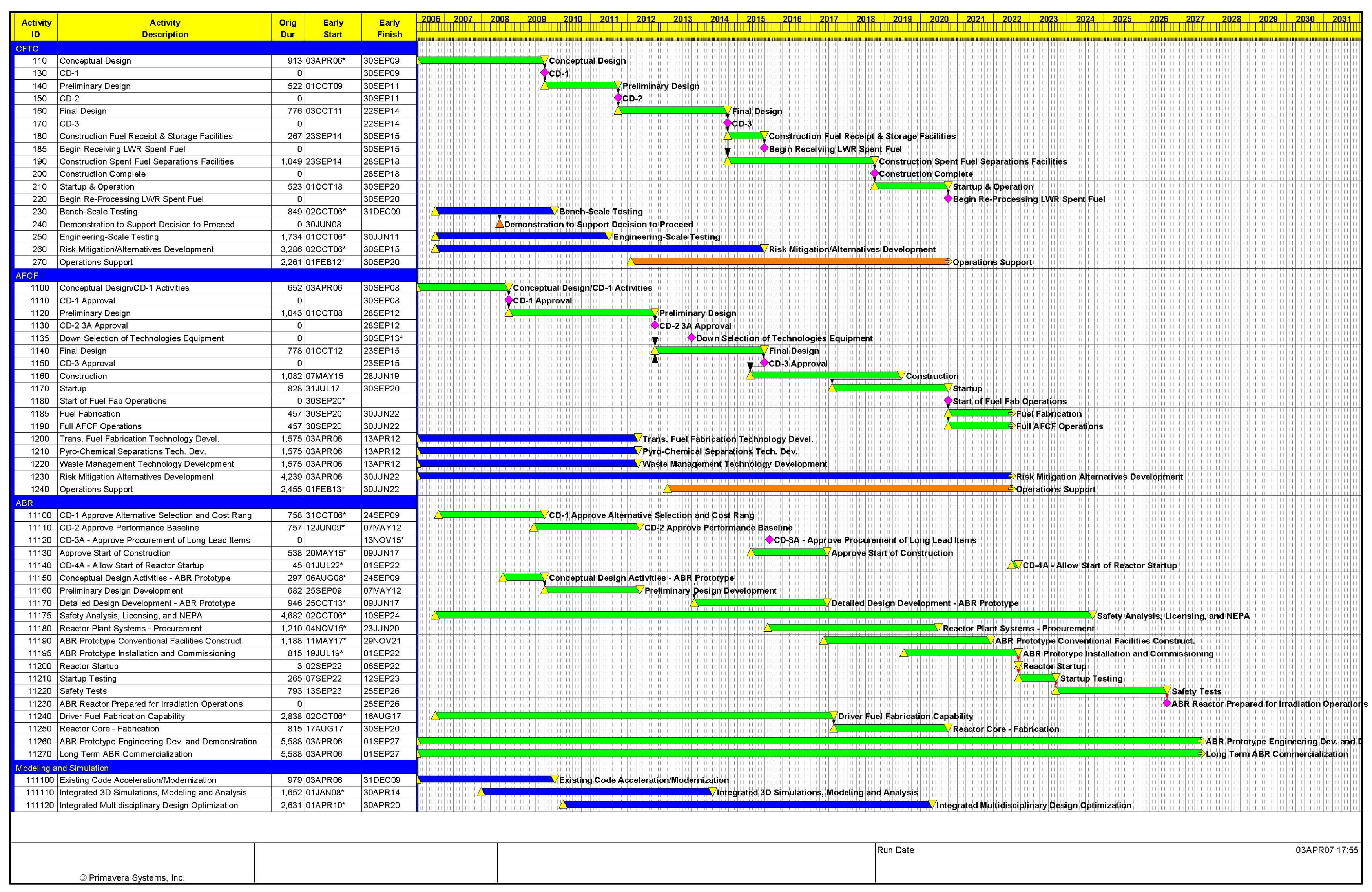


July 25,2007

Table 2. GNEP Overall Milestones Projection

\begin{tabular}{|c|c|}
\hline & Date \\
\hline \multicolumn{2}{|l|}{ FY07 } \\
\hline \multicolumn{2}{|l|}{ Systems Integration and Analysis } \\
\hline AFCI Status Report to Congress - draft to DOE & January 2007 \\
\hline FY-07 Comparison Report to Congress - draft to DOE & February 2007 \\
\hline $\begin{array}{l}\text { Establish Partnership Knowledge Center (PKC) Steering Committee consisting of } \\
\text { representatives inside and outside of the GNEP community. }\end{array}$ & April 2007 \\
\hline Initial GNEP waste form descriptions & August 2007 \\
\hline Small reactors requirements & August 2007 \\
\hline $\begin{array}{l}\text { Report on waste form and waste process technology specific data developed to } \\
\text { support an Integrated Waste Management Strategy }\end{array}$ & August 2007 \\
\hline $\begin{array}{l}\text { DOE-NE technical input for Secretarial recommendation to congress on the need for } \\
\text { a second repository }\end{array}$ & September 2007 \\
\hline Initial Qualitative Program Risk Factor Assessment & September 2007 \\
\hline GNEP deployment systems analysis & September 2007 \\
\hline \multicolumn{2}{|l|}{ LWR Spent Nuclear Fuel Separation Technologies } \\
\hline $\begin{array}{l}\text { Complete Engineering Alternatives Study (EAS) inputs to the Programmatic } \\
\text { environmental Impact Statement (PEIS) for a spent fuel recycling facility }\end{array}$ & June 2007 \\
\hline Provide input for industry engagement on conceptual design studies & June 2007 \\
\hline Develop remote contactor design concepts and initiate test component fabrication & September 2007 \\
\hline \multicolumn{2}{|l|}{ Transmutation Technologies } \\
\hline Develop Reference commercial ABR Concept & September 2007 \\
\hline First mechanical tests performed on 155 dpa HT-9 Duct (AC)3) & September 2007 \\
\hline \multicolumn{2}{|l|}{ Transmutation Fuels and Separations Technologies } \\
\hline AFCF $30 \%$ conceptual design for review & January 2007 \\
\hline Insert FUTURIX-FTA irradiation test in Phenix reactor (external) & May 2007 \\
\hline Begin ATR irradiation of metal transmutation fuels containing Ln & September 2007 \\
\hline Revision of fuels handbook/with available characterization data & September 2007 \\
\hline \multicolumn{2}{|l|}{ GNEP Reactors for International Deployment } \\
\hline Select SMR technology for near-term deployment & May 2007 \\
\hline Complete initial needs/requirements assessments & September 2007 \\
\hline \multicolumn{2}{|l|}{ Modeling and Simulation } \\
\hline $\begin{array}{l}\text { Complete simulations of heat transport and oxygen diffusion coupled with thermal } \\
\text { expansion in } \mathrm{UO}_{2} \text { fuels with metal cladding }\end{array}$ & September 2007 \\
\hline Complete models of thermo-mechanical properties and phase stability of metal fuels & September 2007 \\
\hline Status report on oxide model development for SE2 & September 2007 \\
\hline Report on uncertainty quantification for selected ATWS sequences & September 2007 \\
\hline $\begin{array}{l}\text { Status report on multiphysics coupling algorithms and their application to nuclear } \\
\text { reactor simulation }\end{array}$ & September 2007 \\
\hline \multicolumn{2}{|l|}{ FY08 } \\
\hline \multicolumn{2}{|l|}{ Systems Integration and Analysis } \\
\hline AFCI Status Report to Congress - draft to DOE & December 2007 \\
\hline
\end{tabular}




\begin{tabular}{|c|c|}
\hline & Date \\
\hline GNEP Technical Requirements & December 2007 \\
\hline FY-08 Comparison Report to Congress - draft to DOE & February 2008 \\
\hline Input and support for NEPA alternatives and technology options evaluations & March 2008 \\
\hline Complete Input to 2008 Decision Package & March 2008 \\
\hline Integrated Waste Management Strategy & March 2008 \\
\hline Global Benefits Analysis of GNEP & March 2008 \\
\hline Report on evaluation of GNEP fuel cycle deployment options & April 2008 \\
\hline Report on initial assessment of global proliferation risk and GNEP impact & May 2008 \\
\hline Report on GNEP Facilities and Fuel Cycle Strategy & June 2008 \\
\hline Decision on startup fuel (oxide or metal) for fast reactor & August 2008 \\
\hline $\begin{array}{l}\text { Implement pilot PKC that demonstrates multiple predefined use cases for specific } \\
\text { applications. }\end{array}$ & August 2008 \\
\hline Evaluation of material management requirement for fuel take-back strategies & September 2008 \\
\hline Report on domestic and global demand for GNEP technology & September 2008 \\
\hline GNEP Initial Facilities Systems Analysis & September 2008 \\
\hline Update GNEP Deployment Systems Analysis & September 2008 \\
\hline \multicolumn{2}{|l|}{ LWR Spent Nuclear Fuel Separation Technologies } \\
\hline Develop Tc solidification flowsheet and initiate bench-scale tests & March 2008 \\
\hline Support $30 \%$ completion of industrial conceptual designs & April 2008 \\
\hline Complete pilot-scale testing of $\mathrm{Cs} / \mathrm{Sr}$ steam reforming process & April 2008 \\
\hline Complete EAS design package for review & April 2008 \\
\hline Develop instrumentation and control systems conceptual designs & May 2008 \\
\hline Initiate procurement of off gas system components for testing & June 2008 \\
\hline Demonstrate metallic waste form for cladding hulls incorporating technetium & September 2008 \\
\hline \multicolumn{2}{|l|}{ Transmutation Technologies } \\
\hline Retrieve FFTF irradiated (up to $200 \mathrm{dpa}$ ) mechanical test specimens & January 2008 \\
\hline ABR Prototype Design Study Complete & May 2008 \\
\hline Sodium component testing infrastructure evaluation & May 2008 \\
\hline Initiate sodium component technology development evaluation & September 2008 \\
\hline Identification of Prototype Design Tools by Industrial Team & September 2008 \\
\hline Complete Study on Alternate Configurations Options & September 2008 \\
\hline Identify key experiments using representativity techniques & September 2008 \\
\hline \multicolumn{2}{|l|}{ Transmutation Fuels and Separations Technologies } \\
\hline Complete AFCF system trade studies & April 2008 \\
\hline Begin ATR irradiation of oxide transmutation fuels & April 2008 \\
\hline Establish a list of advanced instruments to be further developed for demonstration & June 2008 \\
\hline AFCF 70\% Conceptual Design for Review & September 2008 \\
\hline Metal Fuel RFFL ready for operation & September 2008 \\
\hline Complete JOYO irradiation test plan & September 2008 \\
\hline
\end{tabular}


July 25,2007

\begin{tabular}{|c|c|}
\hline & Date \\
\hline Complete FUTURIX-FTA PIE plan & September 2008 \\
\hline SESAME framework completed & September 2008 \\
\hline \multicolumn{2}{|l|}{ GNEP Reactors for International Deployment } \\
\hline Initial screening of next-generation SMR concepts & March 2008 \\
\hline Select next-generation SMR(s) for pre-conceptual design & June 2008 \\
\hline \multicolumn{2}{|l|}{ Modeling and Simulation } \\
\hline $\begin{array}{l}\text { Document the GNEP business (why) and functional (what) requirements for all } \\
\text { Modeling and Simulation activities. }\end{array}$ & December 2007 \\
\hline Formal software releases in support of ABR design studies & September 2008 \\
\hline GNEP System Level Planning Tool Design Document & September 2008 \\
\hline \multicolumn{2}{|l|}{ FY09 } \\
\hline \multicolumn{2}{|l|}{ Systems Integration and Analysis } \\
\hline AFCI Status Report to Congress - draft to DOE & December 2008 \\
\hline FY-09 Comparison Report to Congress - draft to DOE & February 2009 \\
\hline Report on evaluation of international implementation issues & March 2009 \\
\hline Detailed fuel cycle performance data for GNEP reference technology option & July 2009 \\
\hline Generate the specification for the hardware system necessary to support the PKC & July 2009 \\
\hline $\begin{array}{l}\text { Databases that contain historical data not currently accessible from modern } \\
\text { repositories will be developed and made available to PKC users }\end{array}$ & August 2009 \\
\hline Integrated total quantitative GNEP risk analysis & September 2009 \\
\hline Update GNEP Initial Facilities Systems Analysis & September 2009 \\
\hline Update GNEP Deployment Systems Analysis & September 2009 \\
\hline Report on cost and performance experience for GNEP technologies & September 2009 \\
\hline \multicolumn{2}{|l|}{ LWR Spent Nuclear Fuel Separation Technologies } \\
\hline Develop initial waste formulation for fission product HLW & December 2008 \\
\hline Develop reference off-gas treatment process & January 2009 \\
\hline Complete initial characterization of mixed transuranic solid product & January 2009 \\
\hline Initiate demonstration of remote waste form packaging & March 2009 \\
\hline Complete evaluation of HLW forms & April 2009 \\
\hline Complete initial demonstration of steam reforming Cs/Sr product & May 2009 \\
\hline Validate UREX process performance with solvent recycle & May 2009 \\
\hline Complete demonstration of Tc solidification process & May 2009 \\
\hline Complete bench-scale demonstration of mixed transuranics solidification & June 2009 \\
\hline Complete bench-scale demonstration of $\mathrm{Cs} / \mathrm{Sr}$ solidification technology & September 2009 \\
\hline Complete initial integrated testing of separation processes with surrogates & September 2009 \\
\hline Support completion of conceptual design for nuclear fuel recycling center & September 2009 \\
\hline \multicolumn{2}{|l|}{ Transmutation Technologies } \\
\hline Sodium Component Test Infrastructure Design/Build Start & October 2008 \\
\hline Retrieve Specimens from MATRIX irradiation in Phoenix Reactor & November 2008 \\
\hline
\end{tabular}




\begin{tabular}{|c|c|}
\hline & Date \\
\hline Startup Fuel Fabrication Options Study with Down Selection & January 2009 \\
\hline Implementation Plan for TREAT Restart & April 2009 \\
\hline ABR Prototype Preliminary Hazards Analysis Complete & June 2009 \\
\hline ABR Prototype Conceptual Design Complete & September 2009 \\
\hline ABR Prototype CD-1 Approval & September 2009 \\
\hline Plan for Prototype Design Tools V\&V & September 2009 \\
\hline Complete Initial Design Options Evaluation & September 2009 \\
\hline Produce new evaluations from and covariance for priority isotopes & September 2009 \\
\hline \multicolumn{2}{|l|}{ Transmutation Fuels and Separations Technologies } \\
\hline Complete AFCF alternatives analysis strategy & December 2008 \\
\hline Acquisition strategy submittal for approval & March 2009 \\
\hline Complete CD-1 package for AFCF & June 2009 \\
\hline Complete FUTURIX-FTA irradiations (external) & June 2009 \\
\hline $\begin{array}{l}\text { Develop baseline pyrochemical flowsheets for treating spent metal and oxide } \\
\text { transmutation fuel }\end{array}$ & July 2009 \\
\hline $\begin{array}{l}\text { Demonstrate feasibility of fast reactor MOX fuel to metal conversion by electrolytic } \\
\text { reduction process }\end{array}$ & August 2009 \\
\hline Demonstrate metal fuel fabrication in RFFL's & September 2009 \\
\hline Demonstrate feasibility of voloxidation of fast reactor MOX fuel & September 2009 \\
\hline Define framework for advanced control logic & September 2009 \\
\hline Evaluate alternative crucibles for TRU recovery & September 2009 \\
\hline \multicolumn{2}{|l|}{ GNEP Reactors for International Deployment } \\
\hline Select near-term PRIMR design for safety evaluation support & January 2009 \\
\hline \multicolumn{2}{|l|}{ Modeling and Simulation } \\
\hline $\begin{array}{l}\text { M\&S tools (legacy and developing) directly supporting the ABR will be identified, } \\
\text { qualified through V\&V assessments, and placed under configuration control in } \\
\text { conformance with a QA plan. }\end{array}$ & December 2008 \\
\hline $\begin{array}{l}\text { M\&S tools (legacy and developing) directly supporting the CFTC will be identified, } \\
\text { qualified through V\&V assessments, and placed under configuration control in } \\
\text { conformance with a QA plan. }\end{array}$ & December 2008 \\
\hline $\begin{array}{l}\text { M\&S tools (legacy and developing) directly supporting the AFCF will be identified, } \\
\text { qualified through V\&V assessments, and placed under configuration control in } \\
\text { conformance with a QA plan. }\end{array}$ & December 2008 \\
\hline Formal V\&V assessment of ABR software & March 2009 \\
\hline Issue Initial GNEP System Level Planning Tool 1.0. & September 2009 \\
\hline Formal software releases for ABR design studies & September 2009 \\
\hline \multicolumn{2}{|l|}{ FY10 } \\
\hline \multicolumn{2}{|l|}{ Systems Integration and Analysis } \\
\hline AFCI Status Report to Congress - draft to DOE & December 2009 \\
\hline FY-10 Comparison Report to Congress - draft to DOE & February 2010 \\
\hline
\end{tabular}




\begin{tabular}{|c|c|}
\hline & Date \\
\hline Transition the pilot into the production level PKC & August 2010 \\
\hline $\begin{array}{l}\text { Create a specification for the addition of future data sets into the PKC that will be } \\
\text { automatically curated }\end{array}$ & August 2010 \\
\hline Update GNEP Initial Facilities Systems Analysis & September 2010 \\
\hline Update GNEP Deployment Systems Analysis & September 2010 \\
\hline \multicolumn{2}{|l|}{ LWR Spent Nuclear Fuel Separation Technologies } \\
\hline Complete initial Cs/Sr waste form characterization & October 2009 \\
\hline Demonstrate off-gas treatment system and waste forms & November 2009 \\
\hline Complete bench-scale demonstration of fission product waste form & March 2010 \\
\hline Complete mockup testing of prototype head-end equipment & July 2010 \\
\hline \multicolumn{2}{|l|}{ Transmutation Technologies } \\
\hline Code validation facilities plan & October 2009 \\
\hline Conceptual Design of Startup Fuel Fab Line & January 2010 \\
\hline Complete tensile and fracture toughness testing of FFTF irradiated materials & January 2010 \\
\hline Restart/construct required validation facilities & September 2010 \\
\hline Scaled demonstration of supercritical $\mathrm{CO}_{2}$ Brayton Cycle & September 2010 \\
\hline Prepare material specimens of advanced materials for JOYO irradiation & September 2010 \\
\hline Issue new revision of materials handbook with FFTF material data & September 2010 \\
\hline Perform uncertainty analysis with new covariance date & September 2010 \\
\hline \multicolumn{2}{|l|}{ Transmutation Fuels and Separations } \\
\hline Oxide Fuel RFFL ready for operation & December 2009 \\
\hline Demonstrate scale-up of ceramic waste process & March 2010 \\
\hline Complete initial testing of synroc and zeolite waste forms for cesium/strontium & April 2010 \\
\hline Identify safeguards requirements for pyroprocessing facility & May 2010 \\
\hline Identify optimum fission product loading and decay heat for ceramic waste form & May 2010 \\
\hline $\begin{array}{l}\text { Select product processing / consolidation technology for uranium product and TRU } \\
\text { product }\end{array}$ & August 2010 \\
\hline Begin PIE of FUTURIX-FTA specimens (dependant upon external schedule) & September 2010 \\
\hline Develop Sphere-pac fuel design concepts & September 2010 \\
\hline Develop Dispersion fuel design concepts & September 2010 \\
\hline Complete Feasibility assessment of innovative processes (microwave, combustion) & September 2010 \\
\hline $\begin{array}{l}\text { Identify and evaluate alternative product processing technologies selecting preferred } \\
\text { alternative }\end{array}$ & September 2010 \\
\hline Establish preliminary TRU recovery process parameters & September 2010 \\
\hline Validate performance of novel crucible materials in cathode processor system & September 2010 \\
\hline Conduct feasibility studies for preferred alternative product processing technology & September 2010 \\
\hline
\end{tabular}




\begin{tabular}{|c|c|}
\hline & Date \\
\hline Establish a test bed with relevant environment for instrument testing & September 2010 \\
\hline \multicolumn{2}{|l|}{ GNEP Reactors for International Deployment } \\
\hline Submit application for NRC design approval for near-term SMR & September 2010 \\
\hline \multicolumn{2}{|l|}{ Modeling and Simulation } \\
\hline Conduct demonstration of simulation capabilities for ABR & December 2009 \\
\hline Issue GNEP System Level Planning Tool 2.0. & June 2010 \\
\hline \multicolumn{2}{|l|}{ FY11 } \\
\hline \multicolumn{2}{|l|}{ Systems Integration and Analysis } \\
\hline AFCI Status Report to Congress - draft to DOE & December 2010 \\
\hline FY-11 Comparison Report to Congress - draft to DOE & February 2011 \\
\hline First Release of New Systems Level Planning Tool & August 2011 \\
\hline Per need-to-know, extend PKC user base to include universities and private industry & August 2011 \\
\hline Update GNEP Initial Facilities Systems Analysis & September 2011 \\
\hline Update GNEP Deployment Systems Analysis & September 2011 \\
\hline \multicolumn{2}{|l|}{ LWR Spent Nuclear Fuel Separation Technologies } \\
\hline Demonstrate process monitoring and control system for separation processes & May 2011 \\
\hline Convert AMUSE code to higher level platform, and incorporate transients & July 2011 \\
\hline Support completion of preliminary design for nuclear fuel recycling center & September 2011 \\
\hline \multicolumn{2}{|l|}{ Transmutation Technologies } \\
\hline ABR Prototype Preliminary Safety Analysis Report Complete & April 2011 \\
\hline Preliminary Design of Startup Fuel Fab Line & July 2011 \\
\hline Initiate Validation Studies for Advanced Methods & September 2011 \\
\hline \multicolumn{2}{|l|}{ Transmutation Fuels and Separations Technologies } \\
\hline Begin ATR irradiation of remotely fabricated fuels & October 2010 \\
\hline TRU metal-fuel specimens for JOYO fabricated in RFFL & December 2010 \\
\hline $\begin{array}{l}\text { Complete voloxidation demonstration and make go/no go decision of inclusion in } \\
\text { initial UREX+ testing. }\end{array}$ & April 2011 \\
\hline Develop process simulation model for treating spent advanced burner reactor fuel & August 2011 \\
\hline AFCF $70 \%$ preliminary design review & September 2011 \\
\hline Start ATR irradiation of dispersion, sphere-pac fuels, targets & September 2011 \\
\hline Complete Nitride fuel fabrication process baseline design & September 2011 \\
\hline Demonstrate electrorefining with salt containing a high TRU concentration & September 2011 \\
\hline Initial model for AFCF aqueous processing module & September 2011 \\
\hline \multicolumn{2}{|l|}{ GNEP Reactors for International Deployment } \\
\hline Down-select to 2 next-generation SMR conceptual designs & January 2011 \\
\hline \multicolumn{2}{|l|}{ Modeling and Simulation } \\
\hline GNEP System Level Planning Tool 3.0 & March 2011 \\
\hline
\end{tabular}


July 25,2007

\begin{tabular}{|c|c|}
\hline & Date \\
\hline \multicolumn{2}{|l|}{ FY12 } \\
\hline \multicolumn{2}{|l|}{ Systems Integration and Analysis } \\
\hline AFCI Status Report to Congress - draft to DOE & December 2011 \\
\hline FY-12 Comparison Report to Congress - draft to DOE & February 2012 \\
\hline Update GNEP Initial Facilities Systems Analysis & September 2012 \\
\hline Update GNEP Deployment Systems Analysis & September 2012 \\
\hline Decision on Transmutation Fuel for Fast Reactor & September 2012 \\
\hline \multicolumn{2}{|l|}{ LWR Spent Nuclear Fuel Separation Technologies } \\
\hline Complete initial characterization of high-level waste forms & July 2012 \\
\hline \multicolumn{2}{|l|}{ Transmutation Technologies } \\
\hline $\begin{array}{l}\text { Complete mechanical testing of specimens from MATRIX irradiation (advanced } \\
\text { materials irradiated up to } 70 \mathrm{dpa} \text { ) }\end{array}$ & November 2011 \\
\hline Validate multiscale materials performance modeling code & February 2012 \\
\hline ABR Prototype Preliminary Design Complete & April 2012 \\
\hline ABR Prototype CD-2 Approve Performance Baseline & May 2012 \\
\hline Complete Validation of First Improved Structural Material & September 2012 \\
\hline \multicolumn{2}{|l|}{ Transmutation Fuels and Separations Technologies } \\
\hline Begin ATR irradiation for high temperature limits & October 2011 \\
\hline Domestic fast spectrum rodlet irradiation capability available & December 2011 \\
\hline Evaluate UREX+1a flowsheet for transmutation fuel & August 2012 \\
\hline Demonstrate on-line product recovery from uranium electrorefiner system & August 2012 \\
\hline Complete AFCF preliminary design & September 2012 \\
\hline Ship initial fuel for JOYO irradiations & September 2012 \\
\hline Complete ATR irradiations of dispersion and sphere-pac fuels, targets & September 2012 \\
\hline Down-select instrumentation for initial demonstration & September 2012 \\
\hline Initial demonstration of advanced control logic & September 2012 \\
\hline Initial model for AFCF pyroprocessing module & September 2012 \\
\hline \multicolumn{2}{|l|}{ GNEP Reactors for International Deployment } \\
\hline Award up to two contracts for conceptual designs of next-generation SMR & March 2012 \\
\hline \multicolumn{2}{|l|}{ Modeling and Simulation } \\
\hline GNEP System Level Planning Tool 4.0 & September 2012 \\
\hline
\end{tabular}




\subsection{Systems Integration and Analysis}

The Systems Integration and Analysis Activity serves three purposes, which taken together, guide and enable the GNEP program:

- Technical Integration, which supports DOE program management of GNEP, risk management and decision management. Technical integration includes ensuring close collaboration between the facility projects, technology development, and R\&D. The following two activities provide the analysis support for this activity.

- System Analysis of the deployment of GNEP facilities beyond the CFTC, ABR, and AFCF, including the global system. Analysis is undertaken of a variety of deployment system alternatives and continually evaluates the predicted performance of various deployment systems as new performance and cost data come available

- System Analysis of the first GNEP facilities (CFTC, ABR, AFCF), where these facilities and the system to support them, as well as the technology choices employed to implement the system, are reevaluated throughout their development to ensure that the optimum technology path is being followed and to allow for a structured decision making approach.

Technical Integration will ensure the coordination of the GNEP program. The systems analysis activities will build on previous nuclear fuel cycle analyses conducted in the U.S. by the AFCI program, as well as international nuclear systems analyses. These analyses will require integration of information from the diverse technology development and R\&D efforts. High-level systematic assessment of GNEP technology and deployment options will be conducted to guide and confirm program decisions. In addition, key factors contributing to overall programmatic schedule, cost, and risk will be identified and quantified.

The systems analyses activities are keyed to the 2008 Secretarial decision and the overall success of the program.

\subsection{Technical Integration}

DOE has designated the INL as the lead for Technical Integration (TI) of GNEP. The objective of TI is to provide optimal efficiency to GNEP by coordinating the various technical tasks towards achieving the common GNEP goals, and by providing support to program management in the areas of budget and financial controls and programmatic review.

The activities described in Sections 2.2 through 2.6 provide the analyses needed to define the program requirements and identify program risks and key decisions. This activity provides the overall technical coordination for the program, using this information to provide risk management, decision making support, interface coordination, and program and project integration.

The GNEP Technical Integration function will provide support to DOE, which has overall management responsibility for the program, including program communications, mission requirements management, and decision management. Technical Integration will assist DOE in maintaining focus of the GNEP mission. A number of key decisions will be required to focus the program, including early decisions on primary features of the facility projects and risk management decisions as the program proceeds.

Technical Integration will support DOE in the decision-making process, including coordination of review teams and support to the Assistant Secretary for Nuclear Energy as needed. Technical Integration is also the primary source for communications and overall program information.

The Technical Integration activity will integrate the information from the GNEP systems analyses, which implicitly integrate information from the other parts of the GNEP program. The systems analysis results will be synthesized to guide and confirm program decisions. In addition, key factors contributing to 
overall programmatic schedule, cost, and risk will be identified and quantified. This activity will also be responsible for reporting, as required, to the Department of Energy, Congress, etc.

Technical Integration will support the technical input to the National Environmental Policy Act (NEPA) process, including comparison with alternatives considered in the Programmatic Environmental

Impact Statement (PEIS). In conjunction with the GNEP timeline for a decision on the GNEP path forward in June FY08, input and integration support will be provided for the CD-1 packages for GNEP facilities; and a Report to Congress on GNEP Facility and Fuel Cycle Strategies is anticipated in the same time frame. In addition, to facilitate communication within GNEP, annual program reports will be developed to communicate highlights within the technology development areas and international partnerships. Finally, the integration area will also provide coordination and oversight of the system analysis activities.

The three facility projects (the CFTC, ABR, and AFCF) must be tightly coordinated, together with the technology development that supports them. Each facility is part of a large system, and the requirements of the technology associated with one facility affect the requirements for each of the others. The GNEP Technical Integrator will work with DOE to ensure consistency and compatibility of detailed requirements, schedules, and associated budgets and management of project interfaces.

Another role of this integration activity is to provide risk assessment for the complex GNEP program. GNEP technologies will continue to mature, and the facility capabilities will adapt to changing circumstances and lessons learned. By intent, GNEP considers the global fuel cycle with a range of locations, technologies, economic systems, regulatory structures, waste criteria, and related factors. Thus, it is important to apply modern risk assessment techniques to assess both the program and deployment risks. In particular, an identification of the key risk contributors can help focus GNEP activities.

Technical Integration will assist DOE with risk management for the program; ensuring risks associated with the program have been identified, analyzed and mitigated. Risk management is concerned with future events, whose exact outcome is unknown, and how to deal with these uncertainties. Risk is a measure of the potential inability to achieve overall program objectives within defined scope, cost, schedule, and technical constraints. The two components of risk are the likelihood of failing to achieve a particular outcome and the consequences of failing to achieve that outcome. The GNEP-TDP will follow the risk management principles of DOE Order 413.3, including the development of a risk management plan.

An initial qualitative risk factor assessment will be conducted (prior to the 2008 decision by the Secretary of Energy), covering the technology development, design, and construction activities. This assessment will be based on the project schedule and cost baselines provided in this GNEP technology development plan. This risk assessment provides baseline data for an updated quantitative assessment as the program evolves.

The GNEP Technical Leads for the facilities and technology development will participate in the technical evaluations and risk assessment for the program, including coordination of technology development activities and alternatives management. While the primary function of the Technical Leads is focused on their individual technology development areas, they are important participants in the Integration activities.

An important role of this activity is to manage the information produced by the program. Because data resulting from experiments, analysis, and reports are expected to reach the petabyte level, a distributed Partnership Knowledge Center (PKC) will be implemented. The PKC includes participants from ten DOE national laboratories where several areas of expertise will be integrated into one open-source distributed framework. This framework will allow the sharing of data and execution of programs, interoperability and collaborative workflow between sites, government, and private enterprise, as well as 
operating system access control across firewalls to maintain individual site and data security. This activity will provide a central repository for detailed information that meets quality and configuration control requirements including the preparation of periodic and requested reports to the DOE and Congress.

The PKC will be implemented to benefit the GNEP program including the scientists within the modeling and simulation community. At the highest level, the $\mathrm{PKC}$ will make available the information required to assess and analyze the accuracy of advanced nuclear energy systems and associated future capabilities. It will utilize the best-in-class data management technologies from each of the ten laboratories to solve some of the most difficult data management challenges. Specifically the PKC will:

- Establish a virtual knowledge center to manage (identify, describe, format, integrate, collect, protect, and disseminate) all forms of data to enable analysis relevant to the overall goals of the NE program.

- Lead the national and international efforts to adopt, develop, and maintain the standardization of critical data and metadata formats to validate and improve data accuracy, consistency, and accessibility.

- Establish GNEP collaboration architecture for sharing data and information within the partnership through the adoption and support of open protocols, tools, services, and distributed data resources.

- Identify and resolve access control issues including those arising from export controlled and proprietary information.

The Technical Integration activity is essential to the coordination of the complex GNEP program. Technical integration is responsible for close collaboration between the facility projects, technology development, and R\&D through coordination of the other campaigns with multiple participants, including national laboratories, industry, and universities. In summary, the Technical Integration activities include the following:

- TI guides systems analyses tasks to ensure that GNEP technologies are optimized for meeting the GNEP objectives

- TI develops review mechanisms for the program to ensure overall coordination and consistency with the program objectives

- TI establishes processes that allow for the integration of novel technical concepts in the program

- TI manages the technical risk of the GNEP technologies by developing strategies that prioritize technical work and provide for risk mitigating alternatives

- TI completes and updates at regular intervals the TDP

- TI focuses the R\&D on key issues for the 2008 secretarial decision

- TI develops and implements a campaign structure within GNEP that takes full advantage of the opportunities offered by modeling and simulation

- TI coordinates GNEP technology work with fundamental aspects that are studied by the Office of Science

- TI provides an overview of technology alternatives and recommends their inclusion in the program 
- TI establishes a technology baseline and maintains configuration control

- TI develops a detailed GNEP Technology Roadmap

- TI supports the development of an international collaborative framework

- TI supports DOE in developing an effective communication strategy

TI is also responsible for supporting DOE in key program management tasks:

- TI reviews and coordinates all campaigns and work packages, insures consistency and eliminates redundancies

- TI establishes an integrated schedule for the program and ensures consistency in the timelines of all campaigns and projects

- TI ensures that program baselines including those of technical activities, cost, and schedule are established and maintained.

- TI provides a monthly detailed review of financial data, conducts variance analyses based on financial data and technical progress, and provides recommendations for corrective actions to DOE

- TI leads the national efforts to adopt, develop, and maintain the standardization of critical data and metadata formats to validate and improve data accuracy, consistency, and accessibility

- TI leads the efforts to identify and resolve access control issues including those arising from export controlled and proprietary information

- TI leads the efforts to ensure that the proper mechanisms and tools exist that will allow scientists and engineers to access information, collaborate, and have a common platform that enables them to make informed decisions

- TI establishes program wide standards for documentation and records control and ensures that these standards are followed

- TI establishes QA standards consistent with DOE practices and program objectives

The Technical Integrator provides overall leadership to this process. He is assisted by two Deputies. This team provides overall technical leadership to the program and ensures coordination through the campaign directors. A technical integration office will be established that supports all program management tasks, and will assemble the key personnel for financial planning and control, information science and engineering, communication, QA and documentation control.

\subsection{Systems Analysis to Support GNEP Deployment}

Deployment systems analyses will be conducted to assess the performance impact of GNEP technologies in the domestic and global context with respect to future deployment. Favorable deployment strategies will be identified and the potential means to optimize their performance will be explored. The four major analysis areas are fuel cycle analysis, waste disposition analysis, economic analysis, and proliferation risk analysis using the approach defined in Section 2.4.1.

The first Deployment Systems Analysis will be completed in FY 2007. The results of this analysis will drive the performance requirements for the technologies and criteria for system technology selection. There will be large uncertainties in some areas (costs, for example), and this information will help target where more information is needed from the technology and facility development program. The Deployment Systems Analysis will be updated yearly. 
The dynamic fuel cycle analyses will address global fuel cycle strategies. The first step is to extend the existing domestic AFCI fuel cycle model to a regional/global fuel cycle. The impact of existing infrastructure and eventual transition to GNEP technology will be evaluated for current nuclear fuel cycle countries (e.g., Japan and France). The fuel cycle dynamics between fuel cycle and reactor states will also be explored for a variety of nuclear growth scenarios. Alternate fuel cycle scenarios based on differing international paradigms or deployment strategies will be identified. The impact of international options with different technology decisions (e.g., LWR recycle, plutonium separation), and impact of specific deployment strategies (e.g., different cooling times, reactor types, fuel burnup, etc) will be assessed.

In the longer-term, a comprehensive evaluation of fuel cycle impacts for transuranic recycle will be conducted. The fuel fabrication, handling, and storage impacts will be quantified, with a focus on safety parameters such as worker dose, criticality, and shielding requirements. This analysis provides important data for the AFCF project, in particular. The impact of uncertainties on the reactor and fuel cycle performance, such as separations efficiencies in the recycling plant, will also be assessed. Furthermore, the identification and evaluation of fuel cycle scenarios will continue as the GNEP technology nears deployment, and the generation of consistent fuel cycle data will be required.

Waste disposal, material storage, and transportation analyses will evaluate how GNEP technology can optimize the future management of used nuclear fuel, high-level radioactive waste, and other storage and waste forms. This includes evaluating both potential impact and remaining uncertainties of closing the fuel cycle on the evolution of waste management, including potential repository benefits.

In the longer term, waste disposition analyses will investigate the waste disposal impact of refined GNEP waste forms and repository design, and perform optimization studies of the storage/transportation and materials management. In addition, global fuel cycle approaches related to spent fuel take-back and alternative international technologies (and disposal sites) will be addressed, including the deployment of reactors in developing countries.

In the economic analyses, international implementation issues will be explored in detail, including the cost of international facilities, partnership agreement impacts, and financing options. The cost estimate data will be updated as the GNEP technology and facility activities progress. In addition, uncertainty analyses will be performed to generate realistic contingency values for facility life cycle costs. The economic analyses will include:

- GNEP Deployment Options

- Projection of ultimate life cycle costs as facilities progress from "1st-of-a-kind (FOAK)" to more mature "Nth-of-a-kind" (NOAK) status.

○ Evaluation of economic impact of various ownership/financing options.

- GNEP International Deployment Options

- Calculation of U.S. dollar-based life cycle costs for fuel cycle facilities constructed and operated in "full fuel cycle service" nations such as Japan, Russia, France, etc.

- Calculation of U.S. dollar-based life cycle costs for small nuclear power reactors constructed in "user" nations where fuel cycle services are provided.

- Support of economic analysis of an overall "supplier-user" international GNEP system, including international transportation, safeguards compliance, and economic compatibility of international facilities.

- Estimation of the economic impact of safeguards and security (including positive economic impact) required to ensure nonproliferation objectives are met. 
For the proliferation risk analysis, feedback will be provided to GNEP technology designers regarding means to reduce the overall fuel cycle proliferation risk. Refinements of the proliferation risk measures will be incorporated into the systems dynamic analysis tools. In addition, the global fuel cycle proliferation risk evaluations will be continually updated, and specific regional analyses will be conducted.

\subsection{Systems Analysis to Support First GNEP Facilities}

This activity will analyze the technology choices for the first GNEP facilities, and identify alternatives and the underlying R\&D that will be needed to successfully design, build, and operate these facilities. This will be an ongoing activity that takes information learned in the technology and facility development activities. This analysis will identify where reorientation of the GNEP system may be needed, and provide technology level integration.

Finally, the technologies must operate together as a system to achieve the GNEP program objectives. System optimization must consider the proposed technologies and how they will interact with the U.S. infrastructure. Implementation of spent nuclear fuel recycling significantly alters the requirements for transportation, storage and disposal of nuclear materials. The once-through cycle requires extensive transportation of intact commercial spent nuclear fuel from reactors to a repository, interim storage at reactor or other sites, and eventual disposal of intact spent nuclear fuel in a geologic repository. Recycle brings changes to each of these requirements and adds new ones for storage and transport of the recycle products and disposal of waste streams. The broad scope of the recycle system will require consideration of these solutions from a systems viewpoint to ensure the whole system is optimized. This will introduce detailed requirements on the nature of the waste forms produced from the separations and recycle facilities.

\subsection{Development of Technical Requirements}

An important role of systems analysis is to define the requirements for the development and deployment of the technologies that are necessary to meet the GNEP mission. Thus, the end result of the systems analyses described here is to specify technical requirements. These requirements quantify the GNEP mission and guide the important technology decisions.

\subsubsection{GNEP Deployment System Requirements}

Having identified reference system architecture for the GNEP system, a second tier of decisions concerning technology choices can be made. These decisions are based upon technical requirements derived from the general goals of the GNEP program and other considerations such as U.S. proliferation policy, U.S. environmental laws, and good engineering and business practices ${ }^{\mathrm{a}}$.

These considerations result in seven technical requirements that must be met by the GNEP deployment system of technologies:

1. The system must be protective of public health, safety, and the environment through up-front consideration in design and incorporation of integrated safety and environmental management systems in accordance with applicable polices, directives, regulations and statutes throughout all phases of the life-cycle.

2. The system must result in a significant improvement in repository utilization, preferably avoiding the need for a second geologic repository this century.

\footnotetext{
${ }^{a}$ The GNEP Technical Requirements Document is under development.
} 
3. The system must allow for adoption of optimized waste management strategies for safe, timely, and economic disposition of waste materials, including use of appropriate waste reduction technologies and technologies for producing robust waste forms.

4. The system must make available the energy value of separated materials for future use.

5. The system must reduce proliferation risk compared to a future global system based on nuclear fuel recycling technologies currently in use in other countries today.

6. The system must be deployable in a timeframe so as to reassert U.S. leadership, and influence fuel cycle development worldwide (20-25 years).

7. The system must remain as economical as possible.

\subsubsection{System Requirements for Initial GNEP Facilities}

The requirements identified in Section 2.4.1 lead to the technical requirements that the GNEP system must meet to be acceptable.

The first requirement ensures that the GNEP system meets health, safety and environmental laws.

The second requirement addresses the technical capacity of a representative repository, which is limited by a set of criteria that include a maximum dose rate, maximum temperature at the drift wall, and maximum temperature at the mid-point between drifts. Studies have been conducted ${ }^{\mathrm{a}}$ that demonstrate that the technical capacity of a geologic repository can be dramatically increased by the following strategy:

- The transuranic elements that generate long term heat loads and almost the entire long-term dose need to be destroyed through a transmutation process.

- The cesium and strontium isotopes that dominate the short term heat loads need to be separated from the spent nuclear fuel for separate management such as decay storage until low activity levels are reached or for disposal in a facility optimized for short-term but high-heat-generation wastes.

- Appropriate wastes forms need to be developed that allow volume reduction and/or packaging changes to account for the reduced heat load.

The potential increase of repository utilization depends on the efficiency of separating cesium, strontium and the transuranic elements. Eliminating $99 \%$ of cesium and strontium and $99 \%$ of all transuranics would result in a potential for $\sim 90$ times capacity increase for a typical repository, based on repository thermal design goals. These are then chosen as technical criteria for the separations technology.

The third requirement derives from the waste minimization goal and translates directly into a requirement that the LWR spent nuclear fuel separations facility not produce any high-level liquid waste streams. Other facilities will be required to minimize waste streams.

The fourth requirement leads to criteria that the transuranics must be isolated for future destruction, or destroyed immediately, and that the uranium, which forms the bulk of the spent nuclear fuel, must be recovered at a level of purity (greater than $99.9 \%$ efficiency of recovery) that enables it to be easily stored for future use or eventual efficient disposal.

The fifth requirement is that the level of proliferation risk must conform to U.S. policy. In particular the system must not include or encourage the separation of pure plutonium. The whole system architecture

${ }^{\text {a }}$ Separations and Transmutation Criteria to Improve Utilization of a Geologic Repository, Nuclear Technology, Vol. 154, p. 95 (2006). 
should utilize a combination of intrinsic proliferation risk reduction features, safeguards technologies and physical protection features to ensure that materials remain unattractive and are very difficult to divert, and that equipment is very difficult to misuse.

The sixth requirement, that the system must be deployable in a timeframe so as to reassert U.S. leadership and influence fuel cycle development, drives the selection of only those technologies that can be implemented in the near-term with minimum technical risk. However, once such leadership is regained, maintaining it over the long term requires robust ongoing $R \& D$ toward more advanced technologies.

The seventh requirement is a general constraint on the system.

\subsubsection{Requirements for Internationally Deployed Reactors}

Success of the full GNEP strategy requires that many countries forgo development of full fuel cycle capabilities in return for assurance of fuel supply and take back for nuclear reactors in their country. Of particular significance will be developing countries whose economies are growing and whose corresponding demand for power and energy is increasing rapidly. If these countries are to avail themselves of the benefits of nuclear power, and install less fossil burning capacity, there must be products geared to these markets. Because many countries in the developing world do not have extensive electricity grids, current commercially-available Generation III reactors are unsuitable due to their size, cost, and complexity. Therefore new types of reactors must be developed for international deployment that are "right-sized" for developing countries, and that are based on technologies, designs, and policies focused on reducing proliferation risk.

Studies are underway to develop an overview of the current energy supply and demand picture in countries representing potential GNEP participants (Poland, Korea, and Brazil are used as representative of potential participants), addressing the supply and end use markets. These studies include the review of estimates of future demand and supply, including the need for new electricity generation and alternatives for achieving that generation. Current government policy and market structures are being analyzed, especially in the electricity sector. This will enable the identification of opportunities for deployment of a new nuclear power facility consistent with the country energy projections that could be implemented in a manner that meets the Global Nuclear Energy Partnership (GNEP) goals and objectives.

Many countries have reactor systems under development that address these markets (Argentina, South Africa, Russia, Japan, and South Korea are all examples). These reactors have been developed independently and have not been assessed from a GNEP requirements perspective.

GNEP systems analysis will perform a requirements study for internationally deployed reactors to inform any recommendation on a path forward for the U.S. in this arena. Such a study will require extensive international participation and may take advantage of the existence of international organizations such as the Generation IV International Forum and the International Atomic Energy Agency (IAEA) -led International Project on Innovative Nuclear Reactors and Fuel Cycles (INPRO). Section 6 describes the program to develop and demonstrate reactors for international deployment.

\subsection{Systems Integration Tools and Approaches}

There are two types of systems analyses within the Systems Integration task: an analysis of the deployment system and an analysis of the first GNEP system and facilities. The results of these analyses will be used in Technical Integration and will provide the foundation for performance requirements of the facilities. The analyses will require similar approaches, and will initially be performed using existing tools. The tools will be continually updated (as will the analyses) as information becomes available from the technology development program. The systems analysis tools as well as all other tools, will be appropriately benchmarked (and some will go through formal verification and validation) as discussed in Section 6. 
As technology refinements are developed and GNEP alternatives are identified for evaluation, key technical questions will be addressed and solved. This will result in the generation of new performance data for new scenarios and the evolution of refined techniques for quantifying nuclear fuel cycle performance. Tools used for Systems Analysis will range from simplified repository performance models to specific reactor transmutation depletion analysis to complex dynamic models. In the AFCI systems analysis activity, a sustained multi-laboratory team has developed a comprehensive set of analysis tools for evaluating the nuclear fuel cycle. Quantification of the fuel cycle benefits often requires a detailed performance evaluation of specific issues (i.e., reactor safety, repository thermal behavior) and/or the development of large, well validated database (e.g., unit costs). Furthermore; these analyses must provide a systematic comparison of fuel cycle scenarios and alternatives. The primary technical areas for these performance evaluations are fuel cycle analysis, waste disposition analysis, economic analysis, and proliferation risk analysis, as described below. The performance data and identified key parameters from the detailed analyses comprise the initial data and comparison basis for the Verifiable Fuel Cycle Simulation Model (VISION) ${ }^{\text {a }}$ code that has been developed in the AFCI program to model the complete fuel cycle.

VISION is a computer-based simulation model that performs dynamic simulations of fuel cycles to quantify infrastructure requirements and identify key trade-offs between alternatives. VISION is intended to serve as a broad systems analysis and study tool applicable to work conducted as part of the AFCI and Generation IV reactor development studies. The model tracks the mass flow of nuclear materials within the fuel cycle and includes different types of delays and feedbacks associated with the construction of nuclear facilities and the decisions to build such facilities. The model provides several time-dependent outputs including mass, long-term heat intervals, long-term dose, total $\mathrm{Pu}-239, \mathrm{Pu}-239 /$ total $\mathrm{Pu}$, and $\mathrm{Pu}-$ 239 equivalent masses. For recycle fuels, the model's major flow control is the availability of elemental $\mathrm{Pu}$ to make recycle fuels. In FY 2006, the VISION model added (1) isotopic flow control and decay, (2) additional data from transmutation analyses (3) simplified models for fuel separation and fabrication, (4) cost parameters, and (5) increased flexibility in transitions and combinations of individual fuel cycle technologies.

The VISION model will be updated, and additional tools will be developed under the Modeling and Simulation Activity (see Section 6). An important metric will be the reduction of uncertainties in the analyses using VISION (and other models). More sophisticated models as well as better data (available through the technology and development program) will be used to inform the 2008 Secretarial decision.

The following sections describe the types of analyses that will be done to support Systems Integration.

\subsubsection{Analytic Approaches}

A variety of systems analyses are required to assess the viability, performance, and dynamic impact of diverse nuclear fuel cycle technology options. There are four major areas identified for specific systems analyses:

- Fuel cycle analysis

- Waste disposition analysis

- Economic analysis

- Proliferation risk analysis.

a. A. M. Yacout, et al., Waste Management 2006 Conference, Tucson, Arizona, February 26 - March 2, 2006. 


\subsubsection{Fuel Cycle Analysis}

The purpose of this task is to systematically assess the fuel cycle performance of proposed GNEP technology and implementation options. Results of previous and ongoing fuel cycle analyses will be synthesized, and key programmatic systems inquiries regarding fuel cycle materials and reactor performance will be answered. In addition, detailed fuel cycle analyses will be performed to address key performance measures and fuel cycle impacts.

Furthermore, dynamics analyses will examine the timing and interaction of fuel cycle system components, including feedbacks from each facility change, option change, or decision; time lags between decisions and impacts; and how the system is expected to respond to changes. The current AFCI fuel cycle models must be extended for global nuclear fuel cycle analysis. A wide variety of scenarios for future nuclear energy capacity (both domestic and international), GNEP deployment strategies, and international technologies will be considered. Furthermore, the uncertainties in process, reactor, and waste disposal performance will be evaluated.

These analyses will provide the consistent fuel cycle data required by the integration, waste disposal, economics, and proliferation risk analysis activities. To complement the detailed design work conducted for the facilities, expected variations of the GNEP fuel cycle implementation will be analyzed. For each study, the GNEP simulation tools will be adapted to the specific scenario, and fuel cycle performance data (material compositions, mass flows, inventories, etc.) will be generated for use in the dynamic analysis or other Systems Analysis areas.

Some of the specific types of analyses and scenarios to be analyzed include the following:

- Impact of fuel cycle on resource utilization.

- Impact of different selections for ABR fuel type, ABR fuel separation technology (UREX+1a, pyroprocessing), and degree of centralization of ABR fuel separation.

- Technical trade-off between sending waste residual after separations back to "reactor states" or kept and disposed in "fuel cycle states."

- Examination of options for uranium disposition, as waste (possibly low-level in the U.S.), storage for use in future fast reactors, use in CANDU reactors, or re-enrichment and refabrication for use in Light Water Reactors (LWR).

- Impact of adding different reactor types (e.g., gas reactors or other Generation-IV systems) to the U.S. baseline of Boiling Water Reactors and Pressurized Water Reactors.

- Impact of planned retirement of the existing global nuclear infrastructure - power plants, uranium mines, conversion plants, enrichment plants, separation plants, and fuel fabrication plants.

- Impact of planned new facilities, especially those envisioned as part of GNEP.

The dynamic analyses will evaluate the timing and material flows for application of the GNEP facilities. The impact of changes in schedule and performance will be assessed. In addition, technology options will be considered to support the NEPA evaluations. This work will culminate in a FY08 report on the evaluation of GNEP facility options.

\subsubsection{Waste Disposition Analysis}

Waste disposal, material storage, and transportation analyses will assess the management of the material streams used or generated within GNEP. This includes evaluation of separated product streams for eventual reuse and waste streams for eventual disposal. GNEP activities and facilities are likely to 
produce several different types of waste, each of which must be analyzed in a systematic, comprehensive manner. This includes evaluating both potential impact and remaining uncertainties of closing the fuel cycle on the evolution of waste management, including potential repository benefits such as increased technical capacity from reduction in decay heat, improved performance from reduced long-term radiotoxicity and dose per unit of energy generated, and increased repository design flexibility.

This analysis area is the focal point for technical integration and cooperation between the GNEP and the U.S. geologic repository program, and will be used to maximize the benefit to both programs. This cooperation is needed to evaluate repository design alternatives with technical potential for dramatic improvements in capacity and performance. The analyses will build off of the fuel cycle analyses discussed above and also incorporate all aspects of waste storage (temporary) and disposal (permanent), material storage, and transportation. This supports future decisions on the implementation of GNEP such as the ability of a single geologic repository to support expansion of domestic nuclear energy use. An important product of these systems analyses and the cooperation with the U.S. geologic repository program will be technical input for the Secretarial recommendation to Congress on the need for a second repository.

Within planned GNEP activities and facilities, there are a variety of material storage, transportation, and waste disposal requirements. This activity will also evaluate alternatives for meeting these requirements, including storage of radioactive material prior to processing, reuse or disposal, transportation of material between GNEP facilities, and disposal of GNEP wastes. Current storage and transportation cask designs and procedures must be evaluated for GNEP use. Alternative storage and transportation strategies to reduce cost and schedule of packaging and transportation of waste will also be evaluated.

An important activity within analysis is the development of an integrated waste management strategy for the GNEP fuel cycle. This strategy will ensure an optimized, safe, acceptable pathway is available for disposition of all wastes. Separation of the components of spent fuel enables tailored management to be developed for each component. Development of the strategy includes evaluation of all separated streams, byproducts, and process wastes from fuel fabrication, reactor operation, and spent fuel separations. Options for disposition of each stream are assessed, including recycle or disposal pathways, appropriate waste forms, and conversion and transportation requirements.

The integrated waste management strategy will also assess the impact of regulations on disposition options. This will include assessing differences in waste classification between the U.S. and other nations which impact the purity requirements for separated materials. It will also include analyses to inform policy makers of areas where current regulations were developed before information was available on the unique characteristics of separated materials. In these areas, regulatory changes may be warranted to help optimize the commercial fuel cycle and safe disposition of all materials. 


\subsubsection{Economics Analysis}

Economic analysis, including a considerable cost estimation effort, is an activity that cross-cuts many elements of the GNEP program, including the demonstration facilities. Program funding requirements must be generated from credible cost estimates to satisfy program sponsors. The economic analysis will require input from the GNEP facility designers and architect-engineer contractors. Where appropriate, life cycle cost analyses will be conducted to demonstrate the economic consequences of major decisions. The Economic Analysis activity will be closely integrated with other Systems Analysis subgroups and the Modeling and Simulation activity, especially in the area of defining the nature of the economic outputs generated by simulation models. Work will also be coordinated with the Generation IV Reactor Systems Economic Modeling Working Group, which is looking at international reactor options. Among the type of analyses and results expected are the following:

- Projected life cycle costs for major GNEP facilities (domestic "capability demonstration" facilities, domestic and international commercial facilities)

- Year by year spending profiles for selected GNEP scenarios

- Projected unit costs of electricity from burner and small modular reactors with breakdown of capital, fuel cycle, and operating costs

In the near-term, economics activities are oriented mainly toward assisting the selection of the most economical, reliable, and productive technologies for the facilities envisioned by GNEP. To this end, the AFCI cost database will be continually updated and integrated into the dynamic fuel cycle model. In addition, a "lessons learned" report on cost and performance experience in the areas of fast reactors, commercial spent fuel reprocessing facilities, recycle fuel fabrication, and major waste handling facilities will compile historical information on facilities such as THORP, Rokkashomura, LaHague, FFTF and BN-600. During initial NEPA planning, support will be provided to scenario formulation and the development of data requirements for socio-economics, transportation, and life-cycle cost analysis. In addition, the initial estimate of domestic and international demand for the GNEP technology will be conducted.

\subsubsection{Proliferation Risk Analysis}

An important requirement for the GNEP fuel cycle is that it employs separations and recycling technology that will reduce overall proliferation risk relative to a future global system based on technologies in use outside of the U.S. today. The main principles being followed to achieve this goal are 1) to facilitate global nuclear power expansion without the spread of enrichment and separations technology, 2) to use processes that do not separate plutonium from the other materials, and 3) to minimize the time in the overall system where the radiation levels associated with the plutonium-bearing materials are low. The safeguards technology for the separations and fuel fabrication facilities will be addressed in the specific facility design tasks and the tools for the evaluation of proliferation risk and physical protection at these facilities will be addressed in the Safeguards crosscutting activity (see Section 8).

These analyses will be utilized to provide an ongoing evaluation of the effectiveness of the complete GNEP fuel cycle relative to proliferation resistance, as compared to current and developing global alternatives. The initial work will develop a reference assessment of global civilian nuclear power conditions. An initial set of measures for proliferation risk will be identified, and a reference assessment of global proliferation risk from civilian nuclear power activities will be performed. Using this evaluation, the potential impact of using GNEP facilities on a global scale will be determined, with feedback provided to the GNEP FY 2008 decision. 
The results of these analyses should provide an assessment of the potential global impact of GNEP. They should also allow judgments to be made on an ongoing basis as to the suitability of the current GNEP directions, and to guide alterations or modifications to planned GNEP activities to best address developing global conditions. As more sophisticated proliferation risk analysis tools become available, earlier results will be updated to provide a dynamic assessment of the impact of GNEP technology.

\subsection{Systems Analysis Support to 2008 Decision on GNEP Path Forward}

The systems analysis activity will provide important information in support of the 2008 Secretarial Decision on the path forward for GNEP. By this date, several systems analysis activities will be completed and products produced:

- Detailed system dynamic studies will be performed to evaluate the planned path forward and identify possible impediments. These studies will include size, timing, and configuration of storage, separations, fuel fabrication, reactors, material transportation paths, and waste disposal. These dynamic studies will lead into system optimization studies that incorporate technical and regulatory issues.

- The economic data and associated uncertainties that have been accumulated by the program will be used for economic studies that assess the value of GNEP both in financial terms, and in external benefits (sustainability, carbon emissions, etc.).

- A waste management strategy will be completed that identifies the path of each waste stream, identifies storage requirements, regulatory issues, transportation needs, and ultimate disposal paths.

- A technical path forward will be produced that identifies for each technology the risks, existing solutions, or - if no solution has yet been demonstrated - a path forward.

- A deployment scenario will be developed that identifies possible deployment paths, risk, cost, economic analyses, and infrastructure needs and requirements.

- Systems analysis will support the development of a business plan for the deployment of a closed fuel cycle, including international partners.

- Finally, a technical information package will be prepared that includes data and analysis results from R\&D, design studies, and systems analysis studies. This package will be provided to the Secretary to use, along with NEPA information and other considerations, in making an informed decision on the technical and business path forward for GNEP. 


\subsection{Cost Estimates and Milestones}

Table 3. Cost Estimates for Systems Integration and Analysis

\begin{tabular}{|l|c|c|c|c|c|c|}
\hline \multicolumn{1}{|c|}{ Cost Estimates (\$M) } \\
\hline \multicolumn{1}{|c|}{ Activities } & FY07 & FY08 & FY09 & FY10 & FY11 & FY12 \\
\hline $\begin{array}{l}\text { Systems Analyses \& } \\
\text { Technical Requirements }\end{array}$ & 5.3 & 10 & 12 & 12 & 12 & 12 \\
\hline Technical Integration* & 5 & 6 & 13 & 13 & 13 & 13 \\
\hline Total & $\mathbf{1 0 . 3}$ & $\mathbf{1 6}$ & $\mathbf{2 5}$ & $\mathbf{2 5}$ & $\mathbf{2 5}$ & $\mathbf{2 5}$ \\
\hline
\end{tabular}

*Includes funding for Partnership Knowledge Center, with additional funding supplied by the Modeling and Simulation Activity.

Table 4. Systems Integration and Analysis Milestones

\begin{tabular}{|c|c|}
\hline Milestones & Date \\
\hline AFCI Status Report to Congress - draft to DOE & January 2007 \\
\hline FY-07 Comparison Report to Congress - draft to DOE & February 2007 \\
\hline $\begin{array}{l}\text { Establish PKC Steering Committee consisting of representatives inside and } \\
\text { outside of the GNEP community. }\end{array}$ & April 2007 \\
\hline Initial GNEP waste form descriptions & August 2007 \\
\hline Small Reactors Requirements & August 2007 \\
\hline $\begin{array}{l}\text { Report on waste form and waste process technology specific data developed to } \\
\text { support an Integrated Waste Management Strategy }\end{array}$ & August 2007 \\
\hline $\begin{array}{l}\text { DOE-NE technical input for Secretarial recommendation to Congress on the need } \\
\text { for a second repository }\end{array}$ & September 2007 \\
\hline Initial Qualitative Program Risk Factor Assessment & September 2007 \\
\hline GNEP Deployment Systems Analysis & September 2007 \\
\hline GNEP Technical Requirements & December 2007 \\
\hline AFCI Status Report to Congress - draft to DOE & December 2007 \\
\hline FY-08 Comparison Report to Congress - draft to DOE & February 2008 \\
\hline Input and support for NEPA alternatives and technology options evaluations & March 2008 \\
\hline Complete Input to 2008 Decision Package & March 2008 \\
\hline Integrated Waste Management Strategy & March 2008 \\
\hline Global Benefits Analysis of GNEP & March 2008 \\
\hline Report on evaluation of GNEP fuel cycle deployment options & April 2008 \\
\hline Report on initial assessment of global proliferation risk and GNEP impact & May 2008 \\
\hline Report on GNEP Facilities and Fuel Cycle Strategy & June 2008 \\
\hline Decision on startup fuel (oxide or metal) for fast reactor & August 2008 \\
\hline $\begin{array}{l}\text { Implement pilot PKC that demonstrates multiple predefined use cases for specific } \\
\text { applications. }\end{array}$ & August 2008 \\
\hline Evaluation of material management requirement for fuel take-back strategies & September 2008 \\
\hline Report on domestic and global demand for GNEP technology & September 2008 \\
\hline GNEP Initial Facilities Systems Analysis & September 2008 \\
\hline Update GNEP Deployment Systems Analysis & September 2008 \\
\hline AFCI Status Report to Congress - draft to DOE & December 2008 \\
\hline FY-09 Comparison Report to Congress - draft to DOE & February 2009 \\
\hline
\end{tabular}




\begin{tabular}{|c|c|}
\hline Milestones & Date \\
\hline Report on evaluation of international implementation issues & March 2009 \\
\hline Detailed fuel cycle performance data for GNEP reference technology option & July 2009 \\
\hline Generate the specification for the hardware system necessary to support the PKC. & July 2009 \\
\hline $\begin{array}{l}\text { Databases that contain historical data not currently accessible from modern } \\
\text { repositories will be developed and made available to PKC users. }\end{array}$ & August 2009 \\
\hline Integrated total quantitative GNEP risk analysis & September 2009 \\
\hline Update GNEP Initial Facilities Systems Analysis & September 2009 \\
\hline Update GNEP Deployment Systems Analysis & September 2009 \\
\hline Report on cost and performance experience for GNEP technologies & September 2009 \\
\hline AFCI Status Report to Congress - draft to DOE & December 2009 \\
\hline FY-10 Comparison Report to Congress - draft to DOE & February 2010 \\
\hline Transition the pilot into the production level PKC. & August 2010 \\
\hline $\begin{array}{l}\text { Create a specification for the addition of future data sets into the PKC that will be } \\
\text { automatically curated }\end{array}$ & August 2010 \\
\hline Update GNEP Initial Facilities Systems Analysis & September 2010 \\
\hline Update GNEP Deployment Systems Analysis & September 2010 \\
\hline AFCI Status Report to Congress - draft to DOE & December 2010 \\
\hline FY-11 Comparison Report to Congress - draft to DOE & February 2011 \\
\hline First Release of New Systems Level Planning Tool & August 2011 \\
\hline $\begin{array}{l}\text { Per need-to-know, extend PKC user base to include universities and private } \\
\text { industry. }\end{array}$ & August 2011 \\
\hline Update GNEP Initial Facilities Systems Analysis & September 2011 \\
\hline Update GNEP Deployment Systems Analysis & September 2011 \\
\hline AFCI Status Report to Congress - draft to DOE & December 2011 \\
\hline FY-12 Comparison Report to Congress - draft to DOE & February 2012 \\
\hline Update GNEP Initial Facilities Systems Analysis & September 2012 \\
\hline Update GNEP Deployment Systems Analysis & September 2012 \\
\hline Decision on Transmutation Fuel for Fast Reactor & September 2012 \\
\hline
\end{tabular}




\subsection{LWR Spent Nuclear Fuel Separation Technologies}

The main objectives for LWR spent fuel separations technology development are to develop a separations system that can be effectively deployed in next-generation spent fuel processing plants of the GNEP supplier nations such that the proliferation risk of reprocessing is reduced relative to current practice, and to extend the U.S. geologic repository capacity by: 1) recycling of transuranic elements for ultimate destruction and recovery of energy content, and 2) reducing the volume of waste, long-term radiotoxicity and heat load in a geologic repository.

The large inventory of accumulated spent commercial reactor fuel in this country $(50,000$ metric tons now, 70,000 metric tons by 2015) will exceed the statutory capacity at Yucca Mountain. Additional SNF could be processed in order to minimize the quantity of spent fuel disposed directly in a geologic repository. Processing of that large quantity of spent fuel requires a technology with known capacity for high-throughput operation. Aqueous processing, which has been operated at the rate of hundreds of metric tons per year in commercial plants in other countries, is ideally suited for this application.

The goals of LWR spent fuel separations technology development are to enhance the performance of the geologic repository, to provide an advanced fuel cycle that reduces the risk of proliferation, and recover transuranic elements from spent fuel so that they can be transmuted or "burned" to recover their energy value and eliminate the health risk that they pose. All of the UREX+ processes provide enhanced use of the repository, improved proliferation resistance over traditional PUREX processing, and a variety of options for energy recovery and transmutation of actinides. UREX+1a has some key advantages over the other UREX+ processes; in particular, by separating and recycling transuranic elements in fast reactors; the inventory of transuranics never goes to the repository, which further enhances repository performance. Additionally, any of the UREX+ processes could recycle separated transuranics for different degrees of transmutation, but the GNEP program has selected fast reactors for the most efficient transmuting of actinides. The UREX +1 a process is most amenable to this approach, and requires the least number of separations processes to meet the criteria for recycle of transuranics into a fast reactor. Also, by not separating plutonium from any of the transuranic elements, the UREX +1 a process provides an additional degree of proliferation resistance as compared to many of the other UREX+ processes. Because of these criteria, the UREX +1 a process has initially been identified as the reference process for near-term development.

\subsection{Performance Objectives}

Recover the Uranium from Spent Fuel at sufficient purity that it can be conveniently stored for future use: To achieve substantial benefits in reduction of waste volume, it is necessary to recover the uranium from spent fuel. The recovered uranium could be stored for future use or disposed as a Class C low level waste.

Separate the transuranics as a group in a solid product form: Substantial benefits in repository capacity can be obtained by significantly reducing the amount of transuranic elements to be disposed of in a geologic repository. This will be achieved by recovering and fissioning them in fast spectrum reactors.

Separate short-lived isotopes, Cesium and Strontium: It is also necessary to recover and isolate the fission products that contribute to spent fuel heat load for the first century after discharge. The key fission products are cesium and strontium, which need to be extracted for separate management, such as decay storage to low activity levels or disposal in an optimized facility. By making the extraction process highly selective and efficient, the resulting cesium/strontium product can be made non-TRU.

Recover and immobilize Technetium and Iodine: To reduce long-term dose at the repository boundaries, it is necessary to recover two key fission products, technetium and iodine, and immobilize them in waste forms suitable for geologic disposal. 
Recover and immobilize other fission gases: To mitigate the environmental issues related to a large spent fuel processing plant, it will be necessary to recover gaseous radionuclides such as tritium, krypton-85, and carbone-14 (as $\left.\mathrm{CO}_{2}\right)$ at reasonably high efficiency and to immobilize them in durable waste forms.

Provide Robust Waste Forms: All other constituents of the spent nuclear fuel, including structural materials and residual fission products, will be incorporated into suitable waste forms for disposal.

\subsection{Status of Technology}

LWR fuel recycling will be carried out in nuclear fuel recycling centers. A prototype Consolidated Fuel Treatment Center (CFTC) is planned for design and construction in collaboration with industry as part of the GNEP implementation strategy; the UREX+1a process has been initially identified as a reference technology for engineering alternative studies of a commercial-scale facility. The UREX+1a process was initially selected as the reference technology because it separates key isotopes from LWR spent fuel into streams that can be managed in a way that meets the GNEP objectives. DOE also believes the UREX+1a process can be used as a bounding case during the GNEP NEPA analysis. It is recognized that there are other processes that may be used to meets these objectives and DOE plans to evaluate the most attractive alternatives during the course of possible industry engagement. The separation steps in the UREX $+1 \mathrm{a}$ process, illustrated schematically in Figure 4, have been demonstrated at bench-scale. The UREX+1a process separates uranium in the UREX process step, at a level of purity that permits (1) re-enrichment, (2) storage in unshielded facilities for near-term or future use, or (3) disposal as low-level waste. The long-lived fission products iodine and technetium are recovered in the front-end processes and the UREX process step, respectively, and immobilized in durable waste forms. The UREX process is a modification of the PUREX process; it is based on extraction of only uranium and technetium from nitric acid solution with tributyl phosphate in n-dodecane. The chemistry of the UREX process is well-understood and builds on the over 50 years of industrial-scale experience of the PUREX process. Although the PUREX process is currently the only large-scale method used to treat spent nuclear fuel world-wide, the UREX solvent extraction process has only been demonstrated with spent nuclear fuel at the bench-scale. However, the demonstrated success of the PUREX process suggests that UREX should scale-up readily.

\subsubsection{Current Knowledge PUREX}

The U.S. has extensive experience in spent fuel reprocessing and large-scale radiochemical operations. Dating back to the Manhattan Project days, the U.S. has been a leader in development of aqueous separation processes on an industrial scale. In the defense nuclear complex, the PUREX process was successfully used in large-scale production operations at Hanford and Savannah River. This process separated pure plutonium for defense applications. Over the course of the 50+ years of large-scale PUREX operations, several significant flowsheet changes have been made to allow for recovery of special nuclear materials. These campaigns have demonstrated the versatility of aqueous separation processes. The downside of the defense-related PUREX process operations is that they produce liquid high-level waste, which must be further treated for long-term disposal. This legacy waste has created a large cleanup effort, primarily because the liquid waste was accumulated over several decades. The goal of the PUREX operations was to produce weapons usable material, not to minimize waste, and this priority is evident by the current legacy of wastes.

The PUREX process was adapted for commercial use and significant improvements were made in waste generation. Commercial facilities were constructed in the U.S. at West Valley, NY, Morris, IL, and Barnwell, SC. Only the West Valley facility was successfully started up and operated. The facility was shutdown when the U.S. policy on spent fuel reprocessing changed and costly plant upgrades were determined to be required. The Morris plant never operated because of design flaws noted during cold 
start-up testing and the Barnwell facility was not commissioned because of changing U.S. policy. Nevertheless, the PUREX process continues to be used in large commercial plants in France, the United Kingdom, and Japan, and these plants have an excellent safety record. The PUREX process was designed to separate pure plutonium, which has been raised as a potential proliferation concern.

\section{Suite of UREX+ processes}

A number of potential flowsheets for the processing of commercial LWR spent fuel have been developed and tested with actual spent fuel at laboratory-scale over the past five years. These processes have been given the generic name UREX+, reflecting the design of the processes for initial extraction of uranium, followed by the extraction of cesium/strontium and the transuranic elements. All of the UREX+ processes are distinguished by the fact that they do not separate pure plutonium.

Each of the UREX+ processes, shown in Figure 3, has been designed for different applications. The $\mathrm{UREX}+1$ and $U R E X+1$ a processes are group extractions of the TRU elements, in which there is no separation of the TRUs. These processes are intended for use in a single-tier system, with the TRUs being directed to fast spectrum reactors as a group for burning. The UREX +3 and UREX +4 processes can be used for fast reactor recycle of plutonium plus neptunium as a recycle fuel product that can be fabricated in a glovebox facility rather than a hot cell, and more easily qualified due to the large relevant database on fuel performance from prior testing programs carried out in EBR-II and FFTF. The UREX+4 process provides the added option of burning americium in specially-designed target assemblies. The residual fission products remaining after these separations steps are comparatively benign (low radiation level and heat generation rate) and can be immobilized at high concentrations in durable ceramic waste forms.

\begin{tabular}{|c|c|c|c|c|c|c|c|}
\hline Process & Prod \#1 & Prod \#2 & Prod \#3 & Prod \#4 & Prod \#5 & Prod \#6 & Prod \#7 \\
\hline UREX+1 & U & Tc & Cs/Sr & TRU+Ln & FP & & \\
\hline \hline UREX+1a & U & Tc & Cs/Sr & TRU & All FP & & \\
\hline UREX+2 & U & Tc & Cs/Sr & Pu+Np & Am+Cm+Ln & FP & \\
\hline UREX+3 & U & Tc & Cs/Sr & Pu+Np & Am+Cm & All FP & \\
\hline UREX+4 & U & Tc & Cs/Sr & Pu+Np & Am & Cm & All FP \\
\hline
\end{tabular}

Notes: (1) in all cases, iodine is removed as an off-gas from the dissolution process.

(2) processes are designed for the generation of zero liquid high-level wastes

U: uranium (removed in order to reduce the mass and volume of high-level waste)
Tc: technetium (long-lived fission product, prime contributor to long-term dose at Yucca Mountain)
Cs/Sr: cesium and strontium (primary short-term heat generators; repository impact)
TRU: transuranic elements (Pu: plutonium, Np: neptunium, Am: americium, Cm: curium)
Ln: lanthanide (rare earth) fission products
FP: fission products other than cesium, strontium, technetium, iodine, and the lanthanides

Figure 3. Suite of UREX+ Processes

Many of the head-end operations required for an advanced reprocessing plant using the UREX $+1 \mathrm{a}$ process are similar to those currently used at the spent fuel reprocessing facilities at LaHague (France), Sellafield (United Kingdom), and Rokkasho (Japan). Dissolution of spent nuclear fuel has been demonstrated at the plant scale, $\sim 800 \mathrm{MTU} / \mathrm{yr}$. While there may be qualities unique to the fuel to be processed that require some head-end conditioning differing from that used at these facilities, the major operations and process streams will be similar. As these facilities are designed for PUREX, the major 
change would be adjusting the dissolver product conditions to meet the lower-acid requirements of the UREX process. Dissolution at lower acid may result in greater amounts of undissolved solids or require longer reaction time. Although spent fuel dissolution is a decades-old technology, conditions that minimize the formation of insoluble solids or increase the solids recycle rate must be fully defined for the UREX feed.

Off-gases emanating from the fuel-chopper and the dissolver will contain radioactive ${ }^{129} \mathrm{I}$, tritium, ${ }^{14} \mathrm{C}$, and ${ }^{85} \mathrm{Kr}$ and $\mathrm{Xe}$. In the current reprocessing plants in Europe and Asia these are not fully captured. If capture and sequestration of volatile radionuclides is required, data on the effectiveness of capture by various adsorbents or scrubbers must be evaluated, and methods to recover the radionuclides and incorporate them into a waste or storage form must be developed.

Post-process treatment of effluents and solidification appear to be where data are most limited. There is extensive plant-scale experience in converting $\mathrm{U}$ and $\mathrm{Pu}$ to solid oxides, and high-level liquid wastes to solid forms, either by calcination or vitrification. Extensive data exist for acid-water evaporation, acid recycling, and waste-water treatment. Information on reagent cleanup and recycle is less extensive. Data on recovery and calcination of trace organics in aqueous streams is likely available, though not for all of the organic species used in a UREX+1a process.

Though the bench-scale results have shown excellent agreement with model predictions, the specific UREX process has only been run for short periods and with fresh solvent, therefore any variations in process chemistry over the longer-term have not been truly elucidated. Because the solvent composition is the same as the PUREX solvent, 30\% TBP in n-dodecane, its long-term stability is well-known.

Additionally, due to the similarity to PUREX, treatment of many of the secondary process waste streams is also well understood.

The recovery of uranium from dilute nitric acid streams has been demonstrated at the plant scale. The simplest route involves precipitation as ammonium diuranate or de-nitration of the uranium, followed by calcination to produce an oxide form; the nitric acid is collected and recycled.

Soluble technetium is coextracted in the UREX process with uranium. There are several options for recovering Tc from the uranium product, an anion exchange method has been shown to be effective in laboratory-scale hot tests. Following separation from the uranium, the Tc must be immobilized in a suitable waste form. Because Tc is highly mobile in the oxidized pertechnetate form and because it has a long half-life $(210,000 \mathrm{yrs})$ it is desirable to immobilize the Tc in a reduced valence state, such as metal. The amount of data available for Tc recovery and immobilization is relatively small. The most promising processes must be studied at the lab-scale to first demonstrate feasibility and then to evaluate their scaleup. Pyrolysis of the Tc-bearing ion exchange resin has been shown to produce free-flowing metallic Tc beads in laboratory-scale experiments and such beads have been converted to a zirconium/technetium alloy, but more work is necessary to confirm the efficacy of this process.

Cesium and strontium are separated by the chlorinated cobalt dicarbollide-polyethylene glycol (CCDPEG) process, and placed in a waste form suitable for long-term decay storage until they have decayed for a few hundred years; at that point the waste could be classified in the US as low-level. The CCD-PEG process was originally developed in the mid 1970's in Czecholslovakia and later used at Mayak, Russia, to recover tens of megacuries of cesium and strontium from high-level waste streams. Developments to the process were later made to make the process more suitable for use in the U.S. (e.g. replacement of nitrobenzene based diluent with phenyltrifluorosulfone). Recently, this diluent was made available from commercial suppliers. Studies have demonstrated that the solvent components are highly stable to radiolytic and hydrolytic degradation and are less flammable than the PUREX solvent. The polyethylene glycol component has a slight solubility in the aqueous phase, and needs to be replenished in the solvent. The product from the CCD-PEG process is a guanidinium carbonate $(100 \mathrm{~g} / \mathrm{L}), \mathrm{DTPA}(20 \mathrm{~g} / \mathrm{L})$ stream 
containing the cesium and strontium, along with barium and rubidium. The reference process for solidification of the product stream is steam reforming. With the addition of clays, the steam reforming product is a mineralized aluminosilicate granular material.

The CCD-PEG process is relatively mature, having been implemented at industrial scale in Russia. Some process chemistry changes have been made from the demonstrated process, namely the solvent diluent and the strip reagent (Russian strip reagent was hydrazine nitrate). Both the diluent and strip reagent have been extensively studied in the U.S. and no technical issues have been identified. Uncertainties of the process are the solvent wash reagent, and when removing entrained solvent components from aqueous streams, what diluent wash reagent should be used.

The solidification of the product stream for the CCD-PEG process has been verified in bench-scale feasibility tests. The steam reforming technology has been used, at an industrial scale, to immobilize low level waste streams, and is currently being investigated for treatment of highly radioactive wastes. The process chemistry for solidification using the CCD-PEG strip reagent as a feed has successfully been through feasibility testing. The acceptance criteria for long-term storage for the solidified cesium and strontium product is somewhat unclear, and must be resolved in parallel with technology development efforts

The transuranic elements are extracted in a two-step process: the first step, TRUEX, efficiently separates the transuranics from all fission products except the lanthanides. The TRUEX process has not been demonstrated with spent fuel beyond the bench-scale, though the process has also been demonstrated at a larger scale for treating PUREX high-level waste in Japan. The TRUEX process has been extensively studied for the past 20 years and is very well understood for the treatment of high-level radioactive wastes. The TRUEX raffinate containing the non rare-earth fission products could be distilled to recover nitric and acetic acids, or acid mixtures for recycle, and to concentrate the fission products for further processing. Whether the fission products are concentrated in a nitric, acetic, or mixed-acid solution is not certain at this time. The nature of the fission product stream will affect the solids processing.

The solidification process also requires further development. In a calcinations process, additives (e.g. silica, alumina, carbon) that will yield a material suited as a high level waste glass or crystalline ceramic precursor must be defined for the expected solid product composition. An interim storage form for the calcined waste that takes into account heat dissipation and chemical compatibility requirements must be designed or selected from available options. Treatment of off-gases containing nitrogen oxides or carbon dioxides will be required. Demonstration of the processing of the TRUEX fission product stream, combined with the lanthanides from the second step, the TALSPEAK process, has not been demonstrated. If this stream is to be vitrified, then waste formulations and envelopes must be developed.

The actinide/lanthanide product from TRUEX is fed to the TALSPEAK process feed adjustment operation. In the feed adjustment process, the $\mathrm{pH}$ of the feed is adjusted by addition of lactic acid and $\mathrm{NH}_{4} \mathrm{OH}$. The feed adjustment process is straightforward and does not require development. The kinetics of the stripping step of the TALSPEAK process have been studied and shown to be important in determining the efficiency of separation of the transuranic elements from lanthanide fission products. Methods for dealing with the comparatively slow kinetics of the TALSPEAK process reactions are currently being studied to ensure adequate separation of the actinides and lanthanides. The TALSPEAK process has been extensively tested for the separation of $\mathrm{Am}$ and $\mathrm{Cm}$ from lanthanides in varying process configurations. There is, however, only a limited amount of data available for the separation of mixed transuranics, including plutonium and neptunium, using the TALSPEAK process. Laboratory-scale testing with actual fuel has been performed with very positive results, but there is additional work that is needed to better understand and define process operating conditions and envelopes, process kinetics, contacting equipment requirements, solvent stability and solvent wash reagents. 
The concentrated lanthanide stream is then combined with the TRUEX raffinate and either converted to solid oxides or liquid fed to a melter to form high level waste glass or another waste form, yet to be defined. The issues involved in producing the final product for the TRUEX raffinate also apply to the TALSPEAK lanthanide product.

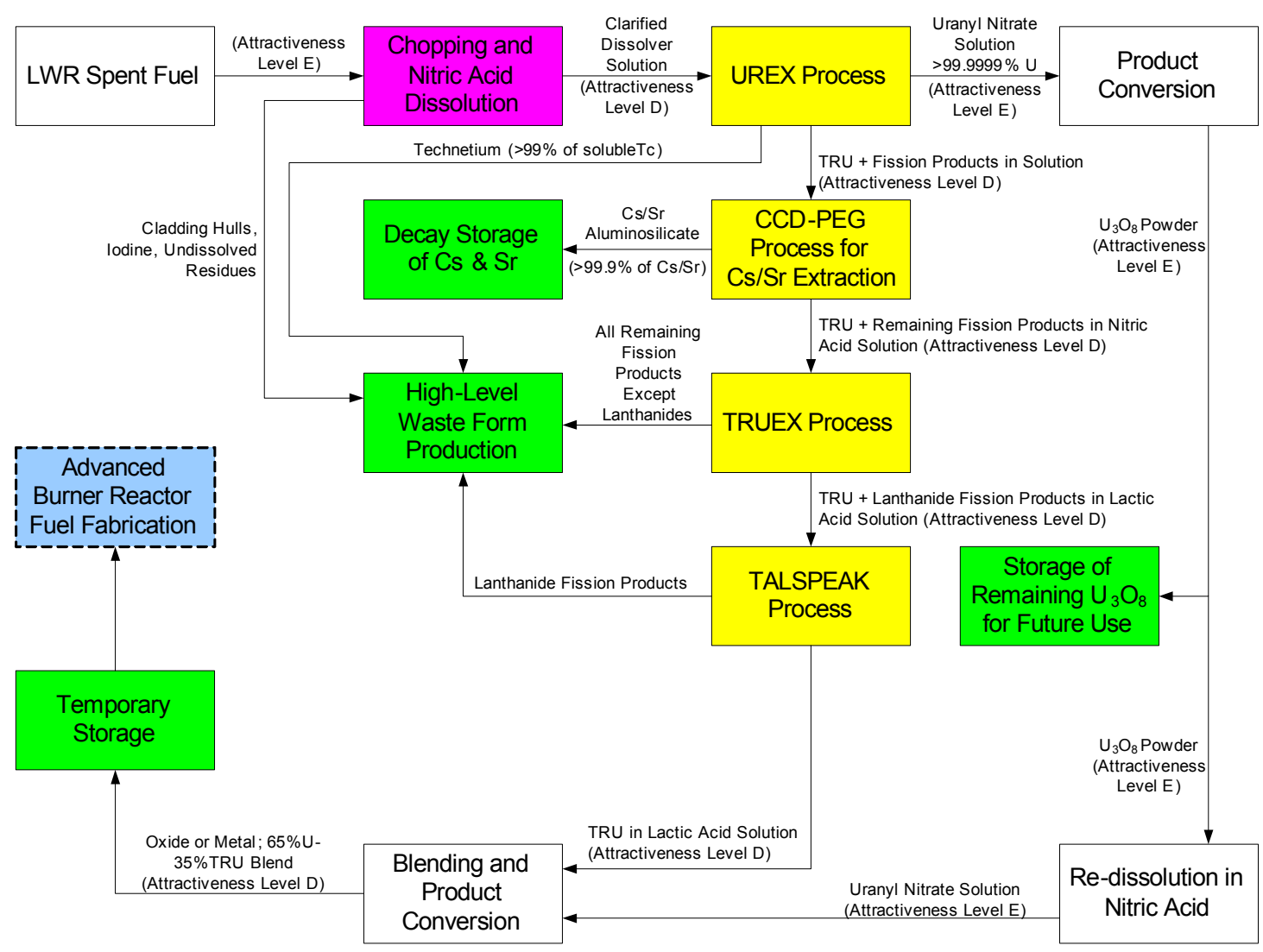

Figure 4. Schematic Illustration of the Reference UREX+1a Separations Process. The process is operated with very dilute solutions of transuranics, making the process streams quite unattractive for diversion. The process streams are categorized as Attractiveness Level D or E, as defined in DOE Order 470.4.

The transuranic (TRU) product stream is concentrated in an evaporator. Lactic acid from the evaporator will likely be recycled. Lactic acid is widely used in the pharmaceutical industry and thus vapor-liquid equilibrium and/or thermal degradation data are available in the open literature. The TRU product from the evaporator may be concentrated in a lactic acid solution, water, or degradation products. Slow calcination of the TRU product will destroy the lactic acid and DTPA present in this stream and convert the TRU to oxides. The degradation products for DTPA and lactic acid may be a complex mix of organic species that must be either compatible with the final solid form or completely converted to gaseous products and treated in the off-gas system. The TRU oxides will then be converted to a stable form for storage and eventual fuel fabrication. The final form of the TRU species must be defined based on the eventual fuel composition and the heat characteristics of the storage form. The primary component will be $\mathrm{Pu}$, though significant quantities of $\mathrm{Np}, \mathrm{Am}$, and $\mathrm{Cm}$ will make handling much more difficult than the $\mathrm{Pu}$ product from PUREX. 
Appendix A discusses the Technology Readiness Levels for the light water reactor spent nuclear fuel separations technologies.

\subsubsection{Separations Technology Development Needs}

Deployment of an industrial-scale spent fuel recycling facility requires a focused effort on process and facility design including the chemical partitioning process segments that make up the UREX+1a process and the supporting technologies for production of the resulting waste forms and for packaging the various products. A modern spent fuel reprocessing plant has not been operated in the U.S. for decades, and much of the related process equipment development and, more importantly, operating experience, has been achieved in other countries. Although many of the design details for certain critical items of equipment are retrievable, it may prove necessary to acquire some designs from foreign sources. An even closer collaborative arrangement with other countries may be required in order to achieve this end. At the same time, many of the needed equipment items are standard chemical engineering hardware and the requisite experience and design details may be available from domestic sources.

The approach used to determine technology development needs is to identify and prioritize technical maturity in the current UREX +1 a process and equipment designs, and to demonstrate individual processes with radioactive materials at the bench-scale. Prototypic engineering-scale unit operation demonstrations will be performed using depleted uranium and surrogate materials in order to provide critical design information for the spent fuel recycling facility project by the start of preliminary design activities. This intermediate testing and demonstration phase will ensure equipment designs and operation will meet the requirements of the facility, prior to the commitment of the significant funding required for the facility, and will support to a reasonable extent a secretarial decision in 2008 on proceeding with the program. The engineering-scale testing will include integrated operation of all of the separation steps, along with key solidification process steps that are not easily decoupled from the separation processes.

\subsubsection{LWR Fuel Technology Development Needs}

\section{Product and Waste Forms}

The UREX+1a process generates a number of product and waste streams that must be converted to appropriate forms for recycle or disposal. These streams include uranium, technetium, iodine cesium/strontium, transuranics $(\mathrm{Np}, \mathrm{Pu}, \mathrm{Am}, \mathrm{Cm})$, lanthanide/fission product waste stream, cladding hulls and undissolved solids, and secondary waste streams. Methods for conversion of these streams to solids are in various states of development, ranging from conceptual to full-scale demonstration.

\section{Transuranic Solidification for UREX+1 a Product}

The solidification of a mixed transuranic stream, containing plutonium, neptunium, americium and curium, has never been attempted on a large-scale. Development and demonstration of a calcination process for the mixed transuranic stream at bench-scale using radioactive materials, is needed. Construction and testing of an engineering-scale calciner with surrogate materials is needed to validate scale up and identify and resolve operational issues. The blending and solidification of the uranium/transuranic streams, with emphasis on production of a homogeneous solid product will also need to be demonstrated at bench-scale using actual radioactive materials.

\section{Cs/Sr Product Solidification}

Similarly, the solidification of a combined cesium and strontium product stream from the UREX+ process has never been done on a large scale. Recent tests on a laboratory-scale steam reformer have shown that an insoluble mineralized product containing the cesium and strontium can be produced. Steam reforming is a commercialized technology, and is being investigated for the treatment of acidic radioactive liquid 
legacy wastes. This program must develop baseline process data for Fluidized Bed Steam Reforming (FBSR) solidification of the $\mathrm{Cs} / \mathrm{Sr}$ product into an alkali aluminosilicate mineral waste form. Testing of the process with non-radioactive materials that are at engineering or larger scale, needs to be performed. The use of stable isotopes of cesium and strontium permits testing to be done in unshielded facilities at reduced costs. Follow-on laboratory and pilot testing must be continued to optimize and validate process parameters and perform product characterization. Special emphasis will be placed at quantifying the effects of radiation on the long term stability and durability of the final storage forms including the potential secondary reactions that may be catalyzed by either radiation or temperature effects.

\section{Tc Conversion and Waste Form}

Technetium is separated from the spent nuclear fuel in the UREX process step. Technetium conversion and solidification methods must be resolved before final design of an advanced spent fuel recycling facility. The conversion of the technetium product fraction to a stable waste form presents a number of challenges. Many current methods for producing stable waste forms involve high temperature conversions or metal alloying to produce forms suitable for long-term storage or disposal. The volatility of the technetium oxide species becomes a limiting factor in selecting a conversion process. Investigations into methods for the separation and recovery of technetium as an individual product fraction must be coupled with the conversion method used to generate the waste form to yield the best combination. Although an ion exchange method has proven effective for the purpose, alternate means for separating the technetium from the uranium product must be investigated, with a focus on obtaining a technetium product that can readily be converted to a stable waste form. With the separation method established, the conversion methods will also need to be demonstrated to yield samples for further evaluation of stability and durability. A detailed evaluation of processing options will be completed and a reference process selected. Laboratory-scale verification of the process must be completed using technetium.

\section{Fission Product Waste Forms}

The final high-level waste stream, containing mostly lanthanide and transition metal fission products, will be converted into a durable waste form such as glass or ceramic. The current reference process for highlevel waste in the U.S. is incorporation into a borosilicate glass. This waste form will be assumed as the reference for the advanced spent fuel recycling facility. The glass formulation for this waste stream will need to be developed in order to ensure that requisite durability requirements are met with the high fission product loadings that are planned. Glass formulation alternatives could include either low-temperature or high-temperature systems, balancing process or product performance criteria with waste loading requirements or restrictions. Optimal glass formulations need to be developed and tested in bench-scale melters using simulated feed materials. Glass properties, including leach rates, must be determined for various formulations.

\section{Product and Waste Form Packaging and Transport}

Development of container designs for interim storage of the transuranic and Cs/Sr products from UREX+ process is needed. Currently there are no DOE approved storage containers for these products, which have very high decay heat generation rates. Container designs will be developed through close interaction with other organizations, such as OCRWM and NNSA. Remote product packaging and transfer systems will be designed and equipment procurement initiated. The remote packaging and transfer equipment will need to be proof-tested in a mockup facility.

\section{Cladding Hull Disposition}

Cladding hulls represent a large waste stream from recycle of spent LWR fuel. Current practice at the La Hague facility in France is to compact the hulls for volume reduction and then dispose as an intermediate level waste. The U.S. is investigating hull treatment methods to determine if the washed hulls can be 
disposed as a low level waste, which will require the removal of transuranic contamination to a level less than $100 \mathrm{nCi} / \mathrm{g}$. Cladding hull handling equipment and process parameters for baseline compaction of the hulls must be developed. The initial input to the development and evaluation of this compaction technology approach will focus on final compaction product requirements and LLW waste acceptance criteria. The French compaction process will form the baseline process for initial test runs. Initial work will be done on surrogate hulls and remote operation will be demonstrated in facilities designed to provide the required technical bases for facility operations. A fraction of the cleaned cladding hulls is intended for use as a matrix material for immobilization of soluble Tc as an alloy and undissolved solids as an imbedded matrix.

\section{Secondary Waste Stream Minimization}

A number of secondary liquid streams are produced in the UREX+ process: (1) spent solvents (after extensive recycle) (2) acid and water that are recycled within the demonstration facility, (3) solvent wash streams to remove degradation products from solvents, and (4) other miscellaneous waste streams. As solvents are recycled in the processes, radiolytic and hydrolytic degradation products are formed. For tributyl phosphate, these degradation products are well known and understood, and most degradation products can easily be removed from the solvent by washing with sodium carbonate solution. For other UREX+ solvents, the nature of the degradation products is less understood as are the methods to remove them from the solvent. Solvent wash methods must be developed for all of the UREX+ processes and demonstrated on the laboratory scale. Eventually, all solvents will degrade to the point where their performance is marginal and solvent washes cannot restore them. A disposal path for each spent solvent must be determined. It is anticipated that each solvent can be cleaned to low contamination levels, and it must be determined if the spent solvents meet any RCRA criteria for hazardous waste (which would render the solvent as a mixed waste). Final solvent disposal paths for each UREX+ solvent must be identified, including methods for solvent decomposition. Methods for treatment of other miscellaneous wastes, as well as determining acid and water recycle mass balances; need to be completed in the conceptual design of the CFTC. Limited testing will be necessary to demonstrate the efficacy of the treatment methods and validate effective acid recovery methods.

\section{Off-gas Capture and Waste Form Development}

The chopping and dissolution of spent nuclear fuel releases numerous volatile by-products, including iodine-129, tritium, carbon-14, krypton, xenon and $\mathrm{NO}_{\mathrm{x}}$. Current international practices include releasing iodine to the sea or atmosphere, release of krypton and xenon to the atmosphere, aqueous scrubbing of tritium and carbon-14, and either release or partial abatement of $\mathrm{NO}_{\mathrm{x}}$. Next generation recycling technologies in the U.S. will need to improve on existing practice. There has been extensive research performed on various off-gas treatment methods, but most of these methods have yet to be demonstrated at a large scale. Iodine, for example, can be efficiently trapped in silver/zeolite filters or with KI, and tritium and C-14 can be trapped in scrubbers. In addition to removing these constituents from the off-gas stream, each by-product must be recovered and converted to an appropriate waste form. Many of these methods and products are yet to be defined for the CFTC. The management of process off-gas and contamination control is critical to the safe operation of any nuclear facility. Information related to technology selection and test performance for off-gas management and contamination control during both chopping and leaching operations will provide the technical bases to support the development and management of the safety basis of the CFTC. A determination of the extent to which the recovery of the noble gases will be demonstrated in the CFTC should be made during of FY-2008 to enable small-scale testing in FY-2008 and 2009. 


\subsubsection{LWR Fuel Partitioning Processes}

\section{Centrifugal Contactor Design for Remote Operation}

The UREX+1a process is based on liquid-liquid extraction processes that separate the fuel components into desired fractions. Industrial-scale equipment used for liquid-liquid processing includes mixer-settlers, pulsed columns and centrifugal contactors. Each of these different types of contacting equipment has been demonstrated on a large scale in nuclear applications, and each has inherent advantages and disadvantages. Development work on the UREX +1 a process has been performed in laboratory-scale mixer-settlers and centrifugal contactors, but the focus for scaled processes has been primarily on centrifugal contactors. This equipment has many potential advantages, but requires detailed remote capabilities for maintenance of the contactors. Most of the centrifugal contactors used for testing are laboratory scale and only preliminary remotely-maintainable designs have been formulated for a large facility. New remote design concepts need to be developed and demonstrated to ensure that contactors can be effectively used in any particular remote environment. In addition, new contactor designs that incorporate advanced features, to enhance operational flexibility, must be developed, fabricated or modified, and tested. All engineering and production scale contactors must be designed to be criticalitysafe by geometry. This constraint may limit the size of the contactor or design features (e.g. water jackets).

\section{Engineering-scale Integrated Centrifugal Contactor Testing}

Over time, impurities or degradation products can accumulate in the solvent and cause operational problems with centrifugal contactors. Additionally, the solution hydraulics of laboratory-scale centrifugal contactors and engineering- or industrial-scale contactors are different. Testing can be performed with an equipment mockup at the engineering-scale, at a fraction of the cost of testing with actual spent nuclear fuel. An engineering-scale integrated centrifugal contactor test mockup will be assembled in an area to allow for testing with limited amounts of radioactive materials, primarily depleted uranium. Additionally, secondary processes, such as waste treatment or product conversion operations, that are closely coupled with the separations processes must be included in the demonstration. However, many of the waste treatment or product conversion processes can be decoupled from the separations process and therefore parallel testing can be performed, utilizing the existing capabilities around the DOE complex.

\section{UREX+1a Flowsheet Validation/Optimization}

The current reference process for the engineering-scale demonstration is the UREX +1 a process. This process is a series of four solvent-extraction process segments that perform the following operations: (1) recovery of $\mathrm{U}$ and Tc (UREX), (2) recovery of Cs and Sr (CCD-PEG), and (3) separation of Pu, Np, Am and $\mathrm{Cm}$ from fission products (TRUEX followed by TALSPEAK). In a large-scale facility, it may be difficult to control flow rates, feed compositions, temperature and other process variables as accurately as was done in the bench-scale testing. Historically, flowsheets are developed with a level of conservatism to meet processing targets for purity and recovery of elements, and allow for variations in process conditions. However, if the process is designed too conservatively, it can result in higher cost or greater waste generation than necessary. This envelope of process operating conditions is best defined and verified in pilot-scale testing. Optimization of process conditions can be done to a certain extent with process modeling, using limited laboratory-scale testing to validate model results.

Specific process optimization testing needed to support the UREX +1 a process design is:

- Separation of technetium from uranium in the UREX process segment

- Uranium/technetium strip product flow rate

- Evaluation of the hydrolysis and potential precipitation of Pu under low acid ( 1 M) conditions 
- Technetium partitioning behavior in acid/water recycle processes

- Cesium/strontium strip reagent concentration and flowrate

- Optimal reductant for feed and method for addition of reductant to feed

- Vapor-liquid equilibria for lactic acid and degradation of lactic acid

- Feasibility of lactic acid recovery/destruction

- Partitioning of fission products in lactic acid recovery

- Process kinetics for the TALSPEAK process

- Solvent stability and lifetime under process conditions for TALSPEAK solvent

- Effects of complexing agents on transuranic stream solidification

- Destruction of complexing agents as necessary to avoid deleterious interaction with other separation processes or solidification processes.

\section{Remote Maintenance/Operation Equipment Mockup}

Equipment designs must be tested for fit-up, maintenance, and operation in a remote test mockup to ensure that all aspects of operation and maintenance can be performed by remote manipulation. A remote equipment test mockup will mitigate the risk of serious and costly equipment problems for equipment to be installed in a highly radioactive environment.

\section{Geometrically-safe Evaporator Design/Demonstration}

DOE orders dictate that when possible, engineering controls shall be used in lieu of administrative controls for criticality safety. Criticality-safe-by-geometry evaporators are certain to be needed in the separations facility for applications where uranium or transuranic elements will be present. Innovative design concepts should be developed and tested with non-radioactive solutions, at an appropriate scale, to demonstrate the effectiveness of the evaporator design(s).

\section{Process Monitoring and Control}

Implementation of advanced process monitoring and control systems has the potential to improve the quality of product materials and decrease the operating costs of the nuclear fuel reprocessing plant. The need for automated controls will be particularly important for closely coupled systems that must respond rapidly to process upset conditions. Similar systems have the potential to provide near real-time measurements needed for materials accountability and control, enhancing the proliferation resistance of the system. Process automation technologies have been pursued vigorously in the chemical processing industries, but implementation in fuel reprocessing has lagged because of the delay in deploying such technology in the U.S. A new fuel recycle plant will need a state-of-the-art "command and control" center where all data for materials accountancy and process operation are collected, interpreted, and readily available for operations personnel. The amount and level of data and information incorporated into this system has never been attempted before: integrating head-end operations, four discrete separation processes, and five or more product/waste solidification processes. Comprehensive studies need to be made prior to the CFTC preliminary design phase to determine the extent to which advanced process monitoring and materials accountancy instrumentation can be introduced into the demonstration.

While the goal of advanced process monitoring and control is to reduce the numbers of samples taken in a recycle facility, it is inevitable that liquid samples will need to be pulled from remote process locations. Chemical process sampling has made significant improvements in industries such as semi-conductors, pharmaceuticals, etc. Investigation of these new methods to determine if they are adaptable to a remote 
environment could lead to breakthroughs in sample reliability, availability, and reduce waste volume from large sample volumes.

\subsection{Consolidated Fuel Treatment Center (CFTC)}

In concept, the CFTC is an industrial-scale facility for processing spent LWR oxide fuel. The GNEP Strategic Plan indicates that one option is that the plant design would be industry-directed, with technical support provided by the GNEP Technology Development Program. Conceptual design studies, including a business plan and input to a GNEP technology roadmap, would serve as a valuable input to the Secretarial decision in 2008 on the GNEP path forward. The Secretarial decision will determine if, or how, DOE will proceed in developing a nuclear fuel recycling center, targeting for Approve Alternative Selection and Cost Range (CD-1) decision by the end of FY-2009. The project would then continue with industry engagement as decided by the Secretary of Energy.

\subsubsection{CFTC Design Activities}

It is envisioned the CFTC will be produced, as an option, through an industry-led design effort. Still, GNEP will comply too the extent applicable and appropriate, with the principles of DOE Order 413.3 in each design stage as follows:

Conceptual Design: This task includes completing the activities in support of Critical Decision 1 (Approve Alternative Selection and Cost Range) including the requirements definition, conceptual design, acquisition planning, risk assessments, alternative analysis, preliminary hazards analysis, preliminary technology needs assessments, NEPA documentation preparation, and preliminary project execution planning, and updated project baselines.

Preliminary Design: This task includes completing the activities in support of Critical Decision 2 (Approve Performance Baseline) including design (sufficiently detailed to support the following) risk analysis, site selection, acquisition plan, technology development, final project execution plan, updated project baselines, and independent reviews.

Final Design: This task includes completing the activities to support Critical Decision 3 (Approve Start of Construction) including detailed design, specifications for long lead procurements, approved safety documentation, independent reviews, technology innovations evaluations, and updated project baselines.

\subsubsection{Technology Development Activities}

Technology development in support of CFTC design and operation will proceed during the design, construction, and startup phases of the project. Activities in FY-2007 and -2008 will be directed toward guiding the conceptual design efforts. They will also provide a basis for evaluating the conceptual design studies and for informing the 2008 Secretarial decision and subsequent down-selection decisions at the completion of the conceptual design stage.

In the near term, the development of separations technology in support of alternatives that may be used in the CFTC will be accomplished in a series of laboratory-scale experiments with actual LWR spent fuel and spent fuel simulants. These experiments have the purpose of optimizing process design, demonstrating process reliability and reproducibility, and gaining fundamental information on pertinent chemical reactions for input into the development of advanced process models and plant simulations.

For the purposes of this plan, the UREX +1 a process is the reference technology for planning CFTC technology development activities. As engagement with industry proceeds and other process alternatives emerge, the technology development activities will be adjusted to meet program needs. It should be noted that many of the technologies being considered for waste and product management are process technology neutral and will support the product objectives of GNEP under a variety of spent fuel separations processes. 


\subsubsection{Bench-Scale Demonstration}

\section{Transuranic Solidification for the UREX+1a Process}

Bench-scale calcination testing of the mixed TRU ( $\mathrm{Pu}, \mathrm{Np}, \mathrm{Am}, \mathrm{Cm})$ product, in a lactic acid stream will be performed with actual transuranics. The goal of this work will be to demonstrate that all of the transuranics can be converted in a single process to oxides. Additional bench-scale testing will be required to demonstrate that the TRU product can be blended with uranium in proportions to meet the ABR fuel fabrication specification, and denitrated to meet the appropriate specifications and can be redissolved. Product rheology will be important for the blended product, as well as chemical composition (complete conversion to oxides). Currently, the fuel fabrication specifications for this material, including the possible need to convert oxides to metal, have not been determined.

\section{Cs/Sr Product Solidification}

Bench-scale testing of the cesium/strontium product will be performed to develop feed and additive ratios, additive compositions, and characterize products. Because this waste stream chemistry can be well represented with non-radioactive elements, this work will be done with stable cesium and strontium. Characterization of the waste product will include physical characterization, leachability, and the thermal conductivity. Bench-scale tests will also be conducted using actual radioactive materials in order to quantify the effects of radiation on the long term stability and durability of the final storage forms including the potential secondary reactions that may be catalyzed by either radiation or temperature.

\section{Tc Conversion and Waste Form}

Methods for conversion of technetium, from pertechnetate to a reduced metallic state, from either a nitric acid stream or an anion exchange resin will be developed in laboratory testing. Both methods are needed, as a final Tc separation scheme in UREX has not been selected, and both Tc separation and conversion will need to be developed in parallel. Technetium metal will then be alloyed with Zircalloy, with or without other metal additives, to produce determine a viable alloy formulation. Upon development, the Tc conversion and waste form preparation will be made with actual material in a bench-scale demonstration.

\section{Fission Product Waste Forms}

In addition to technetium and the gaseous fission products, the fission product waste contains the transition metals stream from the TRUEX process, the lanthanide stream from the TALSPEAK process. A borosilicate glass has been initially identified as the waste matrix, due to existing HLW qualification for Yucca Mountain. Waste formulation development capabilities are well developed at several DOE laboratories and initial waste formulations will be developed by modeling and use of surrogates. Validation testing of candidate waste formulations will be made with actual radioactive materials (either actual waste streams from bench-scale testing or representative radioactive amounts in surrogate streams).

\section{Cladding Hull Disposition}

Compaction is the baseline process currently selected for disposition of the cladding hulls. Depending on the level of residual contamination, the compacted hulls may be disposed of as low-level or high-level waste. Bench-scale demonstration of hull cleaning methods are needed to demonstrate the effectiveness of cleaning methods, so that a determination can be made on the disposition of the hulls as low-level or high-level waste.

\section{Secondary Waste Stream Minimization}

Other important secondary streams need to be accounted for an overall plant waste minimization. These include: 
- the acid recovery derived from three operations: (1) dissolver and hull wash, (2) extraction processes, and (3) off-gas recovery

- all of the solvents used in the extraction processes

- treated radionuclide-free water generated by the various unit operations.

Bench-scale test will be conducted with radioactive solutions to determine the most efficient methods for acid recovery, solvent reconditioning and eventual disposal and treatment of process water to generate a radionuclide-free water.

\section{Off-gas Capture and Waste Form Development}

Several alternative trapping systems such as molten hydroxides $(\mathrm{NaOH} / \mathrm{KOH})$, solid sorbents, impregnated membranes, etc. will need to be tested at bench-scale. One or two of the most promising candidates may have to be developed for deployment at the engineered demonstration scale.

The long half-lives of 129I and 14C will require development of a robust waste form that sequesters the radionuclides over geologic time-frames. Conceptually, the two disposal paths are to (1) capture concentrated tritiated water on molecular sieves from a dry head-end process and (2) allow the tritiated water to accumulate in the plant water-based systems until the entire water inventory must be treated and discarded. Isotopic separation of the tritiated water from the plant water is possible, but is thought to be prohibitively expensive.

Disposition options will have to be re-analyzed against present regulations. Disposal forms need to be investigated, which will include materials (e.g. cement) that tightly bind the tritiated water long enough for the tritium to decay. Recovery of tritium for beneficial use should also be analyzed in consideration of demand and avoidance of disposal costs. The implications, if any, of the ${ }^{3} \mathrm{H}$ embedded in the cladding will have to be also analyzed.

Environmental impact analysis of emissions from the CFTC, and the nature of the spent fuel, particularly age and burnup, will determine whether or not the release of $\mathrm{Kr} / \mathrm{Xe}$ is acceptable. The possible separation and trapping of $\mathrm{Kr}$ and $\mathrm{Xe}$ may be needed. If this were the case, then processes such as pressure swing absorption or scrubbing off-gases with fluorocarbons will have to be tested, compared and developed. It is almost certain that an industrial scale plant will be required to separate these gases cryogenically and store the short-lived $\mathrm{Kr}$ for decay. The non-radioactive Xe may have some commercial value that could offset some of the extra cost.

The recovery and scrubbing of NOx will be an essential component of the off-gas treatment. Depending on the overall design of the dissolver an effective system will have to be designed for recovery and recycle of the nitrogen oxides as nitric acid. This implies the need to fractionate concentrated acid and process water for recycle. Some alternatives will have to be tested at bench-scale for deployment at the CFTC.

\section{UREX+1a Flowsheet Validation/Optimization}

Laboratory testing of various portions of the UREX+1a process, where uncertainty or potential for optimizing the process (reducing flows, reagent concentrations, etc) will be tested in the laboratory using surrogate materials, or solutions from actual tests, if available. The primary focus of this work will include Tc separation in the UREX process and better understanding the process chemistry for actinide/lanthanide separation in the TALSPEAK process, and possible tests of curium isolation for future flowsheet applications. 


\subsubsection{Scale-up Demonstration using Surrogate Materials}

Understanding process interaction and issues associated with longer term operation with solvent recycle may also be addressed by operation of an engineering-scale demonstration using depleted uranium and surrogate feed materials. This demonstration may be important to identify and resolve issues that have not have been addressed by bench-scale testing of individual unit operations. The four solvent extraction processes may be operated in an integrated manner, as well as, any associated processes that are closecoupled. Waste processing may be decoupled from the extraction process by surge tankage, and can be demonstrated separately using existing infrastructure around the DOE complex. Issues relative to the integrated demonstration also include development of process monitoring and control systems, which will be far more complex that those found in existing radiochemical facilities.

Specific engineering-scale integrated demonstration activities that may be carried out are described below.

\section{Integrated operation of $U R E X+1$ a solvent extraction processes}

Operation of all four UREX +1 a process segments in an integrated manner is important to understand process interactions, as well as to begin to develop control and monitoring schemes. To ensure representative hydraulic performance, all solvent extraction processes could be operated with 5-cm centrifugal contactors. The UREX process can be closely coupled to the CCD-PEG process (no surge capacity between them). The TRUEX and TALSPEAK processes will probably require some intermediate surge tankage, and possibly treatment, between processes to ensure complexants are not carried over from one process to the other. Process operations will include feed adjustment, solvent wash, and diluent washes of the aqueous streams leaving the process.

\section{Transuranic Solidification for the UREX+1a Process}

Scale-up testing of the calcination equipment to prototypic-scale will be required, and can be done with surrogates. It is recognized that it is difficult to simulate the transuranics, particularly plutonium, but this effort will focus on equipment design issues, rather than product properties.

\section{Cs/Sr Product Solidification}

Engineering or full-scale testing can be performed in existing pilot facilities using the formulation data obtained from bench-scale testing. Again, this testing can be performed with stable cesium and strontium. Product materials can be characterized in the same manner as the material from bench-scale testing.

\section{Tc Conversion and Waste Form}

Optimum methods for the conversion of Tc-99 to a chemically stable, unreactive zirconium-technetium mixture, using zirconium from the cladding, will be investigated. This would immobilize both fission product Tc-99 and activation product Zr-93 from the cladding by converting them to a metallic zirconium-technetium alloy. The cladding hulls are about $96 \%$ metallic zirconium and could in principle be used directly to make a Zr-Tc alloy suitable for disposition. If, however, the zirconium is purified, (see below) the hulls could be converted directly to high purity zirconium (free of most fission products and free of actinides). A portion of the purified zirconium metal could be melted with technetium metal to produce the alloy. Performance tests will be performed with Tc/Zr alloys to identify and resolve issues associated with this waste form. Once a viable process and waste form are developed and demonstrated, scaled testing of the conversion process can be performed, if necessary, using rhenium as a surrogate material. Depending on process parameters, it may be possible to prepare a metal alloy waste form in prototypic equipment at an existing DOE facility. If not, a prototypic-scale product could be produced using rhenium. Due to the lack of maturity of the conversion process, it is unlikely that scaled testing could be completed by 2008 . 


\section{Fission Product Waste Forms}

Engineering-scale testing can be performed in existing melter pilot plants within the DOE or research complex, using surrogate materials. Because these waste streams can be adequately decoupled from the separations process, they do not need to be part of any integrated engineering-scale cold demonstration that may be required.

\section{Waste Form Packaging}

The recovered radiochemical forms developed in the bench-scale work will require specific waste packaging or conversion to a form for which cost effective packaging can be developed. The waste forms will be very dependent upon the site specific waste acceptance criteria (WAC), as well as on Nuclear Regulatory Commission (NRC) and Department of Transportation (DOT) regulations. Heat transfer will also be key issue for the storage form packages for the cesium/strontium and mixed TRU products.

\section{Secondary Waste Stream Minimization}

Secondary waste minimization can be accomplished by identifying which stream can economically be recycled. To accomplish this, an efficient plant design that accounts for the integration between unit operations is key. This integration will require a detailed chemical process simulation of the entire plant. A steady state model can quickly provide the information needed for this optimization. A model will be developed to support this need.

\section{Off-gas Capture and Waste Form Development}

Alternatives tested at bench-scale will result in a down-select process that can be developed at engineering-scale. Design parameters for off-gas capture equipment will be determined. The waste forms will be tested to verify waste acceptance criteria and transportation requirements. In nearly every case, the radioactive species may be replaced with a non-radioactive isotope for the development and, if needed, demonstration phases.

\section{Remote Maintenance/Operation Equipment Mockup}

During preliminary design of the CFTC, when facility and remote concept specific information should be available, the availability of a remote test mockup must be assessed. Either an existing mockup facility will be equipped with equipment for testing of remote operation, maintenance, etc. or a new mockup facility must be designed, constructed and equipped with remote equipment in a layout representative of the reference process chosen for initial deployment in the CFTC.

\section{Online Monitoring and Process Control}

Online monitoring of process parameters including process chemicals and fissile material is needed to enhance safeguards and reduce the dependency on process samples. Sampling introduces bias, requires tankage between unit operations contributing to facility footprint expansion, generates liquid wastes, and generally requires several hours before the analytical results are available to make process decisions. Test solutions containing single components and their mixtures will be analyzed and a chemometric model will be developed for quantitative monitoring of target analytes. Online monitoring techniques will be tested and selected for these analytes. The data acquisition /archiving/storage capability and real-time computer display of analyzed data will be customized for the reference separations process application. Such a system will yield great advances in the tracking and accountancy of fissile materials throughout the entire separations process. A process control system will be included in the tests with surrogate materials.

\subsubsection{R\&D in Support of Technology Development (risk mitigation and alternatives)}

The activities described in this section are carried out to provide alternative solutions for important parts of the process where a high or moderate risk is present. 


\section{TALSPEAK Process Alternatives}

Recent advances in molecular agents more efficient for selective component sequestrations have been based on a more fundamental understanding of agent-component molecular interactions. It has been shown that optimum interactions have two features: optimum sizing and optimum group orientations. Taken together, agents that are orders of magnitude more effective at sequestration have been identified and their performance documented. Application of this methodology could provide improvements in the lanthanide/TRU separation portion of the UREX+ process. To accomplish this, structural information and high-level quantum calculations can be applied to develop a validated molecular model using elements previously shown to provide for an intrinsic lanthanide/actinide separation. Combinatorial computational chemistry using public computational codes then can be used to design candidate separations agents optimized for complexation and separation of lanthanides from transuranics. These materials in turn can be synthesized and tested with the major radionuclides found in the lanthanide/TRU part of the UREX+1a process. Because such highly specific extractants also tend to be unstable against hydrolysis and radiolysis, laboratory testing under representative process conditions will be necessary to validate these materials for practical applications.

\section{Centrifugal Contactor Design for Remote Operation}

New remote design concepts will be developed and demonstrated to ensure that contactors can be effectively used in any particular remote environment. In addition, new contactor designs that incorporate advanced features, to enhance operational flexibility, must be developed, fabricated or modified, and tested. The goal of this work is to create a complex-wide contactor design that incorporates the best features of existing DOE and commercial designs and remote maintenance features, to generate a design that could be fabricated in commercial shops, using cost effective production methods (e.g. casting vs. milling). A commercial-scale processing facility would require several hundred contactors, and existing DOE and U.S. commercial designs and capabilities are not adequate to meet future requirements.

\section{Alternative Tc Waste Forms}

Stabilization of Tc-99 presents challenges due to the relative volatility of technetium. However, there are several alternative stabilization technologies that could mitigate the volatilization issue by utilizing low temperature stabilization processes to produce a durable form.

A low temperature phosphate ceramic form was developed to stabilize an eluted Tc-99 waste stream. A magnesium potassium phosphate ceramic was developed to treat the separated technetium stream. Dense and hard ceramic forms were fabricated from acidic reactions of the waste and precursor chemicals. The resultant forms were characterized and leach tested using the American Nuclear Society (ANS)

ANSI/ANS 16.1 test and the Product Consistency Test. The relative durability was relatively good as measured by both tests. Additionally, iron-phosphate waste forms were developed and demonstrated for the immobilization of DOE mixed wastes.

Low temperature glass waste forms were developed for the vitrification of Rocky Flats plutonium-bearing wastes. Dense glass forms were fabricated at temperatures as low as $700^{\circ} \mathrm{C}$. The process temperatures used to fabricate these glasses were much lower than typical borosilicate glasses and would be expected to minimize Tc-99 volatilization. A prime objective of the study was to demonstrate limited recovery of plutonium from the form utilizing chemical means. From this perspective, the glasses preformed well. The aqueous leach response of the glasses was not specifically measured. However, based on the response to acid dissolution testing and understanding of the leach behavior of borosilicate glasses, the durability is expected to be relatively good. 


\section{Development of Co-precipitation Processes for Actinide Recovery}

The present scheme for the UREX+ processes is to solidify the actinide product streams by direct denitration or calcinations to produce a form usable for recycle fuel fabrication if oxide is the chosen fast reactor fuel. Such processes, however, may not produce the best particle morphology and size distribution for high-quality fuel fabrication. An alternative method is to use an oxalate precipitation method for the co-precipitation of actinides in the appropriate composition blend. Such a process is the current reference in the French program, and extensive information is available through the CEA-DOE collaboration. Experiments will be carried out to ensure that there is not a selective precipitation of one species, and the process will be evaluated for feasibility of industrial-scale application. This technical activity in an alternative product conversion method addresses a high technical risk issue of TRU product form.

\section{Cs/Sr Separation Process Alternatives}

The Fission Product Extraction (FPEX) process simultaneously separates cesium and strontium from spent nuclear fuel (UREX raffinate). Preliminary testing has been performed on this process, and indicates that it has potential advantages over the baseline cesium strontium process (CCD-PEG). The cesium/strontium product stream from the CCD-PEG process contains about $120 \mathrm{~g} / \mathrm{l}$ organics, which complicate the solidification process. The FPEX process back-extracts the cesium and strontium in a dilute nitric acid stream, which is much easier to concentrate and solidify. The technical maturity of this process is not sufficient for it to be considered for the baseline separations processes. Laboratory testing of the FPEX process chemistry will be performed, including studies to determine the affects of complexants from the UREX process on cesium and strontium separation, as well as solvent stability, solvent cleanup, etc. Recent testing with a monocrown calixarene cesium extractant indicates that the extractant can be used at higher concentration than the previous extractant and is more stable to acid hydrolysis. Characterization testing of this new extractant will be performed. Finally, laboratory and cold pilot plant testing of the process in centrifugal contactors will be performed to validate the process performance.

\section{Alternative Extraction Contacting Equipment for Solids Handling and/or Kinetics}

Alternative, proven contacting equipment, such as pulsed columns and mixer settlers, will also be evaluated and tested with certain UREX + processes, at the appropriate scale, to ensure that processes which may require equipment providing longer residence times, or greater tolerance of solids, will function properly. Equipment mockups will be designed and constructed for scaled testing of select portions of the UREX+ process, as required. In particular, the two vulnerable areas of the UREX+1a flowsheet, in terms of contacting equipment, are the capability to handle solids in the UREX process, and the possible residence time requirements for the TALSPEAK process, which may be greater than available with current, conventional centrifugal contactors.

\section{Alternative Cs/Sr Waste Form}

Alternative product forms for cesium and strontium (zeolites, or taylored wasteforms for cesium and strontium such as Synroc), were identified as viable alternatives in an AFCI engineered product assessment. These wasteforms will be evaluated as alternatives to the mineralized steam reforming product. At this time, there are no waste or storage form criteria for the cesium and strontium product, so there is some risk in focusing on a single waste form meeting the criteria ultimately selected.

\section{Feed Clarification}

Clarification of the dissolved fuel product prior to separation processes is required to prevent fouling of the separations equipment. In order to design an effective feed clarification system, it is necessary to understand the ability of the downstream processing equipment to tolerate solids. The design of feed clarification and separation process equipment are interrelated and each must be selected with 
consideration of the other process. An evaluation will be made of how solid/liquid separations are performed at commercial reprocessing plants and identification, to the extent possible, of any pertinent information and processing issues that may lead to process efficiencies and improved economic performance. Potential enhancements to separation efficiency may be necessary for the reference process, depending on the selection of separations equipment.

\section{Thermodynamic Data for Process Modeling}

Laboratory data (distribution coefficients, extraction constants, etc.) will be obtained and incorporated into AMUSE or other process models to improve model predictive performance and/or provide new modeling capabilities. Collection of thermodynamic data to incorporate into process and simulation models are needed for separation and product conversion processes. These data will be used to expand the capabilities of existing models or fill in gaps where data currently are not available. The UREX $+1 \mathrm{a}$ process flowsheet utilizes aqueous-soluble hydroxamic acids to control $\mathrm{Pu}$ and $\mathrm{Np}$ partitioning from that of $U$ and Tc. As hydroxamic acids have not been widely been used on an industrial scale in nuclear fuel processing, there is a need to understand the thermodynamic properties of these materials under processrelevant conditions. The various species formed by complexation of hydroxamic acids with tetravalent and hexavalent actinides $(\mathrm{U}, \mathrm{Np}$ and $\mathrm{Pu})$ must be characterized and the thermodynamic parameters for these complexation reactions over conditions relevant to the UREX+1a processing flowsheet measured. The fundamental chemical knowledge generated will allow for more accurate modeling and simulation of the UREX+1a flowsheet and will support developing the safety/regulatory basis for the UREX+1a processing facilities. This technical activity addresses several technical risks including TALSPEAK process chemistry, Pu stability, technetium partitioning, and zirconium and molybdenum extraction behavior.

\section{Chemistry of Entrained Phases}

Previous work has shown that the primary means for metals of low extractability (e.g. cesium in the PUREX process) to contaminate the organic product stream is by their dissolution in small drops $(\sim 1 \mu \mathrm{m}$ diameter) of entrained aqueous phase in the organic extractant. Such small drops, or hazes, can be formed by the dispersive mechanisms of drop breakage and by chemical precipitation. The formation, behavior and mitigation of hazes is most important at industrial scale but can be investigated in focused small-scale tests and by examination of the system chemistry and turbulence characteristics of the process equipment. Studies will be performed to understand and improve the decontamination performance of the liquidliquid extraction processes. This technical activity addresses several technical risks, primarily carryover of complexants, but also including Pu stability, technetium partitioning, and zirconium and molybdenum behavior.

\section{Geometrically-safe Evaporator Design/Demonstration}

Existing designs of geometrically-safe evaporators will be evaluated, and if engineered controls are preferred or required in addition to administrative controls for criticality safety in the CFTC, a geometrically-safe evaporator will be constructed and tested with surrogate feed materials.

\section{Zirconium Refining and Recycle}

Given the large volume of the cladding hull waste stream, significant savings could be achieved if the Zircalloy hulls could be decontaminated to 'free-release' levels. It is conceivable that the hulls could be decontaminated to a level suitable for beneficial reuse in fuel fabrication. Processing of the metal cladding waste by refining can be used to separate pure zirconium from the contaminants.

Investigation of the technical feasibility of refining spent hulls for recovery/reuse of zirconium will be investigated. This task will be coordinated with interested industrial partners to determine if the recycle hulls could be used to fabricate transmutation fuels. Small-scale Zircalloy hull refining tests will be 
performed and the purity of the products determined. Such an approach may have to be combined with an enhanced decladding process. An oxidative decladding process, where the fuel is segmented and oxidized at elevated temperatures or with oxidative agents in aqueous solution may provide enhanced decontamination to support cladding recycle. An alternative head-end treatment using nitrogen oxides to effectively release the volatile radionuclides by oxidizing the $\mathrm{UO}_{2}$ to $\mathrm{U}_{3} \mathrm{O}_{8}$ potentially provides another effective decladding and volatile species release treatment. Additionally, decontamination of the Zircalloy hulls via the ZIRFLEX process or by HF dissolution will be examined. Before beginning investigation of these alternatives, an evaluation will be performed, including discussions with interested commercial companies, to determine the level of interest and technical feasibility of refining cladding hulls for re-use.

\section{GNEP Transformation}

The development of the UREX +1 a process as a possible alternative for the CFTC can benefit in the short and medium term from the new tools provided by work in the fundamental sciences and in the computing sciences.

Better modeling of the chemical processes and better understanding of their fundamental chemistry will lead to better control of the reaction dynamics, and better estimates of the losses that need to be dealt with. Accurate modeling of the equipment might lead to more optimized designs, in particular for the processes that require interface chemistry to occur such as the contactors.

High fidelity modeling of the equipment and of the whole plant can result in significant short term capital and operating cost savings by reducing the footprint of the plant, increasing its operating efficiency, and reducing waste form production.

In the longer term, better separations technologies, which are currently characterized by an empirical research model will benefit from better measurements of fundamental properties, better thermodynamic modeling of the processes, and better optimization tools for integrating these processes and designing plants. In the longer term, novel processes could be developed based on better simulation capabilities at the molecular level.

Waste forms are one of the ultimate product of GNEP and must be demonstrated to survive for extremely long times in complex geological environments. Currently that demonstration is essentially empirical and therefore affected with rather large uncertainties. Better understanding of the fundamental physical phenomena and the capability to model the evolution of waste forms in complex geological media will bring added confidence to the nuclear enterprise.

\subsection{Engineering Alternatives Study}

The Engineering Alternative Studies (EAS) will evaluate alternatives supporting an industrial-scale (3,000 metric tons of LWR spent fuel per year) spent fuel recycling plant. These studies, a near-term effort to be completed in FY-2007, is intended to provide an engineering basis for developing the Draft GNEP PEIS, as well as guiding and evaluating possible conceptual design studies for the CFTC. A comprehensive set of Functional and Operational Requirements (F\&ORs) has been developed to provide a basis for the studies, and the evaluation of the influence of these requirements on plant design will be used to help establish the specifications for conceptual design of the CFTC. The EAS completed a 30\% progress review in December 2006, and a 60\% progress review in February 2007, with completion of the studies planned for June 2007. Subsequent studies may be identified to complement conceptual design studies and support the 2008 Secretarial decision. 


\subsection{Development of Enabling Technologies}

A successful demonstration of LWR Spent Nuclear Fuel Separations will require significant efforts in three key enabling technology areas, Safety, Safeguards and Proliferation Risk Reduction, and Modeling and Simulation.

\subsubsection{Safeguards and Proliferation Risk and Safety}

The PUREX process is used at several international plants to reprocess spent fuel in order to recover uranium and plutonium for mixed oxide (MOX) fuel. The IAEA has established guidelines to prevent the diversion of nuclear material at reprocessing plants based on two scenarios: abrupt diversion and protracted diversion. These guidelines are established to maintain accountancy of fissionable material to ensure that significant quantities of weapons-grade nuclear material are not diverted over a specified time frame. At reprocessing plants, the accountancy of $\mathrm{Pu}$ drives the nuclear material accountability. Reprocessing plants maintain Pu accountancy by a combination of containment and surveillance, process monitoring, and chemical analysis of selected samples.

For the front end of the reprocessing cycle, the initial plutonium inventories for the spent fuel prior to shearing and dissolution are based upon burn-up profile calculations. The fuel compositions obtained from these calculations have large uncertainties, and more detailed analyses are performed once the fuel is dissolved. The dissolved spent fuel solution is sent to the accountability input tank, the analysis of which is the input for Pu accountancy. The spent fuel treatment process is monitored using a system based on both a book inventory (obtained from chemical analyses of process samples) and a process inventory (obtained from process data). In process, bulk quantities of $\mathrm{Pu}$ are measured in real time by monitoring bulk volumes, process flow rates, solution densities, etc. using sophisticated computerized accounting systems. Chemical analysis is most appropriately done in an on-site laboratory. The Pu content of the hulls and process waste are obtained prior to compaction or vitrification. The liquid PUREX Pu product stream is usually not analyzed; rather samples of the $\mathrm{PuO} 2$ or $\mathrm{MOX}$ powder derived from the solutions are collected, weighed and analyzed. The bulk mass and volume are measured, and samples of the powder are taken from a batch or individual canisters for more detailed analysis. An authentication system is to be employed at the Rokkasho Reprocessing Plant to authenticate that each sample was obtained from a specific batch. Neutron coincidence measurements and high-resolution gamma spectroscopy are used to analyze the bulk powder in the processing glovebox to obtain the $\mathrm{Pu}$ content of the entire glovebox. At the LaHague plant of AREVA, the solution volume and density of the liquid uranyl nitrate product are monitored while at Rokkasho, the $\mathrm{U}_{3} \mathrm{O}_{8}$ powder is analyzed by low-resolution gamma emission spectroscopy to monitor the enrichment.

The primary analytical techniques used to maintain plutonium material accountancy in large reprocessing plants include mass spectrometry, hybrid K-edge X-ray fluorescence densitometry, spectrophotometry, potentiometry, alpha, beta and gamma spectrophotometers, neutron coincidence counters, and gravimetry. Other techniques are also available for specific Pu accountancy applications. An analysis of the uncertainty associated with the application of analytical techniques (uncertainties from methods alone) to $\mathrm{Pu}$ accountancy showed that accumulated uncertainties for dissolver and product solutions are high when compared to the IAEA goal of detecting $8 \mathrm{~kg}$ of $\mathrm{Pu}$ in a 30-day period. However, it should be possible to meet the IAEA goals if the techniques with lowest measurement uncertainties are used. In addition, the IAEA has additional monitoring measures in place for reprocessing plants, including continuous monitoring and sample authentication.

Under the current strategy for processing LWR fuel, it will be necessary to monitor and account for all transuranics, not just plutonium (neptunium, americium and curium). This will require that new accountancy methods (or modifications to the current methods) be developed in order to track transuranics. New instrumentation that will reduce analysis time and increase accuracy will be necessary. 
It should be recognized that some of the streams will be easier to monitor, relative to a PUREX facility, given that some of the high gamma emitters (from the decay of Cs) will be separated from the transuranic elements.

In a group actinide recovery process, such as UREX $+1 \mathrm{a}$, the lanthanide fission products may be recovered together, along with the actinides. The lanthanide fission products produce a significant radiation field. A quantity of 10 kilograms of the TRUEX product, upon solidification, will have a radiation field well in excess of $100 \mathrm{Rem} /$ hour at one meter. The TALSPEAK process step separates the transuranics from the lanthanide fission products. In the UREX+1a process, the TALSPEAK product would be blended with a liquid uranyl nitrate solution in the proportions required to meet the fuel specifications for the Advanced Burner Reactor fuel. In this manner, the products of the UREX+1a process may be maintained as Attractiveness Level D material (as defined in DOE Order 470-4), making possible significant reductions in cost for plant security in the future. Close interaction with process and safeguards personnel, at an early stage of design, allows for the inclusion enhanced safeguards methods. The benefits of this interaction are that the LWR separations process flowsheet will be reconfigured to optimize material accountability, physical protection, and proliferation resistance, before completion of facility design.

The Physical Protection System (PPS) for preventing theft and sabotage at the CFTC will be designed to defend against a Design Basis Threat (DBT), addressing both insider and outsider threats. The physical protection measures will monitor and enable authorized access and activities and detect, delay and respond to prevent unauthorized access, activities, or events. A global perspective will be taken to enable international acceptance and broad implementation.

The PPS will satisfy the relevant DOE and NRC regulatory requirements derived from their statutory authority and jurisdiction. In addition, the PPS will be designed to meet IAEA requirements in the amended Convention on the Physical Protection of Nuclear Materials and to be consistent with the IAEA guidelines for The Physical Protection of Nuclear Materials and Facilities (INFCIRC/225/current version). Furthermore, the ABR PPS will be integrated with the material control and accountability (MC\&A) systems to increase the effectiveness of each system, especially against the potential insider adversary, and to further reduce costs.

The technical approach is to design-in physical protection throughout all phases of the project to improve effectiveness and to reduce intrusiveness and costs. The physical protection program will be based on the internationally recognized Design and Evaluation Process Outline (DEPO) system engineering methodology. In addition, GEN-IV Proliferation Resistance and Physical Protection (PR\&PP) assessment methodologies will be incorporated, as appropriate, to evaluate the design. Gap analyses will be conducted to identify and define security technology research and development needs and will be coordinated with the NNSA R\&D program for funding consideration.

As a result of new policy requirements or identified technology gaps, new security R\&D needs may be identified. For example, new policy requirements may be necessary to institutionalize multinational facilities that support joint ownership and operations while protecting materials, information, and technologies. Security R\&D may be needed to facilitate large system integrated physical protection modeling and analysis, to accommodate unprecedented secure transportation systems and to enable the cost-effective implementation of strengthened capabilities.

Safety of spent fuel reprocessing and high-level waste chemical treatment facilities is well established and currently practiced in the U.S. and worldwide. Future facilities will be designed to meet all regulations related to chemical and radiological safety, as well as current environmental standards. A comprehensive safety risk analysis would be performed consistent with DOE 10 CFR 830. In addition safety data collected during the CFTC would be used to support design certification of the commercial scale facility. 


\subsubsection{Safety and Licensing of the Consolidated Fuel Treatment Center}

The safety and licensing requirements of spent fuel reprocessing and high-level waste chemical treatment facilities are well-established in the US. However, only one commercial reprocessing plant has operated under an NRC license in the US: the Nuclear Fuel Services West Valley Plant in New York licensed in 1966. Of course, several fuel fabrication facilities are licensed by the NRC. Most of these have undergone recent review.

Over the years there has been an evolution in the details of the licensing process for commercial nonreactor nuclear facilities. For DOE facilities, 10CFR830 became effective in 2001 and with DOE Standard 1189 provides the requirements and implement guidance for the authorization basis of DOE's nuclear facilities. For commercial facilities, Subpart H, "Additional Requirements for Certain Licensees Authorized to Possess a Critical Mass of Special Nuclear Material", has been added to 10 CFR Part 70. This section supplements the general requirements for nuclear facilities specified in 10 CFR Part 20, 10 CFR Part 50, 10 CFR Part 70.22 and 70.23 and 10 CFR Part 100. Subpart H is being exercised in the ongoing licensing review for the MOX Fuel Fabrication Facility to be constructed for the disposal of excess weapons grade plutonium. The review of this license application is being done using guidance found in NUREG-1520, "Standard Review Plan for the Review of a License Application for a Fuel Cycle Facility" (March 2002). This review standard provides description of the areas of review, purposes of reviews, review procedures and acceptance criteria. The hallmark feature of subpart $\mathrm{H}$ is the requirement to submit an Integrated Safety Analysis that differs in detail from a conventional PRA.

There are several categories of information required by the NRC in a license application and comparable information is required for DOE. These are:

- General information on the applicant and resources as specified in 10 CFR 50.33 and 10 CFR Part 70.22(a) (1).

- The activities for which special nuclear material is requested.

- The location and equipment that will be used for this work.

- Technical qualifications and training program

- Proposed program to protect health and minimize danger to life or property.

- Technical Information

- An Environmental Report per subpart A of 10 CFR 51

- A Safety Analysis Report (SAR)

- A listing of "inspections, tests \& analyses", together with their acceptance criteria, that are to be performed to show the facility is safe to operate

- An emergency plan to be activated in the event of a radiological emergency at the plant

- Evidence that local authorities deem the emergency plans workable, are willing to participate in their further evolution and will fulfill their roles.

It is expected that the CFTC will reflect through its design, construction and operation an extremely low probability for accidents that could result in the release of significant quantities of radioactive fission products or actinide elements. This would be demonstrated through a Safety Analysis Report, which would contain information delineated in 10CFR70.22.

The application must include an Integrated Safety Analysis to demonstrate compliance with the requirements that: 
- The risks of each credible, high-consequence event are limited. [High consequence events are those that result in (1) worker exposures in excess of $100 \mathrm{rem},(2)$ acute exposures to a person outside the controlled area in excess of $25 \mathrm{rem}$, (3) intake of $30 \mathrm{mg}$ or more of soluble uranium outside the controlled area, or (4) acute chemical exposure that could endanger the life of a worker or could lead to irreversible or serious, long-lasting health effects to an individual outside the controlled area.]

- Engineered controls and administrative controls are available that will limit the consequences of credible events initiated internally or externally to the facility.

- Nuclear criticality under normal and credible abnormal events is prevented.

- A safety program is in place that will assure compliance with the requirements

The Integrated Safety Analysis required of the license applicant must identify:

- Radiological hazards associated with processing special nuclear material

- Chemical hazards

- Facility safety hazards

- Potential accident sequences caused by process deviation or other internal or credible external events

- Baseline design criteria

- Quality standards and records for design and construction

- Fire protection systems provisions

- Natural phenomena hazards

- Items relied upon for safety

- Facility/site emergency plan

- Provisions for continued operation of essential utility services in the event of an accident

- Qualifications of the facility designers, constructors, and operators

It is further required that facility and system design and facility layout be based on defense-in-depth practices.

Separations plants and fuel fabrication plans will be required to be licensed to hold Special Nuclear Material (SNM) in accordance with 10CFR70. These requirements include consideration of physical protection and safeguards and control and accounting of SNM.

\subsubsection{Simulation and Modeling of LWR Spent Fuel Processing}

An efficient plant design and process control requires extensive thermal and material integration between unit operations and at a larger scale between the major process segments. This integration will require a detailed chemical process simulation of the entire plant. For many unit operations, e.g. heat exchangers, pumps, and tanks, the data currently available are sufficient for an integrated design. However, some operations will require data that are currently unavailable. In key critical areas, notably conversion of process streams to final solid forms, significant unknowns exist.

Much of the data required to simulate a chemical reprocessing plant for spent nuclear fuel based on a UREX +1 a extraction process already exist in the open literature or have been incorporated into process codes such as AMUSE or Aspen ${ }^{\circledR}$. Experimental data are required for the front end fuel dissolution; 
where high-acid processes have been demonstrated and low-acid processes do not generally yield complete dissolution. Tank designs have been developed for process plants, though novel designs and instrumentation may require some optimization; criticality analysis for each process stream is required to size and select tanks. Although the processes that comprise UREX +1 a have not been demonstrated in long-term tests, the existing data for UREX, TRUEX, and CCD-PEG are likely sufficient for initial plant simulations, given the other uncertainties.

Post-process treatment of effluents and solidification appears to be where data are most limited. Though Aspen ${ }^{\circledR}$ does contain databases on waste-water treatment and solids drying and handling, there is not much plant-scale experience in converting spent fuel components, other than $\mathrm{U}$ and $\mathrm{Pu}$, to solid forms. Extensive data exist for acid-water evaporation, and waste-water treatment. Data on recovery and calcinations of trace organics in aqueous streams are likely available, though not for all of the organic species used in a UREX +1 a process. There are extensive data on gas treatment in Aspen ${ }^{\circledR}$ though experimentation may be required for the specific adsorbents used in radionuclide capture.

The need exists to develop a LWR reprocessing steady state process model using existing tools, such as Aspen ${ }^{\circledR}$ in conjunction with AMUSE. The needs of these models are:

- Short-term - steady state model to be used for process design

- Intermediate term - transient model that will be used to predict process response to changes in flowsheet conditions. The goal is to use this model in conjunction with safeguards instrumentation in order focus development needs. This model will also be used to train operators to understand process operation and response to upsets.

- Long-term - develop chemical process models more tailored to actinide elements. These models will better predict actinide thermodynamic and thermo-chemical behavior. 


\subsection{Cost Estimates and Milestones}

Table 5. Cost Estimates for the LWR Spent Nuclear Fuel Separation Technologies

\begin{tabular}{|l|c|c|c|c|c|c|}
\hline \multicolumn{7}{|c|}{ Cost Estimates (\$M) } \\
\hline \multicolumn{1}{|c|}{ Activities } & FY-07 & FY-08 & FY-09 & FY-10 & FY-11 & FY-12 \\
\hline $\begin{array}{l}\text { LWR Separations } \\
\text { Technology Development }\end{array}$ & 22.8 & 46 & 78 & 79 & 60 & 32 \\
\hline $\begin{array}{l}\text { CFTC Design \& } \\
\text { Construction Support* }\end{array}$ & 16.6 & 41 & 125 & 150 & 170 & 190 \\
\hline \multicolumn{1}{|c|}{ TOTAL } & $\mathbf{3 9 . 4}$ & $\mathbf{8 7}$ & $\mathbf{2 0 3}$ & $\mathbf{2 2 9}$ & $\mathbf{2 3 0}$ & $\mathbf{2 2 2}$ \\
\hline
\end{tabular}

* Includes safety and licensing analysis 
Table 6. LWR Spent Nuclear Fuel Separations Technology Development Milestones

\begin{tabular}{|c|c|}
\hline Milestones & Date \\
\hline Complete EAS inputs to the PEIS for a spent fuel recycling facility & June 2007 \\
\hline Provide input for industry engagement on conceptual design studies & June 2007 \\
\hline Develop remote contactor design concepts and initiate test component fabrication & September 2007 \\
\hline Develop Tc solidification flowsheet and initiate bench-scale tests & March 2008 \\
\hline Support $30 \%$ completion of industrial conceptual designs & April 2008 \\
\hline Complete pilot-scale testing of $\mathrm{Cs} / \mathrm{Sr}$ steam reforming process & April 2008 \\
\hline Complete EAS design package for review & April 2008 \\
\hline Develop instrumentation and control systems conceptual designs & May 2008 \\
\hline Initiate procurement of off gas system components for testing & June 2008 \\
\hline Demonstrate metallic waste form for cladding hulls incorporating technetium & September 2008 \\
\hline Develop initial waste formulation for fission product HLW & December 2008 \\
\hline Develop reference off-gas treatment process & January 2009 \\
\hline Complete initial characterization of mixed transuranic solid product & January 2009 \\
\hline Initiate demonstration of remote waste form packaging & March 2009 \\
\hline Complete evaluation of HLW forms & April 2009 \\
\hline Complete initial demonstration of steam reforming Cs/Sr product & May 2009 \\
\hline Validate UREX process performance with solvent recycle & May 2009 \\
\hline Complete demonstration of Tc solidification process & May 2009 \\
\hline Complete bench-scale demonstration of mixed transuranics solidification & June 2009 \\
\hline Complete bench-scale demonstration of $\mathrm{Cs} / \mathrm{Sr}$ solidification technology & September 2009 \\
\hline Complete initial integrated testing of separation processes with surrogates & September 2009 \\
\hline Support completion of conceptual design for nuclear fuel recycling center & September 2009 \\
\hline Complete initial Cs/Sr waste form characterization & October 2009 \\
\hline Demonstrate off-gas treatment system and waste forms & November 2009 \\
\hline Complete bench-scale demonstration of fission product waste form & March 2010 \\
\hline Complete mockup testing of prototype head-end equipment & July 2010 \\
\hline Demonstrate process monitoring and control system for separation processes & May 2011 \\
\hline Convert AMUSE code to higher level platform, and incorporate transients & July 2011 \\
\hline Support completion of preliminary design for nuclear fuel recycling center & September 2011 \\
\hline Complete initial characterization of high-level waste forms & July 2012 \\
\hline
\end{tabular}




\subsection{Transmutation Technologies using Fast Reactors}

Transmutation is one of the three key technologies necessary for the successful implementation of GNEP. The role of the fast reactor in the GNEP fuel cycle is to produce neutrons for consuming the TRU product separated from LWR spent fuel, as described in Section 3.0. This process is commonly called "actinide burning" and relies on the transmutation of TRU into fission products with more desirable waste characteristics.

A wide variety of reactor transmutation strategies were considered in the AFCI Program; this program included extensive international collaborations for systematic comparison of transmutation performance. Two major criteria for the reactor transmutation technology decision are: (1) the capability for repeated recycle of grouped TRU (the UREX+1a product) and (2) low technical risk. Based on the first criterion, a fast reactor system with an associated closed fuel cycle (see Section 5.0 for fuel cycle technology description) was chosen as the reference technology; recycle of TRU in thermal reactors would likely be limited to a fraction of the original inventory. A variety of fast reactors can be considered for the transmutation demonstration, but the sodium-cooled fast reactor technology has superior technical maturity; the other options (lead-cooled or gas-cooled fast reactors or accelerator-driven systems with either coolant option) require viability research and development that could delay or prevent successful technology demonstration. Therefore, the sodium-cooled fast reactor technology is being pursued as the reference, or baseline, technology for the GNEP transmutation demonstration.

The development and deployment strategy for the transmutation reactor has already been described as part of the overall GNEP strategy. It will rely on a government-industry relationship, where one option is that industry could build a prototype ABR and the government will support industry by running the R\&D and technology development tasks that support that prototype; the government will also run a longer-term R\&D program that will develop advanced technologies that contribute to the long-term pathway for commercially competitive transmutation reactors.

\subsection{Advanced Recycling Reactor Performance Objectives}

Specific criteria will be applied to each demonstration project to assure technology performance will be adequate for the comprehensive GNEP mission. The GNEP program will follow the process described in Section 3. As the demonstration proceeds, the performance objectives will be refined to reflect the mitigation of technical risk and interaction of the key technology areas. For the fast reactor transmutation technology, performance objectives have been identified based on the need for future commercial deployment.

\subsubsection{Demonstrate Transmutation of Transuranics}

The TRU present in LWR spent fuel (primarily $\mathrm{Pu}, \mathrm{Am}, \mathrm{Np}$, and $\mathrm{Cm}$ ) are the primary contributors to key waste disposal parameters (e.g., long-term heat load, peak repository dose, and radiotoxicity). The TRU also comprises the primary proliferation concern in the spent fuel materials; and the GNEP strategy utilizes group separation of the transuranics, avoiding a pure plutonium product. Therefore, a critical goal of the GNEP advanced fuel cycle strategy is to exclude the TRU from the final waste. The TRU is contained in the fuel cycle by application of the LWR separations and fast reactors recycle technologies described in Sections 3.0 and 5.0. Each recycle pass, a fraction of the TRU are consumed by fissioning in the fast reactor, producing additional power and gradually eliminating the TRU inventory in the nuclear fuel cycle. The integrated development of all three technologies will fully demonstrate the waste management benefits possible using the GNEP closed fuel cycle.

The fast reactor transmutation technology demonstration must successfully irradiate transmutation fuels created from TRU recovered from LWR spent nuclear fuel. The remaining TRU must be recovered to demonstrate the net consumption of TRU and recycled back to the fast reactor for further destruction. 
Thus, the reactor demonstration utilizes transmutation fuels fabricated by the fuel recycle demonstration from both LWR and fast reactor sources, and provides spent fuel to the fuel recycle demonstration.

\subsubsection{Demonstrate Cost Reduction Design Features}

Although the sodium-cooled fast reactor technology is mature, the capital cost of previous experimental reactors has been high. Recent cost studies ${ }^{\mathrm{a}}$ estimate that the capital cost of current designs may be $\sim 25 \%$ greater than conventional LWRs. Furthermore, the capital cost of the fast reactor is the primary driver for any cost difference between the current once-through cycle and the GNEP closed fuel cycle. It should be noted that fast reactors have never been commercially deployed and, thus, have not yet benefited from significant return on experience that would help reduce costs via design simplification and innovative design features; likewise, fast reactor research has been implemented at a relatively low level for at least a decade, and technology options for cost reduction have remained in paper form without experimental R\&D and demonstration. For the GNEP application, it is important to achieve a level of economic competitiveness that enables system installation in accordance with market principles. To this end, a variety of innovative SFR design features and technologies are being considered, possibly including configuration simplifications (e.g., reduced number of coolant loops, improved containment design), advanced reactor materials (e.g., improved fuel burnup, higher temperatures, improved reliability), and advanced energy conversion systems (e.g., supercritical $\mathrm{CO}_{2}$ Brayton cycle for higher efficiency). In addition, current design techniques introduce conservative design margins as a result of lack of certainty and validation of analysis techniques. The eventual goal is to ensure competitive energy cost (per unit power generation) compared with other energy sources.

\subsubsection{Demonstrate Fast Reactor Safety}

The most recent fast reactor constructed in the U.S., FFTF, was designed and built in the 1970's, before many of the modern safety principles had been developed. The ABR design will incorporate the proven safety features for a fast reactor in order to demonstrate the safety of this type of reactor. This will include traditional safety principles, including "defense-in-depth", along with more recent developments in passive or "inherent" safety. To achieve defense-in-depth usually requires the incorporation of multiple, diverse and redundant safety systems in the design so that the probability of an accident that would result in large releases of radiation to the environment is extremely low. It also incorporates multiple barriers between the radioactive material and the public

Traditionally, the reactor design has achieved safety through active defense-in-depth using engineered systems that require an action to have an effect. Passive safety is a different and complementary approach, where the design takes advantage of the inherent characteristics of a fast reactor to provide additional protection without requiring any system action, whether automatic or manual. For example, it has been shown that sodium-cooled fast reactors (SFR) can have favorable reactivity feedbacks that promote passive response to off-normal conditions. In previous reactor experiments ${ }^{\mathrm{b}}$, inherent shutdown for extreme conditions was demonstrated. For GNEP, the safety of fast reactors used for commercial purposes will be demonstrated through analysis and testing of the ABR, designed using both traditional and advanced concepts to achieve superior safety performance.

\subsubsection{Provide Capability for Fast Spectrum Fuel Irradiation}

Previous experimental and demonstration SFRs have utilized plutonium and enriched uranium fuel forms. The application of transmutation fuels containing the entire mix of transuranics must be demonstrated. In

\footnotetext{
a "Accelerator-Driven Systems (ADS) and Fast Reactors (FR) in Advanced Nuclear Fuel Cycles," Nuclear Energy Agency, Organization for Economic Co-operation and Development, 2002

b. Planchon et al., "Implications of the EBR-II Inherent Safety Demonstrate Test," Nuclear Engineering and Design, 101. Campbell et al., "FFTF Loss of Flow Without SCRAM Experiments with GEMs," HEDL-TC-2947.
} 
addition, the utilization of advanced fuels (high burnup) and structural materials is important to cost reduction; extensive irradiation testing is required.

\subsubsection{Demonstrate Reactor Safeguards and Security}

The transmutation technology demonstration will also employ modern reactor safeguards. The safeguards objective is to provide for the timely detection of diversion of a significant quantity of nuclear material and to provide for the detection of undeclared nuclear materials and activities, as outlined by the IAEA.

In addition, design features and operational protocols important for reactor security will be demonstrated. The PPS, which prevents theft and sabotage, will be designed to defend against a Design Basis Threat, addressing both insider and outsider threats. The physical protection measures will monitor and enable authorized access and activities and detect, delay, and respond to prevent unauthorized access, activities, or events.

\subsection{Status of Technology}

The SFR chosen for the GNEP transmutation demonstration relies primarily on technologies already developed and demonstrated for sodium-cooled reactors and associated fuel cycles that have successfully been built and operated in worldwide fast reactor programs. The first usable nuclear electricity was generated by a fast reactor, EBR-I, in 1951. In the U.S., SFR technology was employed in the $20 \mathrm{MWe}$ EBR-II that operated from 1963 to 1994. EBR-II R\&D included development and testing of metal fuel, demonstration of a closed fuel cycle, and passive safety tests. The $400 \mathrm{MWt}$ Fast Flux Test Facility (FFTF) was completed in 1980. FFTF operated with a full core of mixed oxide (MOX) fuel, and performed SFR materials and component testing. The U.S. SFR development program stalled with cancellation of the Clinch River demonstration reactor in 1983, although DOE research for advanced SFR technology continued until 1994.

Significant SFR research and development programs have also been conducted in Russia, Japan, France, India, and United Kingdom. The only currently operating fast power reactor is BN-600 which has reliably operated since 1980 with a $75 \%$ capacity factor (note that BN-600 uses highly enriched uranium fuel and does not recycle transuranics). Currently operating test reactors include PHENIX (France), JOYO (Japan), BOR-60 (Russia), and FBTR (India). The most modern fast reactor construction project was the 280 MWe MONJU in Japan that was completed in 1990. In addition, SFR technology programs have recently been started in both Korea and China, with the Chinese Experimental Fast Reactor scheduled for startup in 2008 and the Indian demonstration reactor to start in 2010.

The Transmutation Fuel for the GNEP fast reactors is required to perform the primary mission. Both metal and oxide fuels are under consideration. The development of this fuel is a major function of the "fast recycle technology" section and requires that the transmutation reactor be built and operated in an expeditious manner. Between now and when the reactor is operational, alternatives such as use of foreign irradiation facilities will be evaluated regarding their ability to contribute to the mission of accelerating the development of transmutation fuel.

Coolant Control Technology includes the necessary engineering and knowledge base to fill, drain and operate flowing sodium systems; clean up and purify the sodium coolant; and operate chemistry control, heating and cooling systems and instrumentation and control. This technology was well established in the U.S. with the liquid metal reactor programs in the 1990s and needs to be re-established to effectively build domestic sodium systems. Extensive technology exists in France, Japan and Russia.

Core Materials include cladding, wire wrap, grid spacers, ducts, sockets, and reflectors. A tremendous amount of materials development has occurred as part of previous liquid metal fast reactor programs. New alloys have been developed in the U.S. and elsewhere which allow very high radiation damage with good performance. These will be evaluated against design and safety requirements for use in technology 
demonstration. Core materials demonstrated in the past will be used for the initial startup core with advanced materials phased in after appropriate technology development.

For Startup Fuel there has been significant U.S. experience with metal (EBR-II) and oxide (FFTF) fuel forms. However, there is no current domestic capability to fabricate such fuels in sufficient quantities for fast reactor transmutation demonstration, although it may be possible to refurbish existing facilities.

The Primary System includes the primary heat exchangers, pumps and subsystems. Coolant temperatures range from $300^{\circ} \mathrm{C}$ to $510^{\circ} \mathrm{C}$ and operate at low pressure (less than $2 \mathrm{~atm}$ ). Austenitic stainless steels are appropriate. Vendors in the U.S. can produce these components with a good deal of development work.

The Reactor Vessel and Structures for fast reactors includes the vessel, guard vessel, redan, lower core support structure, core barrel/restraint system, upper internal structure, and the reactor vessel enclosure. These structures are typically austenitic stainless steel (either 304 or 316 series). For long system lifetime $(60+$ years), there are a number of high-temperature materials usage and codification issues that will need to be resolved in preparation for licensing.

The Balance of Plant power conversion technology for a standard steam cycle includes the steam generator, turbine, condenser, and associated piping and instrumentation. The sodium to water heat exchanger technology is mature in foreign countries, but needs to be established in the U.S. The other balance of plant components and subsystems are well established for the steam cycle. Sodium leak prevention and detection is an issue that must be addressed. Supercritical $\mathrm{CO}_{2}$ Brayton cycle is also an option for power conversion that may lead to overall cost reductions for SFR technology. This technology is low maturity and needs significant development. The other balance of plant components and subsystems are well established for the steam cycle but need development for the $\mathrm{CO}_{2}$ Brayton cycle.

The Containment includes the containment structure and associated systems that provide consequence mitigation for severe accidents. These systems are similar to existing power reactor containment systems, and are a very mature technology.

A Seismic Isolation system is being proposed for the fast reactor to demonstrate the feasibility and benefit of seismic isolation systems to nuclear applications. Seismic isolators are a reasonably mature technology; however, they need to be demonstrated in nuclear applications especially their ability to withstand harsher environments such as higher temperatures and radiation fields without degradation.

The Instrumentation and Control for the advanced recycling reactor is expected to adopt advanced digital control systems proposed for advanced LWRs. The project will investigate advancements in instrumentation to increase reliability and ability to withstand the harsh operating environment of a sodium-cooled fast reactor.

The opaque sodium coolant presents Maintenance and Inspection challenges that require some engineering development. Significant improvements in detection and repair techniques are envisioned beyond the existing technology utilized in SFR test reactors. Innovative ideas are being considered for inservice inspection and repair. Remote handling and sensor technology for use under sodium are being developed worldwide, including ultra-sonic techniques.

The Fuel Handling techniques and components employed in previous fast reactors were reliable but very complicated and expensive (e.g., double-rotatable plugs, in-core storage of spent fuel); therefore, the technical risk is low. Recent design innovations may simplify the approach but require the development and demonstration of a specialized in-vessel handling machine.

Appendix A discusses the Technology Readiness Levels for the fast reactor transmutation technologies. 
The Fast Reactor Component Design resources and tools are available from the previous U.S. fast reactor program and in most cases, reflect international standards. However, the current design process includes conservative margins, and significant cost savings may be possible with higher fidelity simulation and optimization methods (see Section 4.4). A limited group of trained designers are available in the national labs and through international collaborations, and it is important to transfer their knowledge and experience to a new generation.

The Fast Reactor Component Testing infrastructure is virtually non-existent in the U.S. to support a fast reactor development program. During the history of fast reactor development in the U.S., the science and technology community had at their disposal small, medium, and large component testing facilities used to mature the sodium component technology through an appropriate technology maturity level (TRL 7) that ensured programmatic success. Most of these testing facilities have either been decommissioned or mothballed to the degree that they cannot be utilized for technology maturation. In addition, the international fast reactor science and technology community has either decommissioned or not maintained their testing infrastructure that supported their past fast reactor development programs.

The Fast Reactor Component Manufacturing Infrastructure is also virtually non-existent in the U.S. because of the lack of demand for fabricating sodium technology components. The manufacturing infrastructure for conventional components that are used in other energy production systems, such as balance of plant component for a steam cycle, do exist today, and the manufacturing base infrastructure will contribute very little programmatic risk (other than competition of resources with the anticipated deployment of advanced light water reactors) to the fast reactor transmutation program.

The available fast reactor Safety Analysis tools developed in the U.S. also reflect the current standard and are utilized in all the major international fast reactor programs. Improvements are envisioned to provide more accurate analyses with modern simulation techniques that could be used to simplify the reactor design and reduce capital cost. A limited group of trained analysts are available in the national labs and thru international collaborations. The transmutation demonstration project provides the opportunity to reestablish U.S. leadership in this important technology area.

The Licensing strategy and regulations are under development. The international standard for fast reactors is severely outdated since the last fast reactor was built in 1990. The NRC has never licensed a fast reactor, although the Advisory Committee for Reactor Safeguards (ACRS) supported review of the FFTF. The FERMI-1 (1966) reactor was licensed by the Atomic Energy Commission. Thus, the regulatory resources and competency to review fast reactor safety needs to be re-established.

The technical risks described above potentially impact the project schedule and cost and, thus, add a certain level of programmatic risk to project execution. Because of the need to develop fast neutron irradiation capability for fuel and materials development quickly, various project tasks such as sodium component and testing infrastructure proceed in parallel with the transmutation reactor design effort. This parallel approach, although it adds project execution risk, is necessary to rapidly re-establish the domestic capabilities for sodium fast reactor technology.

\subsubsection{Key Technology Development Needs}

Based on the current status of SFR technology summarized in Table A-2, four key technology needs have been identified:

1. Closed fuel cycle demonstration. Previous experimental and demonstration SFRs have utilized plutonium and enriched uranium fuel forms. The application of transmutation fuels containing the entire mix of transuranics must be demonstrated. To achieve the transmutation mission, the subsequent self-recycle of the TRU must also be demonstrated.

2. Establishment of domestic infrastructure. The viability of SFR technology is well established; however, the U.S. infrastructure for this technology is severely eroded. A focused, sustained 
demonstration project will be required to reinvigorate the domestic SFR capability as well as the needed human resources. In the interim, international partners are expected to play an important role in the initial technology testing and may also be needed as an early source of SFR components.

3. Capital cost reduction. A variety of innovative technologies and design features are being considered for SFR cost reduction including configuration simplifications (e.g., reduced number of coolant loops, improved containment design), advanced reactor materials (e.g., improved fuel burnup, higher temperatures, improved reliability), and advanced energy conversion systems (e.g., supercritical $\mathrm{CO}_{2}$ Brayton cycle for higher efficiency). An important part of the transmutation demonstration will be to test the efficacy of these advanced technologies and design options and to validate design margins.

4. Reactor safety validation and licensing. Technology gaps center around two general areas: assurance of passive safety response and techniques for evaluation of bounding events. The advanced SFR designs exploit passive safety measures to increase reliability, and the ability to measure and verify these passive features must be demonstrated. The approach to identify bounding events for specific designs and investigate the fundamental phenomena to mitigate severe accidents is a key issue for SFR licensing.

An important activity for the 2008 project decision is to translate these needs into technical requirements for the fast reactor transmutation demonstration. The relative priority of the performance objectives given in Section 4.1 needs to be firmly established; the development program will clearly be configured to assure the demonstration of transmutation. However, the cost and schedule impact required to address the other objectives and needs (e.g., safety, cost reduction design features) will need to be assessed. Thus, the near-term design activity (Section 4.3.1) must separately evaluate the cost and schedule impact for each performance objective.

\subsection{Fast Reactor Development Program}

The complete GNEP vision requires development and demonstration of an integrated fuel cycle including LWR and fast reactor spent fuel processing, fast reactor recycle fuel fabrication and irradiation, and safe and reliable reactor operation using transmutation fuel. Few test fast reactors are in existence today, with at least one, PHENIX in France, scheduled for shutdown within a few years. Thus, the development, design, and operation of a fast reactor that is specifically tasked with resolving near- and long-term transmutation technology issues is critical to the success of GNEP. The fast reactor transmutation demonstration must account for the four key technology issues identified in Section 4.2.1: closed fuel cycle demonstration, establishment of domestic infrastructure, capital cost reduction, and reactor safety validation and licensing. The basic construct of the Fast Reactor Development Program consists of three elements: (1) the near-term activity of preparing the 2008 secretarial decision (2) the medium term activity of designing and building a prototype ABR, and (3) the long-term activity of developing the advanced technologies and tools for the evolution and deployment of commercially-viable next generation advanced recycling reactors.

\subsubsection{Technical Information}

To inform the 2008 Secretarial decision on whether to proceed with proposed GNEP facilities, technical input will be provided to answer the following eight questions:

1. What is the technology maturity and associated technical risks?

2. What is the economic projection for a closed fuel cycle?

3. What is the program business plan, including cost estimates, schedules, and the role of industry? 
4. What are the implications on U.S. infrastructure?

5. What is the international interest?

6. What are the non-proliferation implications?

7. What are the nuclear sustainability implications?

8. What are the implications on U.S. leadership?

The work performed under the advanced recycling reactor technology development program will address all elements. To this end, five significant tasks that will contribute most of the information are:

A gap analysis for sodium fast reactor technologies will review the current US status of these technologies, will point out areas where expertise or infrastructure has been lost and will provide priorities for recreating the needed expertise and infrastructure. This gap analysis will be developed on the basis of generic concepts, with input from potential industrial partners where available.

A technology development plan for sodium reactors that will prioritize the needed technology and infrastructure development to meet the objective of building an advanced recycling reactor. This plan will include anticipated cost and schedule estimates.

Industrial input that will describe schedules and costs for designing and building the first advanced recycling reactor.

An options study that will overview possible advanced technologies and design options for the advanced recycling reactor, estimate their technical risk and potential for performance improvement, in particular cost reduction.

A simulation plan that will define the needs for advanced simulation, outline the possible benefits in terms of cost savings and safety improvements, and define the validation path for the new generation of software.

\subsubsection{Advanced Burner Reactor Prototype Design and Construction}

The primary objective of the fast reactor transmutation technology demonstration is to demonstrate destruction of transuranics recovered from the LWR spent fuel and thereby demonstrate the benefits of the fuel cycle closure to nuclear waste management. To facilitate this demonstration, a fast reactor, the ABR Prototype, is required to provide an environment prototypic of future commercial reactors. This phase of the fast reactor transmutation technology demonstration program is comprised of the Phase 2 activities discussed in Section 4.0

The Advanced Burner Reactor Prototype will support development of the necessary licensing database for the ultimate commercial reactors that are required to transmute large quantities of transuranics recovered from the LWRs. Two different categories of the licensing database are required. The first is associated with the performance characteristics of fuel containing transuranics. Essentially all thermal and fast spectrum reactor fuel experience has been with uranium fuel and some with plutonium containing fuel. There is little experience with fuel fabrication including other transuranics, such as neptunium (Np), americium $(\mathrm{Am})$, and curium $(\mathrm{Cm})$. A large-enough demonstration, involving representative compositions of transuranics, is necessary to establish the feasibility and viability of transmutation in fast spectrum reactors. These transmutation fuels will be developed in another facility and produced in sufficient quantities for testing.

Second, the Advanced Burner Reactor Prototype will also play a key role in establishing the licensing database in terms of demonstrable safety characteristics. The inherent passive safety potential of the sodium-cooled fast reactor needs to be demonstrated through a combination of tests and analyses in order 
to take advantage of its application in the future commercial plants. In addition, the impact of recycled transuranics on safety performance of the fast reactor needs to be fully resolved to support the licensing of commercial plants.

The ABR Prototype design and construction project deliverables include the design, development, installation, and checkout of the reactor systems with its primary auxiliary systems, the balance of plant systems with its secondary auxiliary systems, the reactor core, the nuclear buildings and conventional facilities, and a training program for new operators and support staff. The fast reactor will be designed and constructed to all applicable DOE and NRC regulations with an appropriate emphasis on public and personnel safety and the safeguards of special materials.

The ABR Prototype design and construction project will be performed in accordance with DOE O 413.3, "Project Management for the Acquisition of Capital Assets," starting with the establishment of Critical Decision-0, Mission Need through Critical Decision 4 - Approve Operations. After the design and construction project is complete, there will be a period of time, approximately one year, in which the plant systems will be operated at reduced power to verify proper overall integrated system performance and functionality, safety system performance verification, before full power reactor operations can begin. The facility will be designed to meet safety requirements and ensure high reliability and availability for the user programs. The fast reactor design will take full advantage of the infrastructure available at the target installation site to ensure that capabilities and infrastructure are not duplicated and associated project cost savings are realized.

The Advanced Burner Reactor Prototype development project is divided into a number of project elements:

- Conceptual Design

- Preliminary Design

- Final Detailed Design

- Reactor Plant Systems Procurement

- Balance of Plant Systems Procurement

- Startup Reactor Fuel Fabrication

- Conventional Facilities construction

- Equipment installation and commissioning

- Safety Analysis, Licensing, and Environmental Impact activities

- Integration Activities

- Project Management.

It is imperative that the ABR Prototype design and construction project be initiated expeditiously because the domestic fast reactor technology base is being lost due to attrition of the experts. The project will provide the avenue to maintain the technology base, advance it further through concurrent R\&D activities, train and develop the next-generation of experts, develop critical industrial infrastructure, and facilitate international cooperation to achieve non-proliferation goals.

The ABR Prototype reactor design and construction project has the following project activities:

- Design Activities - The reactor design activities will go through a three-phase process of increasing design detail; conceptual design where the feasibility of the reference reactor concept is created and alternatives are evaluated preliminary design where the design is detailed 
sufficiently to create a baseline cost and schedule estimate that can be placed under configuration management, and detailed design where detailed drawings of the final design are created and procurement specifications are produced. The design activities will be accelerated for the critical path items once they are known.

- Procurement Activities - After detailed design is complete, specifications for the nuclear steam supply system and balance of plant systems and component will be prepared. The systems and components will be competitively procured in accordance with appropriate procurement rules. Long-lead items will have been identified during the preliminary design activities and their procurement will occur early in the procurement phase to reduce their impact on the critical path. It may be desirable to obtain some components overseas rather than in the U.S.

- Startup Reactor Fuel Fabrication - The startup core for the reactor will be fabricated from known fuel types, either uranium-plutonium metallic alloy, uranium metallic alloy, or mixed oxide. The startup fuel will be fabricated in accordance with the fuel specifications generated during the detailed design phase of the project. Depending upon the ultimate size of the ABR Prototype machine, a new startup fuel fabrication facility may need to be developed to handle throughput requirements. If the fuel fabrication requirements are modest (meaning for a smaller reactor size), then modifications to an existing facility may provide a more cost effective solution. In addition, other source options for the startup fuel, besides from new or existing U.S. facility are being explored.

- Conventional Facilities Construction - The start of conventional facilities construction will occur after the detailed design activities are complete and the appropriate licensing process has been completed. The conventional facilities include the reactor building, balance of plant building, control and personnel building, cooling towers, and balance of plant auxiliaries building, among other auxiliary building. The reactor construction project will take advantage of the infrastructure at the site where it is located to ensure that new facilities do not duplicate the existing site infrastructure.

- Equipment Installation and Commissioning activities - After the conventional facilities are built and the reactor and balance of plant systems are fabricated and procured; the equipment will be installed in their respective buildings and will be individually checked out to verify operability. After initial checkout and testing, the components of a system will be verified to operate in accordance with the systems specifications. In addition, during this phase of the project, the necessary operating and maintenance manuals will be prepared, reviewed, and instituted for reactor operations. The operating and maintenance crews will be trained and qualified on these procedures to ensure that the reactor plant is operated in an efficient and compliant manner.

- Safety Analysis, Licensing, and Environmental Impact activities - During the design of the reactor, safety analyses will need to be conducted to demonstrate that the reactor, as-designed, meets the safety criteria. The safety analysis activities will result in documents such as a preliminary hazards assessment, a preliminary safety analysis report, a final safety analysis report, a preliminary probabilistic risk assessment, and a final probabilistic risk assessment. Assuming NRC licensing, the final goal of the licensing activities will be obtaining authorization to construct and then operate the reactor. The environmental impact activities include a programmatic environmental impact statement that reviews the reactor mission, the strategies to accomplish that mission, and various alternatives, and then finally select an appropriate site for the reactor.

- Integration activities - Because the reactor project needs to interface closely with the other parts of the overall GNEP project (e.g., the GNEP project elements that produce the startup fuel, 
transuranic fuel, and transuranic material for the reactor), integration activities will be essential to ensure that the overall project succeeds.

- Project Management - The reactor design and development work will be performed in accordance with the DOE Order on Project Management, DOE O 413.3. The activities under the project management element include the project office, project quality assurance, environment safety and health, engineering oversight, and home office activities.

\subsubsection{Technology Development and R\&D for the ABR Prototype reactor}

The overall technology development program will support the ABR Prototype reactor and the ultimate commercial deployment of the advanced recycling reactors. This program is subdivided into a near-term technology development program and a longer-term R\&D component. The expected scope of the nearterm technology development program is discussed in this section. The longer-term R\&D component is discussed in Section 1.3.3. In addition, the facility needs and the role of international collaborations are highlighted in subsequent sections.

\section{Technology Development}

The technology development consists of the near-term activities needed to facilitate the fast transmutation reactor design and construction project. This consists first of a preliminary design activity to provide basic performance and design features to guide the technology development efforts. The remaining engineering development activities will be clarified as priority needs for reactor design and construction are identified. One obvious priority is the development of fuel fabrication facilities to support the reactor. Other technology development activities are expected to support design activities (e.g., sodium components, fuel handling, etc.); this work will be guided by the 2008 gap analysis to specify and prioritize the component demonstration requirements based on the specification of the transmutation reactor design. Another important activity is to validate the design tools used for the reactor.

\section{Advanced Recycling Reactor Reference Concept}

Early in the ABR project, a preconceptual level reference concept must be specified to provide input to the prototype reactor requirements and goals, to guide the technology development priorities, and to provide input to the systems analysis team for defining the relevant performance requirements. The general approach will be to start with existing sodium fast reactor designs and perform a series of options studies to establish initial technology down selection. The technology development and research activities will be designed to reflect the targeted advanced recycling reactor operating conditions.

\section{Reactor Fuel Supply for the Advanced Recycling Reactor Prototype Startup Core}

Fast reactor fuels will need to be fabricated for the startup reactor core and the subsequent cores. The AFCF will provide transmutation fuels for testing and qualification; however, the AFCF will not be able to provide fuel for the startup core or early fuel replacement batches. Furthermore, the conversion of the reactor to transmutation fuel will be a gradual process; in addition, there may be an extended need for a supplemental fuel supply to support operation and testing. Therefore, the initial reactor core will be composed of conventional fast reactor fuel, either a metallic U-Pu-Zr enriched U-Zr fuel or a mixed U-Pu oxide fuel. This section will describe the selection and fabrication of this initial startup fuel for the fast reactor.

A critical short-term decision relates to the form of the fast reactor startup fuel. Mixed oxide fuel and metal alloy fuel are the most mature fuel forms available for fast reactor application, and the U.S. has substantial experience with either fuel type. Selection of a startup startup fuel for the reactor will be based on a combination of factors, including fabrication schedule and objectives, fuel performance and reliability, reactor safety and the impact that safety-related design accommodations have on construction 
and operating cost, and mission schedules. The required facilities and schedule for the fuel fabrication and qualification will be specified as well as the schedule for the final design decision.

The strategies for qualifying the initial startup core will depend on the choice of fuel type, the nature of the as-fabricated fuel, the fuel operating conditions in the reactor, and the specifics of the existing database for that fuel type. If U-Pu-Zr is selected, the most likely strategy will adapt the EBR-II MarkV/VA safety case. Initial burnup and temperature limits for the startup fuel will be set to conservative values, such as 5 to 8 at $\%$ burnup and $475^{\circ} \mathrm{C}$ to $525^{\circ} \mathrm{C}$ peak cladding temperature, which might require some initial reactor operation at less than design power. A number of qualification assemblies will be identified and placed within the first core, intended to lead the core startup fuel in attaining design burnup. These assemblies will collectively operate over the range of operating conditions while the remainder of the core operates at less than design-basis power. Some number of these assemblies will also address startup core operation near the uncertainty design limits of power and temperature. Some of the assemblies will be placed for the purpose of interim-lifetime examination, which will provide the basis for increasing the burnup and temperature limits to the design basis. Depending on the exposure capabilities for cladding and assembly hardware in the startup core, further irradiation of the qualification assemblies could be pursued to provide a basis for additional increases to startup fuel burnup limits to values of 20 at $\%$ or greater.

If mixed oxide fuel is selected for the startup core, then the logical strategy would be to adapt the safety case used for FFTF Series I and II fuel (for mixed fuel in 316SS cladding and assembly hardware) or for FFTF Series III.a fuel (for mixed oxide fuel in D9 cladding and assembly hardware). Initial burnup limits could be set at values established for FFTF operation -8 at.\% burnup for mixed oxide fuel in 316 SS cladding, or 10 at.\% for mixed oxide fuel in alloy D9 cladding - and core power and temperature could likely be set at design values after initial startup physics testing. However, a number of qualification assemblies would need to be identified for surveillance and end-of-life examination. Again, depending on the exposure capabilities for cladding and assembly hardware in the startup core, further irradiation of the qualification assemblies could be pursued to provide a basis for additional increases to startup fuel burnup limits to values of $20 \%$ or greater.

\section{Design Component Testing and Demonstration}

As discussed in Section 1.3.1, one of the first major activities in the overall technology development program is to perform a gap analysis regarding the current state of the sodium component technology development. One of the major SFR technology needs is to re-establish a domestic infrastructure for this fast reactor technology. Because the U.S. has not had a fast reactor development program for decades, it is expected that this gap analysis will find that the U.S. lacks the technical and commercial infrastructure to support sodium component technology development. Therefore, the performance testing needs for the reactor components requires either (a) new facilities for SFR technology testing, (b) restart or refurbishment of dormant existing facilities, or (c) reliance on international partners to conduct such technology testing. Some potential facilities are noted in Section 1.3.2, and the role of international collaboration is highlighted.

One option is that if defined by industry, the technology development for the ABR Prototype reactor is expected to be executed in the following four phases: (1)Phase I, Feasibility Tests, (2) Phase II, Key Features Tests, (3) Phase III, Component and Subsystems Tests, (4) Phase IV, Systems Tests.

- Phase I will determine whether various design aspects of the reactor design are considered feasible to proceed through the design phase.

- Phase II tests key features of the proposed component technology to verify that the options will work as anticipated. 
- Phase III of the technology development program will include the testing of key plant components to verify performance characteristics and safety responses in a prototypical environment.

- For Phase IV, safety tests will be scheduled with the reactor. These tests will confirm the anticipated performance of the various systems and components as integrated in the reactor system.

Specific features will be defined by the ABR Prototype reactor design and construction project. In addition, the national labs will prepare a long-term plan for utilizing the Advanced Burner Reactor Prototype to test and demonstrate GNEP advanced recycling reactor advanced technologies. These advanced technologies may include the heat transfer components and power conversion systems, reactor and balance of plant control systems, fuel handling equipment, instrumentation, seismic isolation system and component studies, reactor core design, shielding, in-service inspection methods and component development and testing, and structure materials among others that support the long-term goals of commercially deploying the advanced recycling reactors.

\section{Validation of Reactor Performance and Simulation Tools and the ABR Prototype}

An existing suite of fast reactor analysis tools was developed as part of the U.S. sodium-cooled fast reactor technology program, and these tools will be used extensively for the initial ABR design efforts. However, many of these codes are based on the computer architecture of twenty years ago when significant modeling assumptions were required to approximate the physics phenomena in a reasonable computer running time. In the long term, a new generation of simulation tools will be identified and tailored to the fast reactor transmutation technology, as discussed in Section 6.0 (Modeling and Simulation). However, the first step for the reactor design will be to update and apply existing codes. The existing U.S. suite of fast reactor analysis tools was developed in parallel with the U.S. sodium-cooled fast reactor technology program; and these tools underwent extensive validation against domestic experiments. However, the quality assurance of this process would not meet modern standards, and an explicit validation of the current state of these design tools will likely be needed for the reactor licensing. The validation of the design tools is part of the project and requires the compilation of significant work in this field to produce a formal documentation procedure to enable the licensing process. The development of new simulation tools will be articulated around a team composed of designers and analysts who will concentrate on developing a priori specifications and will validate the codes for their specific applications and software experts who will design, develop, and verify the computational tools.

A large volume of experimental data is available for code validation applications, with varying levels of quality, completeness, and accessibility. Historical U.S. data from the Fast Flux Test Facility (FFTF), the Experimental Breeder Reactor (EBR-II), the Zero Power Physics Reactor (ZPPR) and possibly from the earlier series of Zero-Power Reactors (ZPR) is particularly pertinent, as is complementary data from a number of European, Russian, and Japanese facilities. A broad range of experimental benchmarks will be established for subsequent comprehensive evaluation and application during the course of the overall project. This selection will be accomplished with the aid of formal covariance data and sensitivity-based techniques in some cases. The effort will initially involve detailed evaluation and documentation of a broad range of benchmarks to provide benchmark specifications that can then be directly used and referenced in the code validation process. A particularly challenging component in this process will be the need to encompass reactor operating data, particularly from EBR-2 and FFTF. This data is required to evaluate the fuel depletion, criticality prediction, reactivity coefficients, and control rod worth against reactor experience. This was a key requirement for the existing fast reactor tools, but needs to be captured into a well-documented and comprehensive qualification package according to current standards. A formalized validation approach that makes optimum use of the information available in existing 
benchmarks needs to be developed and utilized. Validation analyses will also involve a definition of needs for further, not currently available, experimental data (e.g., experiments that are sensitive to Minor Actinides remain very limited today). As discussed above, the prototype ABR will be a test bed for these new simulation and validation tools and processes.

\section{Fast Reactor Technology Demonstration and Research Support Facilities}

There are a number of support facilities that will be required to execute the technology development plan in support of the ABR prototype. As noted above, several potential partners (France, Japan, and Russia) have currently operating fast test reactors. Therefore, significant opportunities exist for international collaboration on SFR research and technology development as noted in Section 2.4. Given the desire for U.S. leadership and impact on GNEP technology, the development or restart of domestic facilities must also be considered.

\section{Sodium Component Testing}

ABR prototype components will need to be tested in a prototypic environment before introduction into the reactor to reduce the project risk. A sodium component testing facility would also provide for the training of engineers, scientists, designers, operators and maintenance personnel who will be responsible for designing, operating, and maintaining sodium components and systems. Some components can be tested in water loops, but eventually all components should be tested in a prototypic environment.

DOE had a facility named Liquid Metal Engineering Center (LMEC) located in California that was used to conduct $\mathrm{R} \& \mathrm{D}$ in liquid metal applications and for testing large sodium components in a prototypic environment. However, the LMEC, along with most U.S. fast reactor development facilities, has been decommissioned and is no longer available for use.

In addition, FFTF had a sodium test loop for testing equipment and training operators. This facility is in the process of being permanently deactivated. A facility, on the scale of the LMEC or the FFTF sodium test loop, may be needed for the testing and development of ABR prototype components. This facility must contain and heat large quantities of sodium to high temperatures and circulate it through loops and prototypic test components. Such a facility can be designed and constructed on an accelerated basis concurrently with the design activities.

\section{ABR Prototype Reactor Start-Up Fuel Fabrication}

Depending upon the size of the ABR prototype reactor and the commercial vendor intent, two fuel fabrication facilities may be utilized for fabricating ABR prototype fuel. In addition, other alternatives, besides these two facilities are being explored such as commercial facilities and obtaining the start-up ABR prototype fuel from international sources.

The Fuel Manufacturing Facility (FMF) at INL has previously fabricated metal and oxide fast reactor fuels. This facility was commissioned in 1986 for consolidation of all EBR-II fuel fabrication activities requiring use of special nuclear material. For much of the operating life of the EBR-II, all its fuel was manufactured in FMF. The building includes a large uranium vault, an induction furnace, gloveboxes and hoods, and radiography and non-destructive assay equipment. The FMF layout consists of two rooms with operating space and a special nuclear materials storage vault.

Although the FMF is currently operational, this facility would require installation or reinstallation of fuel fabrication equipment and modifications to the building ventilation system to accommodate additional plutonium containment requirements. Some of the necessary equipment is available in storage, but much of it would need to be redesigned or modified, and an updated safety analysis would be required for fuel fabrication operations in FMF. The requirements for fuel fabrication and a plan for preparing the facility will be developed in FY 2006 and 2007 and will serve subsequent budgeting and planning needs. 
Rooms 125 and 126 of the Plutonium Facility -4 (PF-4) at Los Alamos National Laboratory have been used historically for ceramic fuel fabrication in support of several nuclear energy missions. Currently, the facility is being used to support fabrication development and sample fabrication of nitride transmutation fuels for the AFCI program. This facility has been proposed for fabrication of mixed oxide startup fuel for the ABR. The facility houses a large number of plutonium gloveboxes and fabrication equipment necessary for ceramic fuels, such as hydraulic presses and dies and sintering furnaces.

Although the PF-4 ceramic fuel fabrication facility is currently operational, this facility would require installation or reinstallation of fuel fabrication equipment for mixed oxide fuel fabrication at the rates necessary to support operation. The requirements for fuel fabrication and a plan for preparing the facility will be developed in FY 2007 and will serve subsequent budgeting and planning needs.

If existing facilities do not prove capable of manufacturing sufficient startup fuel for the ABR, a new facility will be considered.

\subsubsection{Next Generation Advanced Recycling Reactor Research and Development}

As a benefit of previous investments in SFR technology discussed in Section 1.2, the majority of the $R \& D$ needs that remain for the SFR are related to performance rather than viability of the system. Therefore, no technical "show-stoppers" are anticipated for SFR reactor technology. The primary issue that may inhibit SFR introduction is a perception of higher capital costs, as compared to conventional nuclear power (LWR) technology. Thus, future R\&D activities have an emphasis on improved economics; this includes innovative design features for cost reductions (e.g., advanced materials, improved thermal efficiency), simplification of safety systems (e.g., favorable and verifiable inherent responses), and improved systems reliability (e.g., refined techniques for in-service inspection and repair). The comprehensive gap analysis and fast reactor concept evaluations conducted for the March 2008 decision will guide the specification of a targeted long-term R\&D plan. Four avenues are envisioned for the investigation and demonstration of the next generation advanced recycling reactor technology:

1. Technology development (for cost reduction design options)

2. Advanced simulation

3. International collaborations

4. Facilities for SFR technology testing

\section{Technology Development for the Next Generation Advanced Recycling Reactor}

Much of the technology development is an extension of the prototype ABR approach described in Section 1.3.2. Two examples of major new areas that require an extended development period are advanced materials and advanced energy conversion technology.

\section{Advanced Materials}

The focus of this research activity is to develop advancements in materials for use in commercial fast reactor transmutation. The development of advanced materials may allow design refinements and/or improved reliability. Potential benefits include simplified heat transfer configurations, improved containment design, and refined component design. For example, low thermal expansion structural materials utilized in the Japanese JSFR design allow much larger sodium pipes reducing the number of coolant loops required. These new structural materials need to be qualified, and the potential for higher temperature operation evaluated

The R\&D approach for advanced material development is to continue the efforts of the multi-lab materials working group established under the AFCI program. In the near term, data will be mined from FFTF-irradiated samples and hardware that was irradiated to high dose. In order to use these materials for 
fast reactors, they must be qualified by the NRC under the specific advanced recycling reactor conditions. Reviews conducted by/for the NRC of General Electric's conceptual design of the Power Reactor Innovative Small Module Liquid-Metal Reactor (PRISM LMR) clearly identified additional materials data, design methodology, environmental effects, and regulatory needs for 60 year lifetime fast reactors operating at high temperatures. The longer-term development of advanced materials will also require new irradiations. A more detailed description of several advanced material activities is given below:

Retrieval and testing of previously irradiated FFTF irradiated materials - Numerous materials were irradiated in the Fast Flux Test Facility and testing was not completed before the research was stopped. This includes hexagonal ducts, which surrounded the fuel assemblies and specimens (tensile, Charpy, compact tension, TEM specimens of HT-9 and Mod9Cr-1Mo) irradiated in the Materials Open Test Assemblies. The total dose accumulated in these materials was up to $200 \mathrm{dpa}$, and the irradiation temperatures ranged from $350-700^{\circ} \mathrm{C}$. The $\mathrm{ACO} 3$ duct will be available in late $\mathrm{FY} 2006$, allowing for specimen machining in FY 2007 and testing in late FY 2007 and FY 2008, as funding allows. The MOTA specimens could be available in FY 2007 to begin testing through FY 2008. Testing of these materials will be directly relevant to the design of the transmutation reactor.

PHENIX irradiations-MATRIX-SMI - To investigate the effects of fast reactor irradiation on the mechanical properties of fast reactor materials, specimens are being irradiated in the Phenix reactor. Materials include HT-9, Mod 9Cr-1Mo, and as well as oxide dispersion strengthened alloys such as $14 \mathrm{YWT}$ and $12 \mathrm{YWT}$. Total dose is up to $70 \mathrm{dpa}$ at irradiation temperatures of $400-500^{\circ} \mathrm{C}$. Irradiations are presently underway. It is anticipated that the irradiations will be completed by 2009 to begin PIE in late 2010. Results from this testing with provide additional qualified data on ferritic/martensitic steels and advanced alloys for design of the transmutation reactor, as appropriate.

ASME Codification of Materials - There are a limited number of materials approved for use at elevated temperature by ASME, where elevated temperature is temperatures at or above $371^{\circ} \mathrm{C}$ for ferritics and $427^{\circ} \mathrm{C}$ for austenitics. ASME code acceptance of a new material typically requires testing of three heats of material; minor modifications of an alloy may not require extensive additional testing. Test data such as tensile, creep, fatigue, creep-fatigue, and other relevant data will be gathered and analyzed from numerous sources. Evaluation of the long-term stability of other $12 \mathrm{Cr}$ steels and weldment reduction factors by international researchers such as Japan will be made.

ASME Codification of Design Methodology - Design methods and criteria that address all failure modes for SFR components will be reviewed and developed. First, identification of all materials, construction, design, and operating issues will be made. This activity will be highly integrated with the ASME Codification of Materials activity, as the two effectively cannot be addressed separately. Issues that will be addressed include but are not limited to those previously identified for the 60-year PRISM LMR and the CRBRP: weldment safety evaluation, elevated-temperature seismic effects, design analysis methods, elastic follow-up, notch weakening, creep-fatigue evaluation, plastic-strain concentration factors, degradation of properties due to long-term exposure and irradiation effects; strain limits; thermal striping; flaw assessment; and construction and operating experience.

\section{Advanced Energy Conversion Systems}

Cost reduction R\&D activities currently being conducted in the Generation-IV program are development of a supercritical $\mathrm{CO}_{2}$ Brayton cycle and development of advanced, high-reliability steam generators.

The use of Brayton cycles offers the possibility of increasing the thermal efficiency of the plant and decreasing the capital costs by replacing the usually larger components in a steam Rankine cycle.

Supercritical $\mathrm{CO}_{2}\left(\mathrm{SC}-\mathrm{CO}_{2}\right)$ has been identified as a candidate fluid because of the temperatures involved in the cycle and the potential compactness of the BOP equipment, the turbine in particular. The $\mathrm{SC}-\mathrm{CO}_{2}$ cycle offers the potential for surpassing $40 \%$ efficiency in energy conversion, even at the typical $550^{\circ} \mathrm{C}$ 
sodium coolant outlet temperature of the reference SFR designs. The initial R\&D should focus on the conceptual design of an $\mathrm{SC}-\mathrm{CO}_{2}$ power generating system coupled to a reference SFR and the evaluation of its performance and potential safety implications. R\&D activities of interest include:

- Conceptual design study and assessments, including thermodynamic optimization for the SFR conditions, studies of the SC- $\mathrm{CO}_{2}$ cycle components, conceptual designs for the sodium-to- $\mathrm{CO}_{2}$ heat exchangers, and investigation of material implications

- Study of technical performance and cost, including investigation of the safety implications of failure of the $\mathrm{Na}-\mathrm{CO}_{2}$ boundary

- Experiments to assess the behavior of $\mathrm{Na}-\mathrm{CO}_{2}$ reactions and the performance of heat exchangers

The primary purpose in the development of high reliability steam generators (SGs) is to reduce the probability of a tube leak (causing a steam-sodium reaction) and to enhance the response time and reliability of detection systems if steam generator tube leak occurs. Higher reliability SGs will result in better operating costs and longer design lifetimes. The main R\&D elements are as follows:

- Steam generator tube leakage is minimized by design or by the use of advanced materials. Advanced designs include the possible use of double-walled SG tubes, the use of shell bellows for mitigating thermal expansion differences between shell and tube-bundle, the possible use of an intermediate medium $\mathrm{Pb}-\mathrm{Bi}$, and the use of advanced steels in the $\mathrm{SG}$ tubes.

- Enhanced leak detection techniques are required to protect against small leaks and to prevent the propagation of tube ruptures. The main activities focus on the development of hydrogen detection sensors, acoustic detection systems, and enhancement of remote field eddy current techniques and ultrasonic techniques for in-service inspection of double-walled SG tubes.

\section{Advanced Simulation for the Next Generation Advanced Recycling Reactor}

The simulation plan described in Section 7 includes a significant campaign to develop advanced reactor simulation tools for the modeling of reactor physics, heat transfer and flow dynamics, structural mechanics, and safety. Improved modeling techniques reduce the uncertainty of computed reactor performance and will have a direct benefit for cost reduction by allowing a relaxation of conservative design margins. Realization of improved precision limits in a licensing environment will require a corresponding validation activity, as described below.

To fully realize the benefit of advanced simulation, an integrated advanced recycling reactor design tool will also be developed concurrently with the modeling improvements. The current reactor design process involves sub-optimizations in a variety of technical areas (e.g., core design, thermal analysis, safety). However, an integrated tool can provide a comprehensive design optimization and streamline the design process. This allows a more detailed and timely evaluation of design changes for cost reduction.

The first step required in the transformation of the GNEP research process for reactor development is a characterization and quantification of all sources of uncertainty in the design process, and their subsequent analysis. This process will serve as the basis for defining development needs and priorities.

The R\&D program to support fast reactor transmutation includes fast reactor technology experiments to validate basic data and simulation models. One ongoing important area is the generation and validation of precise nuclear data, as described in the following subsection. Similar efforts need to be initiated for the validation of thermal, structural, and safety modeling. These new activities will be guided by the simulation plan developed for the 2008 decision. 


\section{Transmutation Physics}

The focus of this activity is to reduce nuclear data uncertainty for actinide transmutation and provide validated physics design codes. Where needed, efforts will be taken to measure new data (cross sections, temperature coefficients, etc.), evaluate data for new cross section sets (for Evaluated Nuclear Data File inclusion), develop data for material assay, and validate codes for physics analysis for the design of fast reactor transmutation systems. The general approach is to make use of existing capabilities and resources in a multi-lab team and to collaborate with international and university participants.

Differential Fission and Capture Cross Section Measurements - Guidance based on evaluation comparisons and sensitivity analyses are used to identify high-priority measurements. New measurements over the appropriate energy range are performed using existing facilities and detectors. New measurements also require production of pure target material of the isotope of interest, production of the thin target, placement in the detector, taking the data and reducing the data.

Produce Nuclear Data Evaluations and Covariance Data - High-quality evaluated nuclear data files and corresponding uncertainty quantification data are needed to reduce and understand the uncertainty in nuclear design calculations. Code capabilities will be enhanced to minimize design uncertainty and provide new user features. For example, once new covariance data is available, a covariance matrix propagation capability within physics design codes will be added in order to quantitatively assess and prioritize the nuclear data needs.

Neutron-induced reactions on major and minor actinides play a significant role in the neutronics and material damages of a nuclear reactor. For fast reactor applications, evaluated nuclear data, fission product production, delayed neutron, and covariance files are needed for all $\mathrm{Pu}, \mathrm{U}, \mathrm{Am}, \mathrm{Cm}$, and $\mathrm{Np}$ isotopes. Also, evaluations on neutron interactions with structural materials (e.g., Fe, Ni) are crucial to correctly predicting the behavior of the reactor.

Measure Gas Production and Displacement Damage - Hydrogen and helium are produced when energetic neutrons interact with materials, and these gases can lead to significant changes in materials properties, such as embrittlement and swelling. For the development of advanced reactors, new structural materials are proposed, and the amount of gas production must be known to assess the properties of these materials under radiation damage. The objective of this research is to measure gas-production (hydrogen and helium) cross sections on materials of importance to new reactor designs. A second objective is to validate nuclear reaction model codes to improve the predictive capabilities of these codes to calculate gas production.

Neutron damage to structural materials occurs in reactors during irradiation resulting in atomic displacements. Data are needed for materials of interest, over a range of neutron energies $(10 \mathrm{keV}$ to 10 $\mathrm{MeV}$ ), to reduce the uncertainties in calculated material damage estimates, to guide the materials program in their choices of advanced materials for fast reactors, and to provide data for the validation of the nuclear design codes.

Sensitivity/Uncertainty Studies - As described in the previous section, fast reactor computational tools will be validated against a select set of evaluated benchmarks. Rigorous computational procedures are available to propagate uncertainties and estimate the accuracy of the performance predictions. This approach can also be used to adjust performance predictions based on the totality of the existing experiment database, with a significant reduction in the total uncertainty. In addition, these analysis techniques are also useful to identify and prioritize needs for additional physics data and to evaluate the efficacy of proposed of measurements. 


\section{International Collaboration for the Next Generation Advanced Recycling Reactor}

The existing U.S. infrastructure is insufficient to meet GNEP objectives for technology development, and there is a strong need to leverage our capabilities with foreign capabilities. Several potential GNEP partners (France, Japan, and Russia) currently have operating fast test reactors. These countries also have limited fast reactor technology infrastructure facilities. However, like the U.S. capability, many of the foreign partners are poorly equipped and have a similar erosion of their capabilities. This opens the possibility for very fruitful collaborations for sharing new capabilities and/or refurbishment of existing facilities; specific discussions are ongoing for many specific activities (e.g., BOR-60, MASURCA, TREAT, etc.).

Agreements have already been negotiated for fast reactor fuels testing in both PHENIX and JOYO; however, these agreements take a long time (years) to negotiate and implement. The basic sodium technology R\&D testing will be required for fast reactor development programs, and many of the design innovations can be tested in a new generation of reactors planned by the U.S., China, Russia, and France. Coordination of these international efforts can help both reduce technical risk and leverage resources; for example, the French have proposed a focused effort on oxide fuels to exchange R\&D results with a U.S. effort on metal fuels. Although international collaborations are a useful pathway for expanded R\&D on fast reactor technology, they are not a substitute for the fast transmutation reactor. U.S. leadership for the GNEP international fuel cycle vision requires domestic fast reactors, which are a critical component of the GNEP fuel cycle nation technology.

Another potential channel for international joint R\&D is the SFR work in the Generation-IV International Forum. The key research areas in the SFR system research plan ${ }^{a}$ include actinide management, innovative design features for cost reduction, safety assurance, reduction in environmental burden, and resistance to nuclear proliferation; thus, the goals are very consistent with the GNEP approach. Specific research items are currently being negotiated for joint projects on SFR Design and Safety, Advanced Fuels, and Component Design and BOP. Sharing U.S. results in advanced recycling reactor R\&D in the GenerationIV context may allow access to significant international work being conducted abroad (e.g., recent technology testing in the PHENIX and JOYO fast test reactors)

\section{Research Facilities for the Next Generation Advanced Recycling Reactor}

A variety of facilities are needed for the development and demonstration of the next generation advanced recycling reactor. This includes the sustained operation of general nuclear testing facilities and complementary SFR technology specific facilities. The precise facility requirements may depend greatly on the level of successful international collaboration. Some key facilities in the previous U.S. fast reactor development program that could be restarted include the following examples.

The Transient Reactor Test Facility (TREAT) is an air-cooled test facility designed to evaluate reactor fuels and structural materials under conditions simulating various contingencies in nuclear reactors. TREAT was designed to study fuel meltdowns, metal-water reactions, interactions between overheated fuel and coolant, and the transient behavior of fuels for high-temperature systems. In 1994, the facility was placed in a standby status. The instrumentation and control systems have been maintained in an operable status, and the fuel is still in excellent condition. Some of the data acquisition systems lack adequate vendor support and will need to be modernized. A nuclear facility restart process would need to be completed before the reactor operation can be resumed.

The Annular Core Research Reactor (ACRR) also offers a capability to address certain transient testing needs in support of transmutation development. Specifically, the ACRR may prove to be well suited for

\footnotetext{
a The Generation-IV “Draft R\&D Program Plan for the Sodium Fast Reactor (SFR)” revision September 2006
} 
initial investigations of transient overpower phenomena in transmutation fuel, using shorter fuel rods or perhaps rodlets from ATR testing. ACRR has a harder spectrum, shorter pulse, larger diameter $(20 \mathrm{~cm})$ but shorter length $(50 \mathrm{~cm})$ exposure cavity. ACRR has programmed transient capabilities to simulate a range or power histories and accident scenarios, and has similar total fluence and energy deposition capabilities. Thus, these types of tests are considered complementary to those that could be performed in TREAT but could be performed sooner. ACRR is in routine operation and preliminary tests are being considered for near-term evaluation transmutation fuel performance.

The Zero Power Physics Reactor (ZPPR) was the U.S. facility for testing the physics properties of advanced fast-spectrum reactors. Testing is done by assembling and operating a reactor that closely resembles the particular design that is under consideration. The facility has a very large inventory of these materials that could be assembled in various combinations to construct any fast reactor configuration. For future configurations of the advanced recycling reactor or commercial fast reactors, critical experiments may be necessary in the ZPPR or other similar facility; the importance and need for such experiments will need to be clarified early in the transmutation reactor safety and licensing activity. There is currently no budget for ZPPR restart in the ABR cost estimates.

One critical need is for fast spectrum fuel irradiations. Once the ABR prototype is operational, it would be the primary vehicle for transmutation fuel testing. However, early fuel testing would be highly desirable. Foreign facilities are one option, and agreements have already been negotiated for limited fast reactor fuels testing in both PHENIX and JOYO; however, these agreements take a long time (years) to negotiate and implement. Another option is modify existing domestic facilities as proposed for the LANSCE Materials Test Station or ATR Gas Test Loop.

The proposed Materials Test Station (MTS) may provide a near-term option to perform fuel and materials irradiation in a fast spectrum (prior to Prototype ABR startup). The MTS could be available to start irradiations starting in FY 2011 at a fast spectrum flux level of $1.3 \mathrm{E} 15 \mathrm{n} / \mathrm{cm}^{2} \mathrm{~s}$. MTS would be located in an existing experimental hall at the LANSCE facility, making use of existing infrastructure. Researchers will independently be able control the flux level and irradiation temperature. Closed loops will allow irradiations of fuel and materials in a liquid metal coolant environment.

The Advanced Test Reactor Gas Test Loop (ATR GTL) is being designed to provide fast spectrum controlled irradiation of fuels and materials. The GTL could be operational by 2010 and feature a minimum unperturbed fast flux of $1.0 \mathrm{E} 15 \mathrm{n} / \mathrm{cm}^{2}$ s over a test volume of $2.54 \mathrm{~cm}$ (diameter) by $15 \mathrm{~cm}$ (length). As with other large test rigs within the ATR, the GTL will possess a state-of-the-art instrumentation and control system that will deliver precise flux and temperature conditions to targets within a controlled gaseous environment. A purpose-built booster fuel system will amplify and focus the ATR's driver fuel flux on the test train while configurable absorber filters will allow precise control over the fast: thermal flux ratio, He/dpa rate, and target heating rate. Off-midplane capsules provide additional irradiation test space at slightly lower flux levels. Cost estimates for MTS and/or ATR GTL are contained in the Fuels section and not ABR cost estimates.

\subsection{Enabling Technology Needs}

\subsubsection{Safeguards and Security}

The safeguards features that are typical of reactor sites are focused on the tracking and accounting of fuel assemblies. These features include:

- Fresh fuel assembly input gate monitors

- Reactor head seals and surveillance

- Reactor reload monitors and surveillance 
- Fresh and spent fuel storage monitors

- Spent fuel discharge monitors.

For example, at the MONJU fast reactor in Japan, two detectors are used to monitor the refueling machine, and one detector monitors fuel transfers between storage and the refueling machine. There are IAEA seals on the fresh fuel storage vault and an IAEA seal on the fresh fuel storage room access portal. These types of features meet or exceed the IAEA timeliness detection goal which is detection of diversion of significant quantities within:

- 1 month for unirradiated direct-use materials,

- Ex: HEU fresh fuel elements, separated Pu, MOX

- 3 months for irradiated direct-use materials

- Ex: All spent fuel ; LEU LWR fuel, MOX, HEU research reactor fuel

- 12 months for indirect-use materials

- Ex: NU and LEU UF6, NU CANDU fresh fuel, LEU fresh fuel

Where significant quantities are defined as:

- $\mathrm{Pu} 8 \mathrm{~kg}$ Total element - except Pu with $>80 \% \mathrm{Pu}-238$ content which is not under safeguards

- U-233

$8 \mathrm{~kg} \quad$ Total U-233 isotope

- $\mathrm{U}(\mathrm{U}-235<20 \%) \quad 75 \mathrm{~kg} \quad \mathrm{U}-235$ contained in uranium (indirect use material)

- $\mathrm{U}(\mathrm{U}-235 \geq 20 \%) \quad 25 \mathrm{~kg} \quad \mathrm{U}-235$ contained in uranium (direct use material)

The fast reactor transmutation demonstration will provide an opportunity to test improvements in safeguards capabilities. Besides the assembly unit tracking that is the current state of the art, techniques can be developed to predict with great accuracy the nuclear material content of each fuel assembly coming in and out of the reactor, enhancing the accuracy of the nuclear materials control system. This spent fuel characterization would also be useful for subsequent processing in the transmutation fuel recycle demonstration (possibly reducing the measurements requirements), as well as giving early feedback on the transmutation performance.

The transmutation demonstration will also guide the development of advanced technologies for remote inspection and maintenance. The long-term operation of advanced recycling reactors in environments with low technical infrastructure will demand a level of autonomous inspection and maintenance operations that is not available today.

For security purposes, the fast transmutation reactor PPS, which prevents theft and sabotage, will be designed to defend against a design basis threat and addressing both insiders and outsider threats. The physical protection measures will monitor and enable authorized access and activities and detect, delay and respond to prevent unauthorized access, activities, or events. A global perspective will be taken to enable international acceptance and broad implementation.

The PPS will satisfy the relevant DOE and NRC regulatory requirements derived from their statutory authority and jurisdiction. In addition, the PPS will be designed to meet IAEA requirements in the amended Convention on the Physical Protection of Nuclear Materials and to be consistent with the IAEA guidelines for The Physical Protection of Nuclear Materials and Facilities (INFCIRC/225/current version). Furthermore, the reactor PPS will be integrated with the material control and accountability 
(MC\&A) systems to increase the effectiveness of each system, especially against the potential insider adversary and to further reduce costs.

The technical approach will be to design-in physical protection throughout all phases of the transmutation reactor project to improve effectiveness and to reduce intrusiveness and costs. The physical protection program will be based on the Design and Evaluation Process Outline system engineering methodology. In addition, GEN-IV Proliferation Resistance and Physical Protection (PR\&PP) assessment methodologies will be incorporated, as appropriate, to evaluate system performance. Gap analyses will be conducted to identify and define security technology research and development needs and will be coordinated with the NNSA R\&D program.

As a result of new policy requirements or technology gaps, new security R\&D needs may be identified. For example, new policy requirements may be necessary to institutionalize multinational facilities that support joint ownership and operations while protecting materials, information, and technologies. Security R\&D may be needed to facilitate large system integrated physical protection modeling and analysis, to accommodate unprecedented secure transportation systems and to enable the cost-effective implementation of strengthened capabilities. These needs and costs will be addressed by the activities in Section 6.0 (Modeling and Simulation).

\subsubsection{Safety and Licensing of the Advanced Burner Reactor}

$\underline{\text { Safety Considerations }}$

Evaluation of the safety of a reactor concept involves consideration of the following categories of events based on their likelihood of occurrence:

- Anticipated Operational Occurrences (AOO)

- Design Basis Accidents (DBA)

- Severe Accidents/Beyond Design Basis Accidents (BDA)

- Emergency Planning Events involving potential offsite releases beyond specified limits.

The AOOs and DBAs are events that are designed to be accommodated by the plant without radiological releases. This implies that the transient response of the reactor to possible perturbations will be controlled/limited before any potential core damage by inherent feedback mechanisms (i.e., passive safety) and/or effective implementation of engineered systems (e.g., control rod scram).

The transient response is determined to a large extent by its kinetic parameters (neutron lifetime and $\beta_{\text {eff }}$ ) and feedback coefficients. The kinetic parameters are determined by the fissile components of the fuel which are based on mission and criticality considerations, while the magnitude and sign of the feedback coefficients can be influenced by choices made during the reactor design (e.g., fuel form, fuel and coolant volume fractions, etc.). These feedback coefficients, coupled with the spectrum of potential transient initiators (e.g., reactivity insertion accidents), the magnitude and sign of temperature/power changes, available control rod worth serve to define the safety response of the system.

The feedback coefficients of primary interest are:

- Coolant density-coolant void

- Doppler effect

- Fuel axial expansion

- Core radial expansion

- Control rod driveline expansion 
In most acceptable SFR designs, the expansion coefficients are negative, while the void coefficient is positive. The progression and consequences of transients are determined by these coefficients, such as the sign and magnitude of temperature changes. The major Beyond Design Basis Accidents (BDBAs) that are generally considered are:

- Loss of main heat sink without scram

- Uncontrolled withdrawal of a control rod resulting in an a transient overpower condition

- Loss of flow without scram (also known as unprotected loss of flow).

A significant variable that also affects the safety characteristics of an SFR is the fuel form selected (e.g., oxide, metal, nitride, etc.). The physical/thermal properties of the fuel are important in accident progression and in the ability to achieve a passively safe design. Several earlier studies have determined that, in general, metal fuel is better in this regard, but additional work and considerations will be involved in the selection of the preferred fuel form for the advanced recycling reactor. Fuel swelling, possible fuelclad mechanical and chemical interactions and compatibility with the sodium coolant in case of fuel clad failures due to defects or during the progression of an accident are also important considerations.

Both the design and development of the safety case for the advanced recycling reactor will rely on a combination of modeling/simulations and experiments. Sodium-cooled fast reactors have been designed and operated throughout the world over the past 50 years (e.g., FFTF, EBR-II, JOYO, PHENIX, BN-600, etc.). Most, however, were "one-of-a-kind", and several were designed as test reactors. The designs were based on relatively old computational methods and data and under different safety regimes and public climate than at present. The "burner" role and anticipated large-scale commercial deployment of advanced recycling reactors under the GNEP program breaks new ground and presents particular challenges. In the past, the model and data uncertainties were accommodated by increasing safety margins; however, utilizing such an approach for the advanced recycling reactor would likely impose significant penalties in the final cost of the system. Therefore, in addition to the use of currently available design tools (which will likely be the basis for the design and safety analysis for the prototype ABR), it is envisioned that a new generation of advanced computational tools would be developed under the Modeling and Simulation element of the GNEP program. Validation and verification (V\&V) of these advanced tools, as well as the current methodologies for design and safety analyses, will be performed under the advanced recycling reactor element. The prototype ABR will include a significant testing-uponstart-up sequence that will provide $\mathrm{V} \& \mathrm{~V}$ for the design and advanced computational tools that will be used for the commercial advanced recycling reactor fleet. Combined with separate effects testing, the prototype start-up testing will be used to provide the verification and validation of the computational tools for the licensing process.

\section{Advanced Recycling Reactor Design Certification and Licensing}

Decisions regarding the licensing authority for the prototype Advanced Burner Reactor have yet to be finalized; however, the NRC will have licensing authority for eventual commercial advanced recycling reactors. The NRC currently licenses commercial nuclear power reactors under Parts 50 and 52 of Title 10 of the Code of Federal Regulations (10 CFR Part 50 and 10 CFR Part 52). While the NRC has over 30 years experience (NRC was established as a result of the Energy Reorganization Act of 1974) with licensing and regulating nuclear power plants plus additional experience through its predecessor organization, the Atomic Energy Commission, this experience has been focused on light-water-cooled reactors (LWRs) and may have limited applicability to new reactor types such as the advanced recycling reactor. There are design and operational issues associated with the advanced recycling reactor that are distinctly different from current LWR issues. The current set of regulations do not necessarily address safety concerns that may be posed by new designs, and the current set may contain specific requirements that do not pertain to new designs. There is also an issue associated with the limited 
background/knowledge at best, and comfort level of NRC staff with sodium-cooled fast reactor technology. Although the NRC has never licensed a sodium fast reactor, it should be recognized that there is a prior history of addressing the safety of sodium-cooled fast reactors, including the Fast Flux Test Facility (by the NRC ACRS), the proposed commercial Clinch River Breeder Reactor, and the PRISM reactor under the Advanced Liquid Metal Reactor program. Several SFR issues were identified and discussed in the course of these reviews that can serve as a basis for the licensing of the advanced recycling reactor.

The U.S. Nuclear Regulatory Commission has embarked on a program of re-examining the regulatory framework for all future power reactors that they might license. Particular attention is given to the varied design features of future reactors and the roles of defense in depth, safety margins, and adequate protection. An important underpinning of the new emerging framework is the role that probabilistic risk assessment (PRA) plays in the gauging of safety for the review of the various new concepts and designs. It is widely recognized that PRA has resulted in a great safety benefit to the operation of the current fleet of reactors and that it can also play a very useful role in the design phase of a nuclear system. Safety Goals for nuclear reactors that relate to the health risks of the public from reactor operation were approved by the Commission in 1986.

The NRC staff, at the Commission's direction, has developed a proposed plan to develop an integrated risk-informed and performance-based revision to 10 CFR Part 50 that would cover power reactor applications, including non-LWR reactor designs. The staff proposes to achieve the Commission's direction to make a risk-informed and performance-based revision to 10 CFR Part 50 by creating a completely new risk-informed and performance-based alternative to Part 50 (to be codified at Part 53; an Advance Notice of Proposed Rulemaking for Part 53 was released on May 4, 2006) that is applicable to all reactor technologies. The development of this new Part 53 will integrate safety, security, and preparedness. This approach will ensure that the reactor regulations, staff processes and programs, are built on a unified safety concept and are properly integrated so that they complement one another. An important objective of this proposed new regulatory structure is to allow for different reactor technologies in a manner that will, in the long term, promote efficiency, stability, and predictability in the licensing of the power plants resulting from these new reactor technologies.

Two major tasks are envisioned by the NRC staff for the creation of 10 CFR Part 53: (1) development of the technical basis for rulemaking and (2) rule development in terms of the needed regulations and associated guidance. Current activities associated with the development of the technical basis are described in SECY-05-0006 [2]. Rule development has to await the establishment of the technical basis. The NRC staff's approach to establishing the technical basis involves development of a TechnologyNeutral Framework (TNF). The TNF is meant precisely to address the innovative features of new and different reactors like the advanced recycling reactor. The framework is a hierarchal structure that combines deterministic and probabilistic criteria for developing technology-neutral requirements, and as such it addresses the difficult technical and policy issues that arise with the development and implementation of this new licensing structure. The TNF could be used to develop technology neutral regulations to be used in conjunction with a technology specific regulatory guide or could serve as an aid for developing technology specific regulations for new technologies individually.

The objective of the technology-neutral framework is to provide the necessary guidance and criteria for a risk-informed regulatory structure for licensing new reactors. To meet this objective, the guidance and criteria need to address the following:

- Safety, security, and emergency preparedness expectations

- Defense-in-depth treatment of uncertainties

- Safety fundamentals 
- Design objectives

- PRA technical acceptability

- A process for the identification of requirements

The framework also addresses $R \& D$ and the use of prototype testing as part of the licensing process. The current version of the framework encourages applicants to propose the research and development necessary to support the licensing of their designs. Such research and development may consist of separate effects and/or integral system tests and may be conducted in full scale or partial scale facilities. In general, the requirements should specify that $R \& D$ would be expected on key plant safety features when these features are new (not previously licensed) or are to be used under conditions that go beyond previous use or experience. The scope of R\&D should be sufficient to verify performance of the features over the range of conditions for which they are expected to function, including the effects of fuel burnup and plant aging.

For the advanced recycling reactor, development of technology specific requirements likely will require that the General Design Criteria (10CFR Part 50 Appendix A), and the contents of the Standard Review Plan be modified for applicability to a sodium-cooled fast reactor. The recommended approach would be for the advanced recycling reactor team to develop draft proposed versions of these documents, and submit them to NRC for review and consideration for possible adoption. Should the DOE be authorized to provide safety authority for the prototype ABR, such development is still recommended; the technical approaches recommended in DOE regulations (10CFR830 and associated Orders) are closely aligned with the NRC's regulations for reactors.

The radioactive source term that would be released under the severe accident conditions is used in evaluating the suitability of potential reactor sites and establishing Emergency Planning Zones (EPZs) around them. The radioactive source term defined for LWRs, published in Title 10 Code of Federal Regulations (CFR) Part 100, specify the percent of the core fission product inventory to use for the analysis. For the ABR, the presence of heavy loadings of transuranics, and their potential release and transport in accident scenarios will need to be established. A risk-informed approach, with a PRA, can be used for performing the accident evaluation because potential hazards can be identified and accident scenarios can be evaluated realistically.

The design of the prototype advanced recycling reactor should take the need to address these questions into consideration. Optimally, the prototype advanced recycling reactor will be sufficiently flexible to demonstrate innovative technologies and design features that could be applied to follow-on commercial plants (e.g., incorporate design features that provide the capability to conduct testing for the purposes of collecting information needed to properly assess the safety performance of actinide burners, including test data to support safety code validation). It should be noted that this additional flexibility may increase the programmatic risk related to licensing under the NRC. Because it is expected that the advanced recycling reactor will be licensed as a passively safe reactor, the prototype ABR should be designed to demonstrate the inherent passive safety characteristics of sodium-cooled fast reactors and simple operation. The prototype ABR reactor could be used to test these passive safety features, including measurement of key feedbacks and autonomous control, as well as demonstrating the commercial feasibility and viability of the advanced recycling reactor design to various utilities throughout the country.

\section{Potential Safety Questions and Issues}

- Uncertainty on licensing requirements because much of the trade study efforts, and initial down select of a preferred design option for the advanced recycling reactor will likely precede requirements/criteria that are promulgated by NRC. 
- Experimental databases and analytical tools available to address safety and licensing issues for sodium cooled reactor are not as comprehensive and mature as for LWRs. This implies a significant $\mathrm{V} \& \mathrm{~V}$ effort and experimental program at the advanced recycling reactor plant, along with separate effects tests to generate data satisfactory for NRC.

- As with previous fast sodium reactor designs, the existence of a positive sodium void reactivity coefficient must be addressed thoroughly. The demonstration that compensating negative feedback processes will prevent energetic neutronic excursions must be convincing and valid over all conceivable operating conditions, with substantial quantified margins. Thorough inpile fuel testing will be required on which to base such analyses, and early development of advanced, high-resolution multi-physics simulation codes will be critical for them.

- A key strategy will be to develop an early, independent, and credible capability to simulate accidents that pose very large challenges to the active and passive safety features of the plant but that do not result in a large release. In other words, it will be more important for the DOE and NRC to be able to map out the region of accident space that does not result in large releases than to be able to accurately calculate the large releases for the more severe accidents. Doing that mapping will allow the establishment of probabilities for the large releases, as well as the sizes of the consequences for each major accident type, to support decisions on which are important, which are not, and why.

- Another difficult challenge will be quantification of the source term to be used for emergency planning analysis under 10CFR 100. The existing NRC formulations for sitting source terms are not applicable to the advanced recycling reactor; thus, a compelling argument for a new source term that is in some sense equivalent to them must be developed. PRA will be important for any such analysis, and consequently this requirement establishes a very early deliverable for the advanced recycling reactor program's risk analysis activities.

- A similar situation applies to the advanced recycling reactor containment, in that the traditional LWR design basis accident does not apply. The advanced recycling reactors licensing documents must define a new containment design basis that convinces the NRC staff that the advanced recycling reactor containment would offer the equivalent (or greater) level of defense in depth as a conventional LWR containment. Again, this analysis would depend on highly credible and early PRA results. 


\subsection{Cost Estimates and Milestones}

Table 7. Cost Estimates for Transmutation Technologies

\begin{tabular}{|c|c|c|c|c|c|c|}
\hline \multicolumn{7}{|c|}{ Cost Estimates (\$M 2006 dollars) } \\
\hline Activity & FY07 & FY08 & FY09 & FY10 & FY11 & FY12 \\
\hline \multicolumn{7}{|c|}{$\begin{array}{l}\text { Advanced Burner Reactor Prototype Design, Construction, Commissioning Cost Estimates. } \\
\text { Costs are highly dependent on reactor plant power level (to be evaluated as part of design } \\
\text { studies, } 1 \text { GWt plant assumed for this profile). The current funding profile supports } \\
\text { reactor startup in } 2023 \text { and is based upon sodium-cooled fast reactor technology. }\end{array}$} \\
\hline $\begin{array}{l}\text { Industry Engagement and Conceptual } \\
\text { Design* }\end{array}$ & 7.5 & 20 & 47 & & & \\
\hline ABR Prototype Preliminary Design & & & 1 & 50 & 73 & 39 \\
\hline ABR Prototype Detailed Design & & & & & & 6 \\
\hline Startup Fuel Fabrication Facility & 0.5 & 5 & 8 & 12 & 14 & 20 \\
\hline Subtotal & 8 & 25 & 56 & 62 & 87 & 67 \\
\hline \multicolumn{7}{|c|}{ Advanced Burner Reactor - Prototype Technology Development Cost Estimate } \\
\hline $\begin{array}{l}\text { Safety Analysis and Licensing (includes } \\
\text { NRC support through FY08) }\end{array}$ & 1 & 4 & 10 & 12 & 10 & 9 \\
\hline Technology Development* & 2.1 & 16 & 14 & 14 & 14 & 39 \\
\hline $\begin{array}{l}\text { Code and Analysis Tool Verification and } \\
\text { Validation* }\end{array}$ & 0.4 & 3 & 4 & 23 & 23 & 23 \\
\hline $\begin{array}{l}\text { Startup Fuel Research, Development, } \\
\text { Qualification, and Testing* }\end{array}$ & 0 & 1 & 4 & 7 & 7 & 7 \\
\hline Reactor Component Testing Facilities & 0 & 3 & 22 & 63 & 64 & 85 \\
\hline Subtotal & 3.5 & 27 & 54 & 119 & 118 & 163 \\
\hline
\end{tabular}




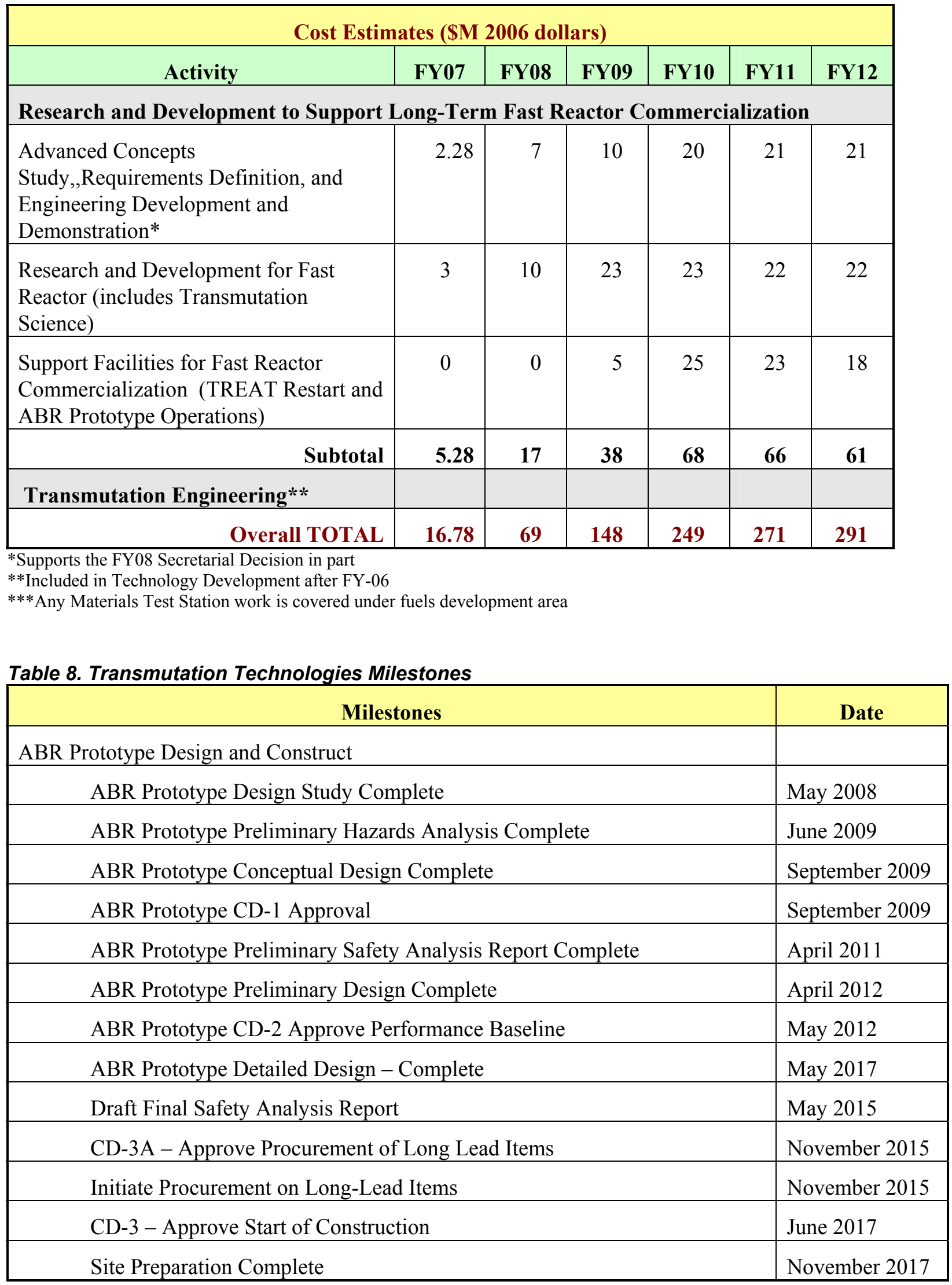




\begin{tabular}{|c|c|}
\hline Milestones & Date \\
\hline Start ABR Prototype Facilities Construction & November 2017 \\
\hline Reactor and BOP Systems Installation - Start & June 2019 \\
\hline Complete Procurement of Long-Lead Items & June 2020 \\
\hline Initiate Reactor Startup Preparations & June 2020 \\
\hline Startup Fuel Fabrication ( 2 cores) Complete & August 2020 \\
\hline Reactor and BOP Systems Installation - Complete & June 2021 \\
\hline Fill Primary and Secondary Systems with Sodium & July 2022 \\
\hline ABR Prototype Reactor Facilities Construction complete & July 2022 \\
\hline Load First Core & December 2022 \\
\hline Pre-Critical Checks with First Core & May 2023 \\
\hline Perform Operational Readiness Review for Startup and Safety Testing & June 2023 \\
\hline Reactor Startup & July 2023 \\
\hline ABR Prototype Startup Testing Complete & June 2024 \\
\hline \multicolumn{2}{|l|}{ Startup Fuel Development and Fabrication } \\
\hline Startup Fuel Fabrication Options Study with Down Selection & January 2009 \\
\hline Conceptual Design of Startup Fuel Fab Line & January 2010 \\
\hline Preliminary Design of Startup Fuel Fab Line & July 2011 \\
\hline Final Design of Startup Fuel Fab Line & July 2013 \\
\hline Startup Fuel Fab Line Construction Complete & August 2017 \\
\hline Start Startup Fuel Fabrication Line ready for fuel fabrication & August 2017 \\
\hline \multicolumn{2}{|l|}{ ABR Prototype Technology Development } \\
\hline Initiate Sodium Component Technology Development Evaluation & September 2008 \\
\hline ABR Prototype Key Features Test Complete & October 2013 \\
\hline ABR Prototype Detailed Design - Phase II Complete & November 2015 \\
\hline \multicolumn{2}{|l|}{ Code and Analysis Tool Verification and Validation } \\
\hline Identification of Prototype Design Tools by Industrial Team & September 2008 \\
\hline Plan for Prototype Design Tools V\&V & September 2009 \\
\hline Code Validation Facilities Plan & October 2009 \\
\hline
\end{tabular}




\begin{tabular}{|c|c|}
\hline Milestones & Date \\
\hline Restart/Construct Required Validation Facilities & September 2010 \\
\hline Initiate Validation Studies for Advanced Methods & September 2011 \\
\hline \multicolumn{2}{|l|}{ Reactor Component Testing Facilities } \\
\hline Sodium Component Testing Infrastructure Evaluation & May 2008 \\
\hline Sodium Component Testing Infrastructure Design/Build Start & October 2008 \\
\hline Sodium Component Testing Infrastructure complete - Phase I & October 2012 \\
\hline Reactor Component Testing Initiation & October 2012 \\
\hline \multicolumn{2}{|l|}{ Advanced Concepts Engineering Study, Development, and Demonstration } \\
\hline Develop Reference Commercial ABR Concept & September 2007 \\
\hline Complete Study on Alternate Configurations Options & September 2008 \\
\hline Complete Initial Design Options Evaluation & September 2009 \\
\hline Scaled Demonstration of Supercritical CO2 Brayton Cycle & September 2010 \\
\hline Prepare material specimens of advanced materials for JOYO irradiation & September 2010 \\
\hline Complete Validation of first improved structural material & September 2012 \\
\hline \multicolumn{2}{|l|}{ Transmutation Research and Development } \\
\hline First Mechanical Tests Performed on 155 dpa HT-9 Duct (ACO3) & September 2007 \\
\hline Retrieve FFTF irradiated (up to $200 \mathrm{dpa}$ ) mechanical test specimens & January 2008 \\
\hline Identify key experiments using representativity techniques & 2008 \\
\hline Retrieve Specimens from MATRIX irradiation in Phoenix Reactor & November 2008 \\
\hline Produce new evaluations and covariance for priority isotopes & 2009 \\
\hline $\begin{array}{l}\text { Complete tensile and fracture toughness testing of FFTF irradiated } \\
\text { materials }\end{array}$ & January 2010 \\
\hline Issue new Revision of Materials Handbook with FFTF Material Data & September 2010 \\
\hline Perform uncertainty analysis with new covariance data & 2010 \\
\hline $\begin{array}{l}\text { Complete mechanical testing of specimens from MATRIX Irradiation } \\
\text { (advanced materials irradiated up to } 70 \mathrm{dpa} \text { ) }\end{array}$ & November 2011 \\
\hline Validate Multiscale Materials Performance Modeling Code & February 2012 \\
\hline
\end{tabular}




\begin{tabular}{|c|c|}
\hline \multicolumn{1}{|c|}{ Milestones } & Date \\
\hline TREAT Restart and Testing & \\
\hline Implementation Plan for TREAT Restart & April 2009 \\
\hline TREAT Startup (if required) & October 2013 \\
\hline & \\
\hline
\end{tabular}

*Note: Phase II of the Detailed Design Activities shows a completion date that would appear to be rather long in duration compared with the completion date of Phase I of the detailed design. The Phase II completion date results from a schedule restraint where the ABR prototype technology development activities are tied to the Phase II detailed design activities.

The schedule assumes that the sodium component technology development work is conducted in parallel with the transmutation reactor design activities which adds a certain amount of project level risk. It also assumes that a conventional fuel type will be used for the initial startup core and subsequent startup fuel reloads until the transmutation fuel is available for use. 


\subsection{Transmutation Fuels and Separations Technologies}

The mission for the Transmutation Fuels and Separations element of the GNEP program is to develop and demonstrate the technologies required to recycle spent nuclear fuel into fast reactors for transmutation. This mission includes fabrication of processed spent fuel from LWR for use in FR and recycling the resulting FR spent fuel, after irradiation, back into the FR, thus demonstrating closure of the nuclear fuel cycle.

Fast Reactors with their accompanying fuel cycle technologies have the mission of destroying, via the fission and transmutation process, the transuranic elements that contribute to the long term heat load, dose, and proliferation risk of spent nuclear fuel. Fast reactor fuel cycle technologies include:

- the fabrication of fuel matrices that can contain significant amounts of transuranic elements that, when inserted in the fast reactor for a sufficient period, achieve destruction of a significant fraction of the transuranic elements; and

- $\quad$ recycling technologies for these fuels that achieve very low fractional losses during the separations and re-fabrication steps, and produce robust waste forms from secondary streams with minimum impact on the performance of a geologic repository.

The objective of the GNEP technology program is to complete the technology development and demonstration at an adequate-scale (engineering-scale) such that decisions can be taken for subsequent commercialization without having to resolve additional extensive scale-up issues.

The major technology categories targeted by the Transmutation Fuels and Separations element of the GNEP program are as follows:

- Transmutation fuels development and performance testing

- Reprocessing of spent transmutation fuels for recycle

- Waste forms resulting from transmutation fuel recycling operations

- Safeguards of the recycling plants.

The Advanced Fuel Cycle Facility (AFCF) is proposed by GNEP to provide advanced, state-of-the-art research facilities to perform the research, technology development and engineering scale demonstration to meet the GNEP objectives.

\subsection{Performance Objectives}

Performance objectives that measure the success of the GNEP Technology and Demonstration Program for transmutation fuels and separations have been established for each of the major technology categories. These performance objectives will guide the Technology Development and Demonstration Program priorities and provide the criteria for determining successful demonstration.

\section{Transmutation Fuels Performance Objectives}

The transmutation fuel performance objectives are as follows:

- Demonstrate pin quantity scaled remote fabrication of one transuranic fuel form, suitable for irradiation testing.

- Develop AFCF capability of fabricating up to 10 ABR lead test assemblies per year (based on $20 \mathrm{~kg}$ TRU per assembly).

- Qualify transuranic fuels for ABR testing following ABR startup. 


\section{Reprocessing of Spent Transmutation Fuel Performance Objectives}

The performance objectives of the AFCF for recycling irradiated transmutation fuel are as follows:

- Develop AFCF capability of processing approximately 1 metric ton of fast reactor transmutation spent fuel per year.

- Establish acceptable impurity levels for feedstocks and products.

\section{Waste Form Development for Performance Objectives}

The performance objectives of the AFCF for waste forms are as follows:

- Provide a suitable waste form for immobilization of cesium and strontium

- Demonstrate enhanced performance of advanced ceramic waste forms for fission products

\section{Safeguards for the Recycling Demonstration}

- Establish MC\&A instrumentation and techniques that meet the IAEA significant quantity tracking objectives

- Provide a test-bed for the testing and demonstration of MC\&A tools.

\section{Modeling and Simulation Performance Objectives}

The performance objective for modeling and simulation are as follows:

- Provide the necessary fuels performance data needed to validate and verify the modeling and simulation tools.

Consistent with the GNEP objectives, the primary objective of the Transmutation Fuels and Separations element of the program is to prepare a set of baseline technologies for commercialization within the next two decades. These technologies will be used in the earlier commercial recycling and fabrication plants, if supported by the national and international nuclear energy and fuel cycle strategies. Thus, it is expected that the activities associated with the early deployment objective will be the major focus of the technology development plan to establish the U.S. leadership as quickly as possible.

To support this early deployment objective for the demonstration of a qualified transuranic nuclear fuel, some initial selections as to fuel types must be made since this decision may drive other technology choices and determine the development in recycling and reactor design. This choice is critical in that it is known that 10 to 15 years of development and qualification activities will be required to obtain a fully licensed fuel for operation in a reactor system. The GNEP transuranic fuel development program has chosen to target two potential fuel systems for accelerated development and demonstration, a metal-based fuel system and an oxide-based fuel system. Targeting these two fuel systems is pragmatic, based on multiple successful fast reactor programs conducted in the U.S. and abroad.

Oxide based fuel is currently operated in sodium cooled fast reactor systems in Japan, France, and Russia. In the U.S., oxide fuel was used successfully as the startup fuel in the Fast Flux Test Facility (FFTF). Traditional MOX fuels have been successfully tested to an excess of $220 \mathrm{MWd} / \mathrm{kgM}(\sim 24 \%)$ burnups in fast spectrums in cold worked stainless steel cladding. Challenges to using an oxide based transuranic fuel lie in the difficulties associated with fabrication of the fuel in a remote environment and demonstrating that the oxide fuel matrix containing significant quantities of minor actinides is stable in the reactor environment.

Metal composition fuel has also been operated in sodium cooled reactor systems and provides safety and performance improvements over other fuel types and systems including oxide. The binary alloy ( $\mathrm{U}, \mathrm{Zr})$ and the ternary $(\mathrm{U}, \mathrm{Pu}, \mathrm{Zr})$ metal composition fuels were successfully demonstrated in the Experimental 
Breeder Reactor-I (EBR-I) and the Experimental Breeder Reactor II (EBR-II) programs in the U.S. In the EBR-II program, metal composition fuels were qualified to $100 \mathrm{MWd} / \mathrm{kgM}$ burnups in austenitic stainless steel claddings and have been successfully demonstrated up to $220 \mathrm{MWd} / \mathrm{kgM}$ burnup in ferritic steel claddings such as HT-9. The fabrication route to metal composition transuranic bearing fuel is well understood since this technology was originally developed towards the end of the EBR-II and Integral Fast Reactor (IFR) programs. The challenge to utilization of metal composition fuel for transmutation lies in demonstration of controlling the Americium volatility during fabrication. Metal and oxide fuels provide the highest probability of success for the GNEP program.

In addition to an early deployment objective, the secondary objective of the GNEP program is to continue long-term research (as started under the AFCI program) in technology areas that require longer-term development with potentially large payoff. Maintaining a long-term R\&D element is important because of the following considerations:

- If the commercial deployment is delayed for any reason, the research may lead to the availability of more effective technologies prior to commercialization

- If the currently targeted technologies for early deployment fail to meet the technical and economic requirements during the development and demonstration phase, the development of an alternative technology may be accelerated to meet the objective without extensive delay

- Finally, the R\&D element of GNEP can advance the state of the art and provide more efficient technologies for the subsequent generation commercial plants to retain the U.S. leadership.

In the next section, a brief description of the current state of knowledge and needs in each technology area is presented.

\subsection{Status of Transmutation Fuels and Separations Technologies}

In general, the technologies required to demonstrate transmutation fuels and separations are at the early stages of the feasibility research. However, the maturity level is different depending on the technology type and the various components of the process technology.

\subsubsection{Transmutation Fuels and Separations Technology Current Knowledge}

The relevant technologies of interest require additional development to achieve readiness for potential commercialization. However, the nature and effort of the additional work required is different for the various technology areas. The current status of the major technology areas is discussed in the following subsections.

\subsubsection{Transmutation Fuel Technology Status}

The GNEP objective is to demonstrate fuels that can be fabricated and satisfy the transmutation performance requirements using group TRU. While the current thinking is mostly concentrated in homogenous core design for fast burner reactors (requiring fertile fuels where uranium is blended with TRU), transmutation targets (TRU included in an inert matrix without uranium) also are a possibility. The knowledge to date with all the fuel types of interest is primarily confined to uranium-bearing fuels. For some of the fuel types (e.g. mixed oxide fuels), considerable experience also exists with fuel containing mixed plutonium/uranium oxides. Currently, there is no minor actinide (MA) -bearing transmutation fuel type qualified for utilization in fast reactors. For all fuel types of potential interest for minor actinide transmutation, the development is still in its early stages of feasibility studies. Based on development to date the most promising fuel types for early deployment are the metal and oxide composition fuels. Since significant unknowns still exist in both fuel systems, development of both fuel systems will be pursued in the near term. Once more information is obtained in initial testing fuel selection will take place. 


\section{Oxide Fuels}

There is considerable domestic FFTF and International (French, Japan, Russia) experience for mixed oxide fuels $\left[(\mathrm{U}, \mathrm{Pu}) \mathrm{O}_{\mathrm{x}}\right]$. The status of the research for MA-bearing oxide fuels is still in its early stages. Some pellets and rodlets containing $\mathrm{Pu}, \mathrm{Am}$ and $\mathrm{Np}$ have been irradiated in the SuperFact experiment in Phenix (France). Oxide TRU fuel compositions are also being prepared for irradiation in JOYO (Japan). The compositions, linear heating rates and burnup levels in these tests are not prototypic. Additional parametric tests are also required for optimizing the fuel design for transmutation.

The feasibility research conducted to date indicates that there are no showstoppers. The limited experience to date indicates that these fuels can be fabricated and a robust fuel pellet can be obtained and irradiated to reasonable burnup levels. The effect of small amounts of $\mathrm{Cm}$ addition to the fuel is not known at this point. Furthermore, no fabrication experience exists with prototypic materials obtained from actual separation processes and using prototypic fabrication processes amenable for remote operations. Also within the general chemical form, the different mechanical forms of the oxide fuels (e.g. homogeneous pellets fabricated by powder processing versus sphere-pac fuel fabricated by gelation processes) are at different maturity levels. Some mechanical forms may be targeted for initial demonstrations while others may be continued under long-term R\&D for potential future payoff.

\section{Metal Fuels}

There is considerable domestic experience for the metal composition U/Pu/Zr from EBR-II reactor related activities. The HEU-Zr version of metal fuel was qualified and used in EBR-II. The Pu containing version of the metal fuel was never licensed but most of the qualification testing was completed under the IFR program. The status of the research for MA-bearing metal fuels also is at the early stages. Metal fuels can be cast at laboratory scale without extensive loss of MA. A conceptual design for large-scale fabrication has been developed but not yet tested. The limited range of compositions $(\mathrm{Pu}, \mathrm{Np}$, and $\mathrm{Am}$. $\mathrm{Zr}$ with and without $\mathrm{U}$ ) investigated to date show good metallurgical properties with no low-melting eutectics. Burnups up to $10 \%$ do not show any unexpected behavior in the fuel. Higher burnup tests are ongoing. The effect of small amounts of $\mathrm{Cm}$ addition to the fuel is not known at this point. Furthermore, no fabrication experience exists with prototypic materials obtained from separation processes and using prototypic processes amenable for remote operations. Innovative fabrication processes can be continued under the long-term research while an initial low-risk process may be developed for early demonstration.

\section{Nitride Fuels}

Domestic research on MA bearing nitride fuels ( $\mathrm{Pu}, \mathrm{Np}$, Am with and without $\mathrm{U}$ ) show that achieving high densities ( $>85 \%$ theoretical density) without excessive loss of Am and $\mathrm{Np}$ is difficult. Partly because of the low-density of the pellets and also, possibly, because of very high-sensitivity of MA nitride compounds to exposure to small amounts of oxygen, maintaining the mechanical integrity of the pellets is proving to be difficult. Pellet fragmentation is observed in low burnup tests (up to 10\%) possibly due to the low density fabrication. The fuel design requires further optimization. While it is too early to give up on nitride fuel development for transmutation, nitride fuels offer higher risk than oxide and metal fuels and would not be the candidate form for the initial phases of an accelerated program. Furthermore, nitride fuel requires $\mathrm{N}-15$ enrichment and N-15 recycling for economical purposes. Because of their promise for high heavy metal loading coupled with high thermal conductivity, it is proposed that feasibility research (laboratory-scale) should continue for deployment in the long-term (20-25 years). Nitride fuels also may be of interest in the future because this fuel type is the primary candidate for lead-alloy cooled breeder reactors considered under the GEN IV program and this technology may be the candidate for the later generation transmutation reactors. Advanced fabrication process research such as combustion and microwave sintering, primarily targeting the nitride fuels so far, may also prove quite beneficial to other fuel forms. The adoption of a non-homogeneous fuel system (e.g., $\mathrm{Pu} / \mathrm{Np}$-nitride fuel or $\mathrm{Am} / \mathrm{Cm}$ oxide 
targets) may solve key technical fabrication issues such as Am-volatility during high temperature processes.

\section{Dispersion Fuels}

The experience with dispersion fuels (mostly carbides) is very limited and MA additions to dispersion fuels have not been tried yet. The fabrication process for such fuels is inherently more difficult. Because of the possibility of achieving high-burnup with such fuels, it is recommended that the feasibility research should continue but such fuels would not be ready for deployment for at least another 20-25 years.

Dispersion fuels also are quite suitable for high-temperature reactor applications and are being considered for gas-cooled fast reactors under the GEN IV program. If such reactors are deployed in the future to meet the GEN IV sustainability requirement, they may also prove to be good candidates for transmutation. Fuel system selection, design optimization, and fabrication process selection must be an early focus of dispersion fuel R\&D.

\subsubsection{Transmutation Spent Fuel Reprocessing Technology Status}

In broad categories, aqueous processing and pyroprocessing are being considered for the demonstration of the fast reactor fuel reprocessing. The choice of the reprocessing type depends on multiple factors: (a) fast reactor transmutation fuel type, (b) process efficiency requirements in terms of decontamination factors and separation factors, (c) throughput requirements and its implications on the commercial deployment cost, (d) spent fuel cooling time, (e) waste form requirements for disposition, (f) technological risk for each separations step leading to TRU product, etc. Neither aqueous processing nor pyro-processing for group TRU extraction from fast reactor spent fuel has been tested at an adequately large scale to assess their viability for commercialization.

\section{Pyroprocessing}

Pyrochemical processes recover actinide materials for recycle by electrochemical or selective oxidation and reduction processes using molten salts and liquid metals as the process solvent. Pyrochemical processes have been under development since the 1950s because of advantages in processing short-cooled fast reactor fuels. Pyrochemical process development and demonstration was an integral part of the U.S. fast reactor program (e.g. EBR I and EBR II). The largest scale application of this technology is the treatment of sodium-bonded spent nuclear fuel in the Fuel Conditioning Facility (FCF) currently conducted at the Idaho National Laboratory (INL). The fuel treatment process is designed to condition spent EBR-II fuel by separating uranium from the transuranic and fission product elements. The uranium product is stored for future use while the transuranic and fission product elements are encapsulated in durable, leach resistant waste forms.

Initially, the goal of the EBR-II/FCF program was to develop an advanced closed fuel cycle for a metal fueled fast breeder reactor. Plutonium was to be co-recovered with the other transuranic elements $(\mathrm{Np}$, $\mathrm{Am}$, and $\mathrm{Cm}$ ), a small fraction of the rare earth fission products, and uranium, and used to fabricate fresh fast reactor fuel. However, when EBR-II was shutdown in 1994, the FCF technology was redirected to treatment of EBR-II fuel for disposal. EBR-II fuel contains elemental sodium within the fuel elements as a thermal bond. Because sodium is a reactive metal, this fuel cannot be directly disposed in the repository. The FCF pyroprocessing equipment has been updated over the years following 1994 to improve performance and efficiency of the process.

\section{Aqueous Processing}

The aqueous process status is discussed under Section 3.2 for LWR Fuel Separations. Some fast reactor fuel types, specifically sodium-bonded metal fuel, is not readily amenable to aqueous processing due to the need for nearly complete removal of sodium from the fuel material prior to contact with water. This is 
problematic in the case of metal fuel, because the bond sodium becomes dispersed throughout the fuel matrix during irradiation. Other complications also arise when considering the aqueous processing of fast reactor fuels. Compared to LWR fuels, transmutation fuels from fast reactors will have a different elemental composition than LWR fuels, in particular, the amounts of certain actinides and fission products. To process these fuels with the UREX +1 a process, flowsheet adjustments will be necessary to achieve the separation criteria. These changes are primarily feed adjustments (possibly dilution) to the dissolved fuel, and/or changes in the flow ratios of solvents and aqueous feed/reagents. Both of these process adjustments may be necessary to ensure that metal concentrations in the solvents do not exceed solubility limits, and cause third phase formation, or other process upsets. The equipment used for aqueous processing of transmutation fuels would be identical to that for LWR fuel. Thus, the readers are referred to Section 3.2 for the technology status.

While spent oxide fuel recycle from fast reactors is not commercially performed at this time, the reprocessing of fast oxide fuel was demonstrated in the 1980's under the Consolidated Fuel Recycle Program at Oak Ridge National Laboratory. Several kilograms of spent fuel from the FFTF $(\sim 100,000$ MWD/MTHM) were chopped, dissolved and co-processed using the PUREX process to recover the U/Pu product stream. This program demonstrated the feasibility of aqueous processing of fast oxide (breeder in this case) fuel. Spent fuel discharged from the SuperPhenix reactor in France was also processed in an aqueous system in the reprocessing plant at La Hague. Further development will be needed, however, to adapt the LWR spent fuel processing parameters to a fast spectrum fuel.

\subsubsection{Waste Form Technology Status}

Waste form process development for conditioning EBR II fuels is partially developed at production scale. Cladding hulls along with noble metal fission products are immobilized in a metal high-level waste form, while salt wastes, containing TRU and fission products are immobilized in a ceramic high-level waste form. Demonstration waste forms have been prepared and characterized with actual EBR-II spent fuel, and a data qualification package has been provided to the Yucca Mountain project for review. These same waste forms are well suited for fission product disposal from advanced burner reactor fuel but it will be necessary to modify processing parameters to meet the GNEP objective. To benefit the repository, it will also be necessary to recover cesium and strontium from the spent salt, prior to immobilization in a ceramic waste form. Methods for recovery of cesium and strontium from spent salt need to be developed. Alternatively, it may be more efficient to allow for Cs and Sr to decay prior to final disposal.

\subsubsection{Recycling Plant Safeguards Technology Status}

There are a small number of PUREX reprocessing and MOX fuel fabrication plants operating around the world. Safeguards implementation at PUREX plants is complex and expensive. First, the amounts of plutonium and uranium in the spent fuel cannot be measured accurately until after the spent fuel is sheared and dissolved. Second, because of the intense radiation environment, all activities are carried out remotely, behind biological shielding. This complicates measurements and the applications of containment and surveillance. Third, the chemical operations are not always stable, and process holdups that may accumulate. Fourth, homogenization of solutions may be problematic, and obtaining representative samples for analysis may limit overall measurement performance.

The international target values for the measurement uncertainty of nuclear materials in a reprocessing plant are very stringent, and continue to push the limit of analytical capability. As IAEA detection goals are defined in absolute amounts, as the scale of facilities increases, there comes a point when measurement uncertainties limit the ability of material balance accountancy to detect losses (or diversions) at the detection goal amounts. For spent fuel reprocessing plants, the IAEA relies on a layered approach of complementary measures to meet its overall verification goals. 
Applying safeguards at reprocessing plants is the most difficult challenge the IAEA faces in terms of declared operations. It is equally challenging for the operators of recycle facilities to maintain the performance of their MPC\&A systems, which are the starting point for IAEA safeguards.

The IAEA goals for allowable uncertainty in nuclear materials accounting are strict and not easily met. Even in the state-of-the art reprocessing plants, the IAEA goal of plutonium inventory error cannot be met with measurements alone. Typically, supplemental measures such as continuous process monitoring, access limitations, continuous inspector presence, containment and surveillance measures are required for operations. Obviously, the supplemental measures along with frequent shutdowns required for inventory (at least annual shutdown inventory under IAEA requirement, sometimes weeks in duration) add complications to commercial-scale operations. In general, meeting materials accountancy goals are easier in fuel fabrication plants (MOX plants) than reprocessing plants.

In the U.S., there is no commercial reprocessing or MOX fuel fabrication facilities. The Nuclear Regulatory Commission has not licensed a reprocessing plant since 1977. In the early 1980's NRC published its performance-based requirements but those requirements have not been applied to a reprocessing or fuel fabrication facility. If one uses the requirements proposed for the future Savannah River MOX plant as a guide, it is clear that such requirements would be very stringent for reprocessing plants and would be very difficult to meet using current technologies. It is important to note that, at present, NRC requirements are expressed as a percent of the active inventory, contrary to IAEA goals expressed in terms of absolute values in $\mathrm{kg}$ of plutonium. Thus, for small throughput facilities, NRC requirements could become very difficult to meet.

Like the NRC requirements, the DOE requirements are expressed as percent of the active inventory. However, they are less stringent than the NRC requirements. For commercial-size plants, meeting DOE requirements would be easier than IAEA goals but for small-scale facilities, meeting DOE requirements by materials accounting measurements alone also is challenging.

Appendix A discusses the Technology Readiness Levels for the transmutation fuels and separations technologies.

\subsubsection{Description of Near-Term Needs}

As evidenced in the technology status summary above, the relevant technologies of interest require additional development to achieve readiness for potential commercialization. However, the nature of the additional work required is different for each technology area. Near-term technology specific needs are discussed in the following subsections. Priority is evident in the cost estimates and establishment of early milestones in Section 5.5. Risk mitigation is evident through-out this plan extending from the primary choice of two fuel types (oxide and metal) for early deployment through the pursuit of long term research and development of risk mitigating technologies and the utilization of separations and recycling technologies that are applicable to multiple fuel forms.

\subsubsection{Transmutation Fuel Technology Needs}

The development of MA-bearing transmutation fuels offers a number of challenges that are unique, compared to currently used power reactor fuels and represent the areas where development activities will be concentrated:

- The TRU fuels must be fabricated containing multiple elements (U, Pu, Np, Am, Cm) compared to $\mathrm{U}$ and $\mathrm{Pu}$ used as feedstock in current commercial fuels. In addition there will be a wide range of isotopic mixes that a fuel fabrication plant will need to process due to the wide range of fuel in the light water reactor industry and fast reactor fuel in a fast reactor recycle system. The multi-element fabrication complicates the control of the resulting phase diagrams 
and the stoichiometry (in the case of ceramic fuels). The redistribution of certain transuranics within the fuel matrix during irradiation is not very well understood at this time.

- The varying thermodynamic properties of the transuranic elements require special attention during the fabrication process development (for example, the high vapor pressure of Am requires low temperature or rapid fabrication processes).

- Unlike conventional fuels fabricated using well-controlled feedstocks, the transmutation fuels must be fabricated using the separated products and must accommodate the outcome of the separation process including impurities (high lanthanide carryover in some separation processes and Curium in short cooled spent nuclear fuel).

- Because of the high-radiation fields resulting from spent nuclear fuel, the transmutation fuels must be fabricated remotely in adequately shielded hot-cells. The major challenge with hot-cell operations is associated with equipment maintenance and quality control, which require handson operations in current fuels.

- For efficient transmutation, the fuel is required to achieve high burnup (20 to 30\%) to minimize the number of recycles. This requires lengthy irradiation tests.

- Finally, fuels with high Am content generate helium at a much higher rate than conventional fuels. The fuel design (both the fuel microstructure and the pin design with adequate plenum space) must accommodate the increased helium generation during irradiation.

Because the fundamental mechanisms characterizing the fuel fabrication and performance are not well understood, the fuel development relies heavily on empirical approaches. Thus, extensive testing is required to address the above issues.

The fuel development process may be divided into multiple phases. Phase I is aimed at developing the technical specifications of the fabrication process and resulting fuels. During that phase, small fuel samples are fabricated, characterized and irradiated. If the post-irradiation examination indicates good fuel performance, based on the results of bench-scale studies, the fabrication process and fuel specifications are developed. If the results indicate questionable fuel performance, another fabrication process or fuel configuration is tried. The whole process is fundamentally based on trial-and-error, which is lengthy and expensive. The fabrication may start with stockpile materials that can be blended together to investigate certain targeted phenomenology. However, co-precipitated TRU materials resulting from representative separations processes also must be used to define the process technical specifications and provide validation that the entire fuel fabrication process is adequate. In addition to extensive characterization, this phase also includes considerable out-of-pile testing to identify some of the early problems (e.g. diffusion-couple testing for fuel-clad interactions, ion-beam irradiations, phase-diagram studies, material properties as a function of burnup, etc.). The work required to complete Phase I is quite extensive.

In Phase II, pin-scale fabrication and irradiation takes place. The objective is to complete the fuel and process design leading into the verification and qualification phases. During the fabrication, fuel characteristics are compared to the initial specifications and the irradiation (and PIE) assures that the fuel performance can be predicted based on matching the initial parameters after fabrication. At this point, transient testing of some of the irradiated pins also is used to develop the limits and safety margins of the given design.

Phase III, which is the verification phase, requires larger-scale fabrication (assembly-scale) to assure that the process quality can be maintained at a scale large enough to justify commercial-scale fabrication. The fabricated fuel is characterized to assure that the measurable meet the specification tested in Phase II. If 
assembly-scale irradiation yields the predicted results without failure or without any unexpected behavior, the fuel design and fabrication process is verified.

Completing Phases I through III requires typically 10-15 years for relatively simple fuel forms. For TRU fuels, to achieve the end of the verification phase in 10-15 years requires a highly resource intensive effort. In Phase I multiple alternatives will be pursued in parallel (both fuel types and fabrication process) until a robust set of technical specification is defined at the end of Phase I. An added complication for transmutation fuels is that the fuel must be qualified for a variable range of composition. The relative ratio of the TRU elements in the fuel is not fixed because of the age and burnup of the LWR spent fuel used to generate the feedstock is not fixed. In addition, there are small changes in the TRU composition through each recycle of the fuel into the fast reactor. Finally, the build-up of impurities through multiple recycle results in varying compositions. Obviously, each step of the development process will not be repeated for every conceivable composition. Composition ranges must be investigated and a technical basis must be established to qualify the fuel for a range of compositions as opposed to a very tight composition specification that is common to current commercial fuels. Advanced modeling and simulation will play and important role in developing and qualifying fuels for a variable composition within the range of interest.

The steps described above apply to all fuel types even though the degree of difficulty may vary depending upon the fuel type and fabrication process. The assessments to date indicate that each fuel type has some advantages and disadvantages compared to others. The development schedule and facility requirements are not a major discriminator in the technology choice.

The fuel development strategy summarized above requires a number of facilities and equipment. Unfortunately, current infrastructure to support this effort is incomplete and requires considerable new investments.

\section{Fuel Fabrication and Characterization}

Typically, glove-boxes are used for fabricating fuel samples in Phase I. The existing infrastructure to continue with the ongoing research on MA-bearing fuels on an accelerated schedule (with the exception of $\mathrm{Cm}$ addition) requires additional glove-box resources. The addition of $\mathrm{Cm}$, however, restricts the glove-box fabrication option considerably and requires a small-scale hot cell fabrication capability even in Phase I. Installation of the necessary characterization equipment into a hot-cell environment also is needed when $\mathrm{Cm}$ is introduced into the fuel. Phase II scale fabrication and characterization requires hotcell operations with and without $\mathrm{Cm}$. Existing hot-cells are of adequate size to meet the needs but must be configured with the necessary equipment. Phase III operations require large hot-cells to accommodate assembly-scale fabrication equipment and such hot-cells currently do not exist in the DOE complex.

In summary, the major needs are as follows:

- TRU materials feedstock

- A bench-scale remote fabrication capability in existing hot-cells for fabrication for the next 10 years

- An engineering-scale (assembly-scale) hot cell fabrication capability in $\sim 10$ years.

- Characterization equipment installed in hot-cells.

\section{Fuel Irradiation}

At present, the early irradiations are performed primarily in the Advanced Test Reactor (ATR), which is a water-cooled thermal reactor. A domestic fast spectrum irradiation capability does not exist and requires the use of International facilities. Some limited irradiations are planned in Phenix reactor in France before 
it is shutdown (2008-2009). Possibilities also exist to perform a limited number of small-scale (10-20 cm rodlets) irradiations in Joyo reactor in Japan after 2009-2010. However, the irradiation space is expected to be limited at any given time. If BOR60 in Russia remains operational beyond 2010, it provides another possibility for fast spectrum irradiation on a limited number of fuel samples. Until the availability of a fast test reactor with unlimited access, most of the irradiation will be done in ATR. ATR flux must be filtered for fast spectrum tests and as such requires long irradiation times to develop adequate burnup. Two other limited alternatives would be to construct a fast-flux booster in ATR but such an approach would result also in limited irradiation space with limitations on the fast flux (on the order of $10^{15} \mathrm{n} / \mathrm{cm}^{2}$-s) resulting in long duration irradiations to achieve high burnups. Furthermore, previous experience indicates that a fast flux booster in a thermal reactor cannot completely mimic a fast spectrum and the data requires additional interpretation to account for thermal tail of the spectrum. The High-Flux Isotope Reactor (HFIR) at Oak Ridge also is available for testing small fuel samples with or without thermal flux suppression. An alternative is to develop a spallation neutron source, as proposed by the Material Test Station (MTS) concept at the end of the LANSCE proton accelerator. However, the achievable neutron fluxes in this approach also are limited by the accelerator current to $\sim 10^{15} \mathrm{n} / \mathrm{cm}^{2}$-s. The data from the MTS also requires additional interpretation as the high-energy tail of the spectrum is not typical of a fast reactor spectrum. Both the ATR booster and MTS concepts will provide meaningful data to partially fulfill the needs for the Phase I activities, reducing the needs for irradiation in foreign facilities. However, the availability of the MTS or a fast flux booster in the next 3-4 years is suspect and either approach does not eliminate the need of a fast reactor testing.

For oxide transmutation fuels, the MONJU reactor in Japan also may be used for pin-scale and assemblyscale testing. However, the reactor is not expected to be available for such testing before 2014. It is also not clear that the reactor can be authorized to irradiate specific assemblies of TRU bearing fuel.

Transient phenomenological testing on small samples in Phase I and II of the development can be performed in the Annular Core Research Reactor that is currently operational and has been used in the past for similar testing. However, the restart of TREAT could be required for pin-scale testing under typical design basis accident conditions needed in Phases III and IV.

In summary, the major needs are as follows:

- Readily accessible and quick turn around fast spectrum testing capability at rodlet and pin scale up to high burnups for the next $\sim 10$ years (This may be the single most critical obstacle to implement an accelerated fuel development program).

- TREAT restart in 8 to 10 years. (Note that TREAT restart may be required earlier to support startup fuel qualification)

- A fast test reactor for irradiation of full-length transmutation fuel pins and lead test assemblies (LTAs) in 8 to10 years.

Post Irradiation Examination. Existing hot cells can be used for another decade, but the PIE equipment must be upgraded and some of the older equipment refurbished. Typical examples: micro-probe, thermal property measurement on irradiated samples. Considerable investment is required in the next five years to support the fuel development and qualification objectives.

In summary, the major needs requiring modest investments are as follows:

- Installation of new PIE equipment and refurbishment of some of the old equipment in existing hot cells. 


\subsubsection{Transmutation Fuel Recycling Technology Needs}

\subsubsection{Aqueous Based Processing}

\section{Flowsheet Development for Aqueous Processing of Transmutation Fuel}

Flowsheet modeling and testing of group actinide separation processes with transmutation fuel compositions is needed. It would be expected that process parameters may need to be adjusted to accommodate the chemical differences between light-water reactor fuel and transmutation fuel. While much of the head-end, separations and product conversion steps would be very similar, process chemistry and equipment performance will need to be verified. Metallic transmutation fuel incorporating sodium bonding would present a challenge for aqueous processing, and is not considered for such processing at this time.

Further enhancements and optimization of the chemical flowsheets will be performed to improve economic performance, the inherent proliferation resistance of the process, and the operational envelope. Such concepts will be sought out by the program and criteria will be established for pursuit. Processes that meet performance criteria based on economic competitiveness and proliferation resistance will be explored through performance confirmation tests.

\section{Thermodynamic Data of Actinide Reductants/Complexants to Support Flowsheet Modeling}

Collection of thermodynamic data to incorporate into process and simulation models are needed for separation and product conversion processes. These data will be used to expand the capabilities of existing models or fill in gaps where data currently are not available. The UREX+1a process flowsheet utilizes aqueous-soluble hydroxamic acids to control $\mathrm{Pu}$ and $\mathrm{Np}$ partitioning from that of $\mathrm{U}$ and $\mathrm{Tc}$. As hydroxamic acids have not been widely used on an industrial scale in nuclear fuel processing, there is a need to understand the thermodynamic properties of these materials under process-relevant conditions. The various species formed by complexation of hydroxamic acids with tetravalent and hexavalent actinides ( $\mathrm{U}, \mathrm{Np}$ and $\mathrm{Pu}$ ) must be characterized and the thermodynamic parameters for these complexation reactions over conditions relevant to the UREX+1a processing flowsheet measured. The fundamental chemical knowledge generated will allow for more accurate modeling and simulation of the UREX +1 a flowsheet and will support developing the safety/regulatory basis for the UREX+ processing facilities.

\section{FPEX Process for Cesium/Strontium Separation}

The Fission Product Extraction (FPEX) process simultaneously separates cesium and strontium from spent nuclear fuel (UREX raffinate). Preliminary testing has been performed on this process and indicates that it has potential advantages over the baseline cesium strontium process (CCD-PEG). The cesium/strontium product stream from the CCD-PEG process contains about $120 \mathrm{~g} / \mathrm{l}$ organics, which complicate the solidification process. The FPEX process back-extracts the cesium and strontium in a dilute nitric acid stream, which is much easier to concentrate and solidify. The technical maturity of this process is not sufficient for it to be considered for the baseline UREX+ processes.

\section{Chemistry of Entrained Phase}

Previous work has shown that the primary means for metals of low extractability (e.g. cesium in the PUREX process) to contaminate the organic product stream is by their dissolution in small drops $(\sim 1 \mu \mathrm{m}$ diameter) of entrained aqueous phase. Such small drops, or hazes, can be formed by the dispersive mechanisms of drop breakage and by chemical precipitation. The formation, behavior and mitigation of hazes is most important at the engineering scale but can be investigated in focused small scale tests and by examination of the system chemistry and turbulence characteristics of the process equipment. 


\section{Online Monitoring}

Online monitoring of process parameters and in particular fissile material is needed to enhance safeguards and reduce the dependency on process samples. Sampling introduces bias, requires tankage between unit operations contributing to facility footprint expansion, generates liquid wastes, and generally requires several hours before the analytical results are available to make process decisions.

\section{Non-aqueous Head-end Fuel Treatment for UREX+ (Voloxidation)}

Control of the volatile radioactive fission products carbon, iodine, tritium, xenon and krypton could be greatly simplified by effectively separating them from the fuel before the fuel is introduced into the nitric acid dissolver. The tritium and iodine distribute between the process off-gas and the dissolver solution and are subsequently distributed throughout facility. One method involving high temperature air oxidation (voloxidation) of the principally uranium dioxide spent fuel has been investigated as an approach for causing release of the volatiles and decladding the fuel. The basis for this approach is that conversion of $\mathrm{UO}_{2}$ to $\mathrm{U}_{3} \mathrm{O}_{8}$ with its crystal expansion would affect release of the volatile radionuclides and would cause the fuel to powder. Release of the volatiles prior to the aqueous nitric acid dissolution would simplify the management and control of the volatile radionuclides iodine and tritium, both of which are regulated.

\section{Alternative Lanthanide/TRU Separations via Molecular Design}

Recent advances in molecular agents more efficient for selective component sequestrations have been based on a more fundamental understanding of agent-component molecular interactions. It has been shown that optimum interactions have two features: optimum sizing and optimum group orientations. Taken together, agents' orders of magnitude more effective at sequestration have been identified and their performance documented. Application of this methodology could provide improvements in the lanthanide/TRU separation portion of the UREX+ process.

\subsubsection{Pyrochemical Processing}

\section{Oxide Reduction and UREX+ Product Conversion}

Oxide reduction technology is applicable to conversion of the transuranic oxide or uranium oxide product from UREX + to metal for re-fabrication into fast reactor fuel and the treatment of spent oxide fast reactor fuel. Systematic study of the thermodynamics, electrochemical transport, and reaction kinetics of the conversion process to metallic fuel forms will be necessary to design an optimal system. Further work is also needed in optimizing material selection for long-lasting anodes that support high current density and structural materials. Highly conductive ceramic anodes have been developed that meet the process requirements but additional evaluation is required. Platinum electrodes have been used for process development studies, because they support a high current density but are prone to chemical attack by lithium. For process development studies, $\mathrm{MgO}$ ceramics and stainless steel were used to avoid structural material corrosion. However, for larger-scale implementation this may not be practical. Thus, there is a need for development of corrosion-resistant materials of construction, including but not limited to coatings. This should include testing with fission product loaded salt in hot cells to verify that proposed materials are robust in conditions truly representative of those that will be encountered in the electrolytic reduction process.

\section{TRU Recovery}

It is necessary to develop an efficient and commercially-viable method for transuranic element recovery from transmutation fuels. Liquid cadmium cathode technology has been used to co-deposit $U$ and transuranics from electrorefiner systems, which is critical for recycled fuel fabrication in a fast reactor system. It has been successfully demonstrated at the engineering scale with blanket fuel from EBR-II, which contains low concentrations of rare earth elements. Further electrochemical experimentation of 
alternative TRU recovery methods is needed, however, to develop a thorough understanding of equilibrium and non-equilibrium distribution of rare earth fission products and TRUs between the cathode product and molten salt phases. Once that information is available, the design, fabrication, testing and evaluation of a commercial-scale system will be performed. Optimization studies for product recovery and TRU/lanthanide partitioning will be performed after the initial TRU recovery tests.

\section{Online actinide Monitoring}

The molten salt electrolyte used in electrorefining contains varying amounts of $U$ and transuranic chlorides. The absolute and relative concentrations of these species are important for MC\&A as well as chemical process control. Time-consuming sampling and computer modeling are currently used to monitor actinide concentrations. An online or near-real-time method of monitoring these concentrations, such as square wave voltammetery, would dramatically improve the ability to maintain MC\&A as well as general process control. The ability to produce $\mathrm{U}$ or U/TRU products to the desired specifications may also be improved.

\section{Modeling of Pyroprocessing}

Commercial chemical process simulation software is inadequate for modeling pyroprocessing, due to the unique nature of its unit operations. However, there is a great need for such a tool to optimize process configuration and parameters. The impacts of process changes on product purity, recycle efficiency, and waste characteristics often need to be quickly determined. Development of a comprehensive yet configurable model of pyroprocessing would provide this functionality, guide future research and development activities, and be an invaluable tool in designing an optimized pyrochemical fuel cycle.

\section{Uranium Electrorefining}

In order for pyroprocessing to be cost-effectively scaled up for reasonable production operations, new electrorefiner designs need to be considered. Key features of a next generation electrorefiner should provide efficient product recovery, yield desired decontamination of fission products from the uranium product, and possess a simplified design for more efficient remote handling, operation, and maintenance. The next generation electrorefiner should also be well integrated with the TRU recovery system. One concept for the next generation electrorefiner is the PEER (Planar Electrode Electrorefiner) concept, which has been developed and is currently being tested for the AFCI program. This concept, and perhaps others, needs to be fully evaluated for development for treating transmutation fuel.

\section{Product Processing/Consolidation}

Coated crucibles are currently used in the cathode processor; metal waste furnace, and casting furnace within the pyrochemical fuel cycle. The coatings are designed to prevent adherence between metal ingots and the crucible walls. However, application of these coatings is labor-intensive, and currently the coatings react with uranium to form a uranium oxide dross. To improve processing throughput, reduce costs, and minimize the need for handling secondary waste streams such as dross and spent crucibles, advanced crucible materials need to be developed. Current work on this area is on developing techniques for fabricating large crucibles with surfaces composed of hafnium nitride. Work in this area needs to continue, and other concepts need to be developed and investigated. Alternative methods for product processing or consolidation will also be examined, including continuous casting and containerless techniques. These methods avoid the need for crucibles altogether, may ease material handling requirements in a remote facility, and yield products of the desired purity.

\section{Criticality Safety}

Pyroprocessing with significant amounts of $\mathrm{Np}, \mathrm{Pu}, \mathrm{Am}$, and $\mathrm{Cm}$ will require specific criticality analysis to properly size and control the process. The existing criticality experiment database may not be adequate 
to validate the criticality analysis. Experimental data on the group actinides to support criticality calculations may be needed to reduce the uncertainty in criticality safety analyses.

\subsubsection{Waste Form Technology Needs}

\section{Advanced ceramic Waste Forms for Pyroprocessing}

In the EBR-II Spent Fuel Treatment or conditioning process, fission product-loaded salt from the electrorefiners is blended with zeolite and glass and heated to produce a ceramic waste form. Ideally, the transuranics should be recycled to fuel fabrication, and only fission product (non-transuranic) chlorides would partition into the salt. The $\mathrm{LiCl}-\mathrm{KCl}$ should be returned to the electrorefiner. It may be necessary to develop an advanced process for removing actinide chlorides from the salt, possibly using a chemical reduction-based drawdown or electrolysis process. Other innovative methods of isolating cesium and strontium from the waste salt and encapsulating them for decay storage need to be investigated, e.g. zeolite ion exchange, in order to meet the GNEP criteria for enhanced repository benefits. Another key issue that needs to be addressed is fission product waste loading in the ceramic waste form. Increasing the loading would reduce waste volume; therefore, it is necessary to determine maximum viable waste loading and associated decay heat for the ceramic waste form.

\section{Technetium Waste Forms}

The conversion of Tc-99 to a chemically stable, unreactive zirconium-technetium mixture, using zirconium from the cladding, will be investigated. This would immobilize both Tc-99 from fission product and Zr-93 from the cladding by converting them to a metallic zirconium-technetium alloy. The LWR spent fuel cladding hulls are about $96 \%$ metallic zirconium and could in principle be used directly to make a Zr-Tc alloy suitable for disposition. If, however, the zirconium is purified, (see Next Generation Technology), the hulls could be converted directly to high purity zirconium (free of most fission products and free of actinides). The purified zirconium metal could be melted with electrolytic technetium metal to produce the alloy. Performance tests will be performed with Tc/Zr alloys to identify and resolve issues associated with this waste form.

In the case of transmutation fuel, the cladding material will not be Zircaloy but stainless steel. The same approach can be used for immobilization of technetium extracted by aqueous processing from transmutation fuel. If pyroprocessing is used for treatment of spent transmutation fuel, however, the fission product technetium is collected in the anode basket together with other transition metal fission products and with the stainless steel cladding hulls. The complete contents of the anode basket are intended for melting/alloying to produce a metallic waste form that is known to be very effective in retaining technetium in environmental conditions representative of the Yucca Mountain repository.

\section{Alternative Waste Forms for Cesium/Strontium Product}

Alternative product forms for cesium and strontium (e.g. zeolites, or an Australian technology called Synroc) will be evaluated as alternatives to the mineralized steam reforming product. At this time, there are no waste form criteria for the cesium and strontium product, so there is some risk in focusing on a single waste form meeting the criteria ultimately selected.

\section{Refining LWR Spent Fuel Cladding Hulls for Potential Reuse}

Processing of the metal cladding waste by refining can be used to separate pure zirconium from the contaminants. Obviously ${ }^{93} \mathrm{Zr}$, which is formed by neutron activation, can not be separated. However, Zirconium-93 has a half-life of $1.5 \times 10^{6}$ years and emits very weak beta decay $(60 \mathrm{keV})$ to ${ }^{93 \mathrm{~m}} \mathrm{Nb}$, which subsequently decays to the stable ${ }^{93} \mathrm{Nb}$ by emitting a $30-\mathrm{keV} \mathrm{X}$-ray. Because of the long half-life and the very weak emissions, ${ }^{93} \mathrm{Zr}$ is not a significant radiological hazard. An evaluation will be performed, 
including discussions with interested commercial companies, to determine the level of interest and technical feasibility of refining cladding hulls for re-use.

\subsubsection{Safeguards Needs}

Compared to current International practice of PUREX processing and MOX fuel fabrication, an additional level of proliferation resistance would be added by full-TRU recovery and recycling technologies being developed under GNEP. This approach reduces the proliferation risk by reducing the attractiveness level of the materials that are separated and re-fabricated into fresh fuel, but the proliferation risk is not totally eliminated. Even under this strategy, adequate materials accounting and other safeguards measures will be needed for the recycling plants.

One of GNEP objectives is to develop and demonstrate a new world standard for the safeguards technology and proliferation resistance associated with the spent fuel recycling plants. One could argue that, by separating a TRU mixture as a group instead of plutonium and by limiting the recycling operations to limited number of states around the world, a new world standard would be achieved. On the other hand, the need for accounting for the materials still exists. It can be argued that diversion and theft risk increases with increasing number of plants, even if such plants are only located in Fuel Cycle States. The accuracy of the current MC\&A instrumentation and techniques may be decreased by the proposed flow-sheets compared to PUREX flowsheets with a separate Pu stream. As discussed before, even for PUREX plants, the current MC\&A techniques are not adequate to meet the IAEA goals. The additional measures such as continuous presence of inspectors, lengthy shutdown for inventory, may prove to have adverse effects in large-scale commercial deployment.

In the long-run the required technologies must be developed and consistent with potential NRC requirements, which must evolve in parallel to the GNEP demonstration program. The facilities started and operated under GNEP might not be licensed by NRC. However, the objective of the demonstration is the subsequent commercialization and NRC will be required to license the commercial plants, early NRC involvement in the safeguards technology development to guide the development of the requirements is very important.

The needs for the safeguards technology development program can be listed in three general categories:

- Advanced instrumentation development

- Safeguards by design methodology development

- Advanced control logic development.

\section{Advanced Instrumentation}

Ideally, in order to achieve near-real time monitoring, the measurements method would provide

- An on-line measuring device that determines precise amount of materials without intrusion; or

- A device that samples and measures streams with a higher, automated repetition rate.

As part of the technology development, advanced technologies must be evaluated for precision, sampling rate, reliability, durability, and cost. Specific candidates for analysis may include:

- Online K-edge Densitometry for mixed U/Pu and Pu aqueous solutions

- Online K-edge Densitometry for separated Np or Mixed Actinide solutions

- Non-destructive assay (NDA) of spent fuel to be pyro-processed to determine U, Pu, and MA (minor-actinide) content in the feed material 
- Non-destructive or destructive assay of reduced uranium-plutonium-MA metal ingot from pyro-processing

- Improved NDA techniques for assaying salt and other Actinide-contaminated waste arising from pyro-processing.

As new instruments and sampling methods are developed, there is a need for testing these capabilities. Earlier tests may be conducted in small facilities with representative materials and representative radiation environment. However, the demonstration phase requires an engineering-scale facility where the new instruments can be tested in a realistic environment where the results can be scaled directly to commercial facility applications.

\section{Safeguards by Design Methodology}

The implementation relies on both experimental and theoretical development along with a large-scale experimental demonstration. Laboratory-scale testing and advanced modeling and simulation will be used for the development. The Advanced Fuel Cycle Facility (AFCF) will be the key in actual verification and demonstration of the concept.

\section{Advanced Control System}

The type of precision required to meet IAEA goals using a single measurement technique are very difficult to achieve. In addition to developing advanced instrumentation, the technology development also must involve development of an integrated control system that uses all available instruments through an intelligent data analyzer. The development of the advanced control system relies heavily on plant modeling and simulation and it requires an engineering-scale facility for demonstration and optimization.

\subsection{Transmutation Fuels and Separations Demonstration Program}

As discussed previously, an engineering-scale facility is needed to achieve the demonstration objective for the Transmutation Fuels and Separations technologies. The design and construction activities associated with the demonstration facility [hereafter referred to as Advanced Fuel Cycle Facility (AFCF)] are presented in Section 5.3.1. The technology development activities that will be conducted in parallel to AFCF design to prepare the technologies for demonstration in AFCF are summarized in Section 5.3.2. Finally, the research activities, which are maintained for mitigating some of the technological risks and which may also lead to subsequent fuel cycle optimization and later demonstration in AFCF, are summarized in Section 5.3.2.4. The activities discussed in the following section emphasize primarily the tasks planned for the next 5 years.

\subsubsection{Advanced Fuel Cycle Facility Design}

The advanced fuel cycle facility (AFCF) is a spent nuclear fuel technology development and demonstration facility. AFCF will be the facility where the demonstration of the following recycling related technologies will be performed at an adequate-scale for subsequent commercial deployment: (a) chemical separations of spent transuranic fuel by both aqueous and pyro-chemical methods, (b) fabrication of transmutation fuels, (c) development of safeguards approaches and equipment for recycling facilities, and (d) development of optimized waste forms for high-level nuclear waste (HLNW) generated in the recycling plants.

The specific functions of AFCF in achieving the overall GNEP objectives are discussed in the next section. 


\subsubsection{AFCF Functions}

The over-arching objective of the AFCF is to perform the technology development and demonstration work at a scale sufficient to provide input for subsequent commercialization. It is envisioned that, once a given process is developed and demonstrated in AFCF, it will be ready for incorporating into the design and construction of the commercial-scale facilities with adequate technologic, engineering, economic, safety security and environmental data. Figure 2 summarizes the objectives of the AFCF. The advanced fuel cycle facility is being designed to provide the following specific functions to meet the GNEP objectives:

- Develop the capability to conduct synergistic bench-scale and engineering scale integrated process development and demonstrations of proliferation-resistant spent fuel treatment using actual FR spent nuclear fuel. AFCF will begin its operations with a base-line technology aimed at the first generation of FR spent fuel treatment plant and introduce modification for continued improvements with time. This objective requires the ability to introduce process improvements, either in the form of new flow-sheets or advanced process equipment.

- Develop the capability to conduct bench-scale and engineering-scale fuel fabrication operations to fabricate TRU-bearing transmutation fuels at the rod and subassembly scale. AFCF will be the only facility in the world where the TRU can be fabricated into fresh fuel at assembly scale. This step is essential for qualifying such fuel for subsequent use in Advanced Burner Reactors. Similar to spent fuel treatment technology objectives, AFCF will begin its operations with a base-line technology aimed at the first generation of FR transmutation fuel fabrication and introduce modification for continued improvements with time. This objective requires the ability to introduce process improvements, either in the form of new flow-sheets or advanced process equipment.

- Conduct engineering-scale fuel cycle research operations that can be used as a test-bed for development and proof-testing of advanced safeguards instrumentation. As an integrated facility, AFCF also has the objective of developing and demonstrating the safeguards envelope concepts utilizing correlated control logic with multiple instruments. As part of the "safeguards by design" strategy, demonstration of near real-time accountability for special nuclear materials and improved transparency of operations will give the U.S. the opportunity to establish a "new world standard" for design and operation of future fuel cycle facilities.

- Develop the capability to assess the waste-forms resulting from the fuel cycle scenario of interest. The facility within its mission must support the development and demonstration of environmentally friendly waste forms; even though all the necessary technologies at an engineering-scale may not be included in the facility functions (e.g. vitrification of the fission products if that is chosen as the preferred disposal route).

- Provide an integrated facility that will permit the movement of fuel materials and analytical samples between separations, fuel fabrication and analytical laboratories, to preclude the need for outside shipments and the associated security issues. The development and demonstration of on-demand fuel fabrication concept with tightly integrated chemical separations and fuel fabrication operations has the objective of enhancing the facility safeguards and proliferation resistance.

- Provide facility flexibility to facilitate the development and demonstration of recycling methods for advanced fuel types that can support a number of fuel cycle strategies. These activities would initially be conducted at laboratory or bench scale and then extended to engineering-scale technology demonstration. 
For the long-term, an engineering-scale LWR spent nuclear fuel separations function also is being considered for AFCF to support the design and operations of the Consolidated Fuel Treatment Center (CFTC). This function depends on the strategy used for the design, construction and operations of CFTC. The LWR spent nuclear fuel separations capability will also enable demonstration of the coupling between the UREX+ process module and the fuel fabrication module for on-demand fuel fabrication.

\subsubsection{Facility Description}

The pre-conceptual design for AFCF is completed as part of the Critical Decision (CD-0) package. This section provides a generic description of the facility based on the pre-conceptual design considerations. In order to meet the design objectives of AFCF, the functions listed in Section 5.3.1.1 will be made available through provision of:

- Large hot cells to validate/demonstrate spent fuel treatment (aqueous and pyrochemical processes) and remote fuel fabrication processes on an integrated engineering scale

- Small hot cells and glovebox laboratories to validate bench-scale unit operations and conduct other related development activities

- Adequate space in process cells for practical, realistic evaluation of on-line, near-real time, materials accountancy and control techniques for the enhancement of fuel cycle system proliferation resistance attributes

- State of the art monitoring and control systems to implement and test advanced safety, safeguards and security systems

- Centrally-located analytical chemistry laboratories for quick-turnaround analytical support to fabrication and separations operations.

\subsubsection{Design Related Activities}

The following will be the major activities planned for FY06 through FY12 under the AFCF design element of GNEP.

\section{Project Management}

AFCF project and its interfaces with the technology development activities will be managed under this task. Project management includes cost and schedule performance, document control, quality control, resource allocations, customer interface, etc.

\section{Trade Studies for Design Strategy}

The facility description provided above is based on pre-conceptual design considerations. During conceptual design, four strategic trade studies will be conducted that will define the AFCF design and construction approach.

The first trade study will establish the basis for a single facility with multiple modules. A multi-module facility where separations and fuel fabrication are closely coupled will reduce both the capital and operations costs, enhance proliferation-resistance and safety of commercial plants after demonstration in $\mathrm{AFCF}$, and reduce the time required to demonstrate the technologies.

The second trade study will explore the strategy of a modular construction phased in time. The current plan calls for modular construction phased in time to level the final design and construction cost over multiple years. However, such an approach introduces added difficulty and cost because of the need to operate some modules while later modules are still being constructed. 
A third study will be used to establish the basis for the minimum size required for each module. The size of each module will be based on the required amount of materials to complete the fuel qualification process (a critical item in demonstrating a closed fuel cycle), and demonstration with adequately sized process equipment such that subsequent commercial-scale facility design is enabled.

In the fourth study, the basis for bench-scale research capability with flexible design in engineering-scale modules will be evaluated based on its economics and programmatic drivers. This facility will be designed to test improvements in future fuel cycle technologies, and will serve as the technology test bed for at least 50 years. However, the bench-scale testing could continue to be done at existing facilities also. The trade study must identify the specific functions of the research module to supplement other capabilities within the complex.

\section{Technology Demonstration Mission Support}

AFCF's primary mission is to demonstrate the recycling technologies at an engineering-scale as a precursor to commercial-scale deployment. AFCF's mission includes the flexibility to test progressive improvements in each technology area discussed in earlier sections. The initial operations of the engineering-scale modules will incorporate the most mature technologies, to demonstrate the engineering feasibility of the first generation plants. Subsequently, improvements will be introduced to support the fuel cycle evolution and the next generation plants. Therefore, it is important to

- Allow enough flexibility in the initial design to accommodate more advanced concepts to be tested and demonstrated in the future. Design the capability to use a variety of reprocessing technologies, which would include advanced UREX+ processing, pyro-chemical processing and pyro-metallurgical processing. Necessarily, the main process area must be a modular and flexible, to accommodate the processes noted.

- Implement a prioritized technology development program to support the design.

In order to achieve these objectives, the candidate technology elements must be identified and their implementation schedule must be prioritized based on technology maturity. To minimize the risk in the initial technology demonstration, a technology development program must be implemented where the technology development tasks are prioritized for risk minimization, consistent with the AFCF design, construction and operations schedule.

Therefore, in the early part of the conceptual design, there will be a series of expert-opinion based studies to identify the critical technology elements and to quantify the risk associated with their large-scale testing in AFCF.

\section{Conceptual Design}

This task includes completing the activities in support of Critical Decision 1 (Approve Preliminary Baseline Range) including the requirements definition, conceptual design, acquisition planning, risk assessments, alternative analysis, preliminary hazards analysis, preliminary technology needs assessments, NEPA documentation preparation, preliminary project execution planning, and updated project baselines.

\section{Preliminary Design}

This tasks includes completing the activities in support of Critical Decision 2 (Approve Performance Baseline Range) including design (detailed to support the following) risk analysis, criticality safety analysis, site selection, acquisition plan, technology development, material diversion, potential assessment, safeguards and security implementation plan, final project execution plan, updated project baselines, and independent reviews. 


\section{Final Design}

This task includes completing the activities to support Critical Decision 3 (Start of Construction) including detailed design, specifications for long lead procurements, approved safety safeguards and security documentation, independent reviews, technology innovations evaluations, and updated project baselines.

\subsubsection{Technology Development Activities}

The technology development activities, as summarized below, place emphasis on the next five years. These activities are key to demonstration of transmutation fuels and separations and will be demonstrated in the AFCF. In addition to the specific activities detailed below, there is an overall technology integration function of the Demonstration Program. This function focuses on interfaces with the other elements of the GNEP program (such as the LWR fuel processing, fast reactor transmutation, modeling and simulation, systems analyses, etc.). In addition, interfaces among the various technology elements (fuels, separations, waste forms and safeguards) are established and brought together in the AFCF. This function also provides the interface to the AFCF project management.

\subsubsection{Fuels Technology Development Activities}

The primary objectives of this program element are to:

- Develop and demonstrate a robust fuel system that efficiently destroys transuranics over the range of isotopic mixtures of interest, and

- Supply requirements and design input to support design and construction of the AFCF demonstration facility design efforts.

This plan outlines the first five years of the advanced TRU fuel development program. The program requires focused activities in three key areas: (1) fabrication development and characterization, (2) understanding of the irradiation behavior, and (3) fuel and process design for demonstration phase.

Fuel fabrication development will be focused on developing methods and equipment that minimize loss of minor actinides and that are amenable to large scale fuel remote fuel production. This activity also produces specimens for detailed characterization and irradiation testing.

Irradiation tests are used to develop a basic understanding of fuel behavior under the range of TRU compositions, fission product impurity concentrations, and operating conditions anticipated for burner reactors. Both steady-state and transient performance will be established through experimental testing. Information from the fabrication, characterization, and scoping irradiation activities (steady state and transient) is used to select a fuel(s) and processes that meet GNEP goals.

For technology development, the focus will be on the oxide and metal fuels until a selection is made for the initial demonstration. The tasks necessary to complete the major activities required for development of advanced fuels are outlined below.

\section{Fuel Development Integration}

The objective of this task is to integrate the fuel development activities (including the R\&D activities discussed in Section 5.3.3.1), International collaborations, and the university research supporting the fuel technology element of GNEP. The interface requirements among the fuel development and the other elements of the GNEP program also are coordinated under this task. 


\section{Fuel Design and Selection}

The objective is to provide overall fuel development coordination including determination of viable fuel forms and concepts to be developed. The following four task areas are currently identified.

- Fuel selection and evaluation: A formal process will be implemented for guiding the process of fuel development and selection. A fuel development working group will be organized of specific fuel experts. The working group will coordinate work around the complex and will also serve as the technical review of fuel performance. Any down-selection of fuel concepts will be determined and coordinated by the technical director and the fuel development working group.

- TRU Fuel Characterization. Characterization activities will focus on providing the thermodynamic, transport, and physical property data required to support an understanding of fuel performance. These data include heat capacity, thermal diffusivity/conductivity, interdiffusion coefficients and eutectic temperatures of fuel and cladding couples, phase equilibria as a function of temperature, interdiffusion behavior between fuels and cladding, density, elastic moduli and creep rates, Existing analytical laboratory and characterization facilities in the DOE complex will be used to perform this task. Due to the high specific activity of TRU materials, some upgrades to existing equipment to decrease the potential for exposure to radiation will be required, as well as some new capabilities. In addition to the properties discussed above, the opportunity to explore more fundamental properties of TRU elements may present itself. This work should be pursued as allowed by funding.

- $\quad$ TRU Fuel Handbook. The TRU fuel handbook provides a reviewed and accepted set of properties and behavior that supports analysis of fuel behavior and is essential for eventual licensing. A new version of the transmutation fuel handbook will be issued with emphasis on metal and oxide fuels. The handbook will provide a consistent set of assessed and validated data on fuel properties and irradiation behavior. The handbook will include correlations for properties and behavior data based on out-of-pile characterization, irradiation experiments, and modeling from domestic sources and as the result of international collaborations. This data will be used for analysis of fuel behavior, as a design tool for transmutation fuel experiments, and for design of ABR test fuel elements. The data will provide the foundation for the ABR TRU fuel safety case.

\section{Fuel Sample Feedstock Characterization and Preparation}

The objective is to provide adequate, consistent, prototypic and well-defined TRU feedstock in support of the advanced fuel development effort. Experience has been gained in the AFCI fuel development program on the availability of consistent, quality TRU feedstocks. Feedstock condition affect fabrication processes to a large degree, particularly for ceramic fuels. Impurity and isotopic content of the TRU feedstock also affects irradiation behavior of the fuel. As such, the large quantity handling, identification of sources, transport, characterization, and pre-treatment of these starting materials is an important task. The scale of the task increases as the program moves towards fuel qualification testing.

For these activities, definition of the appropriate characterization techniques and development of standardized measurement methodologies is required. Obvious among these are a complete analysis of impurities and isotopic content. Characterization data will be used to draft detailed feedstock requirements. This activity is conducted in coordination with the separations effort and becomes more closely linked as larger quantities of feedstock are required for qualification testing.

Additional characterization for oxide feedstocks includes particle size and morphology, surface area, oxygen to metal ratio, and moisture content. The development of calcining processes or washing steps to 
reduce moisture or reprocessing chemistry impurities must be evaluated and the resultant product materials fully characterized.

Laboratory-scale processes for the production of metal feedstocks through reduction of oxides must be developed to ensure a consistent supply of materials for fabrication, characterization, and irradiation testing of metallic fuels. Metallic feedstocks require little characterization beyond chemical and isotopic analysis due to the nature of metal fuel fabrication progresses. Existing analytical laboratory and characterization facilities will be used to the extent possible for this work, although some new equipment will be required.

\section{Fuel Fabrication Development}

The fuel fabrication development will be performed starting with fabrication at small-scale and progressively evolving into larger-scale fabrication with increased throughput.

The objective of the small-scale fabrication development is to provide specimens for irradiation testing of TRU fuels and to develop fabrication processes that result in low transuranic loss and are scaleable to large scale production in support of ABRs.

The development of sample/prototype fuel rods must be conducted on two scales; 1) lab scale glove box fabrication with manual operations and 2) in a remote fuel fabrication laboratory (hot-cell). Development of metal and oxide fuels will initially be completed in glovebox laboratories installed within the DOE complex. Due to the requirement to minimize TRU loss while scaling up volume throughput, development of new fabrication processes and equipment will be required. Equipment will be developed and tested on surrogate materials to quantify loss of volatile components prior to installation in a TRU facility. When new equipment is developed, it will be designed to serve as a test bed for remote operations. Final testing of new processing concepts and equipment in glovebox facilities with TRU materials will ensure robust operation prior to installation in remote fabrication laboratory (RFFL).

Fabrication development using human handling of materials in gloveboxes provides the foundation for the genesis of new fuels, but is limited to handling small quantities of neptunium and americium. Transition to a remote fabrication laboratory (hot-cell) allows the fabrication of larger-scale irradiation test pins and the inclusion of prototypic mixtures of actinides, including curium, and provides a test bed for the development of remote fabrication processes and equipment. The fabrication of irradiation test pins in the hotcell laboratory will provide the technical foundation for the development of a full scale full fabrication facility (AFCF) and key elements of technical basis for qualification of a fuel fabrication process.

The objective of the remote fuel fabrication laboratory (RFFL) is to provide a remote TRU fuel fabrication facility adequate to support GNEP requirements for irradiation testing of prototypic TRU fuels and to provide a bridge to development of larger scale processes and equipment in the AFCF. Fabrication of fuel containing all of the transuranic elements found in SNF ( $\mathrm{Am}, \mathrm{Pu}, \mathrm{Np}$, and $\mathrm{Cm}$ ) requires that fabrication be conducted remotely, in a shielded cell, due to the high radiation dose. Feedstock preparation, product quality assurance, and equipment maintenance must all be performed remotely. The RFFL also provides a necessary intermediate step between glovebox-scale fabrication operations and larger-scale remote operations.

Developed capabilities to equip the RFFL will be installed in an existing hot cell to allow for remote fabrication of metal and oxide fuels. Existing analytical laboratories and characterization facilities will be used to support fuel characterization and property measurement, although some new equipment will be required. As part of the general approach to design and equipment selection, the extent to which commercially available equipment can be modified for remote operations will be examined. 
Due to the nature of hot cell operations, the design of equipment and processing operations is critical. Equipment will be designed, tested, and optimized at bench-scale in the RFFL before implementing on a larger engineering-scale at AFCF. A subset of RFFL activity will continually develop improved processes and equipment that are scaleable to AFCF. If advances in equipment result in substantial process efficiencies or reduced TRU loss, equipment in use will be replaced with improved equipment. The RFFL serves both as an interim fuel fabrication facility, pending commissioning of the AFCF and a guide for the AFCF design. The remote fabrication research will produce TRU fuel early in FY 2008 to meet GNEP irradiation testing needs.

\section{TRU Fuel Irradiation Testing and PIE}

The objective of this activity is providing fuel behavior data on advanced fuels containing the full range of TRU isotopic and lanthanide chemistry prototypic of the reference GNEP fuel cycle. Due to the complex behavior of fissile materials under irradiation, fuel development cannot proceed except through a program focused on irradiation of prototypic fuels. Irradiation testing of advanced TRU fuel is required for:

- Determination of fuel performance during normal and anticipated off-normal conditions

- Verification that fuel fabrication processes and specifications result in a robust fuel

- Quantification of fuel safety behavior during severe accident conditions including reactivity transients

- Validation and verification of fuel performance codes.

Detailed post-irradiation examination of irradiated specimens provides the fuel performance data required to proceed with engineering scale demonstration.

Irradiation tests are conducted as a series of experiments beginning with relatively simple drop-in screening experiments and progressing to more complex instrumented pins in semi-prototypic irradiation environments and ending with full lead test demonstrations. Experiments to determine fuel behavior during severe reactor transients are conducted in reactors designed for this purpose such as TREAT and ACRR.

Current tests under the AFCI program are ongoing and include $\mathrm{Pu}, \mathrm{Am}, \mathrm{Np}$ additions to metal and nitride fuel. These tests will be completed within the next two years. Testing of metal and oxide compositions containing lanthanides (simulating carryover from recycle processes) and curium will also be performed in ATR starting in FY08. Additional tests investigating the composition effects, fabrication process variables, etc., will continue in ATR at least for another decade.

Testing in thermal spectrum reactors such as the ATR provides a limited picture of fast reactor fuel performance due to the distribution of fissions in the fuel and the lack of appreciable cladding irradiation damage. In order to begin to address these areas, irradiation tests to high burnup are needed to assure that the fuel forms will perform as specified in the program requirements. The only fast test reactors in the world are located outside of the U.S., necessitating joint irradiation test programs. The first of these, the FUTURIX-FTA test, will begin in the Phenix reactor in France during FY 2007. U.S. fuels that are part of the test were fabricated and shipped to France in FY 2006. A test plan and initial fabrication planning for a joint irradiation in the JOYO reactor in Japan beginning in FY 2008 will be completed as soon as possible. Remote fuel fabrication will be needed to support these tests.

Results from post-irradiation examination will show the effect of irradiation on fuel thermal and mechanical properties, fission gas behavior and release rates, fuel dimensional changes including swelling, anisotropic growth, and inferences as to creep rates as a function of burnup and the resulting 
fuel-clad mechanical interactions, microstructural stability including restructuring, densification, and diffusion of species, fuel-clad chemical interaction and equilibrium and nonequilibrium phase formation.

The scope of post-irradiation examination tasks includes continuation of efforts already underway for irradiation of TRU-bearing metal and nitride fuels irradiated in the AFC-1 series of experiments. PIE planning and specific equipment preparation for Phénix-irradiated samples will begin in FY07. The resulting data will be evaluated for assessing the fuel behavior and its safe operations in the ABR reactor environment. Post-irradiation examination will also include the determination of fission product yield and distribution within the fuel matrix through micro-probe analysis. Post-irradiation testing may also include the use of in-pile and out-of-pile testing to determine the transient fuel behavior. Within the next 5 years, additional capabilities must be added to the PIE facilities. These major capabilities that currently limit the analyses are the shielded microprobe and thermal characterization equipment on irradiated fuels.

\subsubsection{Transmutation Fuel Recycling Technology Development Activities}

\section{Aqueous Based Processing}

FPEX process development - Laboratory testing of the FPEX process chemistry will be performed, including studies to determine the affects of complexants from the UREX process on cesium and strontium separation, as well as solvent stability, solvent cleanup, etc. Recent testing with a monocrown calixarene cesium extranctant indicates that the extractant can be used at higher concentration than the previous extractant, and is more stable to acid hydrolysis. Characterization testing of this new extractant will be performed. Finally, laboratory and pilot plant testing of the process in centrifugal contactors will be performed to validate the process performance.

Thermodynamic data for process modeling - Laboratory data (distribution coefficients, extraction constants, etc.) will be obtained and incorporated into AMUSE or other process models to improve model predictive performance and/or provide new modeling capabilities. This will be done for the various solvent extraction steps that might be performed in processing transmutation fuels including the processes already outlined for the UREX+ flowsheet and alternatives such as FPEX, if such alternatives prove to be viable.

Phase entrainment and mixing - Studies will be performed to understand and improve the decontamination performance of the liquid-liquid extraction processes, particularly with regard to mixing, phase entrainment and phase separation. Measurements of mixing (droplet size, etc) will be made for different contacting equipment under different operation conditions. Methods to avoid or mitigate the effects of haze formation and cross phase carryover will be developed.

Advanced sampling methods - Enhanced sampling methods and new technologies for online monitoring of process parameters and compositions will be developed to improve process operation and MC\&A measurements. Test solutions containing single components and their mixtures will be analyzed and a chemometric model will be developed to quantitatively monitor target analytes. Online monitoring techniques will be tested and selected for the targeted analytes. The data acquisition /archiving /storage capability and real-time computer display of analyzed data will be customized for the UREX application.

Head-end pretreatment - Voloxidation methods to remove volatiles from chopped fuel segments, and enhance fuel dissolution have been under development. To provide a benefit to the UREX +1 a flowsheet, near quantitative removal of volatile constituents are needed. Preliminary testing indicates that this has not been accomplished to date. Additional testing to determine if changing process parameters enables this technology to achieve near quantitative separation of volatiles will be conducted. Depending on the success of the testing, the fate of using voloxidation as an enhanced head-end treatment will be determined. 
Reprocessing development integration - The objective of this task is to integrate the reprocessing development activities (including the R\&D activities discussed in Section 4.3.3.2), International collaborations, and the university research supporting the fast reactor reprocessing technology element of GNEP. The interface requirements among the reprocessing development and the other elements of the GNEP program also are coordinated under this task.

UREX+1a process modeling - Process modeling coupled with laboratory and continuous pilot-scale testing of various UREX +1 a flowsheets will be performed to develop optimized flowsheets for the processing of fast spectrum transmutation fuels. Laboratory and pilot plant data will be used to validate the modeling results. Modified flowsheets will be developed, if necessary, to accommodate the different composition of transmutation fuels and these flowsheets will be tested in appropriate contacting equipment.

\section{Pyrochemical Processing}

Process simulation for pyrochemical processing - Material balance process flowsheets will be developed and evaluated for prototypic advanced burner reactor fuel compositions. These studies will guide process development activities by producing a set of design requirements for each unit operation as well as the integrated system. Moreover, these flowsheets and the data generated from experimental studies will form the basis for detailed process simulation.

Oxide reduction and UREX+ product conversion - A systematic evaluation of thermodynamics, electrochemical transport, and reaction kinetics of the reduction process including assessment of effects of rare earth fission product on the process will be completed to provide a foundation for electrolytic cell design. This set of experimental data will guide development of cell designs ultimately leading to an optimized design for a commercial system. Complete characterization of fission product partitioning into the salt phase needs to be completed, and the effect of these fission products on the anode and cathode processes needs to be well understood. Performance assessment of candidate ceramic anodes and corrosion resistant structural materials will be completed to identify optimum materials and fabrication properties. The methodology for removing residual $\mathrm{LiCl}-\mathrm{Li}_{2} \mathrm{O}$ salt from reduced oxide fuel needs to be developed and tested. All of these activities need to feed into the design and development of an engineering-scale oxide reduction system.

$T R U$ recovery - A series of experimental studies will be conducted to elucidate the electrochemical behavior of the transuranic elements in molten salts containing uranium and fission product elements. These studies will include evaluating inert and consumable anode systems, as well as inert and solvent metal cathode systems. Key parameters to be evaluated include product recovery efficiency and fission product decontamination, especially under conditions in which the salt has a high fission product concentration. Results from the studies will be used to develop an optimized design for a commercially viable TRU electrolysis cell.

Online actinide monitoring - Square wave voltammetry, and perhaps other analytical techniques, will be fully developed to provide detailed mass balance data for material control and accountability. Experimental studies will provide information concerning the sensitivity of the technique, calibration or reference material requirements, and the effect of rare earth fission products on the process.

Uranium electrorefining - Experimental studies will be completed to fully evaluate the electrochemical performance of the PEER. In addition, the design requirements for an on-line product recovery system will be developed and a prototype system will be integrated with PEER and its performance evaluated. EBR-II spent fuel treatment in the Fuel Conditioning Facility will continue in support of pyroprocessing technology development. Specifically, further testing in the Mark-V electrorefiner will be done to characterize the electrorefining process with high TRU and fission product concentrations in the salt. The results of the experimental studies should allow for equipment and process design optimization. 
Product processing / consolidation - Two types of product processing systems will be evaluated, one for consolidation of uranium product and one for consolidation of TRU product. The design requirements for the two systems must be fully determined. Once these requirements are determined, a prototype system can be designed, fabricated, and tested if different from current generation systems. One of the major experimental needs is the development of novel crucible materials. Novel crucible materials and designs will be developed and their performance evaluated in current generation cathode processors under prototypic process conditions. Alternative consolidation systems (e.g., continuous casting) will be identified, assessed against current product requirements and experimental studies conducted with the most promising system to evaluate its performance. A preferred technology will be selected based on the results of the experimental studies.

Process integration - An engineering-scale integrated pyrochemical process demonstration will be completed once a baseline flowsheet has been identified and individual unit operations have been developed. The integrated demonstration will provide insight into resource and operational requirements of the system, which are needed for a commercial-scale demonstration of the technology.

\subsubsection{Waste Form Technology Development Activities}

\section{Ceramic Waste Form Development}

The ceramic waste form has been highly developed for encapsulating waste from the EBR II fuel conditioning process. However, performance would be improved if waste form loading were increased. Experimental studies will be conducted to identify optimum waste form loading and maximum allowable decay heat. The results of these experimental studies will be used in simulations to identify optimum repository loading schemes. Furthermore, it is necessary to complete laboratory scale experiments aimed at selecting operating parameters for the process. Qualification of engineering-scale ceramic waste process equipment is also needed.

\section{Cs/Sr Waste Form for Pyroprocessing}

Experimental studies will be conducted to evaluate potential methods to recover Cs and $\mathrm{Sr}$ from spent pyrochemical salts and encapsulate those materials in a durable waste form. Criteria will be established for product purity and waste form performance as part of the experimental study.

\section{Alternative Tc Waste Forms}

Alternative waste forms and/or improved waste formulations for technetium will be developed. Investigation into destruction of ion exchange resins, reduction of technetium to metal, and alloy formulations with Zircalloy will be developed. Waste form performance characterization will be performed in conjunction with development or understanding of waste form criteria.

\section{Alternative Cs/Sr Waste Forms for UREX+}

Alternative waste forms for the cesium/strontium product stream will be investigated using zeolites and tailored waste forms such as Synroc. Laboratory-scale formulation testing will be performed to determine the waste loading, stability and heat transfer properties of the immobilized cesium strontium product. Stable cesium and strontium isotopes will be used for initial testing.

\section{Waste Form Development Integration}

The objective of this task is to integrate the waste form development activities (including the R\&D activities discussed in Section 4.3.3.3), International collaborations, and the university research supporting the fast waste form technology element of GNEP. The interface requirements among the waste form development and the other elements of the GNEP program also are coordinated under this task. 


\subsubsection{Recycling Plant Safeguards Activities}

MC\&A in a recycling plant present challenges that must be overcome to demonstrate the viability of fast reactor recycling. The primary objectives of the activities conducted in this area are to:

- provide an improved materials accounting method that can be implemented in a commercial facility, and,

- demonstrate a safeguard by design methodology.

This plan outlines the first five years of the safeguards development program. The program requires focused activities in three key areas: (1) instrumentation research, (2) advanced control system, and (3) safeguards by design method.

\section{Instrumentation Research}

Any recycling and fuel fabrication plant designed for safeguards will include the standard measurements. Ideally, in order to achieve near-real time monitoring, the measurements method would provide:

- An online measuring device that determines precise amount of materials without intrusion; or

- A device that samples and measures streams with a higher, automated repetition rate.

Using the sampling approach during continuous processing, for instance, will require higher repetition sampling systems. The number of data points needs to be optimized; otherwise computer databases could become swamped. Also, there is a need for an automated sampling system to avoid an excessive number of plant personnel.

As part of the research, advanced technologies must be evaluated for:

- precision

- sampling rate

- measurement

- reliability

- durability

- cost.

For direct materials accounting, the advanced technologies would rely on active or passive measurement techniques. Passive measurements are possible when a signature radiation exists and it has sufficient penetration and intensity to provide timely data.

If radiation signatures can be stimulated active measurements have added advantages. Using active measurement strategy, near real time in situ measurements are possible. The energy and intensity of interrogation radiation (IR) can be varied to provide the required response intensity and to activate different responses from different nuclides. Because IR can be adjusted and turned on or off, in theory, measurement in environments with large background radiation can be accommodated.

For active, nondestructive, quantitative fissionable material identification, the following techniques are being investigated: ${ }^{\mathrm{a}}$

- Accelerator stimulated x-ray fluorescence (AXRF)

\footnotetext{
${ }^{\text {a }}$ Frank Harmon, Idaho State University, Private communications (August 2005)
} 
- Neutron integral cross section spectroscopy (NICS)

- Delayed neutrons

- Delayed neutron lifetime measurements (DNL)

- Delayed gamma rays.

The proposed approach assumes that research scale (grams to kilograms level) facilities are available for testing the instruments and developing the uncertainty and error bands of such instruments to be developed. The research-scale facilities do not need to mimic the integrated processes for the separations and fuel fabrication facilities. Rather, these facilities need to address separate effects testing some of which can be done with surrogate materials. However, the nuclear materials accounting instruments need to be tested with radioactive materials at sufficient quantities and in relevant environments to properly quantify the instrument characteristics. Therefore, hot-cell environments will be developed for these tests.

\section{Advanced Control System}

In addition to developing advanced instrumentation, the proposed approach also involves development of an integrated control system that uses all available instruments through an intelligent data analyzer. In this approach all the plant data (safety and operational control data in addition to safeguards data) are analyzed via an intelligent analyzer using cross-correlation among various measurements. Because data coming from non-safeguards instrumentation are used, this approach requires the development and implementation of a tamper-proof data authentication method.

The advanced control system involves developing multi-variable correlations among many measurements, including the standard non-nuclear measurements (pressure, temperature, tank level, etc.) and nuclear measurements. Based on a multi-variable and multi-attribute signature analyses a "safeguards envelope" will be developed. When the correlated parameters fall outside the safeguards envelope, the data analyzer will trigger an alarm, which will prompt further assessment of the plant conditions.

The development of the advanced control system relies heavily on plant modeling and simulation and it requires an engineering-scale facility for demonstration.

\section{Safeguards by Design Approach}

This approach relies on the integration of the safeguards methodology into the design such that engineered barriers are built into design against diversion and theft without jeopardizing the plant operations. Because developing such an approach on actual engineering design would be cost prohibitive, the approach heavily relies on virtual engineering based on mechanistic modeling and simulation. In the area of advanced modeling and simulation, a program called SESAME (Simulation Enabled Safeguards Assessment Methodology) has been initiated. SESAME provides a virtual design of a separations and fuel fabrication plant using "Safeguards by Design" methodology. Within the virtual test bed provided by SESAME, the following are included:

- Walk-through models and overall system simulation model

- Detailed mechanistic models for plant components (including all instrumentation)

- Control and monitoring system logic.

The virtual test bed will be used to

- Perform engineering design optimization for the plant (with emphasis on safeguards)

- Develop proliferation signatures based on multi-variant and multi-attribute data analyses method to define the "safeguards envelope" 
- Directly compare various technology options (with emphasis on their safeguards characteristics)

- Address the plant-scaling issues primarily for instrumentation needs and locations

- Test the proliferation-resistance assessment methodologies being developed in other programs and under the systems analysis element of GNEP

- Perform "war-games" on the simulated design to identify areas of vulnerability.

During the 5-years the development of SESAME will continue in coordination with the Simulation Laboratory element of the GNEP program. However, it is important to emphasize that simulation and modeling by itself is not convincing unless a parallel experimental program supports it. The overall approach also relies on the availability of research-scale and engineering-scale test facilities for verification. The modeling and simulation along with verification and benchmark tests will form the basis of the safeguards by design approach.

\subsubsection{R\&D Activities in Support of Technology Development}

In addition to the technology development activities described above that support the initial demonstration of fast reactor recycling, long-term R\&D also will be conducted to ensure the long-term viability of the fast reactor fuel cycle. The following sections describe the R\&D activities that will be conducted in the next 5 years that could mitigate risk in the base metal and oxide fuel technologies or provide economic feasibility to the fuel cycle. The activities below have been identified as areas that will either mitigate risk of program elements or provide alternatives that may provide high probability of longterm success.

\subsubsection{Transmutation Fuel R\&D Activities}

\section{Nitride Fuels}

The objective of the nitride fuel R\&D in the next 5 years is to develop a fabrication process that results in structurally stable fuel pellets. The research will focus on fabrication process development at small scale and structural characterization of the resulting pellets. Fabrication tests will be conducted over a range of fabrication parameters, e.g. powder size, sintering temperature, press pressure, etc...In addition, low temperature or low heat fabrication processes will be developed in coordination with the university research to minimize the loss of Am during fabrication. Research on innovative processes such as microwave processing, combustion synthesis, etc., will continue. Such processes, if proven feasible, may also improve fabrication processes for other fuel types, especially ceramics. Nitride fuels may be a good alternative for the baseline transmutation fuels in the future. If lead-alloy cooled fast reactors are deployed in the long run, nitride fuels may also be used for transmutation in such reactors.

\section{Dispersion Fuels}

High-temperature dispersion fuels research will focus on design concept and laboratory-scale fabrication tests. Some initial irradiation of the fuel samples in ATR also will be conducted to assess the design options. In collaboration with the Gen IV program and universities, the assessment of the candidate matrix materials for dispersion fuels will continue and the results of the FUTURIX-MI tests in the Phenix reactor will be incorporated into the fuel design considerations. Dispersion fuel is a good candidate for transmutation in the long-term because of their potential for achieving higher burnup than conventional homogeneous fuels. Also, if gas-cooled fast reactors are deployed in the future, high-temperature dispersion fuels are the baseline fuel option for such systems and may be used for transmutation. 


\section{Sphere-Pac Fuels}

Sphere-pac fuels (possibly in oxide form) are very amenable to remote fuel fabrication. As compared to powder processing for oxide fuels, which is the baseline fabrication process, sphere-pac fabrication may offer considerable simplification in the fabrication. However, performance data on sphere-pac fuels, especially for transmutation applications is quite limited. Basic R\&D will continue in sphere-pac fuels. Small fuel samples will be fabricated and characterized. Samples also will be irradiated in the ATR reactor. In addition, as part of the trilateral collaboration on joint irradiations in JOYO, sphere-pac fuel samples will be fabricated and characterized for potential irradiation in JOYO reactor in Japan and they will be shipped to Japan.

\section{Transmutation Targets}

The baseline transmutation concept under GNEP relies on homogeneous core with group TRU included in the fuel. An alternative option may be to put non-fertile MA targets into the reactor. A longer-term option may also be partitioning Am (possibly with $\mathrm{Cm}$ ) and transmuting Am targets in a moderated pin. The research will continue in developing potential matrix materials for such targets and small sample fabrication and characterization will be the main focus of the research. ATR irradiation of small samples also will be performed later during the 5-year research.

\section{Fundamental Modeling}

In collaboration with the office of science, fundamental atomistic-scale modeling of the fuels will be developed. In the long-run, such models are expected to replace the empirical models currently used in fuel performance codes. It is anticipated that at least 10 years of dedicated efforts are needed for such models to reach the maturity needed for use in the performance predictions.

\subsubsection{Transmutation Fuel Reprocessing R\&D Activities}

\section{Alternative Pyrochemical Solvent Studies}

The majority of the separations work completed to date has focused on fluoride and chloride molten salts. However, other solvent systems such as iodides, other ionic liquids, or liquid metals may provide process improvements in terms of actinide recovery efficiency or waste minimization. Alternative solvent systems will be identified and experimental studies initiated to determine their performance in spent fuel processing.

\section{Alternative Actinide Recovery Systems}

Centrifugal contactors are extensively used in solvent extraction systems to effect the separation of actinides and fission products. These same devices have been successfully tested in pyrochemical process systems. However, additional development work is required to fully evaluate the viability of these systems in a commercial pyrochemical processing plant. Other options for actinide recovery will also be considered and investigated.

\section{Thermodynamic and Transport Properties}

Experimentally derived thermodynamic and transport properties of transuranic elements and several fission products in molten salt and liquid metal systems are important to process optimization and the development of novel processing systems.

\section{Hybrid Separation Systems}

Aqueous polishing of waste streams from a pyroprocessing plant may lead to improved waste consolidation and provide more opportunities to recycle spent salts. Process modeling will be used to 
identify waste minimization and recycle strategies. Once identified, experimental studies will be conducted to validate process improvements.

\section{Alternative An/Ln Separation Ligands}

Structural information and high-level quantum calculations can be applied to develop a validated molecular model using elements previously shown to provide for an intrinsic lanthanide/actinide separation. Combinatorial computational chemistry using public computational codes then can be used to design candidate separations agents optimized for complexation and separation of Ln versus TRUs. These materials in turn can be prepared and tested with the major radionuclides found in the Ln/TRU part of $\mathrm{UREX}+1 \mathrm{a}$.

\section{UREX+ Process Improvements}

Because of the long term mission of developing fuel cycles for the future in the AFCF, R\&D activities are difficult to define. Continued research into new processes that increase product recovery, process economics and process flexibility will be performed in laboratory-scale and engineering scale tests.

\subsubsection{Waste Form R\&D Activities}

\section{Alternative Waste Forms}

Alternative waste form materials for pyroprocessing will be identified and experimentally evaluated for storage of select fission products or process wastes.

\section{Zirconium Refining and Recycle}

Investigation of the technical feasibility of refining spent hulls for recovery/reuse of zirconium will be investigated. This task will be coordinated with interested industrial partners to determine if the recycle hulls could be used to fabricate transmutation fuels. Small-scale Zircalloy hull refining tests will be performed and the purity of the products determined.

\subsubsection{Safeguards R\&D Activities}

For the next five years, the long-term research on safeguards technology is limited to developing novel concepts for advanced instrumentation and control systems. The research will be primarily conducted by universities under the guidance of program staff. Limited laboratory testing and assessment of novel concepts will be performed. The emphasis will be in assessing the technical feasibility of the novel concepts with direct comparison to technologies selected for initial demonstration in AFCF.

\subsection{Enabling Technology Needs}

A successful demonstration of transmutation fuels and separations technologies in the AFCF will require modeling and simulation support and security for the operation of the facilities.

\subsubsection{Recycling Plant Simulation}

\subsubsection{Recycling Plant Simulation Needs}

As indicated earlier, the fuel development process is lengthy and expensive primarily because it relies heavily on an empirical approach. Once a fuel form is qualified, there is little incentive in making additional improvements since each deviation from the initial qualified process requires a similar series of experiments that are lengthy and expensive. Therefore, the initial qualified fuel is typically the one that meets the specifications but it is possibly not one with the optimal performance. As part of the technology development process, predictive models for both fuel fabrication and fuel performance will be developed, taking advantage of the advanced computational capabilities and recent advances in fundamental material 
science behavior. In the first decade it is anticipated that engineering models based on a semi-empirical approaches can be developed to help the fuel and process design. Such models would primarily aim at estimating trends to minimize the number of trial and error experiments. Such models can also be used to envelope the composition and process parameters of interest while conducting experiments for a limited number of discrete parameters. A longer term need would be to gradually replace the semi-empirical constitutive models with more fundamental multi-scale models, further reducing the number of tests needed to qualify the subsequent generation of transmutation fuels.

\subsubsection{Recycling Plant Simulation Activities}

Fuel performance models provide effective tools for understanding fuel behavior as a function of temperature and burnup. Underlying fundamental models are used as required to understand complex behavior during irradiation. The fuel modeling effort occurs on two major fronts. These are 1) integral fuel performance modeling and 2) fundamental modeling of specific fuel behaviors. The modeling effort thus spans from fundamental quantum mechanical models for the understanding of the phenomenology up to finite-element models used for understanding of fuel irradiation conditions and fuel design. Fundamental modeling and simulation work will be performed under the Simulations Laboratory element of GNEP and will be closely coordinated with the experimental efforts. An integral fuel performance code structure will be developed to support irradiation testing. As detailed fundamental models become available for specific irradiation behaviors, these will be assessed and inserted into the integral fuel performance code for testing and validation against fuel performance data.

\subsubsection{Security}

Activities performed in support of the Transmutation Fuels and Separations program will require adequate security for the operation of facilities and for the protection of nuclear materials. The activities in support of future implementations of security features as they related to fuel fabrication, utilization, and recycling facilities will be conducted in the Safeguards and Security program element. These activities will be coordinated with the Transmutation Fuels and Separations program element through interface arrangements and communication.

\subsection{Cost Estimates and Milestones}

The target date for the operation of the initial module(s) of AFCF is $\sim 2020$.

The major 5-year milestones are provided in Table 9. As shown in this table, a number of tracking milestones are listed during the conceptual design phase until Critical Decision 1 (CD-1) scheduled for June 2009. To support this decision, the CD-1 package will be completed and submitted to DOE by February 2009. In addition to Conceptual Design Report, other important elements of the CD-1 package include (a) cost, schedule, technology risk and impact associated with AFCF facility, (b) cost, schedule and impact of the technology development needs to support the facility design, construction and operations, (c) data that will be used in system level studies for assessing the attributes (such as economics, proliferation-resistance, safety, etc.) of closing the fuel cycles. 
Table 9. Transmutations, Fuels, and Separations Technologies Milestones

\begin{tabular}{|c|c|}
\hline Milestones & Date \\
\hline \multicolumn{2}{|l|}{ AFCF Design Milestones } \\
\hline AFCF $30 \%$ Conceptual Design for Review & January 2007 \\
\hline Complete AFCF system trade studies & April 2008 \\
\hline AFCF 70\% Conceptual Design for Review & September 2008 \\
\hline Complete AFCF alternatives analysis strategy & December 2008 \\
\hline Acquisition strategy submittal for approval & March 2009 \\
\hline Complete CD-1 package for AFCF & June 2009 \\
\hline AFCF $70 \%$ preliminary design review & September 2011 \\
\hline Complete AFCF preliminary design & September 2012 \\
\hline \multicolumn{2}{|l|}{ Transmutation Fuel Development Milestones } \\
\hline Insert FUTURIX-FTA irradiation test in Phenix reactor (external) & May 2007 \\
\hline Begin ATR irradiation of metal transmutation fuels containing Ln & September 2007 \\
\hline Revision of fuels handbook/with available characterization data & September 2007 \\
\hline Begin ATR irradiation of oxide transmutation fuels & April 2008 \\
\hline Metal Fuel RFFL ready for operation & September 2008 \\
\hline Complete JOYO irradiation test plan & September 2008 \\
\hline Complete FUTURIX-FTA PIE plan & September 2008 \\
\hline Complete FUTURIX-FTA irradiations (external) & June 2009 \\
\hline Demonstrate metal fuel fabrication in RFFL's & September 2009 \\
\hline Oxide Fuel RFFL ready for operation & December 2009 \\
\hline Begin PIE of FUTURIX-FTA specimens (dependant upon external schedule) & September 2010 \\
\hline Begin ATR irradiation of remotely fabricated fuels & October 2010 \\
\hline TRU metal-fuel specimens for JOYO fabricated in RFFL & December 2010 \\
\hline Begin ATR irradiation for high temperature limits & October 2011 \\
\hline Domestic fast spectrum rodlet irradiation capability available & December 2011 \\
\hline \multicolumn{2}{|l|}{ Fuels R\&D Milestones } \\
\hline Develop Sphere-pac fuel design concepts & September 2010 \\
\hline Develop Dispersion fuel design concepts & September 2010 \\
\hline $\begin{array}{l}\text { Complete feasibility assessment of innovative fabrication processes (microwave, } \\
\text { combustion) }\end{array}$ & September 2010 \\
\hline Start ATR irradiation of dispersion, sphere-pac fuels, targets & September 2011 \\
\hline Complete Nitride fuel fabrication process baseline design & September 2011 \\
\hline Ship initial fuel for JOYO irradiations & September 2012 \\
\hline Complete ATR irradiations of dispersion and sphere-pac fuels, targets & September 2012 \\
\hline
\end{tabular}




\begin{tabular}{|c|c|}
\hline Milestones & Date \\
\hline \multicolumn{2}{|l|}{ Reprocessing and Waste Form Development Milestones } \\
\hline $\begin{array}{l}\text { Develop baseline pyrochemical flowsheets for treating spent metal and oxide } \\
\text { transmutation fuel }\end{array}$ & July 2009 \\
\hline $\begin{array}{l}\text { Demonstrate feasibility of fast reactor MOX fuel to metal conversion by } \\
\text { electrolytic reduction process }\end{array}$ & August 2009 \\
\hline Demonstrate feasibility of voloxidation of fast reactor MOX fuel & September 2009 \\
\hline Evaluate alternative crucibles for TRU recovery & September 2009 \\
\hline Demonstrate scale-up of ceramic waste process & March 2010 \\
\hline Complete initial testing of Synroc and zeolite waste forms for cesium/strontium & April 2010 \\
\hline Identify safeguards requirements for pyroprocessing facility & May 2010 \\
\hline Identify optimum fission product loading and decay heat for ceramic waste form & May 2010 \\
\hline $\begin{array}{l}\text { Select product processing / consolidation technology for uranium product and } \\
\text { TRU product }\end{array}$ & August 2010 \\
\hline $\begin{array}{l}\text { Identify and evaluate alternative product processing technologies selecting } \\
\text { preferred alternative }\end{array}$ & September 2010 \\
\hline Establish preliminary TRU recovery process parameters & September 2010 \\
\hline Validate performance of novel crucible materials in cathode processor system & September 2010 \\
\hline $\begin{array}{l}\text { Conduct feasibility studies for preferred alternative product processing } \\
\text { technology }\end{array}$ & September 2010 \\
\hline $\begin{array}{l}\text { Complete voloxidation demonstration and make go/no go decision of inclusion } \\
\text { in initial UREX+ testing. }\end{array}$ & April 2011 \\
\hline $\begin{array}{l}\text { Develop process simulation model for treating spent advanced burner reactor } \\
\text { fuel }\end{array}$ & August 2011 \\
\hline Demonstrate electrorefining with salt containing a high TRU concentration & September 2011 \\
\hline Evaluate UREX+1a flowsheet for transmutation fuel & August 2012 \\
\hline Demonstrate on-line product recovery from uranium electrorefiner system & August 2012 \\
\hline Validate TRU recovery efficiency and fission product decontamination & April 2013 \\
\hline Determine feasibility of recycling zirconium from spent hulls & May 2013 \\
\hline Demonstrate on-line actinide monitoring system for MC\&A & June 2013 \\
\hline Demonstrate prototype safeguards system for pyroprocessing plant & July 2013 \\
\hline Complete testing to provide data to baseline integrated process demonstration & July 2013 \\
\hline Validate Cs / Sr recovery process from spent process salts & August 2013 \\
\hline Complete equipment selection for initial demonstration in $\mathrm{AFCF}$ & September 2013 \\
\hline
\end{tabular}




\begin{tabular}{|c|c|}
\hline Milestones & Date \\
\hline \multicolumn{2}{|l|}{ Safeguards Development Milestones } \\
\hline SESAME framework completed & September 2008 \\
\hline $\begin{array}{l}\text { Establish a list of advanced instruments to be further developed for } \\
\text { demonstration }\end{array}$ & June 2008 \\
\hline Define framework for advanced control logic & September 2009 \\
\hline Establish a test bed with relevant environment for instrument testing & September 2010 \\
\hline Initial model for AFCF aqueous processing module & September 2011 \\
\hline Down-select instrumentation for initial demonstration & September 2012 \\
\hline Initial demonstration of advanced control logic & September 2012 \\
\hline Initial model for AFCF pyroprocessing module & September 2012 \\
\hline
\end{tabular}

The cost estimates to support the above milestones are provided in Table 10.

Table 10. Cost Estimates for Transmutations, Fuels, and Separations Technologies

\begin{tabular}{|l|c|c|c|c|c|c|}
\hline \multicolumn{1}{|c|}{ Cost Estimates (\$M) } & & & & & \\
\hline \multicolumn{1}{|c|}{ Activities } & FY07 & FY08 & FY09 & FY10 & FY11 & FY12 \\
\hline AFCF Design & & & & & & \\
\hline Conceptual design & 9 & 30 & 40 & & & \\
\hline Preliminary design & & & & 80 & 90 & 90 \\
\hline Final design & & & & & & \\
\hline Design support & & & & 15 & 20 & 20 \\
\hline \multicolumn{1}{|c|}{ Subtotal design (Operating) } & $\mathbf{9}$ & $\mathbf{3 0}$ & $\mathbf{4 0}$ & $\mathbf{1 5}$ & $\mathbf{2 0}$ & $\mathbf{2 0}$ \\
\hline \multicolumn{1}{|c|}{ Subtotal design (Capital) } & $\mathbf{0}$ & $\mathbf{0}$ & $\mathbf{0}$ & $\mathbf{8 0}$ & $\mathbf{9 0}$ & $\mathbf{9 0}$ \\
\hline \multicolumn{1}{|c|}{ AF Subtotal } & $\mathbf{9}$ & $\mathbf{3 0}$ & $\mathbf{4 0}$ & $\mathbf{9 5}$ & $\mathbf{1 1 0}$ & $\mathbf{1 1 0}$ \\
\hline Fuel Development & & & & & & \\
\hline Fuel Design and Analysis & 2.8 & 3.5 & 3.5 & 3.5 & 3.5 & 3.5 \\
\hline Fuel Feedstock Char. and Prep & 0.7 & 4.5 & 4.5 & 4.5 & 4.5 & 4.5 \\
\hline TRU Fuel Fabrication Develop. & 9.0 & 30 & 33 & 33 & 33 & 33 \\
\hline TRU Fuel Irradiation and PIE & 22.6 & 32 & 40 & 40 & 40 & 40 \\
\hline Fuel Development Subtotal & $\mathbf{3 5 . 1}$ & $\mathbf{7 0}$ & $\mathbf{8 1}$ & $\mathbf{8 1}$ & $\mathbf{8 1}$ & $\mathbf{8 1}$ \\
\hline
\end{tabular}


July 25,2007

\begin{tabular}{|c|c|c|c|c|c|c|}
\hline \multicolumn{7}{|l|}{ Cost Estimates (\$M) } \\
\hline Activities & FY07 & FY08 & FY09 & FY10 & FY11 & FY12 \\
\hline Fuel Development R\&D & 0.4 & 8 & 8 & 8 & 8 & 8 \\
\hline \multicolumn{7}{|l|}{$\begin{array}{l}\text { Reprocessing and Waste Form } \\
\text { Development }\end{array}$} \\
\hline \multicolumn{7}{|l|}{$\begin{array}{l}\text { Transmutation Fuel Recycle } \\
\text { Technology Development }\end{array}$} \\
\hline Pyroprocessing + EBR II** & 8.40 & 19.2 & 17 & 18.5 & 20 & 20 \\
\hline Aqueous & 0 & 5 & 7 & 8 & 10 & 10 \\
\hline \multicolumn{7}{|l|}{$\begin{array}{l}\text { Waste Form Technology } \\
\text { Development }\end{array}$} \\
\hline Pyroprocessing + EBR II** & 1.25 & 4.5 & 3 & 3 & 2 & 2 \\
\hline Aqueous & 0 & 1.7 & 2 & 2.3 & 2.3 & 2.3 \\
\hline \multicolumn{7}{|l|}{ Transmutation Fuel Recycle R\&D } \\
\hline Pyroprocessing & 0 & 2.5 & 3.75 & 4 & 4.3 & 4.3 \\
\hline Aqueous & 0 & 1.3 & 1.4 & 1.5 & 1.5 & 1.5 \\
\hline \multicolumn{7}{|l|}{ Waste Form R\&D } \\
\hline Pyroprocessing & 0 & 0.5 & 0.5 & 1 & 1 & 1 \\
\hline Aqueous & 0 & 0.3 & 0.5 & 0.5 & 0.5 & 0.5 \\
\hline Subtotal Pyroprocessing & 9.65 & 26.7 & 24.25 & 26.5 & 27.3 & 27.3 \\
\hline Subtotal Aqueous & $\mathbf{0}$ & 8.3 & 10.9 & 12.3 & 14.3 & 14.3 \\
\hline Combined Subtotals & 9.65 & 35 & 35 & 39 & 42 & 42 \\
\hline Safeguards Development & 0.6 & 10 & 15 & 17 & 17 & 17 \\
\hline
\end{tabular}

* Fundamental modeling cost estimates is covered under the Simulation Laboratory section of the plan.

** Includes EBR-II Spent Fuel Treatment 


\subsection{GNEP Reactors for International Deployment}

The Global Nuclear Energy Partnership seeks to create an international regime to support large-scale growth in the worldwide use of nuclear energy. Fully meeting the GNEP vision may require the deployment of thousands of reactors in dozens of countries, many of which are in the developing world and do not use nuclear energy currently. Some of these needs will be met by large-scale Generation III and III+ reactors ( $>1000 \mathrm{MWe})$ and Generation IV reactors when they are available. However, because many developing countries have small and immature electricity grids, the currently available Generation III $(+)$ reactors are unsuitable since they are too large, too expensive, and too complex. Therefore, GNEP envisions new types of reactors that must be developed for international deployment that are "right sized" for the developing countries and that are based on technologies, designs, and policies focused on reducing proliferation risk. Other countries such as France, Russia, Japan, Korea, and South Africa are moving forward with the development of such reactors, so it is vital that the US also embark on the development of suitable reactor systems in order to influence the technologies that are deployed internationally and position US industry for leadership in this growing international market. In the U.S., the Generation IV R\&D program is already investigating several small and medium-sized reactor concepts for various domestic applications, and some of these concepts may prove relevant to GNEP application.

The primary objective of this program element of GNEP is the development and demonstration of appropriately-sized reactor designs that can provide the world, particularly developing countries, with safe, simple and robust sources of energy to meet their expanding needs for electricity, potable water and district heating at an affordable price, while minimizing the negative impacts on the local and global environment associated with large-scale burning of fossil fuels. The deployment of these reactors, which we designate as "proliferation-resistant international modular reactors" (PRIMR), combine with the GNEP policy of reliable fuel services to provide an attractive energy solution to many countries without the need for them to develop the more proliferation-vulnerable parts of the nuclear fuel cycle.

Several reactor concepts have been proposed for this purpose, ranging from advanced adaptations of conventional light-water reactors to novel battery-like concepts with sealed reactor vessels and fully autonomous operations. Multiple US and international studies have been conducted in recent years to assess the desired features of reactors that are desirable for global deployment in terms of both meeting user needs and reducing proliferation concerns. ${ }^{\mathrm{a}, \mathrm{b}}$ The consistent conclusion has been that small and medium sized reactors $(\mathrm{SMR})^{\mathrm{c}}$ address these needs better than existing commercially available designs, which have power levels generally exceeding 1000 MWe. This conclusion is based on a number of observations, including capital investment, electricity grid capacity, plant complexity, and country demographics. Because of these considerations, and because larger sized Generation III nuclear plants are already commercially available, the GNEP program will focus on the development and demonstration of SMRs for international deployment.

\subsection{Program Strategy}

Successful deployment of PRIMR systems will require not only the development of specific reactor technologies, but also the resolution of challenging infrastructure, legal and regulatory issues. Also, it will be important to understand and address the wide range of physical and temporal interests and needs

\footnotetext{
a "Innovative Small and Medium Sized Reactors: Design Features, Safety Approaches and R\&D Trends," IAEA-TECDOC1451, May 2005.

b "Report to Congress on Small Modular Nuclear Reactors," US Department of Energy, May 2001.

c According to the International Atomic Energy Agency, "small" reactors are defined to have power outputs up to 300 MWe and "medium" reactors have outputs between 300 and 700 MWe.
} 
of the diverse global market. The type and size of nuclear plants, as well as the level of need for new physical and/or administrative infrastructure, will vary considerably over the spectrum of developing countries.

Figure 5 describes at a high level the principal activities of the PRIMR deployment program, which includes three major components: infrastructure development, reactor development and regulatory development. Implementation of the plan will require the combined contributions of the federal government, industry, the national laboratories and academia. The technology development and demonstration portion of the PRIMR deployment program is described in the following sections and focuses on the reactor development component of Figure 5.

The program will start with an assessment of user country needs and constraints, followed by the rigorous development of system requirements. This will be done using input from the international community via the International Atomic Energy Agency (IAEA) and bilateral and multi-lateral working groups. Based on the identified requirements, an assessment of technology development needs and system deployment options will be performed. Technology options will include such choices as: reactor fuel and coolant, primary system design (pool, loop, integral), and secondary system design (power conversion, process heat, cogeneration). Deployment options include considerations such as: acquisition strategy (competitive vs. directed), demonstration strategy (prototype vs. first-of-a-kind unit), siting strategy (in US or elsewhere), and licensing/certification strategy (domestic vs. foreign).

A dual-path approach has been selected for PRIMR development and demonstration. The first path provides a fast-track deployment of a near-term SMR design to facilitate US leadership in the rapidly emerging nuclear market and provide U.S. credibility in meeting key GNEP objectives. The near-term PRIMR development also will be used as the vehicle to address and demonstrate infrastructure and regulatory development needs, i.e. plant licensing, domestic and international policies, international agreements, etc. As such, the initial SMR system is not expected to exemplify all of the features of a PRIMR system, but should manifest many of those qualities while also being derived from sufficiently mature technologies to realistically meet the needs of currently emerging countries with some nuclear experience. The second path focuses on specific technology developments that are needed to deploy a next-generation SMR to a broader global market with further enhancements in plant safety, robustness, safeguards, proliferation resistance and economics.

The plan anticipates strong industry involvement from the outset to lead the design development and international deployment. This will ensure a rapid transition to a commercial enterprise. National laboratories and universities will be needed to develop the advanced technologies needed to fully meet PRIMR system requirements. International collaborations will be pursued in nearly every aspect of the program and maximum use will be made of existing organizations, agreements, and collaborations.

\subsection{Support for 2008 Record of Decision}

The initial focus of the PRIMR program will be to conduct those activities needed to inform the scheduled 2008 decision by the Secretary of Energy regarding the path forward for GNEP. These include an assessment of the global need for PRIMR systems, a detailed assessment of technical requirements for such systems, the selection of a near-term SMR design for demonstration, and the initial screening of next-generation design concepts. These activities will establish a firm basis for proceeding with the development and demonstration of PRIMR systems and provide sufficient information to reliably estimate the cost and schedule for full demonstration of these systems. 


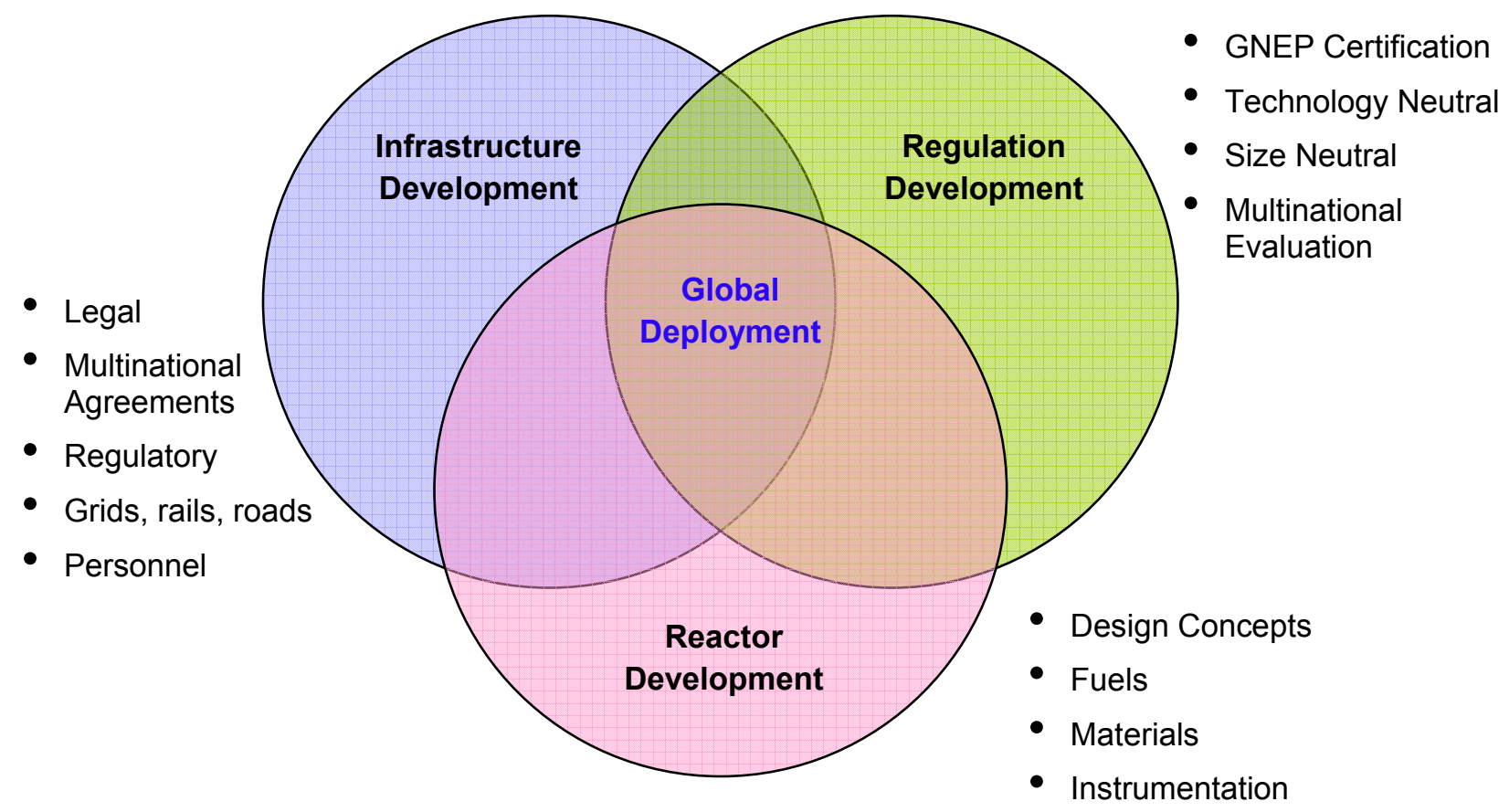

Figure 5. Principal activities to develop GNEP reactors for international deployment

\subsubsection{Global Needs Assessment}

A global needs assessment will be performed to understand the needs and constraints of the developed and developing countries of the world. Considerable data already exist to support this "market" study, hence the study will involve harvesting these data, filling identified gaps, and interpreting the data within the GNEP context. An initial characterization of global energy demands and projections was performed late in FY 2006.d This study, which concluded that 500-1000 new SMRs may be needed by 2050 worldwide to meet the anticipated energy demand, will form the basis of a more refined investigation of energy supply needs for the full range of country economies.

The IAEA has been very active in recent years in assessing the design, safety, and economics of SMR systems. Because IAEA membership includes the full spectrum of developed and developing countries, they will be a valuable resource for the coordination of many activities related to the PRIMR program. In particular, the IAEA-sponsored International Project on Innovative Nuclear Reactors and Fuel Cycles (INPRO) has positioned itself as the organization representing user nations and has formulated a program to assist emerging nuclear nations with infrastructure issues and technology evaluations. The activities and outcomes of INPRO will be extensively leveraged for several aspects of the PRIMR program, including the global needs assessment.

d "Potential of Small and Medium Sized Reactors (SMR) to Support the GNEP Vision," Advanced Systems Technology and Management, Inc. (draft November 1, 2006). 


\subsubsection{Requirements Definition}

For successful deployment within the GNEP context, PRIMR systems must: (a) meet all the safety, reliability, economics, and proliferation goals established for the DOE Generation IV program, (b) be sized for market conditions in developing countries where energy demand per capita, institutional maturity and industrial infrastructure vary considerably, and (c) be capable of utilizing fuel cycle/waste management support within the GNEP reliable fuel services and fuel recycling paradigm. Realization of these top-level requirements gives rise to a number of second-level requirements involving reactor technology choices.

The PRIMR program will generate detailed and substantiated requirements for PRIMR systems. It is expected that some of the desirable features will be mutually exclusive, or at least competitive with other features, so a prioritization or weighting of requirements will be established also. The desired outcome from this assessment is the eventual formation of a "GNEP Certification" process that will ensure that reactor systems deployed worldwide satisfy implementing policies of GNEP.

Arrangements are already underway to establish SMR Working Groups jointly with Japan and Russia. Additional bilateral and multilateral arrangements are expected as GNEP progresses. These Working Groups will be instrumental in establishing an international consensus on PRIMR requirements.

After the PRIMR requirements have been established, a PRIMR system evaluation methodology will be established, including specific evaluation criteria. This task will draw heavily from recent and ongoing efforts in the DOE Generation IV program and the Advanced Fuel Cycle Initiative. Specifically, Working Groups from these two programs have developed a number of relevant tools for the evaluation of safety, reliability, economics, and proliferation risk. Additionally, other technology maturity evaluation methods, such as the "technical readiness level (TRL)" scale used by the National Aeronautics and Space Administration, will be considered for evaluation of PRIMR system maturity.

\subsubsection{Design Selection}

A dual-path approach to PRIMR deployment has been selected that includes an early demonstration of a near-term SMR and the longer-term development of reactor technologies for the next-generation SMR. The selection of a near-term SMR, which is intended to be responsive to existing foreign power demands, will be made early in the program. This will provide GNEP with a commercially viable system that can help resolve key infrastructure and regulatory issues for a rapid deployment of a PRIMR system by 2016. It will also provide rapid opportunity for GNEP to reach its international objectives of significantly increasing the use of nuclear energy worldwide. It is expected that the initial system selected for nearterm deployment will not fully meet all of the ultimate PRIMR requirements, but will be selected based on its balance of requirements, technology readiness, and user country needs. For example, initial contacts from several developing countries have indicated a clear preference for water-cooled reactors because of the large global experience base with these types of reactors. A trade study will be conducted in FY2007 to evaluate near-term designs with a goal to select a system that GNEP will support by facilitating resolution of regulatory and infrastructure issues.

According to two recent IAEA reports, e'f more than 60 SMRs are being studied by various countries with a diverse set of features and spanning the full gamut of technology and design maturity. After completing the detailed requirements assessment, an initial screening of potential next-generation SMRs will be

e Status of Innovative Small and Medium Sized Reactor Designs 2005: Reactors With Conventional Refueling Schemes, International Atomic Energy Agency, IAEA-TECDOC-1485, March 2006.

f Status of Innovative Small and Medium Sized Reactor Designs 2006: Reactors Without Onsite Refueling, International Atomic Energy Agency, (in publication). 
conducted, and several concepts (4-5) will be selected for further development. Later, one or two systems will be selected for final design development based on their potential for meeting all or most of the established requirements with a reasonable level of additional technology development.

\subsection{PRIMR Technology Demonstration}

Satisfying all of the requirements for GNEP Certification will require development, testing and demonstration of new reactor technologies, potentially including fuels, materials, instrumentation, safeguards, physical security, and advanced manufacturing technologies. Even for the near-term PRIMR demonstration, some advanced technologies may need to be developed, such as sensors and instrumentation for reactor control and nuclear material safeguards. It is important to start this development process early so that advanced PRIMR systems can be available as soon as possible for deployment to emerging countries.

Primary activities for the next-generation PRIMR involve the development of detailed design requirements, including the establishment of criteria and metrics to permit a thorough evaluation of candidate systems. Industry-lab partnerships will be sought to develop pre-conceptual designs of concepts that could potentially meet the established criteria through a competitive bid process. The submitted designs will then undergo an objective review to be performed by an integrated industry-laboratoryuniversity team. Down-selection to 2-3 promising concepts will result in contracts to develop conceptual designs. Reactor vendors will take lead responsibility for design development with the national laboratories and universities providing the supporting R\&D. This process should be performed in conjunction with foreign partners but with consideration of domestic policies and business opportunities. Once conceptual designs are evaluated, a decision will be made on building prototype reactors to gather the experience and data needed to support design approval by the NRC - a key step in making the designs commercially attractive for international deployment.

The technical implications resulting from the requirements discussed earlier give rise to a number of technology needs. For the most part, especially for fuels and materials, technology development needs apply to the deployment of the next-generation SMRs, since the near-term plant must be based substantially on existing and demonstrated reactor technology. However, some cross-cutting technologies, such as advanced instrumentations and controls, safeguards, physical protection, and manufacturing technologies, may be needed or desirable for even the near-term PRIMR system.

This major task area is best served by considerable involvement of the international R\&D community, including national laboratories and universities. Existing or new bilateral and multilateral collaborations will be utilized to advance the state-of-the-art in several areas pertinent to PRIMR systems. Many countries are already developing SMRs and would mutually benefit from collaborations on basic and applied R\&D. Because of the significant overlap in the requirements and objectives between GNEP and the Generation IV International Forum (GIF) for the next-generation SMR, these two programs will cooperate closely in defining research topics and program funding to the maximum extent possible. Additionally, the International Nuclear Energy Research Initiative (I-NERI) will be used to build on and foster international collaboration. Universities are well suited to contribute to this R\&D, which can be accomplished through direct programmatic agreements or by leveraging projects within the domestic Nuclear Energy Research Initiative (NERI).

\subsection{Commercialization and Deployment}

It is ultimately the responsibility of commercial nuclear plant vendors to provide SMR designs to the global market. Hence, it is vital that the PRIMR development program have strong industrial participation from the outset. For the industry to engage in a full and committed manner, they must see positive business benefit. At the same time, it is unlikely that industry will develop SMRs for commercial 
offering without funding support from the government because of perceived risks of deployment to developing countries and the numerous infrastructure and regulatory barriers. Incentives and contractual arrangements will be developed for industrial participation consistent with government objectives, and a clear path for a transition to full commercial deployment will be defined early in the program. There is likely to be a market for several competing designs offering different strengths and providing alternative paths for future expansion as the economies of developing countries expand. Thus, there will be options for multiple industrial partners within the program. It is also plausible for international industrial partnerships to form as suppliers, thus requiring international agreements on contributions, property rights and liability.

\subsection{Cost Estimates and Milestones}

Table 11. Cost Estimates Projection for PRIMR System Development and Demonstration

\begin{tabular}{|c|c|c|c|c|c|c|}
\hline \multicolumn{7}{|c|}{ Cost Estimates (\$M) } \\
\hline Activities & FY-07* & FY-08 & FY-09 & FY-10 & FY-11 & FY-12 \\
\hline \multicolumn{7}{|l|}{ PRIMR System Integration } \\
\hline Coordination and integration* & & 0.3 & 0.4 & 0.4 & 0.4 & 0.4 \\
\hline Support services & & 0.1 & 0.1 & 0.1 & 0.1 & 0.1 \\
\hline \multicolumn{7}{|l|}{ Infrastructure Development } \\
\hline $\begin{array}{l}\text { Needs/Requirements assessments } \\
\text { and international collaborations* }\end{array}$ & & 0.2 & 0.5 & 0.5 & 0.5 & 0.5 \\
\hline $\begin{array}{l}\text { Country-specific infrastructure } \\
\text { assistance (evaluations, site } \\
\text { selection, trade studies, etc.) }\end{array}$ & & 0.1 & 1.5 & 1.5 & 2 & 2 \\
\hline \multicolumn{7}{|l|}{ Reactor Development } \\
\hline Near-term Design & & 1.3 & 3.5 & 4 & 4 & 4 \\
\hline Next-Generation Designs & & 2.5 & 2.5 & 2.5 & 8 & 8 \\
\hline $\begin{array}{l}\text { Technology Development (fuels, } \\
\text { materials, I\&C, safeguards, } \\
\text { manufacturing) }\end{array}$ & & 0.5 & 3 & 5 & 7 & 8 \\
\hline Total & $\mathbf{0}$ & 5 & 11.5 & 14 & 22 & 23 \\
\hline
\end{tabular}

*Funding for this activity in FY07 is from DOE RW funds. 
Table 12. Top Level Milestones for PRIMR System Development and Demonstration

\begin{tabular}{|l|l|}
\hline \multicolumn{1}{|c|}{ Milestones } & \multicolumn{1}{c|}{ Date } \\
\hline Select SMR technology for near-term deployment & May 2007 \\
\hline Complete initial needs/requirements assessments & September 2007 \\
\hline Initial screening of next-generation SMR concepts & March 2008 \\
\hline Select next-generation SMR(s) for pre-conceptual design & June 2008 \\
\hline Select near-term PRIMR design for safety evaluation support & January 2009 \\
\hline Submit application for NRC design approval for near-term SMR & September 2010 \\
\hline Down-select to 2 next-generation SMR conceptual designs & January 2011 \\
\hline $\begin{array}{l}\text { Award up to two contracts for conceptual designs of next-generation } \\
\text { SMR }\end{array}$ & March 2012 \\
\hline Complete NRC Final Design Approval for near-term SMR design & January 2014 \\
\hline Complete conceptual design of next-generation SMR(s) & September 2015 \\
\hline Select next-generation design for prototype construction & January 2016 \\
\hline Begin operation of next-generation SMR prototype & September 2020 \\
\hline
\end{tabular}




\subsection{Modeling and Simulation}

Modeling and simulation has always been a key tool in nuclear engineering. From the earliest times, primitive computers were used to obtain predicted quantities through interpolation of experimental data. More recently, computer based analyses have been used to predict detailed quantities that could not be readily measured in situ, for example, the aging of structures, power distributions in cores, transient safety behavior, etc. Until the early 80's nuclear engineering was at the forefront of computer applications, making massive use of the largest machines available at the time. Nevertheless, these machines remained very limited when compared to the requirements for an explicit modeling of key phenomena in a reactor. Thus, the codes developed at the time were rather simplified, using lumped parameter models for predictions of neutronics, thermohydraulics, and structural mechanics quantities. These codes were validated on a very large experimental database, developed over the years for specific projects. The validation process used at the time was coarse, as it could only compare macroscopically measured data and macroscopically calculated quantities. Frequently, the validation process consisted of simply comparing these experimental and calculated quantities as the tools and techniques available for a more formal validation process were missing.

These same tools are the ones available for the GNEP program today and constitute the starting point for design activities. We expect that their use will lead to significant negative consequences for the projects. There are three principle reasons for this assessment -- first, the validation process needs to be repeated with more formalism, even though this might not be possible due to the disappearance or lack of documentation for the experimental data. Furthermore, these tools are embedded with many approximations and uncertainties that eventually lead to significant cost increases for the projects. Finally, modeling tools available for researchers in critical areas, in particular for the development of advanced fuels, are not predictive, and force a research approach that is largely empirical, and therefore expensive, lengthy, and extremely risky. There is a broad consensus that a project guided by good science embedded in modern simulation tools has a much higher probability of success.

Preliminary evaluations of the critical areas where modern simulation tools are required for the success of GNEP have been undertaken over the past year, in particular during a workshop held December 2005 at LLNL, and a workshop held August 2006 in Washington DC. The following list, while it is not exhaustive, provides key priorities:

- Core simulation tools (neutronics, thermohydraulics, structural mechanics) need to be updated and validated to give accurate and trustworthy predictions of plant behavior during normal, incidental, and accidental conditions.

- Fuels and materials behavior models need to be built to enable acceleration of the research process in these two critical areas, and significantly increase the probability of success.

An important use of advanced modeling and simulation methods is for process and facility design to optimize integration of IAEA safeguards as part of the overall design optimization process for a given facility (see Appendix A and Section 5.2.3.4 for details).

Subsequent discussions have also identified the need for organizing a staged development process, whereby critical needs would be met in a timely manner to satisfy project needs in the short, medium, and long term.

The GNEP simulation plan below includes a detailed list of the major simulation goals of the program together with a framework for identifying and prioritizing specific simulation targets during the course of the GNEP program. This section is organized as follows: 1) a background and overview of the opportunities presented by advanced simulation; 2) a methodology and framework for prioritizing simulation activities; 3) GNEP simulation goals, and 4) a list of additional domain-specific simulation 
opportunities within the GNEP framework. This will be done in close collaboration with the DOE's Office of Science.

An activity that will be extremely important to the success of modeling and simulation is a disciplined approach to verification and validation $(\mathrm{V} \& \mathrm{~V})$. V\&V plans will be developed very early in the modeling and simulation activity. This will require a well-defined, coupled experimental program.

\subsection{Opportunity}

Computer simulation addresses critical needs of the GNEP program in providing the tools necessary for safety assessments, design activities, cost, and risk reduction. Existing tools based on a large experimental database are likely to be insufficient. For most of the technologies related to the three major GNEP demonstration technologies, testing is extremely expensive, protracted, and in some cases unfeasible. Furthermore, the existing experimental database is insufficiently documented to support a modern validation process. Complementing or replacing testing with high-fidelity computer simulation will make it possible to collect simulated data that can, in conjunction with a sound experimental validation program, be used to understand fundamental processes that affect facility efficiency, safety, and cost. One can, for example, imagine virtual prototyping of reactor cores yielding data that leads to more accurate identification of design margins, allows early experimentation with novel design concepts, and ultimately significantly reduces plant certification timelines. In other areas, such as advanced fuel fabrication, atomistic fuel simulations could ultimately make it possible to target a small subset of promising candidate fuel types for further experimentation, greatly reducing the number of experiments to be performed.

Such simulation-based methods are within the reach of modern supercomputers, which currently are approaching a peak theoretical performance of one petaFLOP/s, about five orders of magnitude faster than a standard desktop computer. In fact, other related industries, such as automotive, airline, chip manufacturers, etc. have demonstrated the effective use of high-fidelity modeling (viz. computational fluid dynamics) as an integral part of the conceptual design and optimization process. Related industries are making remarkable progress in reducing experiments in favor of high-end simulation - e.g. pharmaceuticals, engine design, turbines, etc. It is clear that we have only scratched the surface of what is possible in the application of advanced simulation to nuclear engineering.

Of course, over the past twenty five years, simulation tools have been in common use among nuclear engineers in a wide range of applications. However, as discussed, most of these can be considered legacy tools that were conceived and developed over twenty years ago, when available computer power was approximately five orders of magnitude less than current state of the art. Equally importantly, over that period significant advances have been made in enabling technologies to more easily leverage this performance. With the tremendous computing power currently available in the form of modern supercomputers (e.g. IBM BG/P, Cray XT3), radical new approaches can be taken that were previously unthinkable. In many cases, leadership class computers can be used to calculate first-principles-based physics on very fine meshes, yielding results with accuracies much greater than current techniques, or with the ability to predict new scenarios that have not been directly tested. In other cases (e.g. molecular dynamics simulations), it is possible to implement completely new techniques now that were inconceivable or impractical twenty years ago. A detailed discussion of the simulation opportunities is given in Section 7.4.

\subsection{Organization}

While it is possible to identify early candidate simulation projects with high potential payback (see Introduction and the next section), the detailed process of downselecting and prioritizing will need to be done in the early phases of the program, in close collaboration with the facilities and technology leads, 
and to some degree dependent on funding levels. For this reason, we have devised a methodology whereby simulation effort will be organized as a close collaboration between the engineers and conduting technology development for designing the GNEP facilities and computational scientists, computer scientists, and applied mathematicians who are experts in various aspects designing numerical software and large application codes for leadership class supercomputers. This will be an iterative decision-making process. Facilities designers formulate short and long-term simulation goals to directly address areas that would greatly impact their engineering and scientific goals. Computational modellers help identify barriers to performing such calculations and assist in priorizing simulation goals, identifying potential "low-hanging fruit", and articulating specific short and long-term scientific and engineering target problems. For the longer-term, more fundamental R\&D on the target problems will include significant advancements in underpinning technologies, such as helping to define next-generation computing architectures in support of GNEP, scalable numerical methods and algorithms, advance visualization, i/o, and data management, in addition to more scientific and modelling challenges (see below). For shorterterm goals the strong emphasis will be on immediate validation and verification of results, definition of supporting experiments, and channeling results into particular GNEP technologies. Critical component of this model is the formation of a team responsible for ensuring that all development efforts, on whatever timescale, feed into particular GNEP facilities needs and timelines, and therein clearly demonstrate improvements in the above-menetioned areas. Furthermore, while the tools initially will be used for facility designers, as they mature a process will need to be developed for knowledge and technology transfer to appropriate certification agencies for ultimate adoption and incoporation into their process.

In the following section simulation needs are prioritized based on overlapping short, medium and longterm goals.

\subsection{Objectives}

Within this framework, emphasis will be placed on the components most directly supporting the design of CFTC, ABR and AFCF facilities. Since one of the overarching goals of the simulation program is the development of a suite of software tools that will enable quantification of margins of uncertainty to aid and accelerate the licensing of new reactor systems, the simulation program will engage and collaborate with the research branch of the Nuclear Regulatory Commission at an early stage to position the program for appropriate levels of engagement in the future.

\subsubsection{Short-Term Objectives}

The short-term goal of the Modeling and Simulation activity is to advance the development of the three major GNEP demonstration facilities, the CFTC, ABR, and AFCF. Improved engineering simulation tools, based on existing modeling codes, software infrastructure and knowledge discovery (e.g., visualization, feature identification) applications, will be created via the integration of existing capabilities and focused on advancing the deployment of the facilities. Tool specifications will be developed in close collaboration with the leads for the three major demonstration projects to ensure that the resulting suites will benefit the development of the facilities. Existing capabilities will be examined, and the most promising will be chosen for integration. Tool development will look to utilize the advances in computing technologies as well as leveraging previous work from programs such as ASC, SciDAC, and TeraGrid. The need for new numerical algorithms and other enabling technologies will be assessed in terms of the facility needs to provide guidance for the intermediate and long-term objectives. It is also important to begin initial development of a GNEP system level planning tool. The system level planning tool will include a transport model that tracks the flow of nuclear materials (isotopic masses) with respect to time and geographic location. The mass change terms are obtained from the next level of modeling in the hierarchy referred to as the "system design models." The output of the systems level model will provide the following databases as a function of global location and time: 
- Raw materials (natural resources)

- Processed materials

- Nuclear materials transportation flow

- Nuclear facilities and their characteristics

- Material storage

- Cost/expenditure

- Proliferation concerns

- Products and byproducts (electricity, hydrogen, waste, etc.)

The systems level planning tool and the lower level models supporting it will be structured such that it can be run in two modes: demand mode where energy demand is explicitly defined and the response of the overall system is quantified, and optimization mode where the desired optimal characteristics of the system are defined based on various constraints and the optimal deployment strategies are predicted. Uncertainty propagation will be an important part of the tool. While this tool will lack maturity in the early stages of GNEP development, it nevertheless will provide useful direction to the overall program.

The technical leads for each of the demonstration facilities will determine the modeling applications upon which they will rely for the successful construction of their facilities. The work processes of the participants in each activity will be carefully examined to obtain an accurate workflow description of the modeling activities. Traditionally, this is a series of independent operations that the analyst must individually combine. The examination will cover the specifics of which applications require input from others, in what formats, and how the data is currently transmitted. There will also be an analysis of the manner in which the suite of applications is used (e.g., multiple flux calculations being performed on a given geometry, or different geometries examined with similar fuel loadings). The end-to-end analysis process will then be examined, looking for opportunities for efficiency improvement. Many of the data transmission steps, sensitivity analyses via parameter variation, model input construction steps, and results analyses will lend themselves to modernization capabilities that have been developed and implemented by other programs. Once the steps of the process and work flow are understood, efficiency and performance optimization will be examined to determine which will provide the greatest benefit to the facility construction process.

For the ABR, the priorities have been determined to be the thermal hydraulics and structural mechanics components. The CFTC requires the current modeling code to be fully integrated with minimally a static, but preferably a dynamic, plant model in order to accommodate non-equilibrium events within the facility. CFTC also desires a substantial improvement in the usability of the CFTC modeling suite. An equivalent analysis with the AFCF lead will provide a similar set of facility-oriented priorities. These priorities will drive the efforts in the workflow analysis and process improvement.

A formal validation process also needs to be established within the GNEP program to bring the full benefits of modern simulation capabilities to the design and safety of the facilities and the research and development process. The purpose of the validation process is to provide for each calculated quantity an estimated uncertainty that takes into account all possible sources of uncertainties in the analysis, and integrates them for each particular situation.

Several approaches have been used in the past in the nuclear area; they range from the very rudimentary to the somewhat sophisticated:

- The rudimentary approach has historically consisted of taking a code - developed to whatever level of sophistication - and comparing its output to data from a set of representative 
experiments. The uncertainties are then estimated on the basis of the comparison. This process does not distinguish the origins of uncertainties and biases, and gives only a vague definition of the domain of validity.

- More advanced approaches have been developed, for example in neutronics and structural mechanics, where reference codes (that provide exact solutions to the basic equations) exist and can be used to estimate numerical biases; uncertainty propagation techniques have been developed, and have been used to estimate the final uncertainties due to nuclear data or mechanical properties. Finally, formal statistical processes have been developed to formally compare integral experimental data and predictive results.

These processes are not satisfactory, as they do not provide maximum confidence in uncertainty predictions. Furthermore, it seems likely that the experimental database currently available is insufficiently documented to support a formal modern validation process. Finally, it is also likely that this database is incomplete and does not contain sufficient experimental data to validate codes capable of very detailed modeling of key phenomena.

Modern methods need to be developed in the short term that incorporate tools such as formal uncertainty propagation techniques, statistical analyses of experimental data, and reference codes that minimize the effects of modeling approximations. Additionally, GNEP will need to acquire and analyze a complete experimental database for validation of the new or updated analysis tools. While these experimental needs have not yet been determined, a formal process will be put in place to do this, and this will include as a first step the analysis of the existing database.

\subsubsection{Intermediate-Term Objectives}

In addition to the codes adopted within the short-term objectives described previously, an analysis will be performed for other existing codes that may provide value but are not currently in general use within the nuclear industry. In particular, these codes could serve to bring additional functionality to the short term efforts without having to rely on the results of the longer-term research activities. Limitations of the existing nuclear code suite will be used to identify possible candidates for inclusion. Once these codes have been identified, verification and validation activities will then define the breadth and depth of possible inclusion into the Modeling and Simulation activity.

There are several possible candidates for this activity that have already been identified by the ABR and CFTC facility leads. The ABR could utilize higher fidelity thermal hydraulics simulations than those currently achievable using commercial CFD applications. These commercial codes do not scale to the levels required by nuclear reactor models simply because there is currently little market for such applications. Hence, replacing the commercial thermal hydraulics code with one capable of greater spatial resolution and execution in a modern HPC environment would bring greater confidence to the simulation results. Structural mechanics is another area of the ABR modeling where the capabilities of existing commercial codes are too limiting. Replacement of these commercial codes with those from the DOE community would again contribute to higher confidence in simulation results. Finally, the CFTC design work would benefit from the coupling of the existing model with a dynamic plant model that would calculate the effects of transients within the facility. The CFTC would also benefit from greater ease-ofuse, another straightforward application of modern computing experience.

The integration of the previous model assessment and development work will define the intermediateterm goal to establish an efficient "end-to-end" modeling architecture. Consistency of cross-model assumptions, data, and approaches will be essential for the success of the long-term, large-scale modeling efforts. This is especially true when data and models address phenomena across vastly different scales, with the results of one calculation becoming the input of another. A set of sub-model requirements based 
on physical constraints, prediction accuracy, and technical and computational consistency within an integrated approach will be defined.

\subsubsection{Long-Term Objectives}

The long-term goal for the simulation program is the development of an architectural model that will facilitate modeling the entire fuel cycle from mining through final disposition of waste material, taking into account interacting factors that are key to the ultimate success of GNEP (e.g., market forces, sociopolitical effects, technology risk). This will facilitate the implementation of a comprehensive suite of simulation tools for the design, analysis and engineering of next-generation nuclear energy systems with enhanced safety, reduced environmental impact, optimal deployment of facilities, and reduced construction cost. To achieve this long-term goal, the GNEP simulation program must address the following areas of research and development:

- Integrated 3D reactor core simulations with rigorous propagation of uncertainty

- Coupled thermal hydraulic and primary loop simulation

- Advanced fuel design and performance

- Fuel behavior engineering

- Advanced secondary loop and balance of plant engineering and analysis

- Advanced fuel cycle design

- Separations facility engineering optimization

- Repository design including seismic, geological, chemical, and thermal modeling and simulation

- Overall nuclear energy systems model development suitable for alternative economic analysis.

\subsection{Campaigns}

This section provides further details on the specific simulation opportunities and challenges that exist for each component of the fuel cycle. As stated earlier, the R\&D program will be orginized by campaigns, with each campaign including experimental and simulation components, thus insuring a strong validation interaction. Here we motivate and describe the simulation aspect selected campaigns.

\subsubsection{Transmutation Fuels}

The fuels simulation campaign will cover the areas of fuels fabrication, fuel performance and depletion, and more fundamental materials science. This last area will help provide more first principles simulation and help to bridge important length and time scales.

Fuel performance modeling places an emphasis on the detailed understanding of the thermal, mechanical, physical, and chemical processes governing fuel rod behavior during normal reactor operation and under accident conditions. Fuel rod performance codes are used extensively in research, by fuel vendors, and by licensing authorities for the prediction of fuel and cladding performance.

A fuel performance code should consist of a clearly-defined mechanical-mathematical framework into which physical models can be easily incorporated. In addition to its use for fuel rod design, the code will be utilized for a wide range of different situations such as the simulation of under-normal, off-normal, and reactor accident conditions. The time scale of the problems may range from milliseconds to years.

All important physical models will be included in the fuel performance code, including models for thermal and irradiation-induced densification of fuel, fuel swelling due to solid and gaseous fission 
products, fuel creep and plasticity, pellet cracking and relocation, fission gas release, oxygen and plutonium redistribution within the fuel, volume changes during phase transitions, formation and closure of center void and treatment of axial forces (between the fuel and cladding), cladding creep and cladding/coolant interactions (such as oxidation), etc.

Additionally, the code must have access to a comprehensive material database for oxide, mixed oxide, carbide, nitride, and inert matrix fuels, and Zircalloy (and advanced zirconium alloys) and steel cladding (with the capability to add new fuel forms and advanced cladding). Also, interfaces must be available for thermal hydraulic and neutronics feedback to the fuel performance models.

Code verification of the mechanical-mathematical framework will be accomplished by comparing code output to exact solutions and by comparing results from different solution techniques. Code validation will be tightly connected to the experimental efforts in this campaign and will include validation of single-physics models, and comparison with experiment for multi-physics validation.

Simulation of basic material properties is the area with the greatest potential for progress and return on investment. Simulations that cover the full fuel cycle will require the ability to treat a wide range of materials and material behaviors across the full range of scales from atomistic to reactor system. Material properties, including nuclear (e.g., reaction cross sections), thermophysical (e.g., thermal conductivity, multi-component phase diagrams), mechanical (e.g., tensile properties, fracture toughness), and chemical (e.g., corrosion rates), must be determined under static, transient, and accident conditions and after irradiation (e.g., radiation-induced hardening, swelling, and embrittlement).

The fuel selection process is an example that illustrates the possible gain. In the design of a reactor, fuel definition along with the choice of coolant is always the first step that then determines the subsequent components of the system. The traditional approach requires fabrication of samples or pins of the new fuel, measurements of physical and mechanical properties, and finally neutron exposure to high fluence under relevant operating conditions with subsequent characterization. This approach requires a great investment of money and time (several years). In some cases, the choice of fuel may have become obsolete or irrelevant as a result of programmatic considerations before the experimental evaluation is complete. A similarly long process is required for the structural materials involved in the fuel pin cladding and other critical in-core components. Modern methods and powerful computing tools are expected to speed the evaluation and selection of advanced fuels and structural materials.

Use of several materials simulation methods will be essential. For example, first principles methods such as quantum density functional theory (DFT) can now realistically be used to determine fundamental material properties, augment experimental information on the phase diagram of multi-component actinide alloys and compounds, predict chemical reactivity and material compatibilities, and support the development of new interatomic potentials that can be used in Molecular Dynamics (MD) simulations involving millions of atoms. The MD simulations can then be used to study defect properties and to determine parameters such as the atomistic reaction rates that are required in coarser scale simulations of degradation mechanisms that take place over long periods of time. These parameters can be employed in reaction rate theory or Kinetic Monte Carlo (KMC) models of microstructural evolution. MD-based dislocation dynamics simulations can also provide the fundamental dislocation-defect interaction parameters required for continuum 3D Dislocation Dynamics (DD) simulations. The 3D DD simulations can then be used to obtain needed information on the constitutive behavior of the materials which is required for use in macroscopic methods such as finite element models of defect interaction and long term defect stability, as well as simulation of behavior under irradiation. Taken together, this family of multiscale simulations can provide predictions from the atomistic and microscopic through to the mesoscopic and macroscopic levels. 
Initial goals will be to determine the set of material properties and behaviors of concern, along with the range of conditions under which these need to be known, and to establish the required degree of accuracy and practical limitations at each level of simulation. This will provide a basis for predicting the expected impact of an advanced simulation program to reduce both the absolute development time and the related uncertainties as part of the overall fuel and materials development effort. The initial technical objectives should include a strategy for determining the best approach for integrating the various multi-scale components (i.e., when to use parameter passing and when models should be more tightly coupled). Verification and validation steps will need to be an integral part of this strategy.

Some possible milestones which help to describe this campaign are listed below. Details will depend on available budget.

Short Term Milestones:

- Fuel Fabrication: Use Off the Shelf (OTS) codes and methods to perform initial simulation of metal and oxide fuel fabrication processes.

- Fuel Performance: Formulate a macroscopic stress closure relationship based on the thermodynamics of a thermo-elastic material. The thermodynamics will incorporate the appropriate internal state variables and other independent variables that would describe mechanical response of a metal or oxide fuel.

- Fuel Performance: Perform quasi-steady high-burn up metal and oxide fuel simulation using OTS codes and compare to a FRAPCON-like calculational results and appropriate experimental data. Include UQ analysis as part of the validation

- Fuel Performance: Perform a coupled single-phase transient calculation using OTS codes on a suite of unstructured meshes focused on fuel performance coupled to the coolant. Effort includes porting thermal-physical properties and mechanical submodels from the fuels experts and legacy fuels codes, and identifying deficiencies from simulation results and 3D effects

- Materials Science: Use experiment and calculation to develop materials properties for micromechanical simulation for a fuel, Na gap/plenum, stainless cladding and wrap. Provide stress/strain input functions, thermal stress/strain, thermal conductivity

- Materials Science: Use currently available theory, models, and data to construct EOS for the metal and oxide core, $\mathrm{Na}$, and cladding material over $\mathrm{P}$-T-composition ranges relevant to reactor operation, including transients.

- Materials Science: Use available data and EOS for fuel materials to model fuel materials models, including thermal expansion, compressibility

Mid to Long Term Goals

- Validation of fuels fabrication simulation tools and detailed simulation of fuels fabrication

- Execute verification \& validation effort for OTS fuels performance codes

- Initiate development of advanced fuels performance simulation tool suite

- Develop advanced multiscale models, and include relevant multiscale closure modeling into continuum-level simulations

- Transient fuel performance studies with tight coupling to coolant to address design basis and severe accidents 
- Enhance user base ifor OTS fuels performance code and interaction with fuels experts and experimentalists

\subsubsection{Fast Reactor Design and Analysis}

The fast reactor simulation campaign will include modern simulation tool development in the areas of neutronics, thermal-hydraulics, balance of plant, and structural mechanics. High performance, first principles, 3-D simulation tools will be developed, along with a lower fidelity transient systems safety simulation tool.

The scope of applications for future neutronics modeling will need to address all reactor physics aspects related to the design, operation and fuel cycle management for reactor systems developed under GNEP. Many computational tools exist for performing stand alone analyses of core reactivity, power production, fuel burn-up, shielding design, and ex-core criticality safety. The challenge is to address each of these analyses in an integrated, self-consistent framework.

The analysis of neutronics for complex systems requires a very high degree of sophistication for the description of the geometry and for physically realistic representation of the energy dependence of neutron cross section data used for modeling. The availability of accurate cross sections and their temperature dependence is necessary for modeling the various aspects of neutron transport and interaction within highly heterogeneous reactor cores. An assessment of pertinent cross section data available through ENDF (Evaluated Nuclear Data Files) and other sources should be performed to determine additional needs for experimental and theoretical nuclear physics work to support the establishment of an adequate nuclear data base for GNEP applications. A comprehensive assessment would also include photonuclear reaction cross sections and cross sections for relevant charged-particle interactions.

Neutronics modeling has traditionally relied on both stochastic (Monte Carlo) simulations and deterministic transport and diffusion theory approaches. Monte Carlo techniques incorporate the basic physics at the level of stochastic particle tracking with the general system geometry and material cross sections governing the particle track histories. Monte Carlo offers the strong conceptual advantage of keeping a close (essentially exact) correspondence between computational and physical geometric and cross section energy dependence models. Nevertheless, Monte Carlo can become computationally impractical for several different classes of problems. These include calculations of small reactivity coefficients, some types of sensitivity/uncertainty propagation studies, time-dependent solutions, and some types of burn up calculations.

For these applications, as well as for several other aspects of neutronics analysis, computational advantages can be achieved with deterministic transport and diffusion theory approaches that complement the Monte Carlo approach. The two basic computational methods, taken together, can provide a much more comprehensive picture of the neutronics aspects of nuclear reactor system behavior than either method alone. The deterministic approach may also be favored by the need for coupling the neutronics models with other deterministic models (e.g., thermal hydraulics system models) with which data is dynamically shared, and in fact neutronics models are ideally organized from the outset to take advantage of inherent couplings of neutronic behavior to the thermal hydraulic, structural, and possibly the radiochemical behavior of the reactor system. Existing and improved stand alone models should be adapted to ultimately serve as sub-models within a multi-physics, multi-scale, and probably multiprocessor approach. The goal is to provide reactor concept design tools that can predict the overall impact of the neutronics on the system as a whole (e.g., plant operations, safety analysis, economics and efficiency) by computing a coupled multi-physics simulation of the underlying behavior with all relevant feedback mechanisms taken into account. 
Existing reactor core thermohydraulics codes use the traditional single-channel or sub-channel approach to model reactor core heat transfer. This is clearly inconsistent with the goal of a first principle type of methodology that this project is pursuing. The advantage of a more first-principles based approach is the ability to generate data for a much greater range of conditions than is possible with empirically based codes. The latter depend greatly on using empirical correlations of global quantities that are valid only for the specific designs for which they were tested - that is, they have very little true predictive capability. A general thermal hydraulics tool has to be capable of treating both single-phase and multi-phase fluid flows in coolants ranging from gas to liquid metal. For the purposes of the fast transmutation reactor, in normal operating conditions single phase fluid models are adequate, but these must be augmented with multiphase and free convection models for accidental scenarios (coolant exposure, pump shutdown, etc.). Additionally, both steady state and transient solutions are required for the full range of phenomena to be studied.

Computational fluid dynamics (CFD) is the general terminology for the numerical solution of the NavierStokes equations. If solved using direct numerical simulation (DNS), the Navier-Stokes equations can represent all regimes of flow from laminar to fully turbulent. Since even the largest and fastest computers available today are not capable of solving the full range of energy transferring scales in a fully turbulent flow, some degree of physics approximation is still required even with this technique, and thus some experimental insight for modeling and validation is needed. A CFD approach can, however, be adopted to achieve the degree of accuracy and confidence that are essential parts of the scopes of this project, provided that the computational burden stays reasonable and that results obtained with this methodology can be physically validated.

For a better understanding of the physics behind the single-phase operational mode of reactors, we can couple high performance stochastic and deterministic neutronics tools to coupled flow and thermal transport tools. The goal is to model in three dimensions, with fine resolution, the local- to global-scale effects for a representative reactor core rod bundle in operational mode. For the simple channel flow of a rod bundle, the code structure of choice may be a structured grid with adaptive mesh refinement. For more complex geometry and piping, an unstructured grid CFD tool may be preferred.

The analyses of accident scenarios pose additional challenges. An accident scenario in a liquid-cooled reactor usually results in boiling or voiding of the coolant and condensation of liquid on cold structures. The excess temperatures and voiding of coolant can cause melting of fuel and cladding. All of these processes are transient, have strong, nonlinear feedback effects on fluid displacement, and the whole process can occur in seconds. The current approach to the analysis of accident scenarios is through the use of semi-empirical tools with adjustable parameters and models determined from experiment. An analysis based on first principles would require multiphase, multi-component fluid dynamics with variable core geometry and the characteristics of the fluid dynamics would vary through initiation to the final stages of the accident.

There are a number of research challenges that must be addressed to design an efficient and accurate modeling tool. The current capabilities for solving incompressible and compressible flow must be extended to the regimes that exist in nuclear reactors with large temperature variations. The high-orderaccurate solution of the Navier-Stokes and heat transfer equations in fluid regimes can be coupled to highorder-accurate solution of heat transfer in solid regimes. These schemes can be extended to use adaptive mesh refinement, and the coupled scheme must be scalable on parallel computers. The coupling of the flow and heat transfer models to the neutronics tools will require research into ways to couple these models which are solved on different grids and evolve at different time scales. Considerable work will be required to develop effective techniques to verify and validate the approach. Through the use of structured and unstructured grids and high-order accurate methods resulting schemes will be very efficient and will allow the rapid evaluation of various design and accident scenarios. 
Structural mechanics software development has been driven by a breadth of applications over the last thirty years which include aerospace, national defense, civil infrastructure, and, in the 70's and 80's, nuclear reactor technology. These developments have led to a number of finite element based computer programs that have mature element technologies and solution algorithms. Existing software that has application relevance in the nuclear fuel cycle area can generally be divided into three categories: linear finite element programs, implicit time integration nonlinear finite element programs, and explicit time integration nonlinear programs. In addition to the general-purpose structural mechanics software just mentioned, the nuclear power industry has a unique need to incorporate soil-structure-interaction (SSI), whereby the coupling between massive concrete containment systems and the surrounding supporting soil is accounted for in earthquake response simulations. Special purpose linear, frequency domain programs were developed in the 70's specifically to simulate SSI effects, and these programs are still the standard tools today. The existing SSI programs typically must idealize the nuclear plant superstructure with very simplistic structural models in order to arrive at reasonably executable models.

In terms of future advancements, there is a compelling need for development and implementation of advanced material constitutive models that can accurately represent the time dependent behavior of materials in extreme environments. These should address the effects of high radiation levels, extreme temperatures, and chemical interactions on material behavior. Advanced materials models should account for the fully $3 \mathrm{D}$, multi-axial states of stress both at low strain rates (normal operations), and at high strain rates (accident scenarios). The development of macroscopic, continuum based phenomenological models must progress in parallel to fundamental materials science research aimed at understanding microscopic material behavior in extreme environments. It is essential that the materials science community work hand-in-hand with the structural mechanics community to ensure that constitutive models represent an appropriate balance between characterization of material behavior and numerical efficiency and stability in finite element implementations.

Recent developments in solid/structural mechanics have moved towards a merging of capabilities from traditional solids hydro-type codes, which have pushed the computational technologies for representing extreme deformations and flow of materials, with traditional structural type elements. Such codes have been developed in frameworks that prevent mesh tangling at extreme ranges of response. This has begun to open up substantially the types of problems that can be modeled for extremely nonlinear accident scenarios. Pushing these developments towards a logical conclusion, it would be very desirable to move towards a single program that can solve multiple problems associated with slow (static and quasidynamic) phenomenon associated with operations, slow accidental events like earthquakes, and also accurately simulate extreme accidents associated with very rapid transients such as pipe breaks.

Direct coupling of multi-physics codes can result in more realistic representations of actual behavior and eliminate the need for grossly-approximated hand-offs between codes representing different physics. There are two areas where coupling of structural mechanics codes can enhance existing capabilities. In reactor analysis, vibrations induced by fluid structure interactions can be a problematic design issue. Explicit coupling of CFD and structural mechanics codes would be useful in rigorously modeling and addressing this issue. Coupling between neutronics and structural mechanics codes would also permit the effects of radiation on materials to be explicitly represented for various structural components. The neutronics coupling would allow direct, time-dependent integration of the effects of radiation on the embedded materials models.

With the advent of high performance computers, a rigorous, fully coupled simulation of a combined soilstructure system is within our computational grasp. With appropriate development of an interface model between the soil and the structure foundation, it would be feasible to execute a time domain simulation, including nonlinearities in the soil and superstructure, with a fully 3D detailed model of the 
superstructure. Such an analysis would bypass the coarse idealizations of the superstructure system currently embedded in typical SSI simulations.

Balance of plant (BOP) modeling (e.g., piping, valves, heat exchangers, pumps, power conversion units, and reactor containment systems) is required during the plant design in order to determine system operating parameters and performance, as well as to perform overall reactor system design optimization. Reactor control system design and development must also include simulation of the balance of plant systems. Finally, reactor safety analysis must include a balance of plant simulation in order to provide appropriate boundary conditions to the reactor core during transient events.

Traditionally, the codes used to perform these simulations have been independent, with minimal overlap of component simulation algorithms. An overall objective of this task is to develop high fidelity balance of plant simulations that can be used for both design and safety analyses and that can be easily used to investigate multiple design options. BOP simulations will require the capability of modeling multidimensional fluid flow, natural circulation, and transients in order to effectively simulate BOP performance. The application must be capable of using code and input uncertainties to quantify uncertainties in reactor limits, and it must have a complete validation and verification package developed. Longer-term requirements include those discussed above, plus the capability of investigating multiple BOP and power conversion system types, highly-detailed component simulations, the ability to operate on next generation computational platforms, multi-physics interfaces, and the ability to verify and validate the algorithm.

Near-term objectives focus on supporting the ABR deployment effort and include the development of a requirement set for BOP simulation, evaluation of existing BOP simulation methodologies, component models, etc., and a down-selection of the most appropriate methodology or methodologies. Intermediateterm objectives include development of appropriate interfaces with the design/optimization, instrumentation and control, and safety codes, integrating the BOP methodologies into this code or codes, identifying existing data to benchmark BOP simulations, outlining additional data that is required to complete benchmarking, and developing a validation package for the BOP simulation to use in ABR licensing arguments. Long-term objectives include developing a fully integrated BOP simulation package that can be used across all technical areas that is flexible enough to incorporate multiple high fidelity process designs (e.g., Rankine cycles, Brayton cycles, multiple heat exchanger designs, and multiple control designs), porting to high performance parallel computational platforms, developing interfaces with other design physics codes, and developing a validation package appropriate for licensing applications. This effort will support reactor system design, instrumentation and control, and safety analysis, providing a more consistent and high fidelity analysis package that will be effective across multiple disciplines.

Below are examples of short term milestones and mid to long term goals. Details here will depend on an available budget.

Short term milestones:

In the short-term, the focus will be on modifying existing codes or writing codes that use existing physics models to run on advanced computers, and identifying gaps in existing data, models, and knowledge that can be addressed in the longer-term.

- Complete deterministic neutronics code

- Fully parallel version with 2nd order formulation using unstructured mesh

$\circ$ Determine design parameter sensitivity analysis.

- Initial high-fidelity benchmarks on large $(1000+)$ processor configurations Push scalability on $\mathrm{BG} / \mathrm{L}$ 
- Complete core thermal-hydraulics code

- Fully parallel CFD with heat transfer

- Rigorously evaluate models for LES of liquid metals

- Rigorously evaluate models for density driven flows in liquid metals

- Initiate development of modern transient system analysis code

The validation of codes would be conducted in the following areas:

- Demonstrate improved transport methods and experiment analysis using modern methods, recalculate

- Superphénix rod worth - original diffusive transport and course mesh methods showed large errors in Superphénix rod worth

- Recalculate EBR II fuel burn-up with modern methods - validate against extensive physics data base.

- Recalculate EBR II blanket isotopic predictions - diffusion transport through steel is very inaccurate and resulting predictions of blanket isotopics were inadequate

- Demonstrate improved ability to analyze fast reactor irradiation experiments

- Recalculate Phénix fuels data with modern transport methods

- Use full 3D neutronics calculations in Phénix to better understand and analyze experimental data

- Demonstrate Improved thermal- hydraulics

- Apply modern CFD methods to simulation of electrically heated, sodium cooled, rod bundle experiments

- Apply fine mesh CFD calculations to better represent and understand thermal-hydraulics in fast reactors and use results as basis for reduced hot-channel factors

- Perform simplified experiments to validate CFD turbulence models for sodium coolant Mid to Longer-term Goals

- Develop algorithms for, and perform, high-fidelity coupled neutronics, thermal-hydraulics, mechanics calculations to further understand passive safety and reduce design margin

- Develop and demonstrate improved formalism for validation, uncertainty characterization, and propagation

- Complete soil-structure coupling framework and perform SSI analysis

- Incorporate existing mechanical response models

- Experiment with higher-order T-H/neutronics coupling as necessary

- Simulate range of passive safety scenarios on full core geometries

- Demonstrate improve models and codes for ex-core components of the primary system and balance of plant

- Develop advanced multiphysics solution algorithms and mesh generation

- Develop advanced multiphase CFD methods

- Implement capability for integrated assessment and optimization of the entire fast reactor plant

\subsubsection{Separations Technologies}

Modeling of a separations process involves many complicated steps, each of which requires knowledge of several areas of physics, chemistry, or engineering. Fuel disassembly involves mechanical processes 
(chopping, and filtering) and/or chemical dissolution in strong acid. The fuel solution is then passed through many stages of solvent extraction in order to separate several fission product and actinide streams. Several separate, solvent extraction processes are required to accomplish this separation, each using different additives and components in the organic phase, as well as different acid concentrations in the aqueous phase. Safety considerations require monitoring of volatile fission product and organic gaseous releases, careful evaluation of component inventories in each stage and even in piping, to avoid costly shutdowns or repairs which must be performed remotely, strict attention to nuclear criticality safety in actinide solutions with widely varying component inventories, and control systems which are based on realistic models of processes, not generalizations or even intelligent assumptions. The hazards of plant operation involve radioactive materials, toxic materials, strong acids, highly flammable materials, and highly volatile materials. Thus, detailed accounting of all components through all process stages is of utmost importance.

Current reprocessing models provide only qualitative descriptions of process behavior. Empirical models of chemical behavior for major components are used to provide overall descriptions of various reprocessing strategies. These empirical models are based on benchtop experiments, and usually assume chemical equilibrium conditions are met instantly. Even then, current models are unable to answer many questions involving phase equilibria, such as precipitation from solution or determining oxidation states, where multiple possibilities exist. Very few reaction rate constants are known, and wherever transient conditions are simulated, they are usually just assumed or selected heuristically.

Hence, in order to support both detailed design and safe operation, the improvement of models for separations processes requires improved chemistry modeling, including both equilibria and kinetics. New fuel materials and requirements arising from nonproliferation concerns demand the use of modern sophisticated modeling tools for the design and optimization of a process consisting of several major steps, each of which presents its own chemical and physical complexity. None of these steps is adequately simulated in a production sense, and some require experimentation to understand or confirm their chemical behavior. Advanced simulation can be used to help understand and optimize these processes, as well as integrate their behavior into the overall model. Added value can come from the optimization of the fuel cycle as a whole, and the possibility of detecting diversions, criticality problems, or possible effluent composition deviations outside specifications.

In addition to improved chemistry, additional elements of separations systems must be modeled which are currently not even considered. Fluid dynamics must be considered in piping as well as in process equipment. Effects of control systems on component inventories, and vice versa, are necessary to adequately understand inventories throughout the plant. Interfaces with nuclear criticality calculations are important for both design and safe operation. Balance-of-plant modeling (such as volatile releases to the environment) must be included. It is essential that computer codes be flexible, adaptable, and modular. They must not only be compatible with other codes which perform related or concurrent calculations, but they must be designed to function within larger systems of codes.

Below are examples of short term milestones and mid to long term goals. Details here will depend on an actual budget. The work here is further broken down to aqueous separations and pyroprocessing.

\section{Aqueous Separations}

Short-term Milestones

- Develop tools to predict thermodynamic properties and kinetic data for actinides and fission products to improve aqueous separations predictions

- Demonstrate initial CFD code for centrifugal contactors including multi-phase flows and turbulence 
- Develop separations plant mass balance using yield predictor models to support cost and proliferation risk reduction goals

The validation experiments would be conducted in the following four areas:

- Obtain partitioning data and kinetic data for U, TRU, Cs, Tc, Eu and Nd to validate test model

- Obtain three phase data for centrifugal contactors to validate the CFD code predictions

- Obtain data for auxiliary units to determine values needed for yield predictor model to obtain a full mass balance for the process

- Complete coupled end-to-end test from receipt of LWR fuel through remote production of actinide-bearing (particularly americium and curium) fuels samples for in-reactor testing

Mid and Longer-term Goals

- Develop tools to predict thermodynamic properties and kinetic data for all actinides and fission products to improve aqueous separations predictions

- Develop CFD modules for unit operations were hydraulics and solids handling are critical for plant performance and reliability

- Full-scale simulation of the plant to increase the accuracy and confidence of calculations used for cost and proliferation risk reduction goals

The validation experiments would be conducted in the following areas:

- Refine and improve calibration of multiphase flow modeling and reaction kinetics

- Integrate molecular-level simulation into advanced solvent extraction contactor simulation

- Demonstrate advanced codes for priority processes

- Continue auxiliary instrumented experimentation in support of modeling and simulation

- Simulation-driven scale-up design and optimization of contactors for multi-stage, multi-feed, solvent extraction

Pyroprocessing

Short-term Milestones

- Electrochemical Cells

○ Initial framework for integrated electrochemical cell simulation capturing salient cell phenomena for electrorefining and electroreduction processes

- Map current distribution in cell

- Identify concentration of ionic species in electrolyte, at anode and at cathode

- Elucidate process reaction kinetics

- Requires parallel computing resources are for efficient solution of coupled nonlinear partial differential equations in three dimensional space and time

- Thermodynamic Properties

- Initial model development describing thermodynamic activity of relevant species based on measured or predicted data

- Build corresponding thermochemistry database to support model development 
- Transport Properties

- Review and evaluate existing correlation models for relevant transport properties

- Develop initial model from review to predict transport parameters

- Reaction Mechanisms

- Evaluate and adapt existing electron transfer reaction mechanisms for electrorefining process

- Develop initial framework for electron transfer reaction mechanisms occurring in electroreduction

The validation experiments for Predictive Model and Cell Simulation Validation would be conducted in the following areas:

- Electrorefining and electroreduction cell fabrication and testing to validate simulation

- Determine diffusion coefficients of relevant species in molten salt systems

- Activity coefficient measurements in molten salt systems

- Electron transfer reaction kinetic studies

- Evaluate effects of "side" reactions on electrochemical systems to

Mid and Longer-Goals

- Electrochemical Cells

- Detailed framework for an integrated electrochemical cell simulation capable of accurately following all salient cell phenomena

- Electrorefiner cell model that simulates complex solid formation at electrode

- Electroreduction cell model that simulates gas evolution at anode and phase conversion at cathode

- Thermodynamics

- Accurate predictive model for thermodynamic properties of species important to pyrochemical systems

- Transport Properties

- High fidelity model describing transport properties in molten salt systems including ion ion interactions via molecular dynamics and other simulation systems

- Reaction Mechanisms

- Final model describing electron transfer reaction mechanism for electrorefining process

○ Detailed framework for electron transfer reaction mechanisms for occurring in electroreduction

\subsubsection{Waste Management and Advanced Waste Forms}

The success of the GNEP initiative would mean that a very different incoming waste stream could be sent to a geologic repository than the waste stream (mostly commercial LWR spent fuel) currently planned This new waste steam, consisting mainly of fission-product wastes from recycling, will ultimately require that a repository be analyzed for the purposes of compliance with NRC regulations, and perhaps have its 
design tailored to take advantage of the significantly reduced loadings (heat loading, mass loading, and much shorter overall half lives) that the new waste stream would represent.

\subsection{Crosscutting Technologies}

Modeling and simulation of advanced nuclear fuel cycles will require a hierarchy of models of vastly different physical systems across a wide range of space-time scales, from detailed molecular dynamics of new materials to systems level simulation of the entire cycle. The final goal will be optimization in the presence of modeling and input uncertainty in order to design safe, reliable, economical, and socially acceptable end-to-end solutions for nuclear energy production. While there have been many advances in fundamental enabling technologies in mathematics and computer science in the past, additional research and development will undoubtedly be required to tackle a problem of this scale. This will be done in close collaboration with the DOE's Office of Science

At each level, new enabling technologies will be required in order to enhance predictive capability, understand and propagate uncertainties, model unresolved physics, and couple multiple physical models at a wide range of space-time scales. Likewise, new research and development is required to analyze, visualize, and optimize the results of such large simulations and to do so in a way that is useful to designers and decision makers who must be fully aware of the limitations of the computational predictions and the uncertainties inherent in the simulated results due to the inevitable uncertainties of input parameters and modeling assumptions. Associated with this is the stringent need to establish careful protocols for simulation code verification (are you solving the model correctly?) and validation (does the model represent reality?). These tools must be uniformly accessible within an integrated computational environment that reduces time-to-simulation, provides compatible geometry representations, and allows for a hierarchy of model fidelity running on workstations to state-of-the-art parallel computer architectures.

Finally, continued research and development of new high performance computer architectures and systems software are required to meet the future needs of this initiative where first-principle simulations of fuel cycle elements are combined for system-level simulation and optimization under uncertainty.

\subsubsection{Multi-physics Coupling}

Predictive simulation of each process within the GNEP fuel cycle requires accurate solutions to multiple, simultaneous nonlinear physical processes. Traditional simulation approaches to this problem involve segmented solution techniques whereby the simultaneous physics are assumed to proceed in a sequential, loosely-coupled manner. Such a solution approach is not nonlinearly consistent, is prone to numerical errors (particularly sensitive to time step size), and in some cases does not even converge (exhibits zeroth order errors). Such an approach is in general not predictive. A fully-coupled, nonlinearly-consistent multiphysics time integration algorithm, such as that offer by Jacobian-free Newton-Krylov algorithms, solves this problem. Multi-physics coupling efforts will also provide common computational tools and interface structures, through executables and/or modules, to unite the varied temporal and spatial discretizations of each physics package to provide a consistent basis for analysis and information propagation. These products and interfaces will be used by facility designers to integrate multiple state-of-the-art physics simulation packages to provide a generalized coupling. The extensive R\&D results conducted in the DOE ASC and DOE/NSF SciDAC programs will be examined and may provide a coupling mechanism for facility-specific research. This work will not only payoff in more accurate, predictive simulation results, but in many cases result in increased efficiency (time to solution) by virtue of being able to take a larger integration time step per given level of desire temporal accuracy.

The algorithmic and software coupling of multiple physics modules and codes will provide analysis capabilities for the design, construction, and operation of near-term facilities (short- and intermediate- 
term objectives) and must integrate the current best-in-class, qualified simulation tools. However, utilizing high-performance computational systems, high-fidelity simulation packages may be tightlycoupled to provide a fully-integrated facility simulation that will provide substantial impact on the viability of commercial-scale facilities. Associated strategies for Multi-physics Coupling include:

- Utilizing and developing advanced computational algorithms for fully-coupled, nonlinearlyconsistent multi-physics time integration techniques

- Providing the improved algorithms via standardized software interfaces for the communication of information from each physics package

- Developing generalized interpolation, integration, extrapolation routines to ensure compatibility of solution with different geometric representations and time-scales

- Integrating tightly-coupled physics packages into a unified module to provide an efficient solution on high-performance computing architectures.

\subsubsection{Optimization and Confidence Analysis}

Sensitivity analysis is used to determine the change in a computed result due to a change in some input parameter used in the calculation. When this sensitivity information is combined with knowledge of input data uncertainties, the standard deviation in the computed result can be determined. Sensitivity and uncertainty $(\mathrm{S} / \mathrm{U})$ analysis will be an important component in the Modeling and Simulation program, not only for performing methods/data V\&V studies, but also for certifying that a proposed system design satisfies all performance and safety specifications. This is especially significant for GNEP because the proposed reactor and fuel processing/reprocessing systems have not been previously characterized by measurements. Specifically, S/U methods can provide the following types of information:

- Improved physical insight into the underlying phenomena governing the system of interest, by indicating relationships between variables. This is often useful for guiding design modifications and interpreting hypothetical accident scenarios.

- Realistic, best-estimate design margins that can reduce the tolerances obtained from boundinganalysis.

- Quantitative ranking of important modeling/data parameters that impact the calculated results. This analysis can identify major sources of uncertainties and can determine the required measurement accuracy in the input data necessary to achieve a desired accuracy in the computed results.

- Rapid (but approximate) evaluation of how design perturbations affect computed output parameters. This can be coupled to a system optimization algorithm.

Although developed most extensively for criticality safety and reactor physics analysis, sensitivity techniques can also be applied to other types of calculations needed in the overall GNEP program, including shielding evaluations for reactors, reprocessing, and transportation systems, fuel depletion studies of actinide burning, core lifetime, and proliferation indicators, ex-core fuel cycle parameters such as source term activities/decay heat, and safety analysis involving reactor kinetics with thermal hydraulics feedback.

Several techniques have been previously developed for $\mathrm{S} / \mathrm{U}$ analysis of the above types of calculations. Among these are deterministic methods based on perturbation theory or automated differentiation methods, and stochastic techniques based on perturbation theory or statistical sampling of the model. The different approaches each have advantages and disadvantages, so that in practice a combination of the methods may be necessary for a given application. Regardless of the approach, a number of significant 
challenges must be addressed. The $\mathrm{S} / \mathrm{U}$ methods should be able to address $3 \mathrm{D}$ system designs, possibly with multi-physics coupling. Time-dependent problems for core burnup and kinetics, as well as radioactive waste transmutation, must be addressed. Nonlinearities can cause problems with first-order perturbation theory methods. An efficient technique to address distributed output parameters (in space or time) must be developed. A realistic collection of uncertainties in data describing neutron and photon interactions, radioactive decay/emission, thermal hydraulic properties, and possibly mechanical properties must be assembled. In spite of these serious difficulties, the required $\mathrm{S} / \mathrm{U}$ methods for the simulation and modeling program should be tractable, since considerable expertise has been gained through previous work.

\subsection{Cost Estimates and Milestones}

Table 13. Modeling and Simulation Cost Estimates*

\begin{tabular}{|c|c|c|c|c|c|c|}
\hline \multicolumn{7}{|c|}{ Cost Estimates (\$M) } \\
\hline Activities & FY07 & FY08 & FY09 & FY10 & FY11 & FY12 \\
\hline Modeling and Simulation & 9 & 53 & 100 & 100 & 100 & 100 \\
\hline Long-term R\&D Total & $\mathbf{9}$ & $\mathbf{5 3}$ & $\mathbf{1 0 0}$ & $\mathbf{1 0 0}$ & $\mathbf{1 0 0}$ & $\mathbf{1 0 0}$ \\
\hline
\end{tabular}

* Funding reflects only DOE-NE contribution. 
Table 14. Modeling and Simulation Milestones

\begin{tabular}{|c|c|}
\hline Milestones & Date \\
\hline \multicolumn{2}{|l|}{ FY07 } \\
\hline $\begin{array}{l}\text { Complete simulations of heat transport and oxygen diffusion coupled with } \\
\text { thermal expansion in UO2 fuels with metal cladding }\end{array}$ & September 2007 \\
\hline $\begin{array}{l}\text { Complete models of thermo-mechanical properties and phase stability of metal } \\
\text { fuels }\end{array}$ & September 2007 \\
\hline Status report on oxide model development for SE2 & September 2007 \\
\hline Report on uncertainty quantification for selected ATWS sequences & September 2007 \\
\hline $\begin{array}{l}\text { Status report on multiphysics coupling algorithms and their application to nuclear } \\
\text { reactor simulation }\end{array}$ & September 2007 \\
\hline \multicolumn{2}{|l|}{ FY08 } \\
\hline $\begin{array}{l}\text { Elicit, analyze, validate, and document the GNEP business (why) and functional } \\
\text { (what) requirements for all Modeling and Simulation activities. The M\&S } \\
\text { requirements should reflect and be constrained by the design and deployment } \\
\text { schedule for the CFTC, the ABR, and the AFCF. }\end{array}$ & December 2007 \\
\hline GNEP System Level Planning Tool Design Document & September 2008 \\
\hline Formal software releases in support of ABR design studies & September 2008 \\
\hline \multicolumn{2}{|l|}{ FY09 } \\
\hline $\begin{array}{l}\text { M\&S tools (legacy and developing) directly supporting the ABR will be } \\
\text { identified, qualified through V\&V assessments, and placed under configuration } \\
\text { control in conformance with a QA plan. }\end{array}$ & December 2008 \\
\hline $\begin{array}{l}\text { M\&S tools (legacy and developing) directly supporting the UREX+CFTC will be } \\
\text { identified, qualified through V\&V assessments, and placed under configuration } \\
\text { control in conformance with a QA plan. }\end{array}$ & December 2008 \\
\hline $\begin{array}{l}\text { M\&S tools (legacy and developing) directly supporting the AFCF will be } \\
\text { identified, qualified through V\&V assessments, and placed under configuration } \\
\text { control in conformance with a QA plan. }\end{array}$ & December 2008 \\
\hline Formal V\&V assessment of ABR software & March 2009 \\
\hline Initial GNEP System Level Planning Tool 1.0. & September 2009 \\
\hline Formal software releases for ABR design studies & September 2009 \\
\hline \multicolumn{2}{|l|}{ FY10 } \\
\hline Demonstration of simulation capabilities for ABR & December 2009 \\
\hline GNEP System Level Planning Tool 2.0. & June 2010 \\
\hline \multicolumn{2}{|l|}{ FY11 } \\
\hline GNEP System Level Planning Tool 3.0. & March 2011 \\
\hline \multicolumn{2}{|l|}{ FY12 } \\
\hline GNEP System Level Planning Tool 4.0 & September 2012 \\
\hline
\end{tabular}




\subsection{International Safeguards and Proliferation Risk Reduction}

This section of the GNEP Technology Development Plan discusses actions to address technical and regulatory aspects of the application of IAEA safeguards at the three planned GNEP facilities (Consolidated Fuel Treatment Facility, CFTC; Advanced Burner Reactor, ABR; and Advanced Fuel Cycle Facility, AFCF). It also anticipates future requirements related to IAEA safeguards of the anticipated future expansion of nuclear energy, including full-scale GNEP system deployment. While the initial three GNEP facilities will be built in the U.S., which as a nuclear weapon state does not pose a risk of host-state proliferation, the international safeguards actions discussed below are also "forward looking" and anticipate the IAEA safeguards challenges that construction of GNEP facilities in non-nuclear weapon states (NNWS) would pose.

The planning horizon of this document focuses on activities to be carried out over the next five years and in particular activities to address critical international safeguards needs in support of GNEP facilities and the Secretary's decision in June 2008 on path forward for GNEP. NNSA is developing a GNEP Nonproliferation Program Plan that will address a much broader set of near and long-term policy needs associated with GNEP, including international outreach and technical collaboration. The NNSA plan will thus provide a nonproliferation context for the narrower set of activities described below.

\subsection{Objectives}

\subsubsection{Support Secretarial Decision in 2008}

In order for the Secretary to evaluate whether to proceed with proposed GNEP facilities, it will be necessary to demonstrate that the enabling technologies for GNEP (materials separation, fast reactors, and recycling) can be implemented in a manner that satisfies IAEA safeguards goals and requirements. In order to provide such assurances, NNSA would participate fully in the design and development of the three GNEP facilities (CFTC, AFCF, and ABR). Such early involvement would enable NNSA to evaluate international safeguards approaches to the three facilities and identify areas of safeguards method and technology development to proceed past CD-1. Full participation with GNEP facility design teams would also enable the GNEP facilities to achieve an optimal balance between design concepts, physical protection arrangements, and international safeguards approaches.

\subsubsection{Tailor IAEA safeguards approaches to CFTC, AFCF, and ABR}

In the near-term, GNEP will seek to apply best practices, proven techniques and state-of-the-art measurement technologies and instrumentation to meet the requirements for international safeguards at the three facilities. Through involvement in the design process for GNEP facilities, modeling and simulation, and adaptation of current safeguards instrumentation, safeguards experts will be able to identify material balance areas and key measurement points for material accounting and monitoring as well as install needed equipment and capabilities.

\subsubsection{Advance the Safeguards "State of the Art"}

GNEP will provide an important opportunity to advance the safeguards "state-of-the-art" through demonstrating the use of advanced simulation and modeling techniques, developing improved process monitoring measures, and developing the next generation of techniques and instruments for materials measurement and analysis as well as containment/surveillance. The three GNEP facilities, and in particular the AFCF, will serve as test beds for advanced safeguards methods and instrumentation under real-world operating conditions. The successful demonstration of these systems and approaches will, in turn, provide the IAEA with proven approaches to ensure the safeguardability of GNEP facilities and technologies under consideration for export to a non-nuclear weapon state (NNWS). 


\subsubsection{Fulfill International Agreements}

Under the U.S.-IAEA Safeguards Agreement (INFCIRC/288), all U.S. nuclear facilities, except those involved in national security activities, are eligible for IAEA safeguards. Early determination of whether individual GNEP facilities will be added to the list of U.S. nuclear facilities that are eligible for IAEA safeguards will enable planning for IAEA safeguards at the individual facility to begin early in the design stages of the facilities. It is assumed that the GNEP facilities will be placed on the U.S. eligible facilities list (EFL), except where, upon careful analysis, implementation of IAEA safeguards can be expected to disclose activities or information of direct national security significance. Any such determination would be specific to the particular location of the facility, and the activity/information could be of current direct national security significance or a legacy of past national security operations at the selected location. The IAEA may, at its discretion, select one or more of the GNEP facilities that are on the EFL for actual IAEA safeguards and inspection. More detailed discussion of the procedures associated with placing a facility on the EFL can be found in the NNSA GNEP Nonproliferation Program Plan.

The GNEP fuel processing and fabrication facilities that are envisioned share similarities with fuel facilities that the IAEA now safeguards, but present many additional and unique challenges. Therefore, it is expected that developing IAEA safeguard approaches will require very thoughtful and iterative development. Accordingly, NNSA will begin work on these approaches at the conceptual design stages of the GNEP facilities, and begin engagement of the IAEA in discussions about IAEA safeguards for these facilities, well in advance of the time when the IAEA would finalize its facility selection decisions.

\subsubsection{Build Support for GNEP}

Early U.S. acceptance and demonstration of IAEA safeguards for U.S. GNEP facilities will promote U.S. objectives by demonstrating that GNEP can facilitate the expansion of nuclear energy while reducing the overall proliferation risk associated with civil nuclear facilities. Such a demonstration will likely be critical in building international support for GNEP.

Over the long term, demonstration of effective safeguard approaches at U.S. GNEP facilities will also help create the pathway for predictable and reliable fuel assurances. Successful implementation of reliable fuel assurances is a necessary element for the success of GNEP. Retransfers of U.S.-origin spent fuel to third parties that would use GNEP-type processing technologies for processing U.S.-origin spent fuel will require U.S. prior consent. Sec 131 of the Atomic Energy Act sets out the factors that the U.S. must take into account in deciding whether to grant such prior consent, including the adequacy of international safeguards as provided for in the applicable Agreement for Cooperation.

\subsection{Assumptions}

\subsubsection{IAEA Safeguards vs. Domestic Safeguards and Security}

In discussing safeguards and security, it is critical to distinguish "domestic" safeguards and security, and the risks they address, from IAEA or "international" safeguards and the host-state nuclear proliferation risk that they address. Within GNEP, there is a corresponding division of labor within DOE for domestic and international safeguards. "Domestic" safeguards include both physical security measures (i.e. guards, gates, and guns as well as facility design features) and domestic material control and accountability (MC\&A) measures designed to detect and deter the loss or theft of nuclear materials or acts of radiological sabotage by sub-state actors. "International" safeguards refer to efforts by the IAEA to detect state-level diversion of nuclear materials by independently monitoring and verifying declarations regarding nuclear facility operations and nuclear materials inventories. IAEA safeguards do not include physical protection, which remains a host-state responsibility. NA-24 retains primary responsibility for international (IAEA) safeguards, whereas NE is responsible for implementing domestic safeguards. 
The IAEA has its own set of requirements for its safeguards. Whether DOE safeguards and requirements in the 470 series of DOE Orders or NRC safeguards and security requirements in 10 CFR 73 (security) and 74 (MC\&A) will be the basis for the domestic safeguards and security approaches implemented by $\mathrm{NE}$ at the GNEP facilities would depend largely on whether those facilities will be licensed by DOE or the NRC.

As a nuclear weapon state (NWS), operation of GNEP facilities within the U.S. does not pose a risk of proliferation, properly defined as the diversion of nuclear materials or the misuse of a facility by the host state (in this case the U.S.) to acquire the nuclear materials needed to produce nuclear weapons. The domestic safeguards and security systems that will be developed and implemented at the U.S. GNEP facilities will address the risks of theft or diversion of nuclear materials from these facilities by a nonstate adversary or "insider" (e.g., a member of the plant operating staff), and the risks of acts of radiological sabotage by a non-state adversary. IAEA safeguards for these facilities will build upon domestic safeguards systems, and provide for independent IAEA verification of nuclear material accountancy at the facilities.

As a result, although domestic safeguards and security are separate and distinct from IAEA safeguards, one objective of the NNSA-led IAEA safeguards development effort will be to ensure that IAEA safeguards considerations are fully considered in developing domestic safeguards and security approaches for the three initial plants. NNSA will have a role for each of the three facility design teams and in the domestic safeguards and security development teams to promote the integration of IAEA safeguards considerations into the overall design and design optimization efforts for the three GNEP facilities. This, in turn, will provide a basis for developing IAEA safeguards approaches that are ready for use as these facilities are commercially deployed in various countries.

\subsubsection{Regulatory Requirements}

This plan assumes that U.S. GNEP facilities will be eligible for IAEA safeguards under the U.S.-IAEA Safeguards Agreement (INFCIRC/288), except where it is found that implementation of IAEA safeguards would reveal national security activities, and that the IAEA will select one or more of these facilities for safeguards. In addition, the ability to use these facilities as test beds and demonstration facilities for advanced approaches to safeguards, security, and proliferation risk reduction suggests that potential future domestic regulatory or international guidelines should also be anticipated in the design of GNEP facilities.

As noted earlier, if the facilities are built and operated under DOE Orders, then the DOE 470 series of Orders would establish the domestic safeguards and security requirements that must be met at the facilities. NNSA, as provided in Order 142.2, would be responsible for implementation of IAEA safeguards at these facilities, and would have the lead in developing and negotiating safeguards approaches that would be implemented if the IAEA selects the facility.

Adding specific GNEP facilities to the U.S. EFL is the first step in planning for IAEA safeguards at those facilities, since the IAEA must first select individual facilities on the EFL for actual implementation of safeguards to take place. Planning for safeguards on those GNEP facilities that are placed on the EFL would entail a number of activities:

- Incorporate IAEA safeguards considerations into facility designs in a manner consistent with the safeguards by design philosophy and draw upon the results of international safeguards systems development presented in Section 3.0 of this plan

- Engage the IAEA on possible selection of one or more of the U.S. facilities, including resolving such matters as whether the U.S. or the IAEA incurs the costs of those safeguards

- Develop facility design information to submit to the IAEA 
- Develop an overall IAEA safeguards approach to the facility to guide negotiation of the applicable Facility Attachment with the IAEA

- Support actual safeguards implementation at those facilities that the IAEA has selected for inspection.

In addition, it will be necessary to determine how U.S. legal and regulatory obligations to protect Restricted Data and Sensitive Nuclear Technology from disclosure to foreign persons, including IAEA inspectors, affect the IAEA safeguards approaches that are developed.

Finally, it will be necessary to determine whether the IAEA or the U.S. will pay for implementation of IAEA safeguards at any GNEP facilities that the IAEA selects. Since the U.S. is a nuclear weapon state, it does not pose a proliferation risk. On the other hand, GNEP involves developing a next generation of fuel processing facilities and reactors, some of which might be built in NNWS where the IAEA is responsible for verification of a state's obligations under the NPT and the Additional Protocol. In addition, GNEP offers an opportunity to demonstrate new safeguards technologies that will be of material interest to the IAEA.

\subsection{Proliferation Risk Reduction Assessment}

The GNEP Program will develop standards for proliferation risk reduction that will guide the design and operation of both individual systems/facilities and the overall GNEP architecture. The standards will then be used to guide the design and operation of GNEP from the perspective of proliferation risk reduction and physical protection. Both proliferation risk (PR) (host state diversion) and physical protection (PP) (non-state adversary theft of nuclear material or radiological sabotage) have intrinsic and extrinsic components that together provide a given level of robustness of a particular system. If goals exist for PR and PP, then design and operational features can be developed and introduced to meet these goals. This kind of assessment is necessarily a holistic assessment of vulnerabilities of a given system or facility to actions by both the host state and non-state actors, and of how to strengthen "system responses" to reduce the associated risks. This analysis takes into account many factors including facility design features, multiple attributes of nuclear material attractiveness, domestic and international safeguards and security measures, adversary pathways, etc. Effectively, the design and operations will be guided by the performance goals. Satisfying the goals may occur through various combinations of intrinsic and extrinsic features. There will, in fact, be interplay between the intrinsic and the extrinsic, and the overall balance would optimize cost effectiveness and efficiency.

The work of the PR \& PP Experts Group under the Generation IV International Forum is directly applicable to GNEP. This working group, which includes participants from several prospective GNEP partners as well as Euratom and the IAEA, is developing the appropriate measures and metrics for evaluating nuclear systems for PR \& PP. Furthermore a systematic, rigorous methodology is being developed to evaluate the measures. The GIF PR \& PP methodology can be adapted to GNEP needs and requirements.

It will be beneficial to begin, at an early stage, assessments of proposed GNEP systems (AFCF, CFTC, ABR) with the PR \& PP methodology. NNSA will lead this assessment, which will encompass a wide range of intrinsic and extrinsic measures for the initial GNEP facilities, including design features, domestic safeguards and security, and IAEA safeguards.

\subsection{Challenges in Meeting IAEA Safeguards Goals and Requirements for GNEP Facilities}

IAEA safeguards must confront a number of proliferation scenarios associated with peaceful nuclear energy production. Such scenarios include attempts by a state to acquire the necessary material for nuclear weapons through: 
- Diversion of declared nuclear materials suitable for manufacturing nuclear weapons or improvised nuclear explosive devices;

- Undeclared production of such materials within declared facilities;

- Using knowledge obtained from peaceful facilities to establish undeclared parallel facilities to support a weapons program; or

- Establishing latent capabilities for later use after abrogating nonproliferation commitments.

GNEP seeks to establish a paradigm for nuclear power development and wide scale deployment subject to safeguards that minimize these risks. IAEA safeguards address the first two risks. GNEP would address the other risks by constraining the spread of sensitive technologies, promoting universal adherence to the Additional Protocol that would enhance IAEA access to nuclear sites, and establish the fundamental distinction between supplier states and those that decide to abstain from enrichment or reprocessing.

\subsection{Goals and Requirements}

The IAEA detection goal for $\mathrm{Pu}$ (not under IAEA seal) is:

- During the annual Physical Inventory Verification, to have a $90 \%$ probability of detecting the diversion of 1 significant quantity (SQ) $(8 \mathrm{~kg})$; and

- To have a $50 \%$ probability of detecting the diversion of 1 SQ of nuclear material within 1 month of its diversion

In addition, IAEA safeguards define the quantitative effectiveness of safeguards by the net uncertainty of the material accountancy that is a consequence of the entire MC\&A system. Material accounting systems focus on the Inventory Difference (ID), which is the starting physical inventory (the input), plus additions to inventory (receipts), minus the known/authorized decreases from inventory (shipments), and the final physical inventory. The IAEA uses the term material unaccounted for (MUF) to refer to this inventory difference. The uncertainty associated with this MUF is the parameter used to measure the net uncertainty of material accountancy that is a consequence of the measurement uncertainty of the entire MC\&A system. Under the IAEA safeguard system, the uncertainty associated with MUF is the essential quantitative measure of the safeguards effectiveness. To satisfy IAEA material accountancy requirements, the measurement uncertainty associated with estimation of the MUF at the closing of the material balance is $2.43 \mathrm{~kg}$ of $\mathrm{Pu}$, which is an absolute number irrespective of the throughput of the plant. Under domestic safeguards, the measurement uncertainty for the inventory difference (the domestic term for MUF) is a very small percentage of the active inventory, so that the actual quantity of $\mathrm{Pu}$ this represents varies with facility throughput.

The overall IAEA safeguards approach that NNSA will develop will involve other methods, such as process monitoring and advanced containment and surveillance. Process monitoring provides a mechanism to detect possible modifications to process chemistry or design that could create or conceal a diversion pathway (e.g., causing different chemical reactions than should take place and that would divert fissile material into process pathways from which it should be absent.) Advanced and redundant surveillance measures can verify the absence of plutonium from those pathways, thus providing additional verification that diversion along those pathways is not taking place. Containment and surveillance systems can ensure that plant operations are not bypassed.

However, the existing IAEA safeguards protocols do not take quantitative credit for the contribution of these other measures, since they are not taken into account in calculating the uncertainty associated with the MUF. 
At large bulk-handling facilities, meeting these goals requires that the IAEA implement some form of process monitoring, typically Near-Real-Time-Accountancy (NRTA), to meet timeliness requirements with the requisite degree of accuracy. The IAEA, if it applies safeguards to the CFTC, AFCF and followon advanced reprocessing and pyroprocessing plants, will employ "solution measurement \& monitoring systems" in part to facilitate NRTA and traditional accountancy, and in part to serve as a C/S system to determine if the plant has been modified or if operations do not conform to operator declarations.

Depending on throughput and measurement capabilities for the various GNEP bulk handling facilities, the required measurement accuracy is anticipated to be very difficult to meet using existing equipment, and the IAEA may negotiate some additional measures under the facility attachment and safeguards approach. With this in mind, the IAEA safeguards approach for these facilities should be both creative (transformational) and extend the current state of the art.

\subsection{IAEA Significant Quantities, Conversion Times and Diversion Scenarios}

Table 15. Significant Quantities

\begin{tabular}{|l|l|c|l|}
\hline \multirow{5}{*}{ Direct-Use Nuclear Material* } & \multicolumn{1}{|c|}{ Material } & \multicolumn{1}{|c|}{$\begin{array}{c}\text { Significant } \\
\text { Quantity }\end{array}$} & \multicolumn{1}{c|}{$\begin{array}{c}\text { Safeguards } \\
\text { Apply To: }\end{array}$} \\
\cline { 2 - 4 } & $\mathrm{Pu}(<80 \% \mathrm{Pu}-238)$ & $8 \mathrm{~kg}$ & Total Element \\
\cline { 2 - 4 } & $\mathrm{U}-233$ & $8 \mathrm{~kg}$ & Total Isotope \\
\cline { 2 - 4 } & $\mathrm{U}[\mathrm{U}-235 \geq 20 \%]$ & $25 \mathrm{~kg}$ & $\mathrm{U}-235$ Contained \\
\hline Indirect-Use Nuclear Material** & $\mathrm{U}[\mathrm{U}-235<20 \%]$ & $75 \mathrm{~kg}$ & U-235 Contained \\
\cline { 2 - 4 } & Natural Uranium & $10 \mathrm{t}$ & Total Element \\
\cline { 2 - 4 } & Depleted Uranium & $20 \mathrm{t}$ & Total Element \\
\cline { 2 - 4 } & Thorium & $20 \mathrm{t}$ & Total Element \\
\hline
\end{tabular}

* NM that can be converted into nuclear explosive components without transmutation or further enrichment

** All NM except direct-use material

Table 16. Conversion Times (Weaponization)

\begin{tabular}{|l|l|}
\hline \multicolumn{1}{|c|}{ Beginning Material Form } & \multicolumn{1}{|c|}{ Conversion Time } \\
\hline $\mathrm{Pu}, \mathrm{HEU}$, or U-233 Metal & Order of Days (7-10) \\
\hline $\begin{array}{l}\mathrm{PuO} 2, \mathrm{Pu}(\mathrm{NO} 3) 4, \text { or other pure Pu compounds; HEU or U-233 oxide or other } \\
\text { pure compounds; MOX or other non-irradiated pure mixtures containing Pu, U } \\
\text { [(U-233+U-235) }>/=20 \% ; \mathrm{Pu}, \mathrm{HEU} \text { and/or U-233 in scrap or other } \\
\text { miscellaneous impure compounds }\end{array}$ & Order of Weeks (1-3) \\
\hline $\mathrm{Pu}, \mathrm{HEU}$ or U-233 in irradiated fuels & \\
\hline U containing $<20 \% \mathrm{U}-235$ and U-233; Th & Order of Months (1-3) \\
\hline
\end{tabular}




\subsection{IAEA High Level Diversion Scenarios}

Abrupt Diversion: The immediate diversion of a significant quantity or greater in a short time (typically a conversion period: 2 weeks to 1 month).

Protracted Diversion: The diversion of portions of a significant quantity over extended periods of time leading to a significant quantity or greater (typically an inventory period: 6 months -1 year).

\section{Safeguards Approaches for GNEP Facilities}

The task of developing IAEA safeguards approaches for the initial three GNEP facilities will bring a facility-specific focus to IAEA safeguards work on advanced reprocessing and pyroprocessing that NNSA and NE have been funding in several national laboratories for the past several years. In addition, much of the instrumentation and C/S effort that NNSA has sponsored in support of developing a detailed IAEA safeguards concept for the Japanese reprocessing plant at Rokkasho-Mura will be transferable, with facility-specific tailoring, to the CFTC facility. Likewise, collaboration with Japan on an IAEA safeguards concept for the JMOX fuel fabrication plant located in Japan will generate technical results that can be applicable to the fuel fabrication module in AFCF. IAEA safeguards measures for the Japanese fast breeder reactors will be assessed for transferability to the ABR.

There are areas where further development will be needed. These include, for example:

- Safeguards technologies for pyroprocessing methods and other advanced reprocessing flow sheets

- Gamma/neutron measurements of TRU materials

- Gamma spectroscopy analysis codes that are better suited for TRU-type materials produced in advanced reprocessing facilities

- Containment/surveillance capabilities, including thermal, laser, active/passive radio-frequency identification devices (RFIDs)

- Authentication for data/equipment sharing between facility operator and IAEA inspector

- Secure wireless communications between safeguard systems

- Use of advanced simulation and modeling methods for process and facility design to optimize integration of IAEA safeguards as part of the overall design optimization process for a given facility.

These are just some of the areas that must be addressed. As the design of the GNEP facilities progresses, we expect that our understanding of and approach to the IAEA safeguards challenges will be further refined. Indeed, this refinement process is one of the principal benefits to be gained from developing IAEA safeguard approaches for the three GNEP facilities, so that if such facilities are built in NNWS as GNEP evolves and commercial deployment begins, there will exist an effective IAEA safeguards approach for these kinds of plants.

\subsection{International Safeguards Approach for GNEP Facilities Role of GNEP Facilities}

Each of the three proposed GNEP facilities would contribute in different ways to achieving the overall policy goals of developing effective IAEA safeguards for the facilities, ensuring that an effective IAEA safeguards approach is developed in a time frame to support possible IAEA selection of the facility for its safeguards and inspection, ensuring that the IAEA has effective safeguards approaches for GNEP 
facilities wherever they might be built, supporting consensus that GNEP reduces proliferation risk, and advancing the technical state of the art for IAEA safeguards.

The CFTC would be an advanced separations facility to separate the components of spent fuel required by GNEP. Its principal mission will be to demonstrate the advanced aqueous separations process on an engineering to commercial scale. As a facility that handles commercial spent fuel, the CFTC would be eligible for selection under the US-IAEA Voluntary Offer Agreement. If selected, it will be subject to international safeguards requirements. "Safeguards by design" will be a key aspect of the overall design of the CFTC in order to optimize safeguards effectiveness and to minimize the cost and operational impact. This will include development of advanced safeguards approaches for a commercial-scale separations facility that uses the new GNEP separations process. Evaluations of CFTC for proliferation risk reduction must commence at the earliest practical time.

The AFCF would have an even more significant role in the GNEP program for safeguards by design. Unlike the CFTC, which would involve one process flow sheet, the AFCF offers the opportunity to explore multiple process flow sheets and to consider and define optimized safeguards approaches to each. The AFCF's flexibility is particularly well suited to support experimental and pilot-scale testing and validation of new safeguards systems and instrumentation. In addition, the AFCF project would include the development of advanced simulation and modeling tools for process and facility design and design optimization. This AFCF-related activity would offer NNSA an opportunity to use modeling and simulation methods to address IAEA safeguards for alternative flow sheets for advanced reprocessing and for pyroprocessing as well as fuel fabrication processes using the products of advanced reprocessing and pyroprocessing.

The AFCF would also be specifically designed to accommodate the Transformational Intelligent Accounting and Control (TIMC) methodology, as described in the NNSA GNEP Nonproliferation Program Plan. The focus would be on the processing portion of the AFCF since it is the chemical separations activities where nuclear material changes form while in a highly radioactive state. The combination of change in chemical form, restricted access to the process material and high ambient background condition are a few of the challenges that must be overcome to provide accurate estimates of the nuclear material inventory that is necessary to meet the safeguards obligation.

The ABR's principle mission is to demonstrate actinide destruction using advanced transuranic fuels in liquid sodium cooled fast reactors. As the ABR is a burner rather than a breeder reactor, and is essentially an "item count" facility, the ABR offers an opportunity to similarly demonstrate safeguards by design approaches to such issues as verifying the absence of blanket assemblies, and to demonstrate technologies for containment and surveillance that would reduce the IAEA resource burden (measured in inspectordays) for safeguarding this type of facility. If the ABR is collocated with the AFCF that would include a processing and fabrication module for handling the ABR fuel, there would also be an opportunity to demonstrate effective and efficient IAEA safeguards approaches for such co-located multi-facility complexes.

\subsection{Comprehensive Approach to Safeguards}

In general, both domestic and IAEA safeguards consist of three main elements: (1) traditional nuclear materials accountancy, including maintaining inventory records, taking actual physical inventories, and so forth; (2) more timely and sensitive safeguards measures (NRTA) that provide a nuclear inventory on a very short-term (e.g., daily) basis; and (3) process monitoring systems that provide timely indication of off-normal process operations that might indicate that diversion or undeclared production is taking place in the period between actual full physical inventories, and $\mathrm{C} / \mathrm{S}$ measures. Both domestic and international systems rely on inspection and verification to ensure that systems are implemented properly and functioning correctly. 
The GNEP facilities would offer test beds for improving these traditional safeguards capabilities through:

- Integration of process monitoring systems into IAEA safeguards

- Material monitoring systems to reduce measurement errors

- Near real-time accountancy techniques for advanced reprocessing flow sheets

- Advanced $\mathrm{C} / \mathrm{S}$ techniques to provide redundant IAEA safeguards system capabilities to verify the absence of plutonium from process streams that are consistent with facility declarations, for example.

These improvements are part of a comprehensive approach to international safeguards for GNEP. Under this approach, NNSA will work with NE to ensure that IAEA safeguards considerations are fully integrated into facility and process design from the earliest facility conceptual design stages onwards, including taking full advantage of the use of process modeling and simulation tools, employing advanced measurement techniques and instrumentation, and data integration and evaluation. The elements of this comprehensive approach to safeguards for GNEP are summarized below.

\subsection{Modeling and Simulation}

Simulation-based design is broadly used in many industries as a proven, cost effective approach to complex design problems - such as those involving facilities containing nuclear processes. With respect to GNEP, simulations of facilities, material flows, processes, transportation, and other critical elements will provide information on potential diversion signatures and the necessary safeguards strategies, designs, and technologies to detect diversion. Simulations will also be used to develop instrumentation requirements and validate tools and data. In short, simulations of facility processes along with safeguards and security systems will allow for optimization of proliferation risk reduction features and detailed costbenefit analysis. While all GNEP facilities will benefit from this approach, there will be a priority effort to develop and apply this powerful tool to processing and fuel fabrication facilities. The advanced simulation and modeling program element in GNEP, and the use of these techniques associated with the AFCF facility, will offer a particularly valuable opportunity to work with the developers of the simulation and modeling codes to incorporate IAEA safeguards into these codes. This effort is essential to model the impact that IAEA safeguards has on process operations and to determine the IAEA safeguards effectiveness.

\subsection{Safeguards by Design}

In designing and implementing IAEA safeguards for GNEP facilities, early integration of advanced safeguards into the facility design process ("Safeguards by Design") will minimize impact on operations, enhance efficiency of the safeguards system, and improve implementation of safeguards requirements to meet international standards and evolving safeguards demands. In short, "safeguards by design" produces a superior, more robust result at a reduced cost.

Safeguards by design will also allow for the integration of safeguards, physical protection, and proliferation risk reduction. This is necessary because beneficial actions in any one of these areas can results in detrimental impacts in at least one of the other areas. For example, materials selected to enhance proliferation resistance by decreasing the level of attractiveness for weapons purposes may complicate safeguards measurements. Moreover, such materials could arguably be more attractive to sub-nationals who are interested in producing radiological dispersal devices. Safeguards by design will be accomplished by having IAEA safeguards experts assigned to GNEP facility design teams, from day one, as full and equal partners. NNSA will lead the IAEA safeguards development effort, and will have a role in the teams for domestic safeguards and security design to ensure an optimal balance among facility design, 
safeguards approaches, and physical protection arrangements that is responsive to IAEA considerations. This integration will be a long term, iterative process essential to the success of the program.

\subsection{Advanced Measurement Technologies and Instrumentation}

Process monitoring for near real-time accounting (NRTA) includes the use of process data (flow rate, temperature, pressure, density, activity, isotopic distribution, etc.) at flow and inventory key measurement points (FKMPs and IKMPs) as well as Other Strategic Points (OSPs) to draw frequent conclusions on plant configurations, operations, and material flows/inventories at the level of a material balance area and/or process unit. These conclusions provide assurances that facility operations are as declared.

In order to meet the verification objectives of the IAEA, several types of measurement and verification technologies are employed. These include non-destructive assay (NDA), analytical/destructive assay (DA), and containment/surveillance $(\mathrm{C} / \mathrm{S})$.

- Nondestructive assay (NDA) refers to techniques that actively or passively interrogate emanations (neutron or gamma radiation, heat, etc.) from the material within a container and then extrapolate the material quantities of the contents of the entire container without opening the container or altering its contents. As a general rule, NDA is performed on entire process systems or containers, can be utilized on homogeneous or heterogeneous materials, and provides quicker measurements, but with higher total measurement uncertainty than destructive analysis (DA) for homogenous samples evenly distributed within a uniform matrix. Qualitative NDA provides information on the nuclear material type and location within the process system or waste container. Quantitative NDA provides an estimate of the mass for a specific isotope. As a result, additional information about material characteristics, obtained by destructive or other nondestructive measures, are often required.

- Destructive assay (DA) involves analysis of a sample's nuclear material content, isotope distribution, and/or other important attributes by methods that "destroy" (or more correctly, alter the composition of) the sample. The DA sample size can be smaller than the sample size for NDA, but it must be taken from homogenous material to be representative. DA measurements typically produce results with lower total measurement uncertainty, provided that the material sampled is homogenous. However, DA generally requires a longer turn-around time for results as well as specialized procedures and personnel protective equipment due to material handling requirements for sampling.

- Containment/surveillance measures encompass a broad range of technologies to ensure that previously measured material in containers remains in place and unaltered and that containers or items containing material remain in designated and recorded locations or move along declared and authorized paths. $\mathrm{C} / \mathrm{S}$ measures can range from seals, to devices that actively and passively certify locations of containers, to sensors that detect the proximity of materials in containers or items that move through processes.

For process facilities, these measurement technologies are traditionally applied to the entry and exit points, feed and withdrawal locations, the processing systems, the waste streams, the output streams, and any associated material storage areas. For reactor facilities, measurements are applied to fresh fuel, the core, spent fuel, transfer processes, and waste disposition. Where necessary, various NDA, DA and C/S systems can be combined and networked to integrate an unattended and remote monitoring capability into the process system.

Many GNEP processes, such as advanced reprocessing, pyroprocessing, and TRU fuel fabrication pose new challenges for international safeguards. In some cases, existing measurement techniques are directly applicable to the materials and conditions envisioned by the GNEP facilities (for example some of the 
technologies currently employed at reprocessing facilities and spent fuel storage locations). In other instances, adaptation of current techniques will be required to specifically address unique material compositions and process environment of the GNEP facilities (radiation background, nuclide isotopic, etc).

In addition, GNEP presents an opportunity to adapt, refine, and develop new measurement capabilities within the traditional technologies of NDA, DA and surveillance to achieve a significant improvement in the state of the art for international safeguards technologies for processing facilities in particular. Therefore, GNEP will adopt a three-phased approach to implement IAEA safeguards requirements:

- In the near-term, GNEP will seek to apply best practices, proven techniques and state-of-the-art measurement technologies and instrumentation to meet the requirements for international safeguards at GNEP facilities. Safeguards experts will work with various design teams to gather information on planned processes and equipment and determine diversion detection sensitivities associated with conventional accounting techniques applied in normal facility operating modes. This information will be used to recommend material balance area structures for material accounting, identify additional key measurement points and process monitoring activities, and implement necessary measurement equipment and capabilities. The NNSA will leverage ongoing collaboration with international partners to identify IAEA safeguards methods and techniques that will provide a near-term direct benefit to the GNEP objective of proliferation risk reduction. Some IAEA safeguards methods and systems will be initially tested at advanced fuel cycle facilities outside of the U.S. with follow-up validation at the U.S. facilities once they are online. This approach will facilitate "safeguards by design" for the U.S. GNEP facilities.

- In the mid-term, GNEP would seek to advance the safeguards state of the art through a development program to improve the precision, speed, sampling methods, and scope of nuclear process monitoring and accountancy measurements. Improved methods and instrumentation would be tested at the AFCF. These improvements will pay a high dividend in both process control and safeguards, as well as result in substantial cost savings. Once again, collaborative efforts with international partners would be leveraged to refine the IAEA safeguards systems through extension of existing safeguards cooperation agreements and negotiation of new agreements as is deemed necessary to advance the GNEP objectives.

- In the long-term, as specific facility designs and operating modes evolve, evaluation of the materials types and characteristics, process equipment and components, fuel types and characteristics would be used to adapt existing measurement techniques and drive the need for additional development. Ultimately, GNEP would seek to develop intelligent monitoring and control systems to meet safeguards requirements. Where appropriate, advanced methods and techniques would be provided to international partners and to the IAEA to strengthen the nuclear non-proliferation regime.

\subsection{Data Integration and Analysis}

Modern instruments and methods have made it possible to extract huge quantities of data from operating processes. For example, at the Rokkasho Reprocessing Plant in Japan, there are approximately one thousand sensors that monitor facility operations from the time that spent fuel arrives through its subsequent processing, product storage, and disposal through waste streams. This complex mix of sensors includes optical, radiation (destructive and non-destructive), mass, ultrasonic, pressure, level, temperature, infrared, load cell, magnetic switch, electronic seal, and volume sensors.

All of these sensors must be integrated and analyzed in near real time to attempt to meet IAEA detection goals in a timely fashion. The IAEA methodology involves first validating sensor input to assure that the 
data is authentic as well as investigating the potential for anomalies and their possible causes with the operator. This poses a special challenge because the IAEA must independently verify and authenticate operator data related to process monitoring, a standard practice in large throughput facilities. With a onemonth deadline on the determination of abrupt diversion, only rapid sensor data integration and analysis can accomplish this task.

To support GNEP, international safeguards systems must therefore have the capabilities to:

- Relay appropriate information to various organizational entities while at the same time meeting data security requirements

- Rapidly investigate summary and raw data to unequivocally separate process upsets, maintenance problems, and calibration and component failures from actual diversion events

- Securely archive data to support audit and inspection

- Report data to IAEA inspectors and allow the IAEA to access or duplicate sufficient measurements to verify and authenticate reported results, while at the same time protecting proprietary information, sensitive nuclear technology, restricted data, and/or other export controlled information.

In an effort to address the challenges mentioned above, GNEP will seek to develop a Transformational Intelligent Monitoring and Control (TIMC) system based on "best in class" intelligent data analysis and security systems developed and applied in other applications (such as intelligent supervisory control and data acquisition systems (iSCADA) and intelligent process control systems (iPCS)). TIMC will also build on developments in information operations and security, advanced secure data acquisition and transmission, and advanced modeling and control algorithms to develop innovative methods, systems and technologies for plant and material monitoring. A focus will be to feed transformational information analyses, control systems, and cyber security and monitoring into the design of the process. This will allow optimizing the design of instrumentation systems, plant layout, and cost-benefit, through extracting maximum knowledge from the combined, synthesized data.

The design of these systems will be carried out jointly with the development of advanced measurement techniques and instrumentation. This approach will allow for the exploitation of intrinsic features and signatures associated with a given nuclear process and/or material to provide data that can be quickly synthesized into safeguards knowledge while increasing cost effectiveness, assessment fidelity and accuracy. The approach may also provide additional security features to guard against the negative effects of possible abrogation of safeguards agreements.

NNSA will participate in the development of these advanced information management systems to identify and pursue their application to IAEA safeguards for the facilities. GNEP will utilize the most modern tools to marry the states of the art in information technology, cyber security, and communications with a systems level approach to process monitoring and safeguards. GNEP will leverage the work performed for intelligent systems to monitor plants for domestic purposes to address specific IAEA safeguardsrelated applications and issues regarding independent IAEA authentication and validation of signals and data from such domestic process monitoring systems.

\subsection{International Outreach and Engagement}

International cooperation in IAEA safeguards-related areas will be an important element of the activities discussed in this section of the roadmap. In particular, NNSA will pursue collaborations with international partners, including under the framework of the U.S.-Russia Civil Nuclear Energy Working Group, which offers opportunities to engage Russia on many of the safeguards areas outlined above. In addition, NNSA will utilize existing bilateral Safeguards Cooperation Agreements (SCAs) with important 
international partners to advance the global partnership objective of GNEP. The International Nuclear Safeguards and Engagement Program (INSEP) have eleven SCAs in effect. These SCAs are legal agreements for collaboration on international safeguards technologies (i.e., material control and accountability, physical protection, secure communications, containment and surveillance, environmental sampling, etc.) that provide an opportunity to integrate state of the art IAEA safeguards technologies into the design of the U.S. GNEP facilities. Collaboration on many of the advanced technologies needed for the GNEP facilities currently being conducted under the SCAs or broader government-to-government agreements on the peaceful uses of nuclear technology. In addition, INSEP has Sister Laboratory arrangements in place with many international partners that may be end-users of the GNEP product. These arrangements are non-binding agreements that advance the peaceful nuclear infrastructure of a state to support deployment of small reactors. INSEP currently has eight Sister Laboratory arrangements in place.

International cooperation will be carefully coordinated to address export control and classification issues. These issues are currently addressed under the auspices of the Safeguards Cooperation Agreements, Sister Laboratory Arrangements and other government-to-government agreements such as the Peaceful Uses of Nuclear Technology agreement with advanced fuel cycle partners and small reactor end-users. NNSA will provide policy and technical support to GNEP to determine how to adequately protect proprietary information from disclosure to international inspectors, as well as Sensitive Nuclear Technology and/or Restricted Data where and if such are present, and other export controlled information.

Finally, GNEP will include outreach to other global partners, including universities, for the purposes of demonstration and training. Outreach will provide a well-informed community of basic scientists and engineers, educators, and political scientists to interface with the general industry, government and the general population, to achieve a common perspective of GNEP. Such common perception is critical to long-term GNEP success. In addition, outreach will help develop the next generation of scientists and engineers trained in nuclear safeguards, security, and the many other disciplines required for expanded global use of nuclear energy in an environment of multi-national confidence with regards to the general reduction of proliferation risk. These professionals will do the work of GNEP in the future, providing safeguards and security advocacy and expertise for evolving nuclear technologies as well as a cadre of trained inspectors. These scientists and professionals will provide an avenue for developing a 'safeguards' culture for GNEP that is similar to the 'safety' and 'security' cultures that are essential elements of effective nuclear energy policy.

\subsection{Cost Estimates and Milestones}

Table 17. Cost Estimates for International Safeguards and Proliferation Risk Reduction

\begin{tabular}{|l|c|c|c|c|c|c|}
\hline \multicolumn{7}{|c|}{ Cost Estimates (\$M) } \\
\hline \multicolumn{1}{|c|}{ Activities } & FY07 & FY08 & FY09 & FY10 & FY11 & FY12 \\
\hline $\begin{array}{l}\text { Participate in GNEP facility design } \\
\text { teams [Safeguards by Design] }\end{array}$ & 0.2 & 2.0 & TBD & TBD & TBD & TBD \\
\hline $\begin{array}{l}\text { Advanced Safeguards Technology } \\
\text { and Approaches }\end{array}$ & 0.3 & 2.5 & TBD & TBD & TBD & TBD \\
\hline International Collaboration & 0.7 & 1.2 & TBD & TBD & TBD & TBD \\
\hline $\begin{array}{l}\text { Proliferation Risk Reduction } \\
\text { Assessment }\end{array}$ & 0.9 & 2.5 & TBD & TBD & TBD & TBD \\
\hline \multicolumn{1}{|c|}{ Total } & $\mathbf{2 . 1}$ & $\mathbf{8 . 2}$ & TBD & TBD & TBD & TBD \\
\hline
\end{tabular}


Table 18. International Safeguards and Proliferation Risk Reduction Milestones

\begin{tabular}{|c|c|}
\hline Milestones & Date \\
\hline $\begin{array}{l}\text { Fully staff GNEP facility design teams with laboratory and headquarters } \\
\text { safeguards experts }\end{array}$ & 2007 \\
\hline Support development of "safeguards by design" approach to GNEP facilities & 2007 \\
\hline Participate in the physical protection design process for GNEP facilities & 2007 \\
\hline Expand GEN-IV and INPRO work on Proliferation Risk Reduction & 2007 \\
\hline $\begin{array}{l}\text { Conduct proliferation and security risk reduction analyses for GNEP } \\
\text { technologies }\end{array}$ & 2008 \\
\hline $\begin{array}{l}\text { Develop proliferation risk reduction criteria for advanced aqueous separation } \\
\text {, pyroprocessing, fuel fabrication, and advanced burner reactors }\end{array}$ & 2008 \\
\hline $\begin{array}{l}\text { Conduct safeguards and proliferation risk reduction assessments of small } \\
\text { reactor concepts }\end{array}$ & 2008 \\
\hline Conduct EIS proliferation risk assessment for U.S. GNEP facilities & 2008 \\
\hline $\begin{array}{l}\text { Advanced research, development, and engineering application of new } \\
\text { safeguards technologies and methodologies }\end{array}$ & 2008 \\
\hline $\begin{array}{l}\text { Conduct advanced research and development on future } \\
\text { nonproliferation and safeguards technologies, including: } \\
\text { Remote monitoring technologies } \\
\text { Computational toolkits and algorithms } \\
\text { Advanced concept demonstrations }\end{array}$ & $2009-2013$ \\
\hline $\begin{array}{l}\text { Engineering application of advanced safeguards technologies and } \\
\text { methodologies for new reactor and material processing facilities, } \\
\text { including: } \\
\text { Integrated information analysis systems and sensor technologies } \\
\text { Tools and methods to analyze TRU fuels and waste products } \\
\text { Advanced remote and unattended monitoring systems }\end{array}$ & $2009-2013$ \\
\hline
\end{tabular}





\section{Appendix A}

\section{Technology Readiness Levels}

Table A-1 provides a definition of each technology readiness level with specific advanced recycling reactor examples. Technology Readiness Levels (TRLs) are a systematic metric/measurement system that supports assessments of the maturity of a particular technology and the consistent comparison of maturity between different types of technology. The TRL approach has been used on-and-off in NASA space technology planning and the Department of Defense for many years. Figure A-1 provides a summary view of the technology maturation process model for NASA space activities for which the TRL's were originally conceived; other process models may be used. However, to be most useful the general model must include: (a) 'basic' research in new technologies and concepts (targeting identified goals, but not necessary specific systems), (b)

Figure A-1. NASA Technology Readiness Levels

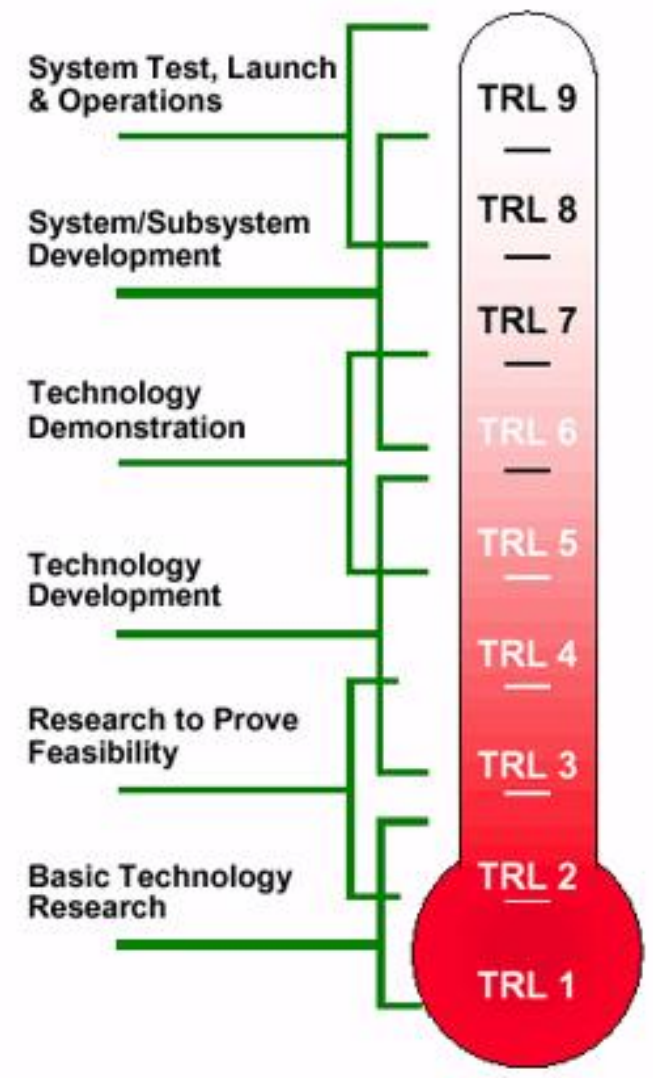

focused technology development addressing specific technologies for one or more potential identified applications, (c) technology development and demonstration for each specific application before the beginning of full system development of that application, (d) system development (through first unit fabrication), and (e) system deployment and operations. 
As discussed in a GAO Report ${ }^{\mathrm{r}}$, the experiences of government and commercial technology development programs indicate that demonstrating a high level of maturity before new technologies are incorporated into product development programs puts those programs in a better position to succeed. For technologies that are successfully incorporated into a product, the gap between a technology's maturity as measured by its TRL and the intended product's requirement was recognized and closed before product development began, improving the chances for successful cost and schedule outcomes. The closing of this gap was a managed result. It is a rare program that can proceed with a gap between product requirements and the maturity of key technologies and still be delivered on time and within costs.

Two conditions are critical to closing the maturity gap. First, the right environment for maturing the technology must exist. Key to this environment is making the science and technology organization, rather than the program or product development manager, responsible for maturing the technology to a high TRL. When a maturity gap persists, manager are given the flexibility to take the time to mature the technology or decrease product requirements so that they can use another, already mature technology. Second, both technology and product managers are supposed by disciplined processes, readily available information, readiness standards, and authority to ensure technology was ready for products. This support enables these managers to safeguard product development form undue technology risks.

${ }^{\mathrm{r}}$ GAO Report, GAO/NSIAD-99-162, "Best Practices, Better Management of Technology Development Can Improve Weapon System Outcomes" July 1999 
A-1. Advanced Recycling Reactor Technology Readiness Levels Definitions

\begin{tabular}{|c|c|c|c|}
\hline TRL & Category & Description & $\begin{array}{l}\text { Advanced Recycling Reactor } \\
\text { Definition and Examples }\end{array}$ \\
\hline 1 & \multirow{3}{*}{$\begin{array}{c}\text { Concept } \\
\text { Development }\end{array}$} & $\begin{array}{l}\text { Lowest level of technology } \\
\text { readiness. Scientific research begins } \\
\text { to be translated into applied research } \\
\text { and development }\end{array}$ & $\begin{array}{l}\text { New discoveries (i.e., in materials } \\
\text { for cladding and ducts) may lead to } \\
\text { performance improvement or cost } \\
\text { reductions. } \\
\text { At this technology readiness level, } \\
\text { the basic properties of advanced } \\
\text { materials might be studied (e.g., } \\
\text { tensile strength as a function of } \\
\text { temperature, irradiation effects, and } \\
\text { compatibility with fast reactor } \\
\text { coolants or fuels) and once shown } \\
\text { that the program understands these } \\
\text { fundamental properties, the } \\
\text { advanced material would mature to } \\
\text { the next TRL level. }\end{array}$ \\
\hline 2 & & $\begin{array}{l}\text { Invention begins. Once basic } \\
\text { principles are observed, practical } \\
\text { applications can be invented. } \\
\text { Applications are speculative and } \\
\text { there may be no proof or detailed } \\
\text { analysis to support the assumptions. }\end{array}$ & $\begin{array}{l}\text { Although sodium-cooled fast } \\
\text { reactor technology is mature, new } \\
\text { discoveries may result in } \\
\text { performance improvements or cost } \\
\text { reductions in future plants. } \\
\text { For example, following the } \\
\text { observation of advanced materials } \\
\text { properties at TRL } 1 \text {, the potential } \\
\text { applications of the new material for } \\
\text { structural materials applications, fast } \\
\text { reactor fuel cladding, etc. can be } \\
\text { defined. At this level, the } \\
\text { application is still speculative; there } \\
\text { is no experimental proof or detailed } \\
\text { analysis to support the conjecture. }\end{array}$ \\
\hline 3 & & $\begin{array}{l}\text { Active research and development is } \\
\text { initiated. This includes analytical } \\
\text { studies and laboratory studies to } \\
\text { physically validate analytical } \\
\text { predictions of separate elements of } \\
\text { the technology. }\end{array}$ & $\begin{array}{l}\text { Analysis of the performance of } \\
\text { SSCs (System, Structure or } \\
\text { Component) produces favorable } \\
\text { results, but testing is needed to } \\
\text { validate the prediction and provide } \\
\text { data supporting key features. } \\
\text { Examples would include testing of } \\
\text { printed circuit heat exchangers to } \\
\text { confirm performance with sodium } \\
\text { and testing of new concepts for } \\
\text { under-sodium in-service inspection } \\
\text { of components and structures. In } \\
\text { addition, a compact fast reactor loop }\end{array}$ \\
\hline
\end{tabular}




\begin{tabular}{|c|c|c|c|}
\hline TRL & Category & Description & $\begin{array}{l}\text { Advanced Recycling Reactor } \\
\text { Definition and Examples }\end{array}$ \\
\hline & & & $\begin{array}{l}\text { concept might depend on the } \\
\text { irradiation and thermo-physical } \\
\text { properties of an advanced material: } \\
\text { TRL } 3 \text { might be attained when these } \\
\text { materials have undergone irradiation } \\
\text { with subsequent post-irradiation } \\
\text { examination and their post- } \\
\text { irradiation thermo-physical } \\
\text { properties are defined and known. }\end{array}$ \\
\hline 4 & \multirow{3}{*}{ Proof-of-Principle } & $\begin{array}{l}\text { Integration of basic technological } \\
\text { components for testing in laboratory } \\
\text { environment. Includes integration of } \\
\text { "ad hoc" hardware in the laboratory. }\end{array}$ & $\begin{array}{l}\text { Laboratory testing of individual } \\
\text { components or portions of systems } \\
\text { has been completed successfully. } \\
\text { Examples would include separate } \\
\text { effects testing of component } \\
\text { performance, such as heat } \\
\text { exchanger plugging tests or } \\
\text { metallurgical compatibility testing } \\
\text { or successful operation of gas- } \\
\text { turbine components that might be } \\
\text { used in a supercritical } \mathrm{CO}_{2} \text { system. }\end{array}$ \\
\hline 5 & & $\begin{array}{l}\text { Integration of basic technological } \\
\text { components with realistic supporting } \\
\text { elements for testing in relevant } \\
\text { environment. }\end{array}$ & $\begin{array}{l}\text { Individual components or portions } \\
\text { of systems have been successfully } \\
\text { tested at less-than-full scale in a } \\
\text { test reactor, out-of-pile test facility } \\
\text { or in another application. } \\
\text { Examples would include successful } \\
\text { testing of a section of a fuel } \\
\text { element in a test reactor or } \\
\text { successful testing of individual } \\
\text { components of a sodium system in } \\
\text { a sodium loop. } \\
\text { For example, a full-size } \\
\text { electromagnetic pump promising a } \\
\text { simpler primary plant system } \\
\text { design will be built and tested with } \\
\text { a fully-immersed sodium } \\
\text { environment (in a sodium } \\
\text { component testing facility) and } \\
\text { tested with its power supply and } \\
\text { control system. }\end{array}$ \\
\hline 6 & & $\begin{array}{l}\text { Model or prototype system testing in } \\
\text { relevant environment }\end{array}$ & $\begin{array}{l}\text { Systems, subsystems or } \\
\text { components have been } \\
\text { demonstrated at less-than-full scale } \\
\text { in a test reactor, in an out-of-pile }\end{array}$ \\
\hline
\end{tabular}




\begin{tabular}{|c|c|c|c|}
\hline TRL & Category & Description & $\begin{array}{l}\text { Advanced Recycling Reactor } \\
\text { Definition and Examples }\end{array}$ \\
\hline & & & $\begin{array}{l}\text { test facility or in another } \\
\text { application. Examples would } \\
\text { include successful demonstration of } \\
\text { individual fuel elements in a test } \\
\text { reactor, successful operation of a } \\
\text { section of a steam generator in a } \\
\text { sodium loop or successful } \\
\text { operation of a supercritical } \mathrm{CO}_{2} \\
\text { energy conversion system under } \\
\text { prototypic but non-nuclear } \\
\text { conditions. }\end{array}$ \\
\hline 7 & \multirow{3}{*}{$\begin{array}{l}\text { Proof-of- } \\
\text { Performance }\end{array}$} & $\begin{array}{l}\text { Demonstration of prototype system } \\
\text { in an operational environment at the } \\
\text { engineering scale. }\end{array}$ & $\begin{array}{l}\text { The SSC or system behavior has } \\
\text { been successfully demonstrated } \\
\text { under prototypic conditions in a } \\
\text { test reactor or in an out-of-pile test } \\
\text { facility if the SSC or system will } \\
\text { never see a radiation environment } \\
\text { during anticipated deployment } \\
\text { operations. Examples would } \\
\text { include successful testing of a fuel } \\
\text { assembly or multiple fuel elements } \\
\text { in a test reactor or successful } \\
\text { operation of a sodium-water steam } \\
\text { generator in a large test loop. }\end{array}$ \\
\hline 8 & & $\begin{array}{l}\text { End of system development. } \\
\text { Technology proven to work in } \\
\text { operational environment at the } \\
\text { engineering to full scale. }\end{array}$ & $\begin{array}{l}\text { The system, structure, or } \\
\text { component (SSC) has been } \\
\text { successfully deployed in operations } \\
\text { of a sodium-cooled test reactor or a } \\
\text { prototype of the SSC has been } \\
\text { successfully deployed in power } \\
\text { reactor operations, or a system } \\
\text { characteristic has been } \\
\text { demonstrated in an experiment (i.e, } \\
\text { the EBR-II passive safety } \\
\text { demonstration). }\end{array}$ \\
\hline 9 & & $\begin{array}{l}\text { Full scale application of technology } \\
\text { in its final form at mission } \\
\text { conditions. }\end{array}$ & $\begin{array}{l}\text { The system, structure or component } \\
\text { has been successfully deployed in } \\
\text { operations of a commercial } \\
\text { sodium-cooled power reactor (or } \\
\text { another commercial power reactor } \\
\text { if the SSC is not sodium-related, } \\
\text { such as containment structures), or } \\
\text { a relevant system behavior has } \\
\text { been demonstrated in such a }\end{array}$ \\
\hline
\end{tabular}




\begin{tabular}{|l|l|l|}
\hline TRL & Category & \multicolumn{1}{|c|}{$\begin{array}{c}\text { Description } \\
\text { Advanced Recycling Reactor } \\
\text { Definition and Examples }\end{array}$} \\
\hline & $\begin{array}{l}\text { reactor. } \\
\text { This TRL does not include } \\
\text { technologies for planned product } \\
\text { improvement of ongoing or } \\
\text { reusable systems. For example, an } \\
\text { advanced fuel handling system } \\
\text { concept for the commercial ABR } \\
\text { plant would not start at TRL 9: } \\
\text { such 'technology' upgrades would } \\
\text { start over at the appropriate level } \\
\text { in the TRL system. }\end{array}$ \\
\hline
\end{tabular}

As shown in Table A-2, the technical maturity of the conventional fast reactor component technology is high, and the technical risk is limited so long as program managers stay within the current fast reactor technology knowledge base. Components with technology readiness levels 7 or above should be ready for introduction into the ABR Prototype. A critical item for the transmutation mission is the development of transmutation fuels as covered in Section 5.0. Several of the fast reactor technology components show a range of technology readiness levels. Some of the reference fast reactor component technologies have already been successfully demonstrated in fast reactors to the degree that could be deployed with little technical risk. However, a number of the advanced fast reactor technologies, that contribute to the longterm goal of a commercially viable fast reactor system, are not mature enough today for inclusion in the ABR Prototype project and therefore require further development. The ultimate goal is successful commercialization of the advanced recycling reactor technology at a cost that encourages deployment. A number of the advanced recycling reactor technologies are not mature enough today for inclusion in the final product and require further development. 
Table A-2. Technology Maturity and Technical Risk for Transmutation Technologies

\begin{tabular}{|c|c|c|}
\hline $\begin{array}{c}\text { Fast Reactor } \\
\text { Component }\end{array}$ & Technology Maturity & Technology Risk Description \\
\hline $\begin{array}{l}\text { Transmutation } \\
\text { Fuel }\end{array}$ & \multicolumn{2}{|r|}{ See Tables A-7 and A-8. } \\
\hline $\begin{array}{l}\text { Coolant Control } \\
\text { Technology }\end{array}$ & TRL 8 & $\begin{array}{l}\text { Conventional technology demonstrated at full scale. } \\
\text { There is very little technology risk associated with } \\
\text { sodium coolant control technologies. }\end{array}$ \\
\hline Core Materials & TRL 8 & $\begin{array}{l}\text { Demonstrated at full scale. Proven steel materials, } \\
\text { but no vendor. }\end{array}$ \\
\hline Startup Fuel & $\begin{array}{l}\text { MOX - TRL 8-9 } \\
\text { Metal U-Pu-Zr - TRL 7-8 } \\
\text { Metal U-Zr - TRL 8-9 }\end{array}$ & $\begin{array}{l}\text { Both MOX and metal startup fuel technologies have } \\
\text { been matured to the degree that they could be } \\
\text { handed off to program managers with very little } \\
\text { technology risk so long as compositions and } \\
\text { performance requirements are within the range of } \\
\text { test results. }\end{array}$ \\
\hline Primary System & $\begin{array}{l}\text { Conventional Primary Plant } \\
\text { Systems - TRL } 8 \\
\text { Compact Primary Plant } \\
\text { Components - TRL 4-6 } \\
\text { Advanced Primary Pumps - } \\
\text { TRL 4-6 }\end{array}$ & $\begin{array}{l}\text { There is very little technology risk associated with } \\
\text { using conventional demonstrated primary plant } \\
\text { system and components. } \\
\text { Compact and advanced primary pumps, which may } \\
\text { be needed to reduce costs, are not mature } \\
\text { technologies and therefore require further } \\
\text { technology development and maturation before } \\
\text { inclusion in fast reactor designs. }\end{array}$ \\
\hline $\begin{array}{l}\text { Reactor Vessel } \\
\text { and Structures }\end{array}$ & TRL 8-9 & $\begin{array}{l}\text { There is very little technology risk associated with } \\
\text { reactor vessels and structures using conventional } \\
\text { demonstrated plant configurations and materials of } \\
\text { construction. }\end{array}$ \\
\hline $\begin{array}{l}\text { Structural } \\
\text { Materials }\end{array}$ & $\begin{array}{l}\text { Advanced stainless steels - } \\
\text { TRL 3-5 }\end{array}$ & $\begin{array}{l}\text { Related to the reactor vessel and structures above, } \\
\text { there is very little technology risk associated with } \\
\text { using known and demonstrated conventional } \\
\text { stainless steels for structural materials. } \\
\text { However, there are advanced materials that are } \\
\text { expected to contribute to reducing the costs of } \\
\text { primary plant systems and structures. These } \\
\text { advanced materials are not ready for program or } \\
\text { product development and need to go through an } \\
\text { appropriate technology maturation process. }\end{array}$ \\
\hline
\end{tabular}




\begin{tabular}{|c|c|c|}
\hline $\begin{array}{c}\text { Fast Reactor } \\
\text { Component }\end{array}$ & Technology Maturity & Technology Risk Description \\
\hline Balance of Plant & $\begin{array}{l}\text { Steam Generators - TRL } 7 \\
\text { Steam Plant - minus steam } \\
\text { generators - TRL } 9 \\
\text { Advanced Energy } \\
\text { Conversion Systems - TRL } \\
\text { 4-6 }\end{array}$ & $\begin{array}{l}\text { Although there were some problems with early } \\
\text { sodium steam generators, there is now substantial } \\
\text { satisfactory experience from EBR-II, France, Japan, } \\
\text { and Russia. } \\
\text { Advanced energy conversion system (CO2 Brayton) } \\
\text { is being considered for cost reduction. This } \\
\text { technology must go through a maturation process } \\
\text { before applications in the ABR program. }\end{array}$ \\
\hline Containment & $\begin{array}{l}\text { LWR Containment } \\
\text { technology - TRL } 9 \\
\text { Advanced Containment } \\
\text { technology - TRL 4-6 }\end{array}$ & $\begin{array}{l}\text { Demonstrated at full scale. } \\
\text { Some features of advanced containment designs will } \\
\text { require technology maturation. }\end{array}$ \\
\hline Seismic Isolation & $\begin{array}{l}\text { Rubber and steel seismic } \\
\text { isolators - TRL } 7\end{array}$ & $\begin{array}{l}\text { There is limited experience ( } 2 \text { plants) in French } \\
\text { LWR designs and there are many applications in } \\
\text { large buildings using rubber/steel isolators. } \\
\text { There is less experience with multiple friction } \\
\text { pendulum systems and some testing and technology } \\
\text { maturation would be needed for widespread } \\
\text { applications. }\end{array}$ \\
\hline $\begin{array}{l}\text { Instrumentation } \\
\text { and Control }\end{array}$ & $\begin{array}{l}\text { Analog Control - TRL } 9 \\
\text { Digital Control Systems - } \\
\text { TRL 7-8 } \\
\text { Advanced passively-cooled } \\
\text { nuclear instrumentation - } \\
\text { TRL } 5\end{array}$ & $\begin{array}{l}\text { Analog instrumentation and control technology have } \\
\text { been demonstrated at full scale in both light water } \\
\text { and fast reactors and are a mature technology. } \\
\text { Digital control systems and advanced nuclear } \\
\text { instrumentation systems are examples of advanced } \\
\text { I\&C components and systems that still require } \\
\text { maturation. }\end{array}$ \\
\hline $\begin{array}{l}\text { Maintenance and } \\
\text { Inspection } \\
\text { Technology }\end{array}$ & $\begin{array}{l}\text { Under sodium inspection } \\
\text { system - TRL } 5 \\
\text { Compact robotic inspection } \\
\text { vehicle TRL } 5\end{array}$ & $\begin{array}{l}\text { New techniques for in-service inspection, especially } \\
\text { under sodium inspection technology, needs to be } \\
\text { demonstrated. }\end{array}$ \\
\hline $\begin{array}{l}\text { Fuel Handling } \\
\text { Systems }\end{array}$ & $\begin{array}{l}\text { Conventional dual rotatable } \\
\text { plug with straight pull - } \\
\text { TRL } 8 \\
\text { Advanced compact } \\
\text { pantograph with single } \\
\text { rotatable plug - TRL } 5\end{array}$ & $\begin{array}{l}\text { A conventional dual rotatable plug with straight pull } \\
\text { fuel handling system could be deployed with very } \\
\text { little technology risk. } \\
\text { For cost reduction mission, a simplified fuel } \\
\text { handling design needs to be developed. }\end{array}$ \\
\hline
\end{tabular}


One key programmatic challenge for the fast reactor transmutation technology demonstration is reestablishing the U.S. infrastructure for designing, manufacturing, and testing this technology. Table A-3 provides an evaluation relevant programmatic risks related to lack of fast reactor infrastructure. Although many of the base sodium technology components were originally developed in the U.S., there are only limited remaining facilities and human resources, and no current industrial fabrication and testing capabilities for sodium-cooled fast reactor components. An urgent need is to re-establish the domestic manufacturing and testing infrastructure to support advanced recycling reactor deployment. International partners can provide contributions in this technology area; however, reliance on external contributions also entails significant program risk. Therefore, without a reinvigorated domestic supporting technology base, there is a large programmatic risk of not meeting programmatic and mission objectives. 
Table A-3. Fast Reactor Infrastructure and Programmatic Risk

\begin{tabular}{|l|l|}
\hline $\begin{array}{l}\text { Fast Reactor } \\
\text { Infrastructure }\end{array}$ & \multicolumn{1}{c|}{ Programmatic Risk } \\
\hline $\begin{array}{l}\text { Fast Reactor } \\
\text { Component Design } \\
\text { Infrastructure }\end{array}$ & $\begin{array}{l}\text { Demonstrated at full scale. The U.S. has not built a fast reactor in } \\
\text { decades and human resources are limited. } \\
\text { Programmatic risk is high because of the lack of U.S. infrastructure to } \\
\text { support commercial deployment of fast reactor technology. }\end{array}$ \\
\hline $\begin{array}{l}\text { Fast Reactor } \\
\text { Component Testing } \\
\text { Infrastructure }\end{array}$ & $\begin{array}{l}\text { Programmatic risk is high because of the lack of U.S. infrastructure to } \\
\text { support fast reactor component testing and development. International } \\
\text { infrastructure is also severely degraded. }\end{array}$ \\
\hline $\begin{array}{l}\text { Fast Reactor } \\
\text { Manufacturing }\end{array}$ & $\begin{array}{l}\text { Programmatic risk is high for the ABR prototype. Infrastructure for } \\
\text { manufacturing fast reactor components is currently insufficient to } \\
\text { support technology demonstration. Subsequent advanced recycling } \\
\text { reactors will benefit from the infrastructure development activities } \\
\text { during the ABR prototype development }\end{array}$ \\
\hline $\begin{array}{l}\text { Fast Reactor Safety } \\
\text { Analysis Tools }\end{array}$ & $\begin{array}{l}\text { Programmatic risk is medium because of the personnel infrastructure } \\
\text { to support safety code development and maintenance. Updating and } \\
\text { validation of safety analysis and design tools is recommended. In } \\
\text { addition, test facilities for safety testing and code validation will be } \\
\text { required. }\end{array}$ \\
\hline Licensing Infrastructure & $\begin{array}{l}\text { Programmatic risk is high. Licensing strategy is unknown. NRC has } \\
\text { very few staff who understand sodium technology. } \\
\text { Technical criteria for licensing need to be clarified and the regulatory } \\
\text { structure re-established. }\end{array}$ \\
\hline
\end{tabular}


Table A-4. LWR Spent Fuel Processing - Definition of Technology Readiness Levels, and TRL for this Technology

\begin{tabular}{|c|c|c|}
\hline TRL & Category & Description \\
\hline 1 & \multirow{3}{*}{ Concept Development } & $\begin{array}{l}\text { Concept for separations process developed; process options (e.g., } \\
\text { contactor type, solvent extraction steps) identified; separations criteria } \\
\text { established. }\end{array}$ \\
\hline 2 & & $\begin{array}{l}\text { Calculated mass-balance flowsheet developed; scoping experiments } \\
\text { on process options completed successfully with simulated LWR spent } \\
\text { fuel; preliminary selection of process equipment. }\end{array}$ \\
\hline 3 & & $\begin{array}{l}\text { Laboratory-scale batch testing with simulated LWR spent fuel } \\
\text { completed successfully; process chemistry confirmed; reagents } \\
\text { selected; preliminary testing of equipment design concepts done to } \\
\text { identify development needs; complete system flowsheet established. }\end{array}$ \\
\hline 4 & \multirow{3}{*}{ Proof of Principle } & $\begin{array}{l}\text { Unit operations testing at engineering scale for process validation with } \\
\text { simulated LWR spent fuel consisting of unirradiated materials; } \\
\text { materials balance flowsheet confirmed; separations chemistry models } \\
\text { developed. NOTE: engineering scale is defined as a process } \\
\text { equipment scale and throughput rate that can with confidence be } \\
\text { scaled to industrial operations levels. }\end{array}$ \\
\hline 5 & & $\begin{array}{l}\text { Unit operations testing completed at engineering scale with actual } \\
\text { LWR spent fuel for process chemistry confirmation; reproducibility of } \\
\text { process confirmed by repeated batch tests; simulation models } \\
\text { validated. }\end{array}$ \\
\hline 6 & & $\begin{array}{l}\text { Unit operations testing in existing hot cells with full-scale equipment } \\
\text { completed successfully, using actual LWR spent fuel; process } \\
\text { monitoring and control system proven; process equipment design } \\
\text { validated. }\end{array}$ \\
\hline 7 & \multirow{3}{*}{ Proof of Performance } & $\begin{array}{l}\text { Integrated system cold shakedown testing completed successfully with } \\
\text { full-scale equipment (simulated fuel). }\end{array}$ \\
\hline 8 & & $\begin{array}{l}\text { Demonstration of integrated system with full-scale equipment and } \\
\text { actual LWR spent fuel completed successfully; short ( } \sim 1 \text { month) } \\
\text { periods of sustained operation. }\end{array}$ \\
\hline 9 & & $\begin{array}{l}\text { Full-scale demonstration with actual LWR spent fuel successfully } \\
\text { completed at } \geq 100 \text { metric tons per year rate; sustained operations for a } \\
\text { minimum of three months. }\end{array}$ \\
\hline
\end{tabular}

* The current TRL for this technology is highlighted in blue. 
Table A-5 . Waste Form Development - Definition of Technology Readiness Levels, and TRL for this Technology

\begin{tabular}{|c|c|c|}
\hline TRL & Category & Description \\
\hline 1 & \multirow{3}{*}{ Concept Development } & Identification of waste form options and related processes. \\
\hline 2 & & $\begin{array}{l}\text { Waste acceptance criteria evaluation, flowsheet development, process } \\
\text { options scoping experiments, and preliminary systems engineering. }\end{array}$ \\
\hline 3 & & $\begin{array}{l}\text { Laboratory-scale simulated waste streams batch testing, preliminary } \\
\text { equipment design testing, systems engineering, and waste form } \\
\text { screening. }\end{array}$ \\
\hline 4 & \multirow{3}{*}{ Proof of Principle } & $\begin{array}{l}\text { Waste form production testing of simulated waste streams, actinide } \\
\text { and non-radioactive fissions products at engineering scale, process } \\
\text { validation, short-term characterization testing, and initial model } \\
\text { development. }\end{array}$ \\
\hline 5 & & $\begin{array}{l}\text { Waste form production with representative radioactive fission product } \\
\text { content at engineering scale, long-term characterization testing, and } \\
\text { waste acceptance criteria confirmation. }\end{array}$ \\
\hline 6 & & $\begin{array}{l}\text { Waste form production of actual process waste streams using full- } \\
\text { scale equipment, process and equipment final validation, and model } \\
\text { verification. }\end{array}$ \\
\hline 7 & \multirow{3}{*}{ Proof of Performance } & $\begin{array}{l}\text { Integrated waste form production in industrial facility using full-scale } \\
\text { equipment; cold shakedown testing of production operations. }\end{array}$ \\
\hline 8 & & $\begin{array}{l}\text { Demonstration of integrated waste form production as part of initial } \\
\text { demonstration of separations systems. }\end{array}$ \\
\hline 9 & & $\begin{array}{l}\text { Full-scale demonstration of waste form production with the full fission } \\
\text { product loading derived from treatment of actual spent nuclear fuel. }\end{array}$ \\
\hline
\end{tabular}

* The current TRL for this technology is highlighted in blue. 
Table A-6 Advanced Recycle Reactor Spent Fuel Processing - Definition of Technology Readiness Levels, and TRL for this Technology

\begin{tabular}{|c|c|c|}
\hline TRL & Category & Description \\
\hline 1 & \multirow{3}{*}{ Concept Development } & $\begin{array}{l}\text { Concept for separations process developed; process options } \\
\text { (e.g., electrolyte composition, process equipment) identified; } \\
\text { separations criteria established. }\end{array}$ \\
\hline 2 & & $\begin{array}{l}\text { Calculated mass-balance flowsheet developed; scoping } \\
\text { experiments on process options completed successfully with } \\
\text { simulated advanced recycling reactor spent fuel; preliminary } \\
\text { selection of process equipment. }\end{array}$ \\
\hline 3 & & $\begin{array}{l}\text { Bench-scale batch testing with simulated advanced recycling } \\
\text { reactor spent fuel completed successfully; process chemistry } \\
\text { confirmed; reagents selected; preliminary testing of equipment } \\
\text { design concepts done to identify development needs; complete } \\
\text { system flowsheet established. }\end{array}$ \\
\hline $4^{*}$ & \multirow{3}{*}{ Proof of Principle } & $\begin{array}{l}\text { Unit operations testing at engineering scale for process } \\
\text { validation with simulated advanced recycling reactor spent fuel } \\
\text { consisting of unirradiated materials; materials balance } \\
\text { flowsheet confirmed; separations chemistry models developed. } \\
\text { NOTE: engineering scale is defined as a process equipment } \\
\text { scale and throughput rate that can with confidence be scaled to } \\
\text { industrial operations levels. }\end{array}$ \\
\hline 5 & & $\begin{array}{l}\text { Unit operations testing completed at engineering scale with } \\
\text { actual fast reactor spent fuel for process chemistry } \\
\text { confirmation; reproducibility of process confirmed by repeated } \\
\text { batch tests; simulation models validated. }\end{array}$ \\
\hline 6 & & $\begin{array}{l}\text { Unit operations testing in existing hot cells with full-scale } \\
\text { equipment completed successfully, using actual fast reactor } \\
\text { spent fuel; process monitoring and control system proven; } \\
\text { process equipment design validated. }\end{array}$ \\
\hline 7 & \multirow{3}{*}{ Proof of Performance } & $\begin{array}{l}\text { Integrated system cold shakedown testing completed } \\
\text { successfully with full-scale equipment (simulated fuel). }\end{array}$ \\
\hline 8 & & $\begin{array}{l}\text { Demonstration of integrated system with full-scale equipment } \\
\text { and actual advanced recycling reactor spent fuel completed } \\
\text { successfully; short ( } \sim 1 \text { month) periods of sustained operation. }\end{array}$ \\
\hline 9 & & $\begin{array}{l}\text { Full-scale demonstration with actual advanced recycling reactor } \\
\text { spent fuel successfully completed at throughput rate consistent } \\
\text { with annual discharge from a cluster of advanced recycle } \\
\text { reactors at a collocated site; sustained operations for a } \\
\text { minimum of three months. }\end{array}$ \\
\hline
\end{tabular}

* The current TRL for this technology is highlighted in blue. 
Table A-7 Fuel Fabrication - Definition of Technology Readiness Levels, and TRL for this Technology

\begin{tabular}{|c|c|c|c|}
\hline TRL & TRL Function & Generic Definition & $\begin{array}{l}\text { Fuel Performance-Specific } \\
\text { Definition } \\
\end{array}$ \\
\hline 1 & \multirow{3}{*}{$\begin{array}{l}\text { Concept } \\
\text { Development }\end{array}$} & $\begin{array}{l}\text { Basic principles } \\
\text { observed and formulated }\end{array}$ & $\begin{array}{l}\text { Technical review leading to identified } \\
\text { technical options. Identification of } \\
\text { criteria for candidate selection. }\end{array}$ \\
\hline 2 & & $\begin{array}{l}\text { Technology concepts } \\
\text { and/or applications } \\
\text { formulated }\end{array}$ & $\begin{array}{l}\text { Fuel candidates selected from options } \\
\text { based on performance data on similar } \\
\text { systems, based on selection criteria. }\end{array}$ \\
\hline 3 & & $\begin{array}{l}\text { Analytical and } \\
\text { experimental } \\
\text { demonstration of critical } \\
\text { function and/or proof of } \\
\text { concept }\end{array}$ & $\begin{array}{l}\text { Analysis and lab-scale experimentation } \\
\text { and characterization addressing } \\
\text { feasibility including small fabrication } \\
\text { tests with surrogate materials. }\end{array}$ \\
\hline 4 & \multirow{3}{*}{ Proof-of-principle } & $\begin{array}{l}\text { Component and/or } \\
\text { bench-scale validation } \\
\text { in a laboratory } \\
\text { environment }\end{array}$ & $\begin{array}{l}\text { Establish proof of concept. Fabrication } \\
\text { of irradiation testing samples in } \\
\text { accordance with requirements. At this } \\
\text { scale, legacy materials are blended } \\
\text { together and a feedstock spec is not } \\
\text { available. }\end{array}$ \\
\hline 5 & & $\begin{array}{l}\text { Component and/or } \\
\text { breadboard validation in } \\
\text { a relevant environment }\end{array}$ & $\begin{array}{l}\text { Fabrication of irradiation testing samples } \\
\text { in accordance with requirements. At this } \\
\text { scale, actual separated materials are used } \\
\text { and feedstock spec are developed. }\end{array}$ \\
\hline 6 & & $\begin{array}{l}\text { System/subsystem } \\
\text { model or prototype } \\
\text { demonstration in } \\
\text { relevant environment }\end{array}$ & $\begin{array}{l}\text { Fabrication at multiple pin level using } \\
\text { actual materials and scalable fabrication } \\
\text { techniques. A full set of fabrication } \\
\text { specifications is developed. Design } \\
\text { parameters investigated. Information is } \\
\text { sufficient to support a Fuel Specification } \\
\text { and a Fuel Safety Case. }\end{array}$ \\
\hline 7 & \multirow[t]{3}{*}{$\begin{array}{l}\text { Proof-of- } \\
\text { performance }\end{array}$} & $\begin{array}{l}\text { System prototype } \\
\text { demonstration in } \\
\text { prototypic environment }\end{array}$ & $\begin{array}{l}\text { Fabrication of reference fuel at assembly } \\
\text { levels using actual equipment and with } \\
\text { actual feedstock materials with statistical } \\
\text { demonstration of performance. }\end{array}$ \\
\hline 8 & & \multicolumn{2}{|c|}{$\begin{array}{l}\text { Prototype fabrication facility completed and qualified through test } \\
\text { and demonstration. }\end{array}$} \\
\hline 9 & & \multicolumn{2}{|c|}{$\begin{array}{l}\text { Actual fabrication facility proven through successful mission } \\
\text { operations. }\end{array}$} \\
\hline
\end{tabular}

\footnotetext{
* The current TRL for this technology is highlighted in blue.
} 
Table A-8 Fuel Performance - Definition of Technology Readiness Levels, and TRL for this Technology

\begin{tabular}{|c|c|c|c|}
\hline TRL & TRL Function & Generic Definition & $\begin{array}{c}\text { Fuel Development-Specific } \\
\text { Definition }\end{array}$ \\
\hline 1 & \multirow{3}{*}{$\begin{array}{l}\text { Concept } \\
\text { Development }\end{array}$} & $\begin{array}{l}\text { Basic principles } \\
\text { observed and formulated }\end{array}$ & $\begin{array}{l}\text { Technical review leading to identified } \\
\text { technical options. Identification of } \\
\text { criteria for candidate selection. }\end{array}$ \\
\hline 2 & & $\begin{array}{l}\text { Technology concepts } \\
\text { and/or applications } \\
\text { formulated }\end{array}$ & $\begin{array}{l}\text { Fuel candidates selected from options } \\
\text { based on performance data on similar } \\
\text { systems, based on selection criteria. }\end{array}$ \\
\hline 3 & & \begin{tabular}{|l|} 
Analytical and \\
experimental \\
demonstration of critical \\
function and/or proof of \\
concept
\end{tabular} & $\begin{array}{l}\text { Analysis and lab-scale experimentation } \\
\text { and characterization addressing } \\
\text { feasibility including property } \\
\text { measurement, and ex-pile tests. }\end{array}$ \\
\hline 4 & \multirow{3}{*}{ Proof-of-principle } & $\begin{array}{l}\text { Component and/or } \\
\text { bench-scale validation } \\
\text { in a laboratory } \\
\text { environment }\end{array}$ & $\begin{array}{l}\text { Establish proof of concept. Performance } \\
\text { phenomena identified with proof-of- } \\
\text { concept irradiation testing of small } \\
\text { samples completed. }\end{array}$ \\
\hline 5 & & $\begin{array}{l}\text { Component and/or } \\
\text { breadboard validation in } \\
\text { a relevant environment }\end{array}$ & $\begin{array}{l}\text { Irradiation testing of prototypic } \\
\text { rods/compacts under nominal } \\
\text { representative conditions (e.g., fission } \\
\text { densities, fuel and cladding } \\
\text { temperatures, cladding damage rates) is } \\
\text { performed and assessed. }\end{array}$ \\
\hline 6 & & $\begin{array}{l}\text { System/subsystem } \\
\text { model or prototype } \\
\text { demonstration in } \\
\text { relevant environment }\end{array}$ & $\begin{array}{l}\text { Prototypic rod/compact and } \\
\text { assembly/element irradiation in } \\
\text { representative environment, under full } \\
\text { range of relevant normal and off-normal } \\
\text { conditions. }\end{array}$ \\
\hline 7 & \multirow[t]{3}{*}{$\begin{array}{l}\text { Proof-of- } \\
\text { performance }\end{array}$} & $\begin{array}{l}\text { System prototype } \\
\text { demonstration in } \\
\text { prototypic environment }\end{array}$ & Irradiation of Lead Test Assemblies \\
\hline 8 & & \multicolumn{2}{|c|}{$\begin{array}{l}\text { Irradiation of multiple test assemblies over multiple years of } \\
\text { fabrication. }\end{array}$} \\
\hline 9 & & Commercial scale use & the fuel in commercial facilities. \\
\hline
\end{tabular}

* The current TRL for this technology is highlighted in blue. 